UNIVERSIDADE DE BRASÍLIA

FACULDADE DE AGRONOMIA E MEDICINA VETERINÁRIA PROGRAMA DE PÓS-GRADUAÇÃO EM AGRONOMIA

CARACTERIZAÇÃO MORFOAGRONÔMICA, FÍSICO-QUÍMICA E TOLERÂNCIA AO NEMATOIDE-DAS-GALHAS DE GENÓTIPOS DE BATATA-DOCE AVALIADOS NO DISTRITO FEDERAL

PAULA ANDREA OSORIO CARMONA

TESE DE DOUTORADO EM AGRONOMIA

BRASÍLIA/DF

FEVEREIRO/2015 


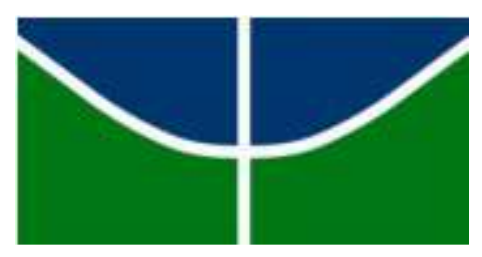

UNIVERSIDADE DE BRASÍLIA

FACULDADE DE AGRONOMIA E MEDICINA VETERINÁRIA PROGRAMA DE PÓS-GRADUAÇÃO EM AGRONOMIA

\title{
CARACTERIZAÇÃO MORFOAGRONÔMICA, FÍSICO-QUÍMICA E TOLERÂNCIA AO NEMATOIDE-DAS-GALHAS DE GENÓTIPOS DE BATATA-DOCE AVALIADOS NO DISTRITO FEDERAL
}

PAULA ANDREA OSORIO CARMONA

\author{
Orientador: Prof. Dr. José Ricardo Peixoto \\ Co-orientador: Dr. Geovani Bernardo Amaro
}

TESE DE DOUTORADO EM AGRONOMIA

PUBLICAÇÃO: NÚMERO 030D/2015

\author{
BRASÍLIA/DF
}

FEVEREIRO/2015 


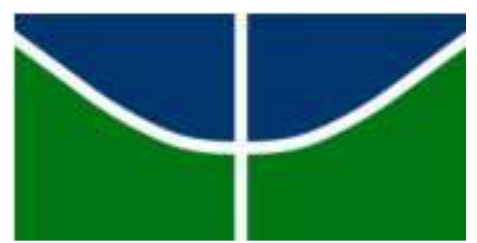

UNIVERSIDADE DE BRASÍLIA

FACULDADE DE AGRONOMIA E MEDICINA VETERINÁRIA PROGRAMA DE PÓS-GRADUAÇÃO EM AGRONOMIA

\title{
CARACTERIZAÇÃO MORFOAGRONÔMICA, FÍSICO-QUÍMICA E TOLERÂNCIA AO NEMATOIDE-DAS-GALHAS DE GENÓTIPOS DE BATATA-DOCE AVALIADOS NO DISTRITO FEDERAL
}

\author{
PAULA ANDREA OSORIO CARMONA
}

TESE DE DOUTORADO SUBMETIDA AO PROGRAMA DE PÓS-GRADUAÇÃO EM AGRONOMIA, COMO PARTE DOS REQUISITOS NECESSÁRIOS À OBTENÇÃO DO GRAU DE DOUTOR EM AGRONOMIA, ÁREA DE CONCENTRAÇÃO PRODUÇÃO SUSTENTÁVEL.

\section{APROVADA POR:}

Eng. Agrônomo José Ricardo Peixoto, Doutor/ Universidade de Brasília - FAV/ Orientador/ CPF: 354.356.236-34/ e-mail: peixoto@unb.br

Eng. Agrícola Ernandes Rodrigues Alencar, Doutor/ Universidade de Brasília - FAV/ Examinador interno/ CPF: 900.558.021-68/ e-mail: ernandesalencar@unb.br

Eng. Agrônoma Neide Botrel, Doutora/ Embrapa Hortaliças/ Examinador externo/ CPF: 286.240.766-68/ e-mail: neide.botrel@embrapa.br

Eng. Agrônomo Jadir Borges Pinheiro, Doutor/ Embrapa Hortaliças/ Examinador externo/ CPF: 947.451.616-20/ e-mail: jadir.pinheiro@embrapa.br

Eng. Agrônomo Agnaldo Donizete Ferreira de Carvalho, Doutor/ Embrapa Hortaliças/ Examinador externo/ CPF: 969.299.796-00/ e-mail: agnaldo.carvalho@embrapa.br

BRASÍLIA/DF, 27 de Fevereiro de 2015. 


\section{FICHA CATALOGRÁFICA}

Carmona, Paula Andrea Osorio

Caracterização morfoagronômica, físico-química e tolerância ao nematoide-das-galhas de genótipos de batata-doce avaliados no Distrito Federal / Paula Andrea Osorio Carmona. -- Brasília, DF, 2015. 227 f. : il.

Orientador: José Ricardo Peixoto

Tese (Doutorado) - Universidade de Brasília. Faculdade de Agronomia e Medicina Veterinária, 2015

1. Ipomoea batatas. 2. Dissimilaridade. 3. Herdabilidade. 4. Características morfoagronômicas e físico-químicas. 5. Meloidogyne spp.. I. Peixoto, José Ricardo. II. Universidade de Brasília. Faculdade de Agronomia e Medicina Veterinária. III. Doutor.

\section{REFERÊNCIA BIBLIOGRÁFICA}

CARMONA, P. A. O. Caracterização morfoagronômica, físico-química e tolerância ao nematoide-das-galhas de genótipos de batata-doce avaliados no Distrito Federal. 2015. 227 f. Tese (Doutorado em Agronomia)- Faculdade de Agronomia e Medicina Veterinária, Universidade de Brasília, Brasília - DF, 2015.

\section{CESSÃO DE DIREITOS}

NOME DO AUTOR: Paula Andrea Osorio Carmona.

TÍTULO DA TESE: Caracterização morfoagronômica, físico-química e tolerância ao nematoide-das-galhas de genótipos de batata-doce avaliados no Distrito Federal.

GRAU: DOUTOR.

ANO: 2015.

É concedida à Universidade de Brasília permissão para reproduzir cópias desta tese de doutorado para única e exclusivamente propósitos acadêmicos e científicos. O autor reserva para si os outros direitos autorais de publicação. Nenhuma parte desta tese de doutorado pode ser reproduzida sem a autorização por escrito do autor. Citações são estimuladas, desde que citada a fonte.

Paula Andrea Osorio Carmona

CPF: 233.543.208-77

e-mail: osorio.carmona@gmail.com 
Dedica este trabalha aa meu pai, Fredy, è Luly par ser exempla canstante na minha vida de dedicaçãa, entrega, respansalilidade, amar e luta.

Dedica também aa hamem da minha vida, Lucas, pela apaia incandicianal em tadas as mamentas, principalmente nas de incerteza, muita camuns para quem tenta trilhar navas caminhas. 


\section{AGRADECIMENTOS}

Agradeço a Deus por ter-me escolhido, por guiar meus passos e ser presença constante na minha vida.

Ao meu irmão Esteban pela complicidade, amor e carinho. Tenho muito orgulho de você.

À minha vó, Gilma, pelas orações, amor e por, mesmo sem entender as dificuldades do desenvolvimento de um trabalho científico, se alegrar com as minhas conquistas e se preocupar com as minhas angústias.

Ao Dr. William Narváez, por ter despertado em mim o interesse pela pesquisa, pelo incentivo, conselhos e amizade.

À UnB, em especial à Faculdade de Agronomia e Medicina Veterinária, pela oportunidade e pela estrutura oferecida para a realização de parte deste trabalho.

À Empresa Brasileira de Pesquisa Agropecuária (Embrapa hortaliças - Centro Nacional de Pesquisa de Hortaliças), pela disponibilização de infra-estrutura para o desenvolvimento científico desta pesquisa.

Ao Prof. Dr. José Ricardo Peixoto, pela orientação, atenção, profissionalismo, amizade e ensinamentos durante a realização deste trabalho. Meus irrestritos agradecimentos pela oportunidade desde o começo e durante todo o tempo na UnB, por ter acreditado em mim e pela sua simplicidade e alegria, que tornaram a realização deste trabalho mais amena.

Ao Dr. Geovani Bernardo Amaro, pela co-orientação, competência, paciência, preocupação, por estar sempre disponível e pela boa vontade em ajudar, todas as vezes em que precisei. Sem você e suas sugestões, este trabalho não teria sido possível. Obrigada pela confiança que sempre demonstrou em mim e no meu trabalho. A você, Dr. Geovani, toda a minha gratidão e carinho.

Ao Dr. Jadir, pela concessão de uso do Laboratório de Nematologia da Embrapa Hortaliças, pelo apoio e assistência durante a condução dos experimentos.

À Dra. Neide, pela disponibilização do Laboratório de Pós-colheita e ajuda durante a realização das análises.

Ao Prof. Dr. Juvenil, pela concessão de uso do microscópio óptico do laboratório de Nematologia da UnB e pelos conhecimentos transmitidos.

À Coordenação de Aperfeiçoamento de Pessoal de Nível Superior, Capes, pela bolsa concedida durante os anos do curso e por fomentar o privilégio de dedicação exclusiva aos estudos. 
À banca examinadora pela disponibilidade, leitura criteriosa, sugestões e apontamentos indicados na redação desta tese.

Aos professores e funcionários do Programa de Pós-graduação em Agronomia.

Aos funcionários da Fazenda Água Limpa: Queen, Monize, Mirão, Homero e Luis Carlos, que sempre estiveram dispostos e alegres para ajudar.

Ao apoio dos funcionários da Estação Experimental de Biologia: Sr. Fábio, Aldo e Evandro.

Ao Sr. Joaquim, Eduardo e Reinaldo, funcionários da Embrapa Hortaliças, pelo trabalho árduo e pesado dispendido na instalação e avaliação dos experimentos, pela companhia e amizade.

Aos funcionários Ricardo e Deusanio, do Laboratório de Pós-colheita da Embrapa hortaliças, pelo trabalho tão bem realizado e por toda a gentileza e disposição durante a realização das análises de carotenoides.

À técnica Danielle, do Laboratório de Nematologia da Embrapa Hortaliças, pela ajuda incondicional durante a instalação e avaliação dos experimentos. Dani, obrigada pela paciência, pelas marmitas e pelas agradáveis conversas.

Ao Prof. Dr. Luiz Antônio Borgo, que gentilmente cedeu o Laboratório de Análise de Alimentos da UnB para a caracterização físico-química das raízes de batata-doce e aos funcionários Márcio e Glauber pela amizade e ajuda irrestrita durante as análises.

À Daiane pela ajuda na avaliação dos experimentos.

A Nancy e Larissa pela grande amizade, confiança, segredos compartilhados e por me ajudarem quando precisei. Obrigada pelos bons momentos que passamos juntas!. Nancylla, mil gracias por tanta generosidade e por estar presente quando precisei de um ombro amigo.

À Cecília pela sua amizade, torcida, alegria, pelos momentos de descontração e por ser a companheira de almoço mais fiel durante a minha permanência na Embrapa Hortaliças.

A todos os amigos que fiz durante as aulas e a execução dos experimentos. Muito obrigada por todo o apoio: Camila, Vanessinha, Rafaela, Débora, Pimentel, Pedro, Karina, Rosa, Angélica, Elonha, Ana Catarina, Elaine e Miguel.

A Andrea e Geraldo, por nossa amizade e pelos agradáveis encontros nos fins de semana.

A todas as pessoas que generosamente contribuíram para a realização deste trabalho...

MUITO OBRIGADA!!! 


\section{SUMÁRIO}

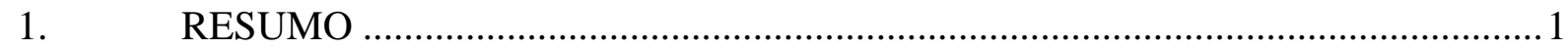

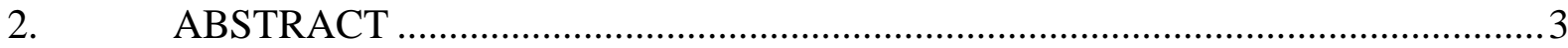

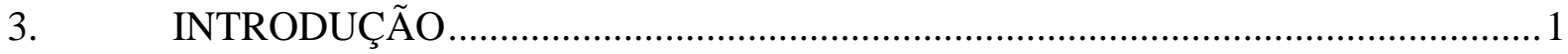

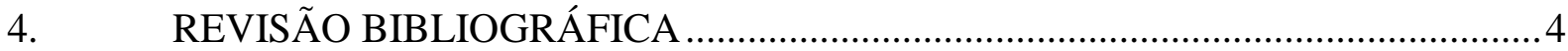

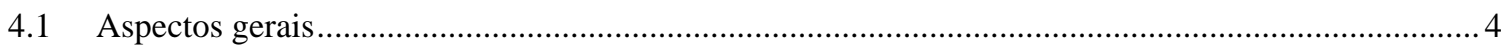

4.2 Botânica e características da batata-doce ................................................................................. 5

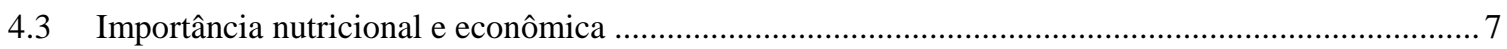

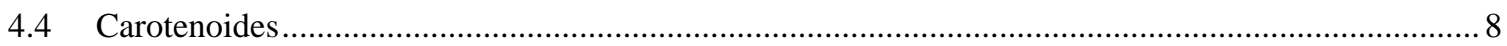

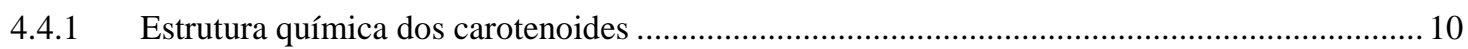

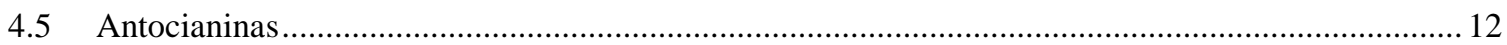

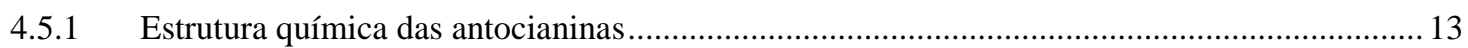

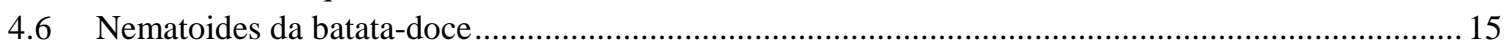

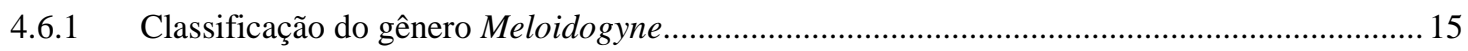

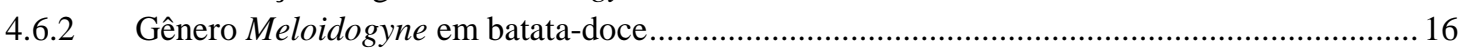

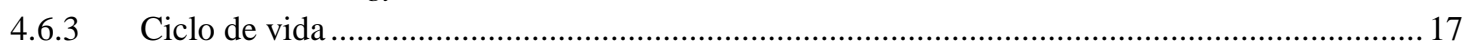

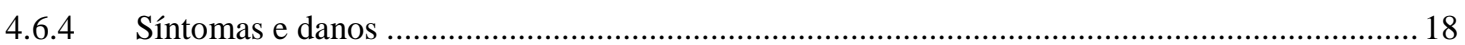

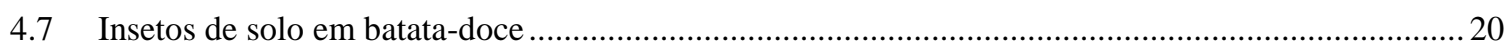

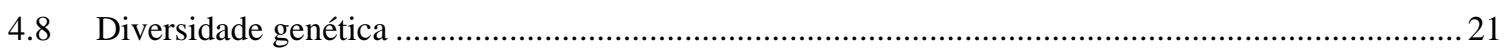

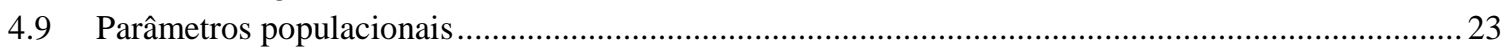

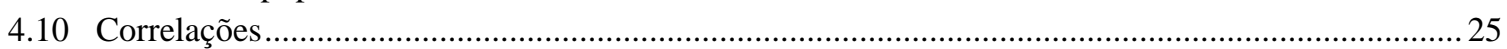

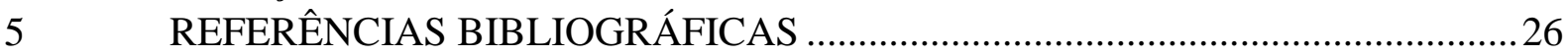

CAPÍTULO 1 DIVERGÊNCIA GENÉTICA ENTRE GENÓTIPOS DE BATATA-DOCE UTILIZANDO DESCRITORES MORFOAGRONÔMICOS E FÍSICO-QUÍMICOS DAS

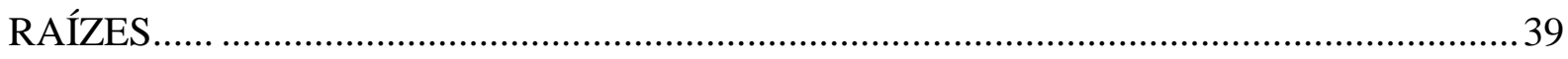

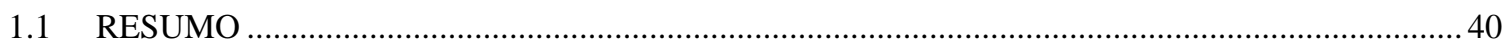

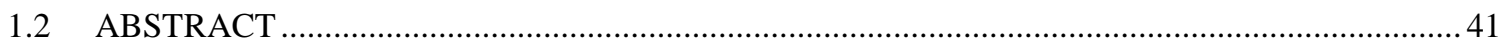

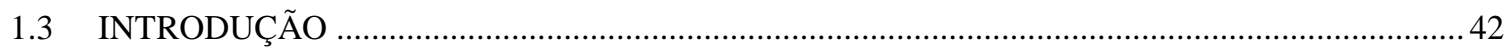

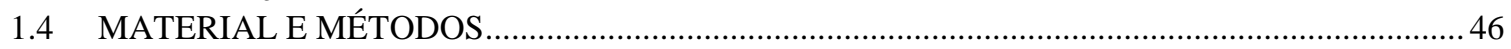

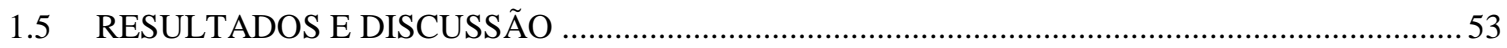

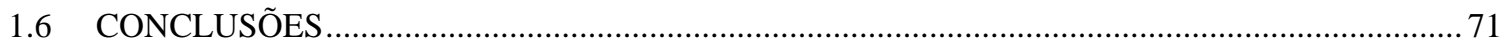

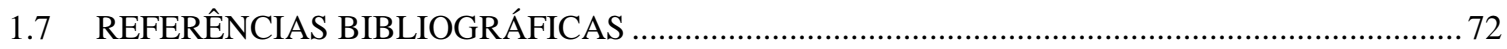

CAPÍTULO 2 CARACTERIZAÇÃO MORFOAGRONÔMICA, FÍSICO-QUÍMICA E QUANTIFICAÇÃO DOS TEORES DE CAROTENOIDES E DE ANTOCIANINAS

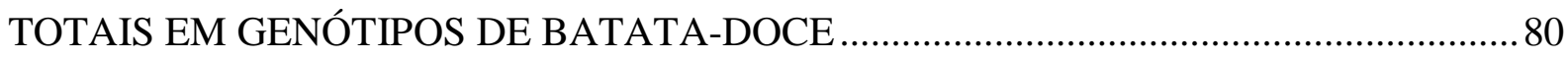

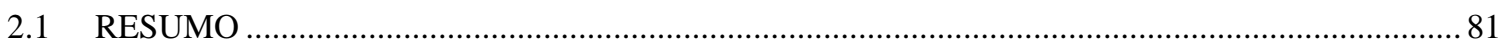

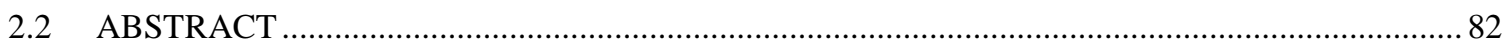

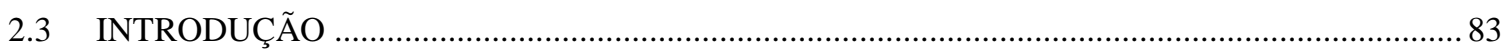

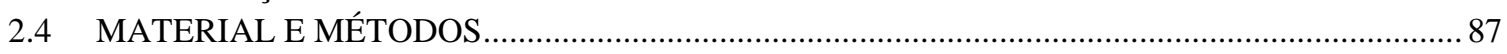

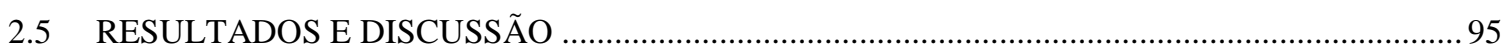

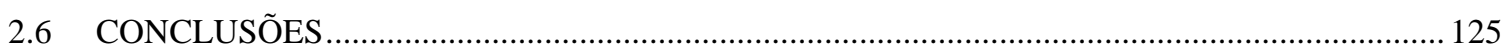

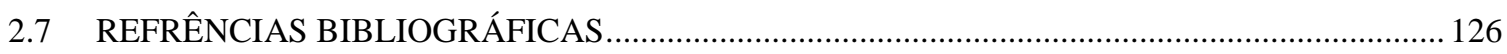


CAPÍTULO 3 DESEMPENHO MORFOAGRONÔMICO DE GENÓTIPOS DE BATATA-

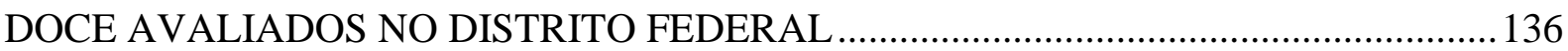

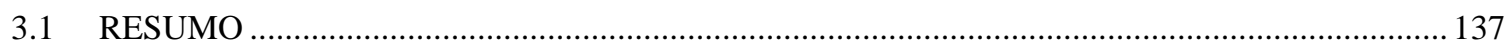

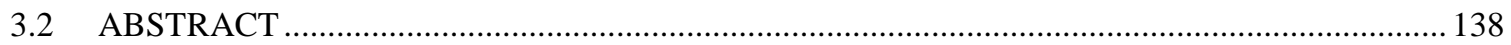

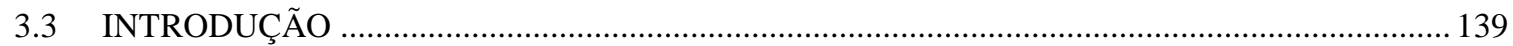

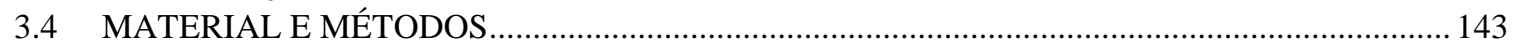

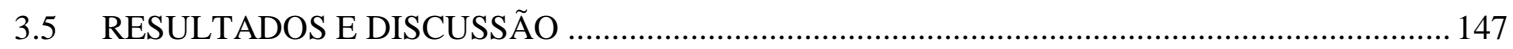

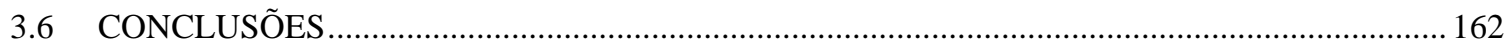

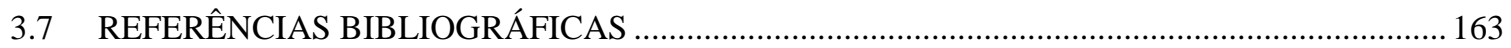

CAPÍTULO 4 REAÇÃO DE GENÓTIPOS DE BATATA-DOCE À INFECÇÃO POR $M$. JAVANICA, M. INCOGNITA RAÇA 1 E M. ENTEROLOBII ............................................. 169

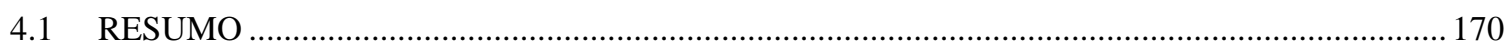

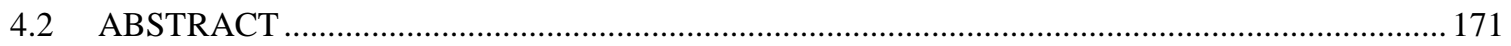

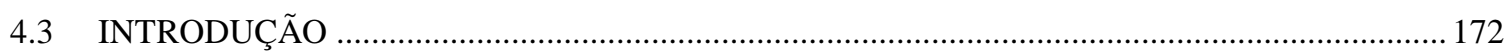

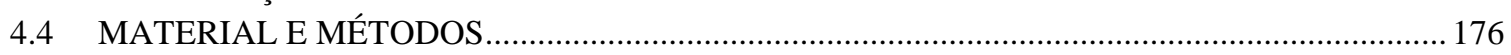

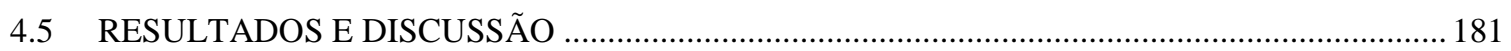

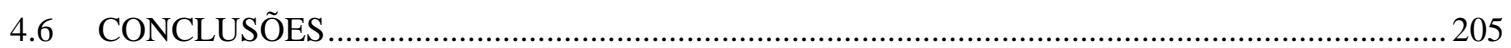

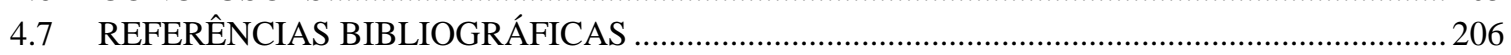

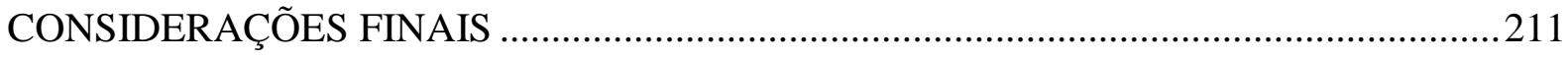

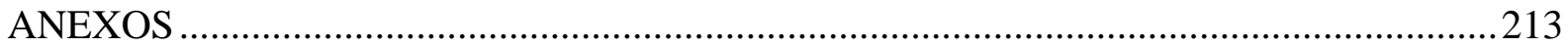




\section{NOMENCLATURA}

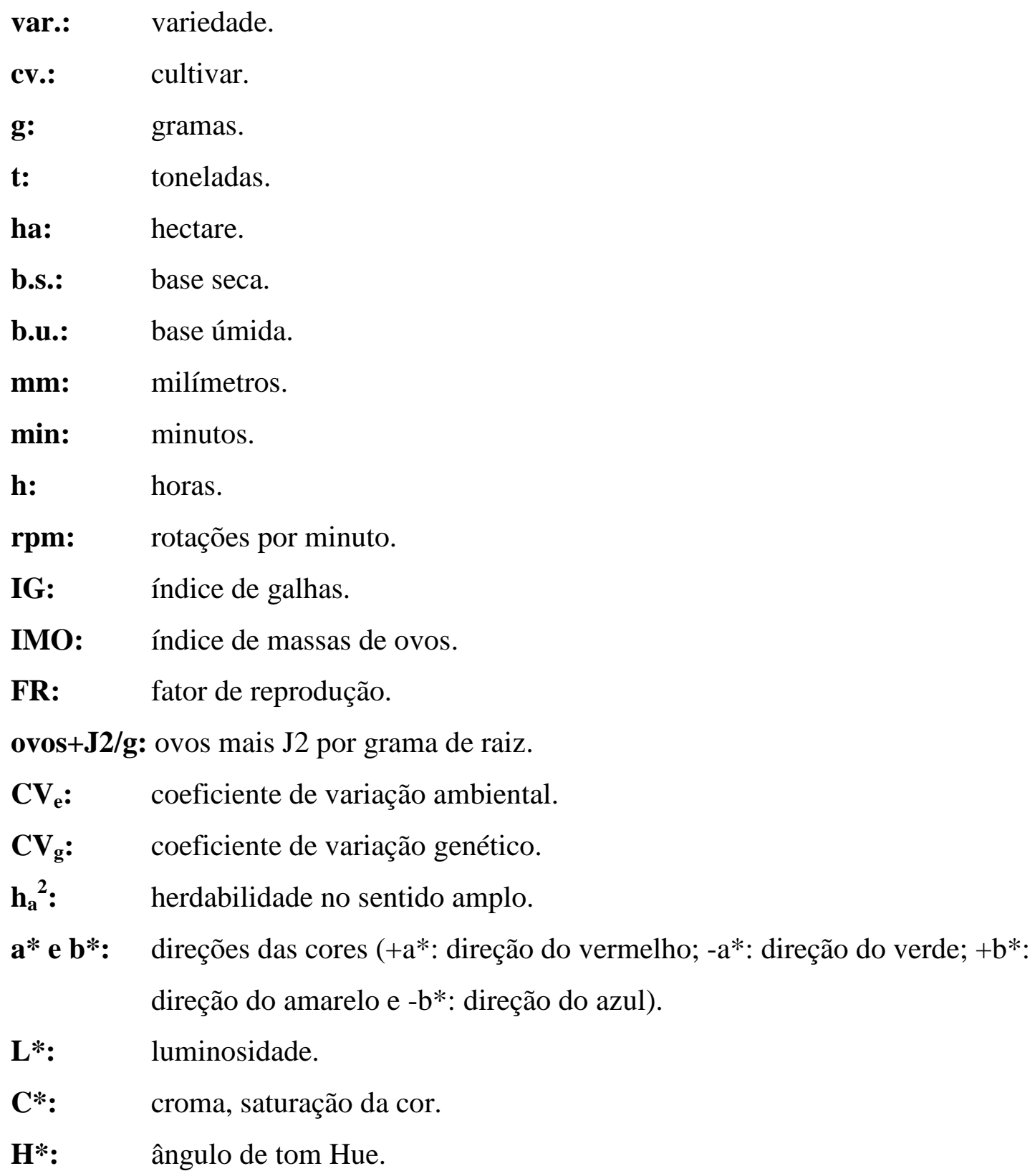




\section{RESUMO}

A batata-doce é uma importante cultura tuberosa cultivada em regiões tropicais, subtropicais e temperadas do mundo. É conhecida como uma excelente fonte de vitaminas do complexo B, ácido ascórbico, $\alpha$-tocoferol, fibra dietética, minerais e polissacarídeos. Adicionalmente, algumas variedades são rica fonte de fitoquímicos, como o $\beta$-caroteno, precursor da vitamina A e antocianinas, compostos fenólicos que apresentam diversas funções fisiológicas no organismo humano. Contudo, vários fatores são limitantes para a produção da cultura; dentre eles, a ocorrência de insetos de solo e nematoides, que danificam severamente as raízes tuberosas, depreciando a sua aparência e provocando danos diretos à produção. Foram realizados três experimentos em campo com o objetivo de avaliar características morfoagronômicas e físico-químicas e a resistência a insetos de solo de clones de batata-doce; e um experimento em casa de vegetação visando avaliar a reação de genótipos de batata-doce à infecção por $M$. javanica, $M$. incognita raça 1 e $M$. enterolobii em Brasília - DF. No primeiro ensaio foram estudados 23 genótipos, sendo avaliados 17 caracteres morfoagronômicos e físico-químicos das raízes. Constatou-se que a maioria dos materiais genéticos avaliados foram similares com relação aos descritores utilizados. Porém há possibilidade de obtenção de variabilidade genética e genótipos superiores, cruzando-se genitores dissimilares como o clone CNPH 69, que se destacou por suas altas produtividades comercial e total; o clone CNPH 59, que apresentou altas produtividades e altos teores de matéria seca e de sólidos solúveis totais; o clone CNPH 80, que exibiu bom formato e moderada resistência aos insetos de solo; a cultivar Brazlândia Rosada, que apresentou altos teores de amido e alta produtividade e o acesso CNPH 55, que mostrou o maior teor de proteína e alto teor de fibra bruta. No segundo experimento foram caracterizados morfoagronomicamente 26 genótipos de batata-doce. Posteriormente avaliaram-se as características físico-químicas de 13 materiais. As cultivares Brazlândia Roxa, Beauregard, BRS Rubissol, Princesa e Brazlândia Branca e os clones CNPH 60, CNPH 46, CNPH 1796 e CNPH 08, com altas produtividades, atingiram mais de $80 \%$ de raízes comerciais. Os clones CNPH 1796, CNPH 80, CNPH 08 e CNPH 05 mostraram aptidão para mesa. Os acessos CNPH 69 e CNPH 66 podem ser boas alternativas para processamento industrial ou alimentação animal. Os clones CNPH 05, CNPH 1232 e a cultivar Beauregard proporcionaram os maiores teores de fibra bruta. Os genótipos CNPH 05, BRS Rubissol, 
Beauregard e CNPH 1796, destacaram-se com relação aos conteúdos mais elevados de proteína bruta. Foi observado na cultivar Brazlândia Roxa o maior rendimento de amido. As maiores concentrações de carotenoides foram observadas nos genótipos Beauregard, BRS Amélia e CNPH 1232. No terceiro ensaio foi avaliado o desempenho morfoagronômico de 30 genótipos de batata-doce. Verificou-se que os clones CNPH 1232, CNPH 1357, CNPH 1298 , CNPH 1197 e CNPH 1208 e as cultivares Beauregard e Brazlândia Branca destacaram-se quanto ao rendimento total de raízes. Os clones CNPH 1310 e CNPH 1192, com altas produtividades totais, apresentaram suscetibilidade aos insetos de solo e os formatos menos desejáveis. As características produtividade comercial, número de raízes comerciais por planta, produtividade total, comprimento, diâmetro, porcentagem de raízes comerciais, formato e número total de raízes por planta, evidenciaram alta presença do componente genético na expressão destes caracteres e grande possibilidade de sucesso com a seleção. No quarto experimento o trabalho objetivou avaliar o nível de resistência de 44 genótipos de batata-doce aos nematoides-das-galhas do gênero Meloidogyne (M. javanica, M. incognita raça 1 e $M$. enterolobii). A classificação dos níveis de resistência foi realizada de acordo com o fator de reprodução dos nematoides. $M$. javanica foi a espécie menos agressiva infectando $9,09 \%$ dos genótipos. A raça 1 de $M$. incognita reproduziu-se exitosamente em 47,73\% dos materiais. M. enterolobii foi a espécie mais virulenta tendo como hospedeiros suscetíveis $79,55 \%$ dos clones avaliados. Dos 44 genótipos de batata-doce avaliados, 52,27\% foram resistentes a $M$. javanica e $M$. incognita raça $1 ; 18,18 \%$ foram resistentes à infecção por $M$. javanica e $M$. enterolobii e 13,64\% foram resistentes a $M$. incognita raça 1 e $M$. enterolobii e simultaneamente a $M$. javanica, $M$. incognita raça 1 e $M$. enterolobii. As correlações entre a resistência à infecção por $M$. javanica, $M$. incognita raça 1 e $M$. enterolobii e as cores da periderme e da polpa dos tubérculos não foram estatisticamente significativas.

Palavras-chave: Ipomoea batatas, dissimilaridade, herdabilidade, características morfoagronômicas e físico-químicas, Meloidogyne spp., fator de reprodução. 


\section{ABSTRACT}

Sweet potato is an important tuberous crop grown in the tropics, sub-tropics and warm temperate regions of the world. It is known as an excellent source of B vitamins, ascorbic acid, $\alpha$-tocopherol, dietary fiber, minerals and polysaccharides. Additionally, some varieties are rich source of phytochemicals, such as $\beta$-carotene, vitamin A precursor and anthocyanins, phenolic compounds which show various physiological functions in the human body. However, several factors are limiting for the production of the culture; among them, the occurrence of soil insects and nematodes, which severely damage the tuberous roots, depreciating their appearance and causing direct damage to the production. Three experiments were conducted, with the objective of evaluating morphoagronomic and physicochemical characteristics and the resistance to soil insects of sweet potato clones; and one experiment in greenhouse to evaluate the reaction of sweet potato genotypes to infection by $M$. javanica, $M$. incognita race 1 and $M$. enterolobii in Brasília - DF. In the first experiment, 23 genotypes were studied, being evaluated 17 morphoagronomic and physicochemical characteristics of the roots. It was found that the most of the genotypes analyzed is similar with respect to the descriptors used. However, it is possible to obtain genetic variability and superior genotypes, crossing genetically dissimilar parents as the CNPH 69 clone, which stood out for its high marketable and total yield; the CNPH 59 clone, which in addition to its high productivity showed high content of dry matter and total soluble solids; the CNPH 80 clone, which exhibited good shape and moderate resistance to soil insects; the Brazlândia Rosada cultivar,

which showed high levels of starch and productivity and the CNPH 55 access; which showed the highest protein content and high crude fiber content. In the second experiment were characterized morpho-agronomically 26 sweet potato genotypes. Subsequently, the physicochemical characteristics of 13 materials were evaluated. The Brazlândia Roxa, Beauregard, BRS Rubissol, Princesa and Brazlândia Branca cultivars and the CNPH 60, CNPH 46, CNPH 1796 and CNPH 08 clones, with high total yield, reached more than $80 \%$ of marketable roots. The CNPH 1796, CNPH 80, CNPH 08 and CNPH 05 clones showed suitability for human consumption. The CNPH 69 and CNPH 66 accessions can be good alternatives for industrial processing or animal feed. The CNPH 05, CNPH 1232 clones and the Beauregard cultivar provided the highest crude fiber contents. The CNPH 05, BRS Rubissol, Beauregard and CNPH 1796 genotypes, stood out in relation to the highest crude 
protein contents. The Brazlândia Roxa cultivar showed the highest yield of starch. The highest total carotenoids content were observed in the Beauregard, BRS Amélia and CNPH 1232 genotypes. In the third experiment the morphoagronomic performance of 30 sweet potato genotypes was evaluated. It was found that the CNPH 1232, CNPH 1357, CNPH 1298, CNPH 1197 and CNPH 1208 clones and the Beauregard and Brazlândia Branca cultivars, stood out in relation to the total yield of roots. The CNPH 1310 and CNPH 1192 clones, with high total yields, showed susceptibility to soil insects and the less desirable shapes of roots. The characteristics marketable yield, number of marketable roots per plant, total yield, length, diameter, percentage of marketable roots, shape and total number of roots per plant, showed high presence of the genetic component in the expression of these characteristics and great possibility of successful with the selection. In the fourth experiment, the study aimed to evaluate the resistance level of 44 sweet potato genotypes to root-knot nematodes of the genus Meloidogyne (M. javanica, $M$. incognita raça 1 e $M$. enterolobii). The classification of the resistance levels was defined by the nematodes reproduction factors. $M$. javanica was the less aggressive specie infecting $9.09 \%$ of the genotypes. $M$. incognita race 1 reproduced successfully on $47.73 \%$ of the materials. $M$. enterolobii was the most virulent specie, which had as susceptible hosts $79.55 \%$ of the clones. Among the 44 sweet potato genotypes studied, $52.27 \%$ were resistant to $M$. javanica and $M$. incognita race $1 ; 18.18 \%$ were resistant to the infection by $M$. javanica and $M$. enterolobii and $13.64 \%$ were resistant to $M$. incognita race 1 and $M$. enterolobii and simultaneously to $M$. javanica, $M$. incognita race 1 and $M$. enterolobii. Correlations between the resistance to the infection by $M$. javanica, $M$. incognita race 1 and M. enterolobii and the colors of periderm and flesh of storage roots were not statistically significant.

Keywords: Ipomoea batatas, dissimilarity, heritability, morphoagronomic and physicochemical characteristics, Meloidogyne spp, nematode reproduction factor. 


\section{INTRODUÇÃO}

A batata doce (Ipomoea batatas Lam.) é uma das culturas alimentares mais importantes no mundo (KIM et al., 2012), sendo frequentemente cultivada em países em desenvolvimento, inclusive no Brasil, especialmente no Nordeste, onde constitui a principal hortaliça consumida (CASTRO e ANDRADE, 1995; COLLINS et al., 1991; ROESLER et al., 2008). Por ser uma planta de clima tropical e subtropical é de fácil cultivo e ampla adaptabilidade, apresentando baixo custo de produção devido à sua rusticidade (SILVEIRA e MALUF, 1993).

No mundo, uma população estimada de três bilhões de pessoas sofre os efeitos da deficiência de micronutrientes. Dentre os grupos que correm maior risco de morte prematura, de deterioração de sua capacidade cognitiva e de contrair doenças por consumirem dietas pobres em micronutrientes essenciais, particularmente em ferro, vitamina A, iodo e zinco, estão as mulheres e as crianças da África Subssariana, da Ásia meridional, do Sudoeste Asiático, da América Latina e do Caribe (GIORI, 2010). A batata-doce é um vegetal altamente nutritivo, rico em vitaminas $\left(\mathrm{B}_{1}, \mathrm{~B}_{2}, \mathrm{C}\right.$ e $\left.\mathrm{E}\right)$, minerais ( $\mathrm{Ca}, \mathrm{Mg}, \mathrm{K}$ e $\mathrm{Zn}$ ), fibra dietética, amido, açúcares solúveis e apresenta alta concentração de $\beta$-caroteno nos seus tecidos (CHANDLER e SCHWARTZ, 1988; FURUTA et al., 1998; KIM et al., 2012; XU et al., 2014).

Os seres humanos necessitam de uma dieta diversificada e nutricionalmente balanceada para a manutenção da saúde, dependendo em grande parte das plantas para as suas necessidades nutricionais diárias (CHAKRABORTY et al., 2010). O interesse nos carotenoides aumentou durante a última década, já que estes compostos não são apenas pigmentos naturais e precursores da vitamina $\mathrm{A}$, eles têm sido propostos como agentes de prevenção de câncer e inibidores de úlcera, doenças oculares e de ataques cardíacos (CHANDLER e SCHWARTZ, 1988; CRAFT e SOARES, 1992; KRINSKY e JOHNSON, 2005).

Outros compostos que têm recebido considerável atenção nos últimos anos são as antocianinas, compostos fenólicos pertencentes ao grupo dos flavonoides e que se encontram presentes em grandes quantidades em variedades de batata-doce de polpa roxa. Os flavonoides apresentam excelentes propriedades biológicas (KIM et al., 2012), devido à sua capacidades para induzir a inibição da proliferação celular, paragem do ciclo celular e 
apoptose em células cancerígenas específicas e às suas atividades antioxidantes, antiinflamatórias, antihepatotóxica, antialérgica, antiaterogênica e antiosteoporótica (BIRT, et al., 2001; DI CARLO et al., 1999).

Vários fatores são limitantes para a produção de batata-doce. Dentre eles, o mais importante é o processo de multiplicação vegetativa, por meio de ramas e raízes, que favorece a disseminação de pragas e doenças durante os sucessivos cultivos, resultando em uma queda significativa da produção (CASTRO et al., 2008). Dentre as principais pragas, destacam-se os insetos de solo e os nematoides-das-galhas, que danificam severamente as raízes tuberosas, depreciando a sua aparência e comprometendo a sua qualidade.

Os nematoides-das-galhas, Meloidogyne spp., estão entre as pragas mais prejudiciais para a batata-doce (GOMES, 2014). Eles estão amplamente distribuídos e são de grande preocupação em relação à produção nos trópicos, subtrópicos e regiões quentes de todo o mundo. Várias espécies de nematoides incluindo $M$. arenaria, M. hapla, $M$. incognita e $M$. javanica infectam a batata-doce (JATALA, 1991).

A ocorrência destes nematoides pode causar rachaduras longitudinais nas raízes, provocando danos diretos à produção e facilitando a penetração e o estabelecimento de muitos organismos secundários e/ou patogênicos, que podem, posteriormente, levar ao apodrecimento das raízes tuberosas. Em adição aos seus efeitos diretos, estes parasitas interagem com outros agentes patogênicos para desenvolver doenças complexas (JATALA, 1991; SILVEIRA e MALUF, 1993).

Os fitonematoides em sistemas de cultivo de produção intensiva têm sido controlados principalmente por nematicidas. No entanto, vários destes produtos foram retirados do mercado nas últimas décadas, devido ao impacto negativo sobre o ambiente e a saúde humana e à demanda dos consumidores por alimentos seguros (OKA, 2010). Por tanto, o uso de variedades resistentes torna-se de grande importância para o controle destes parasitas.

Em relação aos insetos, no mundo, 270 espécies foram registradas como pragas de batata-doce em condições de campo ou armazenamento; destas Euscepes postfasciatus (Fairmaire), a broca da batata-doce, é a principal praga da cultura em alguns países da região do Caribe, oeste da Índia, sul do Pacífico, América Central e América do Sul, incluindo o Brasil (MENEZES, 2002). O ataque das larvas de insetos de solo mesmo que não danifiquem severamente as raízes tuberosas, formam orifícios e galerias superficiais que depreciam a sua aparência (SILVA et al., 2004). 
Todavia, a utilização de inseticidas na batata-doce não tem sido recomendada como prática de controle por ser ineficiente e antieconômica (JACKSON e BOHAC, 2006; FREITAS et al., 2001). Contudo, considerável atenção tem sido dada ao manejo de insetos de solo com a utilização de variedades resistentes, constituindo-se numa importante alternativa de controle (FRANÇA e RITSCHEL, 2002; WANDERLEY et al., 2004).

Desta forma, as estimativas de diversidade genética em qualquer espécie vegetal fornecem uma base para a elaboração de estratégias futuras para o melhoramento de culturas, conservação e uso sustentável (SAN-SAN-YI et al., 2008), sendo necessárias para a organização dos bancos de genes e para a identificação de combinações parentais que produzam progênies com máxima variabilidade genética, aumentando assim as chances de obtenção de indivíduos superiores (GONÇALVES et al., 2008).

Assim, a avaliação de genótipos de batata-doce é de fundamental importância para que a variabilidade possa ser utilizada de forma eficiente no desenvolvimento de novas cultivares (MASSAROTO, 2008).

Para subsidiar tais estudos, as atividades propostas neste trabalho são relevantes, no sentido de valorizar os recursos genéticos por meio de sua caracterização e seleção de materiais promissores. Seguindo este propósito, a presente pesquisa teve como objetivos gerais avaliar as características morfoagronômicas e físico-químicas; quantificar os teores de carotenoides e antocianinas totais e avaliar a resistência a insetos de solo e a reação à infecção por $M$. javanica, $M$. incognita raça 1 e $M$. enterolobii de genótipos de batata-doce do Banco de Germoplasma mantido na Embrapa Hortaliças. 


\section{REVISÃO BIBLIOGRÁFICA}

\subsection{Aspectos gerais}

A batata-doce [Ipomoea batatas (L.) Lam.] é uma dicotiledônea da família Convolvulaceae (COLLINS et al., 1991), que teve origem na América Tropical e foi levada para a Europa pelos portugueses e espanhóis, difundindo-se posteriormente para os demais continentes, sendo, atualmente, cultivada nas zonas tropicais, subtropicais e temperadas do mundo (CASTRO et al., 2009). O gênero Ipomoea abrange de 600 a 700 espécies, 500 delas concentradas nas Américas, principalmente nativas e com poucas espécies introduzidas (BORGES et al., 2009).

Com base na variabilidade de cores de polpa, a batata-doce com cor de polpa variando do branco ao creme é uma cultura generalizada no Pacífico, enquanto a batata-doce com polpa variando do amarelo ao alaranjado encontra-se predominantemente nos Estados Unidos (SHEKHAR et al., 2015).

Apresenta ampla adaptabilidade ecológica e agronômica, a qual está relacionada à variabilidade genética existente nas espécies cultivadas. A cultura é cultivada desde o paralelo $35 \mathrm{~N}$ até o paralelo $35 \mathrm{~S}$ e desde o nível do mar até quase $3.000 \mathrm{~m}$ de altitude. Na América do Sul, é cultivada na Cordilheira dos Andes, na Selva Amazônica, nas grandes planícies subtropicais e temperadas do Cone Sul, e, sob irrigação, no deserto na costa do Pacífico (HORTON e EWELL, 1991).

É a sexta cultura mais importante em termos de produção global depois do arroz, o trigo, a batata, o milho e a mandioca (GRACE et al., 2014; SHIH et al., 2009), sendo cultivada em mais de 111 países (SENANAYAKE et al., 2013).

Países em desenvolvimento produzem e consumem quase toda a batata-doce do mundo (HORTON e EWELL, 1991). Cerca de $80 \%$ da produção está na Ásia, 1,5\% na África e 4\% no restante do mundo. Apenas $1,5 \%$ da produção está em países industrializados como Estados Unidos e Japão. A China destaca-se como o maior produtor mundial atingindo 85 milhões de toneladas anualmente (FELTRAN e FABRI, 2010).

É uma cultura de grande repercussão socioeconômica para o Nordeste, que apresenta a maior área plantada (15.839 ha), com uma produção de 142.053 t e um rendimento médio de $9,43 \mathrm{t} \mathrm{ha}^{-1}$, representando $28,11 \%$ da produção nacional. O estado de Sergipe, com uma 
produção de $44.397 \mathrm{t}$ e rendimento médio de $14,37 \mathrm{t} \mathrm{ha}^{-1}$ é o maior produtor do Nordeste e o segundo produtor nacional. Contudo, a região Sul, com uma área plantada de 15.835 ha, é a maior produtora, com uma produção em 2013 de 227.354 t e um rendimento médio de 14,36 t $\mathrm{ha}^{-1}$, representando 44,99\% da produção nacional. O estado do Rio Grande do Sul, com uma produção de 166.354 t é o primeiro produtor nacional e maior produtor do Sul, embora seu rendimento médio $\left(13,42 \mathrm{t} \mathrm{ha}^{-1}\right)$ seja considerado baixo, comparativamente com Santa Catarina (17,42 $\left.\mathrm{t} \mathrm{ha}^{-1}\right)$ e Paraná (18,07 t ha $\left.{ }^{-1}\right)$ (IBGE, 2013).

Já as regiões Sudeste, Centro-Oeste e Norte, são responsáveis por 23,63; 1,99 e 1,28\%, respectivamente da produção nacional. Apenas para o rendimento médio por área é que as regiões Sudeste e Centro-Oeste se destacam (17,39 e 31,53 $\mathrm{t} \mathrm{ha}^{-1}$, respectivamente), ficando na frente das outras regiões do país, segundo dados do IBGE (2013).

É uma hortaliça que se destaca pela facilidade de cultivo, rusticidade, ampla adaptação a diferentes tipos de solo e clima, alta tolerância à seca e baixo custo de produção (ANDRADE JÚNIOR et al., 2012; RUKUNDO et al., 2013).

No Brasil, esta cultura tem sido cultivada, ao longo do tempo, de maneira empírica pelas famílias rurais de todas as localidades, principalmente para seu próprio consumo e secundariamente para a alimentação do gado e venda (CASTRO et al., 2009; FELTRAN e FABRI, 2010; HORTON e EWELL, 1991). A maioria das propriedades agrícolas são caracterizadas por manter estrutura de trabalho envolvendo apenas mão-de-obra familiar, utilizando a batata-doce como cultura de subsistência (CASTRO e OLIVEIRA, 2007).

Consequentemente, tem sido gerada pouca informação científica sobre aspectos técnicos e socioeconômicos da cultura, seus produtores e consumidores. Também, pouco é conhecido sobre as pragas da batata-doce e das variedades que são mais comumente cultivadas por agricultores ou preferidas por consumidores (HORTON e EWELL, 1991).

\subsection{Botânica e características da batata-doce}

Segundo Huamán (1992) a classificação sistemática da batata-doce é: família Convolvulaceae, tribo Ipomoeae, gênero Ipomoea, subgênero Quamoclit; seção batatas; espécie Ipomoea batatas (L.) Lam. É o único membro da família hexaplóide, com número base de cromossomos $x=15(2 n=6 x=90)$.

É uma planta tuberosa que apresenta ciclo curto de produção (4-5 meses), sendo cultivada como cultura anual, apesar de ser perene. A família Convolvulaceae inclui cerca de 
45 gêneros e 1.000 espécies, mas apenas Ipomea batatas é de importância econômica como alimento (SENANAYAKE et al., 2013).

A planta possui caule herbáceo de hábito prostrado, com ramificações de tamanho, cor e pilosidade variáveis; folhas largas, com formato, cor e recortes variáveis; pecíolo longo; flores hermafroditas, mas de fecundação cruzada, devido à sua autoincompatibilidade esporofítica; frutos do tipo cápsula deiscente com duas, três ou quatro sementes com $6 \mathrm{~mm}$ de diâmetro e cor variando desde castanho-clara a negra. Da fertilização da flor à deiscência do fruto transcorrem seis semanas (EDMOND e AMMERMAN, 1971; HUAMÁN, 1992).

As cultivares de batata-doce apresentam diversos hábitos de floração. Em condições normais, algumas cultivares não florescem, outras produzem poucas flores e outras florescem profusamente (HUAMÁN, 1992).

O sistema radicular da batata-doce possui dois tipos de raiz: a de reserva ou tuberosa, que constitui a principal parte de interesse comercial, e a raiz absorvente, responsável pela absorção de água e extração de nutrientes do solo. As raízes tuberosas se formam desde o início do desenvolvimento da planta, sendo facilmente identificadas pela maior espessura, pela pouca presença de raízes secundárias e por se originarem dos nós (HUAMÁN, 1992; SILVA et al., 2008). Uma planta produz de uma a várias raízes tuberosas na maturidade, geralmente entre 4 e 7 (SENANAYAKE et al., 2013). As raízes absorventes se formam a partir do meristema cambial, tanto nos nós, quanto nos entrenós. São abundantes e altamente ramificadas, o que favorece a absorção de nutrientes (HUAMÁN, 1992; SILVA et al., 2008).

As raízes podem apresentar formato redondo, oblongo, fusiforme ou alongado. Podem conter veias e dobras e possuir pele lisa ou rugosa. Além das características genéticas o formato e a presença de dobras são afetados pela estrutura do solo e pela presença de torrões, pedras e camadas compactadas do solo, justificando-se a preferência por solos arenosos (HUAMÁN, 1992; SILVA et al., 2008).

Tanto a pele quanto a polpa apresentam diversas colorações, que podem variar entre alaranjada, vermelha, vermelha-arroxeada, roxa, salmão, amarela, creme e branca. A intensidade da cor pode variar com as condições ambientais em que a planta cresce. A escolha depende muito da tradição do local de comercialização, pois alguns locais preferem raízes tuberosas de pele roxa e polpa creme e outros de pele e polpa claras (HUAMÁN, 1992; SILVA et al., 2008). 


\subsection{Importância nutricional e econômica}

A batata-doce produz dois tipos de alimentos úteis a partir da mesma planta: as raízes tuberosas e a parte aérea, sendo que a parte aérea contém duas vezes o nível de proteína das raízes. Enquanto seu teor de proteína é relativamente baixo, a qualidade da proteína é extraordinariamente alta, ocupando em países em desenvolvimento a terceira posição entre as principais culturas alimentares na produção de proteína por área e tempo (kcal/ha/dia), que é superior à do arroz e dez vezes maior do que a da mandioca, tendo potencial para fornecer cerca de dois milhões de toneladas métricas de proteína no mundo inteiro (FELTRAN e FABRI, 2010; FONSECA et al., 2008; HORTON e EWELL, 1991; MOULIN et al., 2012; WALTER et al., 1984).

A batata-doce fornece também um teor de calorias relativamente alto $(36,30 \mathrm{kcal} / \mathrm{ha} / \mathrm{dia})$ quando comparada a outras culturas como a mandioca, o trigo, o arroz e o milho, que fornecem 28,90; 32,24; 36,07 e 37,98 kcal/ha/dia, respectivamente (SCOTT et al., 2000). A porcentagem de matéria seca das raízes tuberosas é de até $44 \%$, e seu principal componente são os carboidratos, com aproximadamente 90\%, principalmente amido (SHEKHAR et al. 2015). Igualmente, as raízes são utilizadas como fonte de fibras dietéticas, que têm potencial para reduzir a incidência de uma variedade de doenças no homem, incluindo o câncer de cólon, diabetes, doenças cardíacas e distúrbios digestivos (VIMALA et al., 2011).

Adicionalmente, esta hortaliça fornece uma série de nutrientes alimentares que são valiosos para combater certos problemas nutricionais graves e generalizados em países em desenvolvimento. A principal dessas características é o teor extremamente alto de carotenoides precursores de vitamina A (como o $\beta$-caroteno) principalmente nas raízes de variedades com cor de polpa alaranjada. A deficiência de vitamina A (xeroftalmia) é um dos principais problemas de saúde pública em alguns países em desenvolvimento. Tanto a parte aérea, quanto as raízes, são fontes importantes de outras vitaminas, principalmente ácido ascórbico. Fornece também quantidades módicas de várias vitaminas do complexo B, incluindo niacina, tiamina, piridoxina, ácido fólico e riboflavina. Destaca-se ainda por possuir minerais, principalmente potássio, cálcio e ferro (FELTRAN e FABRI, 2010; FONSECA et al., 2008; HORTON e EWELL, 1991; MOULIN et al., 2012; ROSE e VASANTHAKAALAM, 2011). Variedades de polpa roxa também possuem quantidades significativas de antocianinas (XU et al., 2014). 
Esta hortaliça é uma matéria prima muito versátil, o elevado número de cultivares com características diferentes é um fator que aumenta a potencialidade de uso industrial, para a produção de etanol e seus derivados e para a extração de amido. Além destes, a batata-doce pode ser usada para a obtenção de produtos industrializados de maior valor agregado como a fabricação de tecidos, papel, cosméticos, adesivos, farinhas pré-gelatinizadas, talharim, corantes, açúcares, xaropes, cereais pré-cozidos, snacks e rações para animais (CASTRO et al., 2008; FELTRAN e FABRI, 2010; LEBOT et al., 2011; MOULIN et al., 2012; SILVEIRA, 2008; SOUZA, 2000).

Embora a batata-doce ainda seja pouco utilizada para a produção de etanol, no Brasil, a espécie apresenta grande potencial (MARTINS et al., 2014). Alves et al. (2014) avaliando o desempenho de clones de batata-doce do Banco Ativo de Germoplasma da UFS para etanol, obtiveram rendimentos médios variando de 76,30 a 178,70 litros de etanol por tonelada de raiz. De acordo com estes autores, os acessos com as maiores médias e com produtividades elevadas podem ser potencialmente competitivos com a própria cana-de-açúcar para a produção de etanol, a qual apresenta rendimentos de 86 litros de etanol hidratado por tonelada de cana (NOGUEIRA et al., 2008).

O plantio de batata-doce está ligado diretamente à finalidade da produção, preferência do mercado e do consumidor (FELTRAN e FABRI, 2010).

\subsection{Carotenoides}

Os carotenoides vêm sendo estudados sob vários aspectos, especialmente, no que diz respeito à sua ação fisiológica e à sua qualificação e quantificação, em razão da sua larga presença em hortaliças e frutas e variedade de arranjos estruturais que levam a uma diversidade de funções (CAMPOS et al., 2006).

Estes compostos são pigmentos orgânicos encontrados em plantas, nas que atuam como antioxidantes, evitando os danos causados por estresses ambientais, como a alta incidência solar, as elevadas temperaturas, a radiação ultravioleta e a seca (GOO et al., 2014). Também desempenham um papel importante como precursores da vitamina A na dieta humana (BECHOFF et al. 2010).

Dentre as deficiências nutricionais de maior importância epidemiológica, a deficiência de vitamina A ainda hoje assume graves proporções no contexto da saúde pública em todo o mundo (MARTINS et al., 2007). Na região das Américas, prevalece como uma doença 
subclínica generalizada em muitos países, onde estima-se que mais de um quarto das crianças menores de 5 anos são afetadas (OPS, 2001).

A vitamina A é um nutriente essencial para todas as espécies animais, devido ao seu papel crítico na reprodução, no sistema imunológico, na visão, bem como na manutenção da diferenciação celular (UNDERWOOD, 1994). A deficiência prolongada dessa vitamina causa alterações no revestimento ocular, levando a um quadro de cegueira irreversível (xeroftalmia e ceratomalácia) (MARTINS et al., 2007) e contribui significativamente para as altas taxas de morbidade e mortalidade por infecções comuns na infância (OPS, 2001).

Existem mais de 600 carotenoides na natureza (GOMES et al., 2005), sendo os hidrocarbonetos: $\beta$-caroteno, $\alpha$-caroteno e licopeno e as xantofilas ou carotenoides oxigenados: $\beta$-criptoxantina, luteína e zeaxantina, os mais importantes encontrados em alimentos (KRINSKY e JOHNSON, 2005). Porém apenas o $\beta$-caroteno, o $\alpha$-caroteno e a $\beta$ criptoxantina são importantes precursores da vitamina A na dieta humana, uma vez que eles são absorvidos e convertidos em vitamina A no organismo (BAUERNFEIND, 1972; GOMES et al., 2005; VAN JAARSVELD et al., 2005). Contudo, o $\alpha$-caroteno contribui com cerca da metade (53\%) da atividade pró-vitamínica A em relação ao $\beta$-caroteno (HUANG et al., 1999).

Os carotenoides também agem como antioxidantes sequestrando radicais livres e oxigênio singlete (ZACCARI et al., 2007). Tal efeito também vem sendo atribuído mais recentemente ao próprio retinol, do qual alguns carotenoides são precursores (BAYDAS et al., 2002). Uma única molécula de retinol ou $\beta$-caroteno é capaz de inativar vários radicais oxigênio singlete antes de ser destruída (GOMES et al., 2005).

Agentes oxidantes provocam danos extensivos ao ADN, proteínas e lipídios. Esse dano (o mesmo que é produzido pela radiação) é um dos principais contribuintes para o envelhecimento e doenças degenerativas relacionadas com o envelhecimento, como o câncer, doenças cardiovasculares, enfraquecimento do sistema imunológico, disfunção cerebral e cataratas (AMES et al., 1993).

Antioxidantes são compostos que inibem ou atrasam a oxidação de outras moléculas através da inibição da iniciação ou propagação de reações em cadeia de oxidação. Entre os antioxidantes naturais encontram-se os compostos fenólicos (tocoferóis, flavonoides e ácidos fenólicos), os compostos nitrogenados (alcaloides, derivados de clorofila, aminoácidos e aminas), os carotenoides e o ácido ascórbico (VELIOGLU et al., 1998). 
Os carotenoides em alimentos são principalmente de origem vegetal, sendo o $\beta$-caroteno o carotenoide pró-vitamínico A mais conhecido e mais abundante. Pesquisas que indicam a batata-doce como uma boa fonte de $\beta$-caroteno têm levado à sua exploração comercial (CHANDLER e SCHWARTZ, 1988; CHAMPAGNE et al., 2010). A cor da polpa das raízes pode apresentar diversos tons de branco, creme, amarelo ou alaranjado, dependendo do teor de carotenoides. Em variedades de polpa alaranjada $90 \%$ de seus carotenoides totais são $\beta$ caroteno (BECHOFF et al., 2010; BENGTSSON et al., 2008; GRACE et al., 2014; K'OSAMBO et al. 1999; VIMALA et al., 2011).

\subsubsection{Estrutura química dos carotenoides}

Os carotenoides são geralmente tetraterpenoides de quarenta átomos de carbono, cujas estruturas básicas apresentam-se nas formas de cadeias alifáticas (Figura 1) ou cadeias alifáticas-alicíclicas (mistas) compostas por 8 unidades isoprênicas de cinco carbonos. $\mathrm{Na}$ molécula estas unidades seguem a chamada regra do isopreno, onde os grupos metilas extremos ou laterais $\left(\mathrm{CH}_{3}\right)$ se situam na posição 1:5 (ligação cabeça-cauda), tendo como exceção as ligações dos grupos metilas centrais da molécula, localizadas na posição 1:6 (ligação cauda-cauda). A pigmentação dos carotenoides é devida à presença de um sistema cromóforo na molécula (Figura 1), constituído por uma série de duplas ligações conjugadas (BAUERNFEIND, 1972; GIUFFRIDA et al., 2013; MELÉNDEZ-MARTÍNEZ et al., 2007).

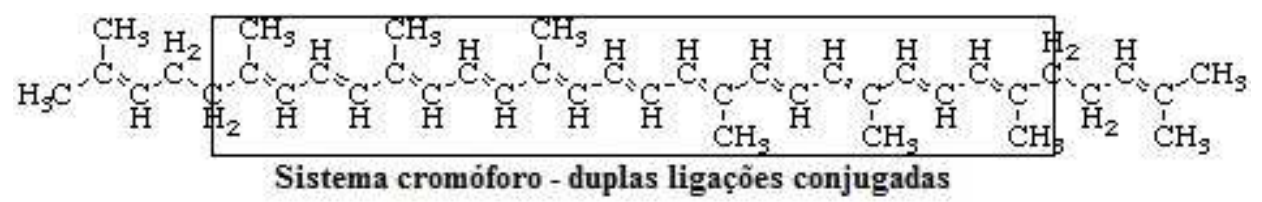

Figura 1 Fórmula estrutural dos carotenoides. Adaptado da IUPAC (1972).

Considerando-se as estruturas químicas presentes nas suas moléculas, os carotenoides podem ser divididos em dois grandes grupos: os carotenoides hidrocarbonetos ou carotenos, que contém somente carbono e hidrogênio e apresentam diversos graus de insaturação e os carotenoides oxigenados ou xantofilas, que contém oxigênio além de carbono e hidrogênio (BAUERNFEIND, 1972; AMBRÓSIO et al., 2006; PAIVA e RUSSELL 1999; GIUFFRIDA et al., 2013).

Em decorrência da presença das insaturações os carotenoides são sensíveis à luz, a temperatura, a acidez e a reações de oxidação. São compostos hidrofóbicos, lipofílicos, 
insolúveis em água e solúveis em solventes, como acetona, álcool e clorofórmio (AMBRÓSIO et al., 2006).

Alguns carotenoides são acíclicos, embora a maior parte deles contém anéis em uma ou em ambas as extremidades da molécula (MELÉNDEZ-MARTíNEZ et al., 2007). Dos mais de 600 carotenoides conhecidos, aproximadamente 50 são precursores da vitamina A. O carotenoide precursor possui pelo menos um anel de $\beta$-ionona não substituído, com cadeia lateral poliênica com um mínimo de 11 carbonos (Figura 2) (AMBRÓSIO et al., 2006).

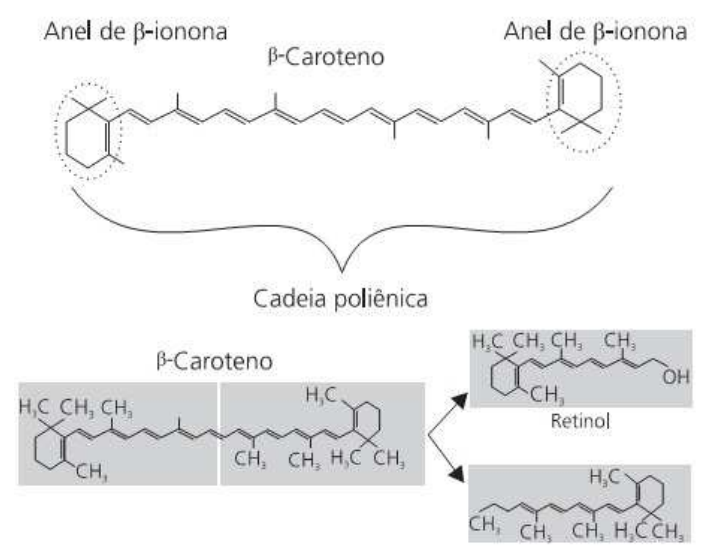

Figura 2 Estrutura química e clivagem do $\beta$-caroteno (AMBRÓSIO et al., 2006).

O $\beta$-caroteno existe naturalmente na configuração termodinamicamente mais estável e menos solúvel, a forma todo-trans, que apresenta a maior atividade pró-vitamínica A (CHANDLER e SCHWARTZ, 1988; COSTA et al., 2002). Contudo, a ocorrência natural de isômeros cis tem sido relatada com certa frequência (COSTA et al., 2002).

Tanto os carotenoides precursores de vitamina A como os não precursores, como a luteína, a zeaxantina e o licopeno, estão associados a uma redução do risco de câncer (KIM et al., 2001; KIM et al., 2012; ZIEGLER, 1991), e os possíveis mecanismos de proteção são por intermédio do sequestro de radicais livres, modulação do metabolismo do carcinoma, inibição da proliferação celular, aumento da diferenciação celular via retinoides, estimulação da comunicação entre as células e aumento da resposta imune (AMBRÓSIO et al., 2006). Adicionalmente, o $\beta$-caroteno é um potente antioxidante com ação protetora contra doenças cardiovasculares (GALE et al., 2001; OSGANIAN et al., 2003). A oxidação do LDLcolesterol é fator crucial para o desenvolvimento da aterosclerose e o $\beta$-caroteno atua inibindo o processo de oxidação da lipoproteína (AMBRÓSIO et al., 2006). 


\subsection{Antocianinas}

As antocianinas compreendem o maior grupo de pigmentos solúveis em água no reino vegetal e pertencem ao grupo dos flavonoides, um constitutivo dos compostos fenólicos (BRIDGERS et al., 2010). São responsáveis pelas cores azul, roxa e vermelha da maioria das plantas (KIM et al., 2012). Em plantas empregadas na alimentação, as antocianinas são encontradas em pelo menos 27 famílias, 73 gêneros e uma infinidade de espécies. São particularmente associadas com frutas, mas também estão presentes em vegetais, raízes, tubérculos, bulbos, legumes, cereais e em certas partes de pétalas, folhas e flores (BRIDLE e TIMERLAKE 1997; GALVANO et al., 2004).

Os flavonoides representam uma grande classe de metabolitos secundários das plantas, dos quais as antocianinas são a classe mais conhecida, devido à vasta gama de cores resultante de sua síntese. As antocianinas são importantes para diversas funções dentro das plantas. A síntese de antocianinas em pétalas é destinada para atrair os polinizadores, enquanto em sementes e frutas pode ajudar na dispersão de sementes, tendo valor considerável na coevolução das interações animal-planta. As antocianinas e outros flavonoides podem também ser importantes dissuasivos (deterrentes) de alimentação, fornecer proteção contra os danos da irradiação UV-B, agir como fitoalexinas e agentes antibacterianos (COOPERDRIVER e BHATTACHARYA, 1998; HOLTON e CORNISH, 1995; KONG et al., 2003).

Até agora foram identificadas mais de 500 antocianinas (CASTAÑEDA-OVANDO et al., 2009) e 23 antocianidinas (formas agliconas das antocianinas) (KIM et al., 2012), das quais apenas seis (pelargonidina, cianidina, peonidina, delfinidina, petunidina e malvidina) são comumente encontradas nas plantas vasculares (CLIFFORD, 2000; KIM et al., 2012).

A batata-doce de polpa roxa (Ipomoea batatas L.) apresenta alta concentração de antocianinas nas raízes tuberosas, sendo a cianidina e a peonidina as principais antocianidinas (GODA et al., 1997; ODAKE et al., 1992; TERAHARA et al., 1999).

Estes pigmentos possuem múltiplos benefícios para a saúde, incluindo propriedades antineoplásicas, redução do risco de doença cardíaca coronária e exercem forte efeito anticancerígeno através de suas atividades antioxidantes e anti-inflamatórias, assim como de suas capacidades para induzir a inibição da proliferação celular, intercepção do ciclo celular e apoptose em células cancerígenas específicas (JIAO et al., 2012; KONG et al., 2003; WANG e STONER, 2008). Também oferecem propriedades antimutagênicas, antidiabéticas e terapêuticas, por exemplo, melhoram a acuidade visual e ajudam no tratamento de problemas 
circulatórios (BRIDGERS et al., 2010; BRIDLE e TIMBERLAKE, 1997; BROWN et al., 2003; CASTAÑEDA-OVANDO et al., 2009; CEVALLOS-CASALS e CISNEROSZEVALLOS, 2003; JIAO et al., 2012).

Outros estudos têm apontado que cultivares de batata-doce ricas em compostos fenólicos, como as antocianinas e outros polifenóis, apresentam alta atividade de sequestro de radicais livres e capacidade antioxidante (FURUTA et al., 1998).

\subsubsection{Estrutura química das antocianinas}

Estruturalmente as antocianinas, substâncias fenólicas, são glicosídeos e acilglicosídeos das antocianidinas, polihidróxi e polimetoxi derivados do íon 2-fenilbenzopirilium ou sais de flavilium (Figura 3) (COOPER-DRIVER, 2001; GALVANO et al., 2004; KONG et al., 2003; STRINGHETA e BOBBIO, 2000).

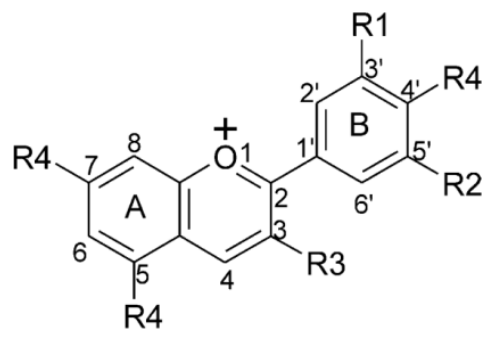

Figura 3 Estrutura geral das antocianidinas (KONG et al., 2003).

Possuem um esqueleto de 15 carbonos, com um anel cromático e outro aromático, e uma ou mais moléculas de açúcar ligadas em diferentes posições hidroxila da estrutura básica (GÓMEZ-ZELEDÓN e JIMÉNEZ, 2001).

A distribuição das seis antocianidinas mais comumente encontradas em frutas e vegetais é: cianidina $50 \%$, delfinidina $12 \%$, pelargonidina $12 \%$, peonidina $12 \%$, petunidina $7 \%$ e malvidina 7\% (KONG et al., 2003). Estas antocianidinas com diferentes substituições hidroxilo ou metoxilo na sua estrutura básica, flavílium ou 2-fenilbenzopirilium, são apresentadas na Figura 3 e na Tabela 4.1.

$\mathrm{Na}$ natureza, milhares de compostos de antocianinas já foram identificados devido à ocorrência de numerosos padrões de substituição, cujas estruturas variam em relação ao número de grupos hidroxílicos, ao grau de metilação destes grupos, à natureza e ao número de açúcares ligados à molécula e à posição dessas ligações, bem como à natureza e ao número de ácidos alifáticos e/ou aromáticos ligados ao açúcar (CASTAÑEDA-OVANDO et al., 2009; 
GALVANO et al., 2004; KÄHKÖNEN e HEINONEN, 2003; KONG et al., 2003; STRINGHETA e BOBBIO, 2000).

Tabela 4.1 Padrões de substituição das antocianidinas mais comumente encontradas em pigmentos naturais (COOPER-DRIVER, 2001).

\begin{tabular}{cccccccc}
\hline \multirow{2}{*}{ Composto } & \multicolumn{7}{c}{ Padrão de substituição } \\
\cline { 2 - 8 } & $\mathbf{3}$ & $\mathbf{5}$ & $\mathbf{6}$ & $\mathbf{7}$ & $\mathbf{3}$ & $\mathbf{4}$ & $\mathbf{5}$ \\
\hline Pelargonidina & $\mathrm{OH}$ & $\mathrm{OH}$ & $\mathrm{H}$ & $\mathrm{OH}$ & $\mathrm{H}$ & $\mathrm{OH}$ & $\mathrm{H}$ \\
Cianidina & $\mathrm{OH}$ & $\mathrm{OH}$ & $\mathrm{H}$ & $\mathrm{OH}$ & $\mathrm{OH}$ & $\mathrm{OH}$ & $\mathrm{H}$ \\
Peonidina & $\mathrm{OH}$ & $\mathrm{OH}$ & $\mathrm{H}$ & $\mathrm{OH}$ & $\mathrm{OCH}_{3}$ & $\mathrm{OH}$ & $\mathrm{H}$ \\
Delfinidina & $\mathrm{OH}$ & $\mathrm{OH}$ & $\mathrm{H}$ & $\mathrm{OH}$ & $\mathrm{OH}$ & $\mathrm{OH}$ & $\mathrm{OH}$ \\
Petunidina & $\mathrm{OH}$ & $\mathrm{OH}$ & $\mathrm{H}$ & $\mathrm{OH}$ & $\mathrm{OCH}_{3}$ & $\mathrm{OH}$ & $\mathrm{OH}$ \\
Malvidina & $\mathrm{OH}$ & $\mathrm{OH}$ & $\mathrm{H}$ & $\mathrm{OH}$ & $\mathrm{OCH}_{3}$ & $\mathrm{OH}$ & $\mathrm{OCH}_{3}$ \\
\hline
\end{tabular}

Existem mais de 250 antocianinas que ocorrem naturalmente e todas são glicosiladas por diferentes açúcares nas posições 3, 5 e 7, mas sempre ocorre a glicolisação na posição C-3. Glicose, arabinose, galactose, soforose e ramnose são os açúcares mais comuns ligados às antocianinas (STRINGHETA e BOBBIO, 2000; WANG et al., 1997). Já os ácidos mais envolvidos na acilação dos açúcares são os ácidos aromáticos, como o p-hidroxibenzóico, o cafeico e o ferúlico (KIM et al., 2012).

Segundo Truong et al. (2010) os pigmentos antociânicos em batata-doce de polpa roxa são predominantemente cianidina ou peonidina, ligados a glicose e/ou soforose, os quais podem ser acilados com ácido cafeico e/ou ácido $p$-hidroxibenzóico e/ou ácido ferúlico.

Vários autores têm demonstrado que os principais constituintes corantes nas raízes de batata-doce de polpa roxa são algumas antocianinas aciladas com alta estabilidade (FAN et al., 2008; GODA et al., 1997; ODAKE et al., 1992; PHILPOTT et al., 2003); podendo estar nas formas mono ou diaciladas de cianidina e peonidina (GODA et al., 1997; JIAO et al., 2012). Estas formas de antocianinas também contribuem para a alta atividade antioxidante da batata-doce de polpa roxa quando comparada à batata-doce de polpas branca, amarela e laranja (TEOW et al., 2007). Ainda segundo Yoshimoto et al. (2001) a antocianina tipo cianidina apresenta maior atividade antimutagênica em relação à antocianina tipo peonidina.

A atividade antioxidante das antocianinas está relacionada com as posições do grupo OH no íon flavílio (TRUONG et al., 2010). Tem sido documentado que a cianidina, com grupo $\mathrm{OH}$ no anel $\mathrm{B}$ das antocianinas, tem atividade antioxidante mais elevada do que a peonidina, a malvidina e a pelargonidina (WANG et al., 1997). Quanto maior o número de 
hidroxilas, maior a atividade como agente doador de $\mathrm{H}$ e de elétrons (BARREIROS et al., 2006).

Adicionalmente, os grupos metoxila e hidroxila, os açúcares e os grupos acila ligados na posição C-3 dos açúcares, têm um efeito importante sobre a cor e a reatividade das antocianinas. Antocianinas com dois ou mais grupos acila exibem excelente estabilidade numa ampla faixa de pH (STRINGHETA e BOBBIO, 2000). Já, a estabilidade das antocianidinas é influenciada pelos substituintes do anel B e a presença de grupos hidroxilo ou metoxilo, que diminuem a estabilidade da aglicona em meio neutro, sendo, portanto, a pelargonidina a antocianidina mais estável nestas condições. Contrariamente às agliconas, os monoglicosídeos (antocianinas ligadas a apenas uma molécula de glicose) e os diglicosídeos são mais estáveis em condições de $\mathrm{pH}$ neutro, pois as moléculas de açúcar evitam a degradação de compostos intermediários instáveis (FLESCHHUT et al., 2006).

Além do tipo, glicosilação e acilação da antocianidina, outros fatores como copigmentação, complexação de metais e pH das vacúolas interferem na cor das antocianinas (YOSHINAGA et al., 1999). Com o aumento do número de hidroxilas, a coloração das antocianinas muda de rosa para azul. Já a presença do grupo metoxila no lugar do grupo hidroxila reverte a tendência anterior (FIGUEIREDO et al., 1996; MAZZA e BROUILLARD, 1987).

\subsection{Nematoides da batata-doce}

Embora um grande número de espécies de nematoides estão associadas com a batatadoce, apenas umas poucas são de preocupação econômica (SCURRAH et al., 2005). Os principais fitonematoides que infectam a cultura são os nematoides-das-galhas: Meloidogyne arenaria, M. hapla, M. incognita e Meloidogyne javanica, seguidos pelos nematoides-daslesões-radiculares: Pratylenchus sp., principalmente Pratylenchus brachyurus e Pratylenchus zeae. Dentre outros fitonematoides associados com a cultura, citam-se: Aphelenchoides bicaudatus, Aphelenchus avenae, Dytilenchus sp., Helicotylenchus microcephalus, Rotylenchulus reniformis, e Scutellonema brachyurus (AGU, 2004a,b; COYNE et al., 2003; SCURRAH et al., 2005).

\subsubsection{Classificação do gênero Meloidogyne}

As espécies de Meloidogyne são uma pequena parte do Filo Nemata (ou Nematoda), que inclui parasitas do homem, dos animais e de plantas, além de espécies de vida livre no solo, 
água doce e no mar (TAYLOR e SASSER, 1978). O gênero Meloidogyne faz parte da classe Chromadorea, ordem Rhabditida, Subordem Tylenchina, Infraordem Tylenchomorpha, Superfamília Tylenchoidea e família Meloidogynidae (KARSSEN e MOENS, 2006).

\subsubsection{Gênero Meloidogyne em batata-doce}

Os nematoides-das-galhas são endoparasitas sedentários de plantas, incluídos dentro do gênero Meloidogyne Göldi, 1892, pertencentes a um relativamente pequeno, mas importante grupo de patógenos polífagos obrigatórios. É considerado o gênero mais destrutivo do mundo (JATALA, 1991; KARSSEN e MOENS, 2006).

Estão amplamente distribuídos no planeta e são a principal preocupação para a produção de batata-doce nas regiões tropicais, subtropicais e temperadas do mundo. Várias espécies de Meloidogyne incluindo M. arenaria (Neal) Chitwood, 1949; M. hapla Chitwood, 1949; M. incognita (Kofoid e White) Chitwood, 1949 e M. javanica (Treub) Chitwood, 1949, infectam a cultura (JATALA, 1991), sendo as últimas duas, as espécies de maior ocorrência em cultivos no Brasil (CHARCHAR e RITSCHEL, 2004).

O grau do dano ocasionado é influenciado pela espécie, raça, o nível de infestação e fatores como temperatura, umidade e tipo de solo (JATALA, 1991). As espécies de Meloidogyne desenvolvem-se bem em solos friáveis, arenosos, que constituem a maior parte das áreas de cultivo de batata-doce (SCURRAH et al., 2005).

Com base em sua capacidade de infectar diferentes hospedeiras, têm sido identificadas quatro raças de $M$. incognita e $M$. javanica e três raças de $M$. arenaria (CARNEIRO et al., 2003; PIEDRA-BUENA et al., 2011). Aparentemente as quatro raças de M. incognita atacam a batata-doce e a capacidade parasitária de cada uma delas varia segundo a suscetibilidade da planta, constituindo-se a espécie mais importante do gênero para a cultura, pois apresenta distribuição circumglobal (JATALA, 1991).

No entanto M. enterolobii (Yang e Eisenback, 1983) é atualmente considerada como uma das espécies mais importantes para América Latina e para os países de regiões tropicais e subtropicais, devido à sua ampla distribuição geográfica, ampla gama de hospedeiras e à sua capacidade para ultrapassar a resistência de importantes culturas, como o tomate, a pimenta e algumas culturas agronômicas que carregam o gene $M i-1$, o qual confere resistência a $M$. javanica, M. arenaria e M. incognita (MOENS et al., 2009; MELO et al., 2011; RODRÍGUEZ et al., 2007). Na literatura, são inúmeros os relatos de plantas descritas como 
resistentes a outras espécies de Meloidogyne e suscetíveis a M. enterolobii (MELO et al., 2011). Fargette (1987) constatou que a cultivar de batata-doce ' $\mathrm{CDH}$ ' cultivada no oeste da África, embora caracterizada como resistente a $M$. incognita, se mostrou suscetível a $M$. enterolobii.

Até o momento não foi detectado genótipo de batata-doce imune ao nematoide-dasgalhas (MASSAROTO, 2008). A rápida taxa de desenvolvimento e reprodução de Meloidogyne em boas hospedeiras, resulta, na maioria das espécies, em várias gerações durante uma safra, conduzindo a danos severos nas culturas (MOENS et al., 2009).

\subsubsection{Ciclo de vida}

O ciclo de vida de Meloidogyne spp. tem início com a deposição pelas fêmeas de ovos em massas gelatinosas compostas de uma matriz de glicoproteína que é produzida pelas suas glândulas retais, a qual mantém os ovos juntos e os protege contra os ambientes extremos e a predação. Estas massas geralmente contêm entre 500 e 1000 ovos em diferentes estádios de desenvolvimento embrionário (JATALA, 1991; KARSSEN e MOENS, 2006; MOENS et al., 2009).

Logo após a deposição dos ovos, ocorre a diferenciação para o primeiro estádio juvenil. Após a ecdise do primeiro estádio juvenil dentro do ovo, se origina o juvenil do segundo estádio (J2) que eclode através de um orifício na extremidade do ovo produzido por impulsos repetidos do estilete. Após a eclosão, o segundo estádio juvenil que é o estádio infectivo, se move para fora da massa de ovos e fica no solo até penetrar nas raízes da hospedeira. A capacidade de sobrevivência de Meloidogyne é aprimorada por várias adaptações fisiológicas e bioquímicas, incluindo a embriogênese tardia, a quiescência e a diapausa, e reservas lipídicas que prolongam a viabilidade até o J2 atingir e invadir uma hospedeira (JATALA, 1991; KARSSEN e MOENS, 2006; MOENS et al., 2009; TAYLOR e SASSER, 1978).

Os juvenis são atraídos por substâncias que emanam das raízes das plantas e penetram as raízes através da região de elongação celular; podendo também penetrar através de rupturas causadas pela emergência de raízes laterais ou através de rachaduras nas raízes tuberosas. Uma vez dentro, elas migram inter e intracelularmente através dos tecidos, separando as células na lamela média no córtex. Elas continuam a migrar até a zona de diferenciação na região vascular, chamada cilindro central podendo causar pouca ou nenhuma lesão. Este processo inclui tanto forças mecânicas quanto secreções enzimáticas do nematoide. Na região 
do cilindro central, o nematoide estabelece o seu sítio de alimentação, mantendo a extremidade anterior do seu corpo (cabeça) em contato com o cilindro vascular da raiz. Em resposta aos sinais do nematoide as células adjacentes à sua cabeça tornam-se hipertrofiadas e multinucleadas em hospedeiros suscetíveis (“células gigantes") e ocorre intensa multiplicação de células vegetais. As galhas podem resultar neste estádio e são produzidas pela introdução de reguladores de crescimento das glândulas de juvenis do segundo estádio nos tecidos vegetais (JATALA, 1991; KARSSEN e MOENS, 2006; MOENS et al., 2009; TAYLOR e SASSER, 1978).

Deste momento em diante como os nematoides desenvolvem-se, tornam-se sedentários e passam por três ecdises mais. Os juvenis do terceiro e quarto estádio (J3 e J4) não se alimentam devido à falta de um estilete funcional. Na última ecdise, os nematoides machos tornam-se longos e filiformes, revestidos externamente pela cutícula do quarto estádio juvenil. Os machos então escapam da última cutícula juvenil e se movem livremente no solo e não há nenhuma evidência de que se alimentem. Eles são frequentemente encontrados na matriz gelatinosa onde eles copulam as espécies anfimíticas. As fêmeas adultas se mantêm sedentárias, e continuam a se expandir à medida que amadurecem, tornando-se piriformes, produzindo grandes números de massas de ovos e consequentemente ocasionando a formação de galhas. O tempo requerido para completar o ciclo de vida depende das condições ambientais prevalentes e da suscetibilidade do hospedeiro (JATALA, 1991; KARSSEN e MOENS, 2006; MOENS et al., 2009; TAYLOR e SASSER, 1978).

Na maioria das vezes a reprodução é partenogênica. Os machos podem ser encontrados em espécies partenogenéticas quando as condições são desfavoráveis para o desenvolvimento da fêmea ou quando a densidade populacional é muito alta e há uma limitação da oferta de alimentos (MOENS et al., 2009).

\subsubsection{Síntomas e danos}

Em batata-doce, as espécies de Meloidogyne atacam tanto as raízes absorventes quanto as tuberosas, ocasionando a formação de galhas de diferentes formatos, porém não conseguem induzir o desenvolvimento de galhas proeminentes como fazem em muitas outras culturas (SCURRAH et al., 2005).

Plantas infectadas por Meloidogyne exibem sintomas gerais associados com pouco crescimento da raiz, incluindo nanismo e murcha transitória da folhagem durante os períodos 
mais quentes do dia, já que a infecção afeta a absorção de água e nutrientes (JATALA, 1991; MOENS et al., 2009).

Os nematoides também causam necrose na ponta da raiz em plantas hipersensíveis e resistentes, enquanto em raízes de cultivares suscetíveis, a necrose é geral (JATALA, 1991; SCURRAH et al., 2005). Amarelecimento, e abundante produção de flores estão também associados com a infecção por Meloidogyne e em alguns casos de extrema hipersensibilidade da planta há um efeito de poda, que resulta na falta de crescimento vigoroso da planta e subsequente perda de rendimento (JATALA, 1991).

Estresses fisiológicos associados com o parasitismo dos nematoides podem induzir a formação de rachaduras longitudinais durante o desenvolvimento e expansão das raízes tuberosas (SCURRAH et al., 2005), afetando não somente a produtividade, mas também depreciando a qualidade e conservação, e prejudicando o aspecto comercial das raízes de batata-doce (HUANG et al., 1986). A profundidade da penetração é dependente do tempo de desenvolvimento das raízes tuberosas (SCURRAH et al., 2005). A diferença entre as rachaduras causadas por fatores abióticos, principalmente por flutuações na umidade do solo, e as ocasionadas pela infecção do gênero Meloidogyne é a presença de nematoides na polpa das raízes rachadas infectadas (JATALA, 1991). As fêmeas podem ser observadas nas raízes tuberosas fatiadas e estão normalmente associadas com células marrons, necróticas, em torno delas (SCURRAH et al., 2005).

Além do dano intraespecífico ocasionado por apenas uma espécie de Meloidogyne, estas espécies também interagem com uma série de pragas e patógenos para desenvolver complexas doenças interespecíficas. Os fungos, que não são patogênicos para a planta hospedeira, podem tornar-se patogênicos na presença destes nematoides. Meloidogyne incognita interage com Fusarium spp. e Pseudomonas solanacearum, causando murchamento severo e morte prematura e inibindo os actinomicetos, que são antagonistas de Fusarium (JATALA, 1991; KARSSEN e MOENS, 2006). A infecção secundária por outros patógenos frequentemente resulta em degradação extensa dos tecidos infectados pelo nematoide (MOENS et al., 2009).

Sabe-se que o uso indiscriminado de nematicidas, além de onerar a produção, coloca em risco a saúde dos aplicadores, consumidores e pode exercer forte pressão de seleção sobre os organismos presentes no solo, selecionando formas capazes de degradar o ambiente rapidamente (RITZINGER e FANCELLI, 2006). 
Dentre as estratégias de manejo, a utilização de resistência é, sem dúvida, uma das alternativas mais desejáveis, já que é compatível com outras práticas de manejo, não necessita técnicas de aplicação especiais, é ambientalmente segura e efetiva na redução da população de nematoides (FANCELLI, 2003; JATALA, 1991; KARSSEN e MOENS, 2006; PINHEIRO et al., 2009).

\subsection{Insetos de solo em batata-doce}

O ecossistema da batata-doce é habitado por muitas espécies de insetos. Todas as partes da planta como raízes tuberosas, caules, ramas e mesmo sementes, são danificadas por estas pragas; sendo que a maior diversidade de artrópodes associados com a batata-doce ocorre no Sul e na América Central, onde a cultura e as espécies silvestres relacionadas tiveram origem (RAMAN e ALLEYNE, 1991).

Os danos são produzidos como resultado da alimentação do inseto nos estádios adulto e, principalmente, larval (RAMAN e ALLEYNE, 1991). Nas ramas, o ataque desses insetos resulta na interceptação da seiva, interferindo nos processos fisiológicos da planta, com consequente atraso no desenvolvimento de sua parte aérea e, frequentemente, causando a morte prematura em cultivares suscetíveis (MENEZES, 2002; WANDERLEY et al., 2004). As estimativas de perdas na produção de raízes tuberosas observadas em campo têm variado de 10 a 50\% em função da diminuição da capacidade fisiológica da planta, resultando em baixos rendimentos (MENEZES, 2002).

Para a cultura, os insetos de solo mais destrutivos são os gorgulhos da batata-doce Cylas formicarius (Fabricius) e Cylas Puncticollis (Boheman) e a broca da batata-doce Euscepes postfasciatus (Fairmaire) (COLLINS et al., 1991; RAMAN e ALLEYNE, 1991).

A broca da batata-doce Euscepes postfasciatus (Fairmaire) é a principal praga da cultura no Sul do Pacífico, na Bacia do Caribe e alguns países de Centro e Sul América (FRANÇA e RITSCHEL, 2002; RAMAN e ALLEYNE, 1991). As raízes tuberosas atacadas podem apresentar-se, externamente, rugosas, escurecidas, com depressões na área atacada e perfurações resultante da emergência dos adultos. Internamente, os tecidos atacados tornamse enegrecidos e endurecidos e, normalmente, encontram-se preenchidos de material fecal (MENEZES, 2002). Adicionalmente, em resposta à alimentação larval de E. postfasciatus, as raízes tuberosas produzem furanoterpenoides. Essas substâncias químicas são tóxicas para mamíferos e adicionam um sabor e odor desagradável, reduzindo totalmente o valor comercial 
das raízes produzidas em função da redução da qualidade (MENEZES, 2002; SHIMOJI e KOHAMA, 1996).

A periderme das raízes tuberosas de batata doce produz vários compostos secundários, incluindo fitoalexinas terpenoides, metabólitos fenólicos, inibidores de protease, e resinas glicosídicas, que possuem atividade biológica (JACKSON e PETERSON, 2000). Harrison et al. (2003) observaram que altas concentrações de ácido caféico na periderme de raízes tuberosas contribuem para a defesa química da batata-doce, inibindo o crescimento dos fungos patogênicos Rhizopus stolonifer, Fusarium oxysporum, Fusarium solani e Lasiodiplodia theobromea. Jackson e Peterson (2000) estudando o efeito de resinas glicosídicas, extraídas a partir da periderme de raízes de batata-doce, sobre a traça das crucíferas (Plutella xylostella), observaram que a concentração destas substâncias correlacionou-se negativamente com a fecundidade e a sobrevivência e o peso larval, após 6 dias de alimentação, e positivamente com o tempo de desenvolvimento das larvas. Segundo estes autores, as resinas glicosídicas apresentam propriedades toxicológicas.

Outros insetos de solo que também podem causar considerável dano ás raízes tuberosas de batata-doce são a larva-arame (Conoderus spp.), a larva-alfinete (Diabrotica spp.) e os besouros Systena spp. (COLLINS et al., 1991).

Partindo do princípio de que não existem inseticidas químicos registrados para a cultura, e devido aos riscos de contaminação para o homem e o ambiente com o emprego destes produtos, a utilização de cultivares resistentes aliada a outras práticas culturais torna-se uma importante estratégia de manejo destes insetos de solo na batata-doce (FREITAS et al., 2001; JACKSON e BOHAC, 2006; MENEZES, 2002).

\subsection{Diversidade genética}

No Brasil, apesar do seu grande potencial, importância econômica e nutricional, a cultura da batata-doce tem sido pouco estudada em termos de melhoramento, com registro de alguns programas iniciados na década de 50. Na realidade, salvo raras exceções, foi uma cultura esquecida pelos órgãos de pesquisa e de fomento (SILVEIRA, 2008).

Por apresentar grande variabilidade genética (CASTRO et al., 2008) a batata-doce permite a seleção para inúmeros propósitos, como obtenção de materiais resistentes a pragas e doenças, maior densidade de raízes, alto teor de matéria seca e produção de biomassa, que 
podem proporcionar maior rendimento para produção de álcool e maior produção de ramas, para alimentação animal (GONÇALVES NETO et al., 2011).

Sua ampla adaptabilidade em terras marginais e rico conteúdo nutricional, também fornecem um enorme potencial para prevenir a desnutrição e aumentar a segurança alimentar em países em desenvolvimento (ZHANG et al., 1998).

Ao longo dos anos, evoluindo de geração em geração, em um processo alheio às entidades de pesquisas, tem ocorrido seleção natural de materiais genéticos de batata-doce, os quais apresentam elevadas características agronômicas mostrando-se altamente promissores (CASTRO e OLIVEIRA, 2007).

O conhecimento da variabilidade genética disponível em um conjunto de genótipos é de grande importância em programas de melhoramento da cultura, sobretudo em procedimentos que envolvam hibridações, por evitar recombinações gênicas semelhantes, com consequente aumento da expressão heterótica em híbridos e de ganhos genéticos em gerações segregantes para as características de interesse. Adicionalmente, permite evitar o plantio de formas genômicas idênticas ou semelhantes e o consequente estreitamento genético das variedades (IVOGLO, 2007; OLIVEIRA et al., 2002; SUDRÉ et al., 2005).

O estudo da diversidade genética de potenciais genitores é uma etapa básica e de fundamental importância para o desenvolvimento de novas variedades (FALEIRO et al., 2005; ZHANG et al., 2014).

A divergência genética pode ser avaliada com base em características agronômicas, morfológicas, moleculares, bioquímicas, fisiológicas, físico-químicas, entre outras (MOULIN et al., 2012). Tradicionalmente a caracterização baseia-se em descritores morfoagronômicos específicos para cada espécie, que possibilitam a separação dos acessos da coleção (FERREIRA et al., 2005; MANIFESTO et al., 2010).

Atualmente há considerável diversidade genômica de batata-doce nas diversas regiões produtoras do país, advinda de segregação sexuada e assexuada e de introduções de plantas provenientes de outras localidades (OLIVEIRA et al., 2000).

A maioria das cultivares atualmente utilizadas foram selecionadas para o consumo humano principalmente. Contudo, o enorme potencial da cultura torna cada vez mais necessária a identificação das aptidões agronômicas desses materiais para outras finalidades (GONÇALVES NETO et al., 2011). 
De acordo com Miranda et al. (1995) as cultivares recomendadas estão estreitamente relacionadas ao local e à época de plantio, à adubação, à finalidade da produção e à preferência do mercado consumidor. Geralmente as variedades comercializadas nos grandes centros urbanos apresentam polpa branca ou creme e película externa (periderme) rosa, roxa ou branca. Também são comercializadas raízes tuberosas com periderme amarela ou creme, com polpa amarela-clara, salmão ou mesmo roxa. Algumas regiões têm indicações próprias de cultivares, tais como: Balão, Três Quinas e Jambo (Manaus, AM); Gonçalves, Variedade 14. Arroba e Peçanha Branca (Minas Gerais); Americana e Rama Roxa (Porto Alegre e regiões próximas, RS); Monalisa, Napoleão e Jacareí (São Paulo); Rosinha do Verdan (Rio de Janeiro); Ourinho e Batata-Salsa (Sergipe); Rainha e Japonesa (Pará); Brazlândia Rosada, Brazlândia Roxa, Brazlândia Branca, Princesa e Coquinho (Brasília, DF).

Segundo Yoneya (2010), na região de Presidente Prudente - SP, principal polo produtor de batata-doce no Estado, com 1,4 milhão de caixas de 24 quilos e plantio de 2.200 hectares, a variedade utilizada por $90 \%$ dos produtores da região é a Canadense, originária da África do Sul, que apresenta periderme rosada e polpa firme e branca, sendo a de maior aceitação por parte dos consumidores.

As cultivares Beauregard (rica em $\beta$-caroteno), introduzida no Brasil pela Embrapa, e BRS Amélia, BRS Rubissol e BRS Cuia, desenvolvidas pela Embrapa Clima Temperado (Pelotas - RS), apresentam produtividades (> $32 \mathrm{t} \mathrm{ha}^{-1}$ ) bem acima da média das cultivares disponíveis no mercado atualmente e possuim excelentes características para consumo de mesa, com possibilidade de serem também utilizadas para processamento industrial.

As variedades Yellow Yam, I.A.C.-Castelo, IAC 66-118 e IAC 271, são também do tipo mesa. Já as variedades forrageiras mais destacadas são as seguintes: Viçosa, I.A.C.-Viçosa, Santo Amaro, Capela, Maryland Golden e Roxa Lobada (C\&P, 2015).

\subsection{Parâmetros populacionais}

As estimativas de parâmetros genéticos permitem conhecer a estrutura genética da população, a inferência da variabilidade genética presente e proporcionam subsídios para predizer os ganhos genéticos e o possível sucesso no programa de melhoramento. Entre os parâmetros genéticos e fenotípicos que podem auxiliar o direcionamento da seleção de genótipos mais promissores, destacam-se as variâncias genéticas e fenotípicas e as herdabilidades (FERRÃO et al., 2008). 
O conceito de herdabilidade, introduzido para separar as diferenças genéticas e nãogenéticas entre indivíduos, é de fundamental importância para a estimação dos ganhos genéticos e para a escolha dos métodos de seleção a serem aplicados (ROSSMANN, 2001).

É possível estimar dois tipos de herdabilidade: herdabilidade no sentido amplo $\left(h_{a}^{2}\right)$ e herdabilidade no sentido restrito $\left(h_{r}^{2}\right)$. No sentido amplo, a herdabilidade pode ser definida como a razão entre a variância genotípica e a variância fenotípica; em quanto no sentido restrito, a herdabilidade pode ser definida como a razão entre a variância genética aditiva e a variância fenotípica (BORÉM, 1998; ROSSMANN, 2001). Para fins de melhoramento genético, a herdabilidade no sentido restrito é a mais adequada, uma vez que considera somente a aditividade, que é a porção herdável da variância genética, que, em última instância, é o que pode ser passado de geração a geração por seleção (ROSSMANN, 2001; JUNG et al., 2008). A herdabilidade no sentido amplo assume maior importância em plantas de propagação vegetativa, nas quais o genótipo é herdado integralmente pelos descendentes (ROSSMANN, 2001; RAMALHO et al., 2008). No caso da batata-doce, a herdabilidade no sentido amplo é importante devido aos efeitos de dominância e epistasia serem mantidos pela propagação vegetativa (GONÇALVES NETO et al., 2012).

O coeficiente de variação genético é outro parâmetro importante que permite inferir sobre a magnitude da variabilidade genética presente na população em diferentes caracteres (FERRÃO et al., 2008). A variação genotípica é usualmente dividida em componentes genéticos aditivos e não-aditivos, figurando entre os últimos a variância de dominância, causada pela interação de alelos no mesmo loco, e a variância epistática que se deve a interações de alelos de locos diferentes (CUNHA et al., 2009).

O conhecimento da variabilidade fenotípica dos caracteres de importância agronômica é imprescindível para o melhorista quanto da definição dos métodos de melhoramento, seleção de genitores, escolha dos locais para a condução dos testes de rendimento, definição do número de repetições e predição dos ganhos por seleção (JUNG et al., 2008). A variabilidade fenotípica resulta da ação conjunta dos efeitos genéticos e de ambiente. Genótipos cultivados em diferentes ambientes podem ter desempenhos relativos distintos. As variações de ambiente podem ofuscar as de natureza genética e quanto maior for a proporção da variabilidade decorrente do ambiente em relação à variabilidade total, mais difícil será selecionar genótipos de forma efetiva (BORÉM, 1998; JUNG et al., 2008; BESPALHOK et al., 2007). 


\subsection{Correlações}

Para explorar todo seu potencial produtivo vários são os caracteres de interesse na cultura da batata-doce, sendo portanto indispensável a investigação das correlações existentes entre estes. A seleção indireta por meio de caracteres correlacionados permite que um caráter de baixa herdabilidade ou de difícil mensuração, seja selecionado por meio de outro caráter que esteja associado a ele (FERREIRA et al., 2003; GONÇALVES NETO et al., 2012).

A correlação é uma medida da intensidade de associação entre duas variáveis, ou uma medida do grau de variação conjunta de duas variáveis, podendo ser positiva ou negativa, quando ocorre aumento das duas variáveis ou acréscimo de uma e decréscimo da outra, respectivamente (ROSSMANN, 2001).

Se dois caracteres apresentam correlação favorável, é possível obter ganhos para um deles por meio da seleção indireta do outro caráter associado. Em alguns casos, a seleção indireta com base na resposta correlacionada, pode levar a progressos mais rápidos no melhoramento do que a seleção direta do caráter desejado. Entretanto, se um caráter correlaciona-se negativamente com alguns e positivamente com outros, deve-se tomar o cuidado de, ao selecionar esse, não provocar mudanças indesejáveis nos outros (ROSSMANN, 2001). 


\section{REFERÊNCIAS BIBLIOGRÁFICAS}

AGU, C. M. Effect of Meloidogyne incognita and Pratylenchus brachyurus on leaf growth of sweetpotato. Tropical Science, v. 44, n. 1, p. 48-50, 2004a.

AGU, C. M. Growth and yield of sweetpotato as affected by Meloidogyne incognita. Tropical Science, v. 44, n. 2, p. 89-91, 2004b.

ALVES, R. P.; ANDRADE, T. M.; OLIVEIRA, A. M. S.; SANTANA, A. D. D.; PINTO, V. S.; BLANK, A. F. Desempenho de clones de batata-doce do Banco Ativo de Germoplasma da UFS para amido e etanol. Horticultura Brasileira, v. 31, n. 2, p. S1694-S1701, 2014.

AMBrósio, C. L. B.; CAMPOS, F. A. C.; FARO, Z. P. Carotenoids as an alternative against hypovitaminosis A. Revista de Nutrição, v. 19, n. 2, p. 233-243, 2006.

AMES, B. N.; SHIGENAGA, M. K.; HAGEN, T. M. Oxidants, antioxidants, and the degenerative diseases of aging. Proceedings of the National Academy of Sciences, v. 90, n. 17, p. 7915-7922, 1993.

ANDRADE JÚNIOR, V. C.; VIANA, D. J. S.; PINTO, N. A. V. D.; RIBEIRO, K. G.; PEREIRA, R. C.; NEIVA, I. P.; AZEVEDO, A. M.; ANDRADE, P. C. R. 2012. Productive and qualitative characteristics of the vines and roots of sweet potato. Horticultura Brasileira, v. 30, n. 4, p. 584-589, 2012.

BARREIROS, A.; DAVID, J. M.; DAVID, J. P. Estresse oxidativo: relação entre geração de espécies reativas e defesa do organismo. Química nova, v. 29, n. 1, p. 113-123, 2006.

BAUERNFEIND, J. C. Carotenoid vitamin A precursors and analogs in foods and feeds. Journal of Agricultural and Food Chemistry, v. 20, n. 3, p. 456-473, 1972.

BAYDAS, G.; KARATAS, F.; GURSU, M. F.; BOZKURT, H. A.; ILHAN, N.; YASAR, A.; CANATAN, H. Antioxidant vitamin levels in term and preterm infants and their relation to maternal vitamin status. Archives of medical research, v. 33, n. 3, p. 276-280, 2002.

BECHOFF, A.; DHUIQUE-MAYER, C.; DORNIER, M.; TOMLINS, K. I.; BOULANGER, R.; DUFOUR, D.; WESTBY, A. Relationship between the kinetics of $\beta$-carotene degradation and formation of norisoprenoids in the storage of dried sweet potato chips. Food Chemistry, v. 121, n. 2, p. 348-357, 2010.

BENGTSSON, A.; NAMUTEBI, A.; ALMINGER, M. L.; SVANBERG, U. Effects of various traditional processing methods on the all-trans- $\beta$-carotene content of orange-fleshed sweet potato. Journal of Food Composition and Analysis, v. 21, n. 2, p. 134-143, mar. 2008. 
BESPALHOK, J.C.F.; GUERRA, E.P.; OLIVEIRA, R. Seleção recorrente. In: BESPALHOK, J.C.F.; GUERRA, E.P.; OLIVEIRA, R. Melhoramento de plantas. 2007. Disponível em: <https://docs.google.com/viewer?url=http\%3A\%2F\%2Fwww.bespa.agrarias.ufpr.br\%2Fpagi nas\%2Flivro\%2Fcapitulo\%252013.pdf >. Acesso em: 24 abr. 12.

BIRT, D. F.; HENDRICH, S.; WANG, W. Dietary agents in cancer prevention: flavonoids and isoflavonoids. Pharmacology \& therapeutics, v. 90, n. 2, p. 157-177, 2001.

BORÉM, A. Melhoramento de plantas. 22. ed. Viçosa-MG: Editora UFV, 1998.

BORGES, A; ROSA, M. S.; RECCHIA, G. H.; QUEIROZ-SILVA, J. R.; BRESSAN, E. A.; VEASEY, E. A. CTAB methods for DNA extraction of sweetpotato for microsatellite analysis. Scientia Agricola, v. 66, n. 4, p. 529-534, 2009.

BRIDGERS, E. N.; CHINN, M. S.; TRUONG, V. D. Extraction of anthocyanins from industrial purple-fleshed sweetpotatoes and enzymatic hydrolysis of residues for fermentable sugars. Industrial Crops and Products, v. 32, n. 3, p. 613-620, 2010.

BRIDLE, P.; TIMBERLAKE, C. F. Anthocyanins as natural food colours - selected aspects. Food Chemistry, v. 58, n. 1, p. 103-109, 1997.

BROWN, C. R.; WROLSTAD, R.; DURST, R.; YANG, C.-P.; CLEVIDENCE, B. Breeding studies in potatoes containing high concentrations of anthocyanins. American Journal of Potato Research, v. 80, n. 4, p. 241-249, 2003.

CAMPOS, F. M.; PINHEIRO-SANTANA, H. M.; SOUZA, P. M. de; STRINGHETA, P. C.; CHAVES, J. B. P. Provitamins A in vegetables marked in formal and free market at Viçosa (MG), Brazil, during three seasons of the year. Ciência e Tecnologia de Alimentos, v. 26, n. 1, p. 33-40, 2006.

CARLO, G. DI.; MASCOLO, N.; IZZO, A.A.; CAPASSO, F. Flavonoids: old and new aspects of a class of natural therapeutic drugs. Life sciences, v. 65, n. 4, p. 337-353, 1999.

CARNEIRO, R. M. D. G.; CARNEIRO, R. G.; NEVES, D. I. das; ALMEIDA, M. R. A. Nova raça de Meloidogyne javanica detectada em Arachis pintoi no estado do Paraná. Nematologia brasileira, v. 27, n. 2, p. 219-221, 2003.

CASTAÑEDA-OVANDO, A.; PACHECO-HERNÁNDEZ, M.L.; PÁEZ-HERNÁNDEZ, M.E.; RODRÍGUEZ, J.A.; GALÁN-VIDAL, C.A. Chemical studies of anthocyanins: A review. Food Chemistry, v. 113, n. 4, p. 859-871, 2009.

CASTRO, L. A. S. de; TREPTOW, R. O.; CAMPOS, A. D.; CHOER, E.; THÜRMER, L. Acessos de batata-doce do banco ativo de germoplasma da Embrapa Clima Temperado recomendados para mesa e processamento industrial. Pelotas: Embrapa Clima Temperado, 2009, 26 p. Documentos 289. 
CASTRO, L. A. S. de; OLIVEIRA, R. P. de. Sistema de produção da batata-doce. Pelotas: Embrapa Clima Temperado, 2007. Sistemas de produção, 10.

CASTRO, L. A. S. de; ROCHA, N. E. M.; ABRANTES, V. L. Avaliação biológica de biroses em plantas matrizes e mudas de batata-doce (Ipomoea batatas). Pelotas: Embrapa Clima Temperado, 2008, 12 p. Circular Técnica 75. ISSN 1981-5999.

CASTRO, O. F. de A.; ANDRADE, A. G. de. Cultura in vitro de meristemas de batata-doce (Ipomoea batatas (L.) Lam.). Pesquisa Agropecuária Brasileira, v. 30, n. 7, p. 917-922, 1995.

CEVALLOS-CASALS, B. A.; CISNEROS-ZEVALLOS, L. Stoichiometric and kinetic studies of phenolic antioxidants from Andean purple corn and red-fleshed sweetpotato. Journal of agricultural and food chemistry, v. 51, n. 11, p. 3313-3319, 2003.

CHAKRABORTY, S.; CHAKRABORTY, N.; AGRAWAL, L.; GHOSH, S.; NARULA, K.; SHEKHAR, S.; NAIK, P. S.; PANDE, P. C.; CHAKRBORTI, S. K.; DATTA, A. Nextgeneration protein-rich potato expressing the seed protein gene AmA1 is a result of proteome rebalancing in transgenic tuber. Proceedings of the National Academy of Sciences, v. 107, n. 41, p. 17533-17538, 2010.

CHAMPAGNE, A.; BERNILLON, S.; MOING, A.; ROLIN, D.; LEGENDRE, L.; LEBOT, V. Carotenoid profiling of tropical root crop chemotypes from Vanuatu, South Pacific. Journal of Food Composition and Analysis, v. 23, n. 8, p. 763-771, 2010.

CHANDLER, L. A.; SCHWARTZ, S. J. Isomerization and losses of trans- $\beta$-carotene in sweet potatoes as affected by processing treatments. Journal of Agricultural and Food Chemistry, v. 36, n. 1, p. 129-133, 1988.

CHARCHAR, J. M.; RITSCHEL, P. S. Avaliação do banco de germoplasma de batatadoce da Embrapa Hortaliças para resistência a Meloidogyne spp. Brasília: Embrapa Hortaliças, 2004, 28 p. Boletim de Pesquisa e Desenvolvimento 03.

CLIFFORD, M. N. Anthocyanins-nature, occurrence and dietary burden. Journal of the Science of Food and Agriculture, v. 80, n. 7, p. 1063-1072, 2000.

COLlinS, W. W.; JONES, A.; MULLEN, M. A.; TALEKAR, N.S.; MARTIN, F. W. Breeding sweet potato for insect resistance: a global overview. In: JANSSON, R. K.; RAMAN, K.V. (Eds.). Sweet potato pest management: a global perspective. San Francisco: Westview Press, 1991. p. 379-397.

COOPER-DRIVER, G. A. Contributions of Jeffrey Harborne and co-workers to the study of anthocyanins. Phytochemistry, v. 56, n. 3, p. 229-236, 2001.

COOPER-DRIVER, G. A.; BHATTACHARYA, M. Role of phenolics in plant evolution. Phytochemistry, v. 49, n. 5, p. 1165-1174, 1998. 
COSTA, M. A. L.; ORTEGA-FLORES, C. I.; PENTEADO, M. V. C. In-vivo structural alterations of the all-trans, 9-cis and 13-cis of beta-carotene isomers. Ciência e Tecnologia de Alimentos, v. 22, n. 3, p. 224-228, 2002.

COYNE, D. L.; TALWANA, H. A. L.; MASLEN, N. R. Plant-parasitic nematodes associated with root and tuber crops in Uganda. African Plant Protection, v. 9, n. 2, p. 87-98, 2003.

CRAFT, N. E.; SOARES, J. H. Relative solubility, stability, and absorptivity of lutein and. beta.-carotene in organic solvents. Journal of agricultural and food chemistry, v. 40, n. 3, p. 431-434, 1992.

C\&P- Criar e Plantar. Batata-doce. Disponível em: $<$ http://www.criareplantar.com.br/horticultura/lerTexto.php?categoria=64\&id=809>. Acesso em: 25 mar. 2015.

CUNHA, E. E.; EUCLYDES, R. F.; TORRES, R. Razões entre componentes da variabilidade de características quantitativas simuladas com efeitos genéticos de dominância e sobredominância. Revista Brasileira de Zootecnia, v. 38, n. 10, p. 1893-1900, 2009.

EDMOND, J. B.; AMMERMAN, G. R. Sweet potatoes: Production, processing, marketing. Wesport: The Air Publishing Company, 58 p., 1971.

FALEIRO, F.G.; JUNQUEIRA, N.T.V.; BRAGA, M.F.; PEIXOTO, J.R. Maracujá: germoplasma e melhoramento genético. In: FALEIRO, F.G., JUNQUEIRA, N.T.V.; BRAGA, M.F. (Eds.). Germoplasma e melhoramento genético do maracujazeiro desafios da pesquisa. Planaltina, DF: Embrapa Cerrados, 2005. p.187-210.

FAN, G.; HAN, Y.; GU, Z.; CHEN, D. Optimizing conditions for anthocyanins extraction from purple sweet potato using response surface methodology (RSM). LWT- Food Science and Technology, v.41, n. 1, p. 155-160, 2008.

FANCELLI, M. Resistência e alternativas de controle de pragas. In: SIMPÓSIO BRASILEIRO SOBRE BANANICULTURA, 5., WORKSHOP DO GENOMA MUSA, 1. 2003, Paracatu. Anais...Paracatu - Cruz das Almas: Nova Civilização, 2003.

FARGETTE, M. Use of esterase phenotype in the taxonomy of the genus Meloidogyne. 2. Esterase phenotypes observed in West African populations and their characterization. Revue de Nématologie, v. 10, p.45-56, 1987.

FELTRAN, J. C.; FABRI, E. G. Batata-doce uma cultura versátil, porém sub-utilizada. Nosso Alho, n. 6, p. 28-31, 2010.

FERRÃO, R. G.; CRUZ, C. D.; FERREIRA, A.; CECON, P. R.; FERRÃO, M. A. G.; FONSECA, A. F. A. da; CARNEIRO, P. C. de S.; SILVA, M. F. Parâmetros genéticos em café Conilon. Pesquisa Agropecuária Brasileira, v. 43, n. 1, p. 61-69, 2008. 
FERREIRA, M. A. J. F.; QUEIROZ, M. A.; BRAZ, L. T.; VENCOVSKY, R. Correlações genotípicas, fenotípicas e de ambiente entre dez caracteres de melancia e suas implicações para o melhoramento genético. Horticultura Brasileira, v. 21, n. 3, p. 438-442, 2003.

FIGUEIREDO, P.; ELHABIRI, M.; TOKI, K.; SAITO, N.; DANGLES, O.; BROUILLARD, R. New aspects of anthocyanin complexation. Intramolecular copigmentation as a means for colour loss. Phytochemistry, v.41, n.1, p.301-308, 1996.

FLESCHHUT, J.; KRATZER, F.; RECHKEMMER, G.; KULLING, S.E. Stability and biotransformation of various dietary anthocyanins in vitro. European journal of nutrition, v. 45 , n. 1 , p. 7-18, 2006.

FONSECA, M. J. de O. SOARES, A.G.; JUNIOR, M.F.; ALMEIDA, D.L.; ASCHERI, J.L.R. Effect of extrusion-cooking in total carotenoids content in cream and orange flesh sweet potato cultivars. Horticultura Brasileira, v. 26, n. 1, p. 112-115, 2008.

FRANÇA, F.H.; RITSCHEL, P.S. Avaliação de acessos de batata-doce para resistência à broca-da-raiz, crisomelídeos e elaterídeos. Horticultura Brasileira, v. 20, n. 1, p.79-85, 2002.

FREITAS, J. A. de; SANTOS, G. C. dos; SOUZA, V. S.; AZEVEDO, S. M. de. Resistência de clones de batata-doce, Ipomoea batatas L., aos nematóides causadores de galhas. Acta Scientiarum. Agronomy, v. 23, p. 1257-1261, 2001.

FURUTA, S.; SUDA, I.; NISHIBA, Y.; YAMAKAWA, O. High tert-Butylperoxyl radical scavenging activities of sweet potato cultivars with purple flesh. Food Science and Technology International, Tokyo, v. 4, n. 1, p. 33-35, 1998.

GALE, C. R.; ASHURST, H.E.; POWERS, H.J.; MARTYN, C.N. Antioxidant vitamin status and carotid atherosclerosis in the elderly. The American journal of clinical nutrition, v. 74, n. 3, p. 402-408, 2001.

GALVANO, F.; FAUCI, L.L.; LAZZARINO, G.; FOGLIANO, V.; RITIENI, A.; CIAPPELLANO, S.; BATTISTINI, N.C.; TAVAZZI, B.; GALVANO, G. Cyanidins: metabolism and biological properties. The Journal of nutritional biochemistry, v. 15, n. 1, p. 2-11, 2004.

GIORI, F. P. Adaptação de metodologia de digestão in vitro e determinação da bioacessibilidade in vitro de $\beta$-caroteno em três variedades de batata-doce de polpa alaranjada. 2010. 57 f. Dissertação (Mestrado em Ciência e Tecnologia de Alimentos) Instituto de Tecnologia, Universidade Federal Rural do Rio de Janeiro, Seropédica, 2010.

GIUFFRIDA, D.; TORRE, G.; DUGO, P.; DUGO, G. Determination of the carotenoid profile in peach fruits, juice and jam. Fruits, v. 68, n. 1, p.39-44, 2013.

GODA, Y.; SHIMIZU, T.; KATO, Y.; NAKAMURA, M.; MAITANI, T.; YAMADA, T.; TERAHARA, N.; YAMAGUCHI, M. Two acylated anthocyanins from purple sweet potato. Phytochemistry, v. 44, n. 1, p. 183-186, 1997. 
GOMES, J. A. A. Resistência de clones de batata-doce a nematoides (Meloidogyne spp.). 2014. 79 f. Dissertação (Mestrado em Produção Vegetal)- Faculdade de Ciências Agrárias, Universidade Federal dos Vales do Jequitinhonha e Mucuri, Diamantina - MG, 2014.

GOMES, M. M.; SAUNDERS, C.; ACCIOLY, E. Vitamin A role preventing oxidative stress in newborns. Revista Brasileira de Saúde Materno Infantil, v. 5, n. 3, p. 275-282, 2005.

GÓMEZ-ZELEDÓN, J.; JIMÉNEZ, V. M. In vitro production of anthocyanins. Acta Biológica Colombiana, v. 16, n. 1, p. 3-20, 2001.

GONÇALVES, L.S.A.; RODRIGUES, R.; AMARAL JÚNIOR, A.T.; KARASAWA, M.; SUDRÉ, C.P. Comparison of multivariate statistical algorithms to cluster tomato heirloom accessions. Genetics and Molecular Research, v.7, n.4, p.1289-1297, 2008.

GONÇALVES NETO, Á. C.; MALUF, W. R.; GOMES, L. A. A.; GONÇALVES, R. J. S.; SILVA, V. F.; LASMAR, A. Aptidões de genótipos de batata-doce para consumo humano, produção de etanol e alimentação animal. Pesquisa Agropecuária Brasileira, v. 46, n. 11, p. 1513-1520, 2011.

GONÇALVES NETO, Á. C.; MALUF, W. R.; GOMES, L. A. A.; MACIEL, G. M.; FERREIRA, R. P. D.; CARVALHO, R.C. Correlação entre caracteres e estimação de parâmetros populacionais para batata-doce. Horticultura Brasileira, v. 30, n. 4, p. 713-719, 2012.

GOO, Y.-M.; HAN, E.-H.; JEONG, J. C.; KWAK, S.-S.; YU, J.; KIM, Y.-H.; AHN, M.-J.; LEE, S.-H. Overexpression of the sweet potato IbOr gene results in the increased accumulation of carotenoid and confers tolerance to environmental stresses in transgenic potato. Comptes Rendus Biologies, nov. 2014.

GRACE, M. H.; YOUSEF, G. G.; GUSTAFSON, S. J.; TRUONG, V.-D.; YENCHO, G. C.; LILA, M. A. Phytochemical changes in phenolics, anthocyanins, ascorbic acid, and carotenoids associated with sweetpotato storage and impacts on bioactive properties. Food Chemistry, v. 145, p. 717-724, 2014.

HARRISON, H. F.; PETERSON, J.K.; SNOOK, M.E.; BOHAC, J.R.; JACKSON, D.M. Quantitation and potential biological activity of caffeic acid in sweetpotato [Ipomoea batatas (L.) Lam] storage root periderm. Journal of Agricultural and Food Chemistry, v.51, n.10, p.2943-2948, 2003.

HOLTON, T. A.; CORNISH, E. C. Genetics and biochemistry of anthocyanin biosynthesis. The Plant Cell, v. 7, n. 7, p. 1071-1083, 1995.

HORTON, D. E.; EWELL, P. T. Sweet potato pest management: a social science perspective. In: JANSSON, R. K.; RAMAN, K. V. (Ed.). Sweet Potato Pest Management: a global perspective. San Francisco: Westview Press, 1991. p. 407-427.

HUAMÁN, Z. Botánica sistemática e morfología de la planta de batata o camote. Centro Internacional de la Papa (CIP), 1992. 
HUANG, A. S.; TANUDJAJA, L.; LUM, D. Content of alpha-, beta-carotene, and dietary fiber in 18 sweetpotato varieties grown in Hawaii. Journal of Food Composition and Analysis, v. 12, n. 2, p. 147-151, 1999.

HUANG, S. P.; MIRANDA, J. E. C.; MALUF, W. R. Resistance to root-knot nematodes in brazilian sweet potato collection. Fitopatologia Brasileira, v. 11, p. 761-766, 1986.

IVOGLO, M. G. Divergência genética entre progênies de café robusta. 2007. 75 f. Dissertação (Mestrado em Agricultura Tropical e Subtropical)- Instituto Agronômico, Campinas - SP, 2007.

JACKSON, D. M.; BOHAC, J. R. Improved dry-fleshed sweetpotato genotypes resistant to insect pests. Journal of economic entomology, v. 99, n. 5, p. 1877-1883, 2006.

JACKSON, D. M.; PETERSON, J. K. Sublethal effects of resin glycosides from the periderm of sweetpotato storage roots on Plutella xylostella (Lepidoptera: Plutellidae). Journal of Economic Entomology, v. 93, n. 2, p. 388-393, 2000.

JATALA, P. Biology and management of plant-parasitic nematodes on sweet potato. In: JANSSON, R. K.; RAMAN, K.V. (Eds.). Sweet potato pest management: a global perspective. San Francisco: Westview Press, 1991. p. 359-378.

JIAO, Y.; YANG, Z.; JIANG, Y.; ZHAI, W. Study on chemical constituents and antioxidant activity of anthocyanins from purple sweet potato (Ipomoea batatas L.). International Journal of Food Engineering, v. 8, n. 2, p. 1-16, 2012.

JUNG, M. S.; VIEIRA, E. A.; BRANCKER, A.; NODARI, R. O. Herdabilidade e ganho genético em caracteres do fruto do maracujazeiro-doce. Revista Brasileira de Fruticultura, v. 30, n. 1, p. 209-214, 2008.

K'OSAMBO, L. M.; CAREY, E. E.; MISRA, A. K.; WILKES, J.; HAGENIMANA, V. Influence of age, farming site, and boiling on pro-vitamin A content in sweet potato (Ipomoea batats (L.) Lam.) storage roots. The Journal of Food Technology in Africa, v. 4, n. 3, p. 7784, 1999.

KÄHKÖNEN, M. P.; HEINONEN, M. Antioxidant activity of anthocyanins and their aglycons. Journal of agricultural and food chemistry, v. 51, n. 3, p. 628-633, 2003.

KARSSEN, G.; MOENS, M. Root-knot nematodes. In: PERRY, R. L.; MOENS, M (Eds.). Plant nematology. Cambridge, MA, USA, 2006. p. 59-90.

KIM, H. W.; KIM, J. B.; CHO, S. M.; CHUNG, M. N.; LEE, Y. M.; SHU, S. M.; CHE, J. H.; KIM, S. N.; KIM, S. Y.; CHO, Y. S.; KIM, J. H.; PARK, H. J.; LEE, D. J. Anthocyanin changes in the Korean purple-fleshed sweet potato, Shinzami, as affected by steaming and baking. Food Chemistry, v. 130, n. 4, p. 966-972, 2012.

KIM, M. K.; AHN, S. H.; LEE-KIM, Y. C. Relationship of serum $\alpha$-tocopherol, carotenoids and retinol with the risk of breast cancer. Nutrition Research, v. 21, n. 6, p. 797-809, 2001. 
KIM, S. H.; AHN, Y. O.; AHN, M.-J.; LEE, H.-S.; KWAK, S.-S. Down-regulation of $\beta$ carotene hydroxylase increases $\beta$-carotene and total carotenoids enhancing salt stress tolerance in transgenic cultured cells of sweetpotato. Phytochemistry, v. 74, p. 69-78, fev. 2012.

KONG, J. M.; CHIA, L.S.; GOH, N.K.; CHIA, T.F.; BROUILLARD, R. Analysis and biological activities of anthocyanins. Phytochemistry, v. 64, n. 5, p. 923-933, 2003.

KRINSKY, N. I.; JOHNSON, E. J. Carotenoid actions and their relation to health and disease. Molecular aspects of medicine, v. 26, n. 6, p. 459-516, 2005.

LEBOT, V.; NDIAYE, A.; MALAPA, R. Phenotypic characterization of sweet potato [Ipomoea batatas (L.) Lam.] genotypes in relation to prediction of chemical quality constituents by NIRS equations. Plant Breeding, v. 130, n. 4, p. 457-463, 2011.

MANIFESTO, M. M.; COSTA TÁRTARA, S. M.; ARIZIO, C. M.; ALVAREZ, M. A.; HOMPANERA, N.R. Analysis of the morphological attributes of a sweetpotato collection. Annals of Applied Biology, v. 157, n. 2, p. 273-281, 2010.

MARTINS, E. C. A.; PELUZIO, J. M.; COIMBRA, R. R.; SILVEIRA, M. A. da; OLIVEIRA, J. das D. D.; OLIVEIRA JUNIOR, W. P. de. Diversidade genética em batatadoce no Tocantins. Bioscience Journal, v. 30, n. 2, p. 429-435, 2014.

MARTINS, M. C.; OLIVEIRA, Y. P. de; COITINHO, D. C.; SANTOS, L. M. P. Panorama das ações de controle da deficiência de vitamina A no Brasil. Revista de Nutrição, v. 20, n. 1, p. 5-18, 2007.

MASSAROTO, J. A. Características agronômicas e produção de silagem de clones de batata doce. 2008. 85 f. Tese (Doutorado em Fitotecnia)- Universidade Federal de Lavras, Lavras, 2008.

MAZZA, G.; BROUILLARD, R. Recent developments in the stabilization of anthocyanins in food products. Food Chemistry, v. 25, n. 3, p. 207-225, 1987.

MELÉNDEZ-MARTÍNEZ, A.; VICARIO, I. M.; HEREDIA, F. J. Pigmentos carotenoides: consideraciones estructurales y fisicoquímicas. Archivos Latinoamericanos de Nutrición, v. 57, n. 2, p. 109-117, 2007.

MELO, O. D. de; MALUF, W. R.; GONÇALVES, R. J. de S.; GONÇALVES NETO, A. C.; GOMES, L. A. A.; CARVALHO, R. de C. Screening vegetable crop species for resistance to Meloidogyne enterolobii. Pesquisa Agropecuária Brasileira, v. 46, n. 8, p. 829-835, 2011.

MENEZES, E. de L. A. A broca da batata-boce (Euscepes postfasciatus): descrição, bionomia e controle. Rio de Janeiro: Embrapa Agrobiologia, 2002, 12 p. Circular Técnica 6.

MOENS, M.; PERRY, R. N.; STARR, J. L. Meloidogyne species- a diverse group of novel and important plant parasites. In: PERRY, R. N.; MOENS, M.; STARR, J. L. (Eds.) Rootknot Nematodes. Wallingford, UK, 2009. p. 1-17. 
MOULIN, M. M.; RODRIGUES, R.; GONÇALVES, L. S. A.; SUDRÉ, C. P.; PEREIRA, M. G. A comparison of RAPD and ISSR markers reveals genetic diversity among sweet potato landraces (Ipomoea batatas (L.) Lam.). Acta Scientiarum. Agronomy, v. 34, n. 2, p. 139147, 2012.

NOGUEIRA, L. A. H.; SEABRA, J. E. A.; BEST, G.; LEAL, M. R. L. V.; POPPE, M. K. Bioetanol de cana-de-açúcar: energia para o desenvolvimento sustentável. Rio de Janeiro: BNDES / CGEE, 2008. 316 p. ISBN: 978-85-87545-24-4.

ODAKE, K., TERAHARA, N.; SAITO, N.; TOKI, K.; HONDA, T. Chemical structures of two anthocyanins from purple sweet potato, Ipomoea batatas. Phytochemistry, v. 31, n. 6, p. 2123-2126, 1992.

OKA, Y. Mechanisms of nematode suppression by organic soil amendments - a review. Applied Soil Ecology, v. 44, n. 2, p. 101-115, 2010.

OLIVEIRA, A. C. B. de; SEDIYAMA, M. A. N.; SEDIYAMA, T.; FINGER, F. L.; CRUZ, C. D. Variabilidade genética em batata-doce com base em marcadores isoenzimáticos. Horticultura Brasileira, v. 20, n. 4, p. 576-582, 2002.

OLIVEIRA, A. C. B. de; SEDIYAMA, M. A. N.; SEDIYAMA, T.; CRUZ, C. D. Avaliação da divergência genética em batata-doce por procedimentos multivariados. Acta Scientiarum. Agronomy, v. 22, n. 4, p. 895-900, 2000.

OPS- Organização Panamericana de la Salud. Visión integrada de la suplementación con vitamina A en las Américas: Informe de la Reunión Regional. Washington, 2001. 43 p.

OSGANIAN, S. K. et al. Dietary carotenoids and risk of coronary artery disease in women. The American journal of clinical nutrition, v. 77, n. 6, p. 1390-1399, 2003.

PAIVA, S. A.; RUSSELL, R. M. $\beta$-carotene and other carotenoids as antioxidants. Journal of the American College of Nutrition, v. 18, n. 5, p. 426-433, 1999.

PHILPOTT, M.; GOULD, K. S.; MARKHAM, K. R.; LEWTHWAITE, S. L.; FERGUSON, L. R. Enhanced coloration reveals high antioxidant potential in new sweetpotato cultivars. Journal of the Science of Food and Agriculture, v. 83, n. 10, p. 1076-1082, 2003.

PIEDRA-BUENA, A.; LÓPEZ-PÉREZ, J. A.; DÍEZ-ROJO, M. A.; ROBERTSON, L.; CASTRO-LIZAZO, I.; BELLO, A. Screening of three sweet potato (Ipomoea batatas L.) cultivars for resistance to different virulence groups of root-knot nematodes (Meloidogyne spp.) under controlled conditions. Crop Protection, v. 30, n. 2, p. 134-140, fev. 2011.

PINHEIRO, J. B.; BOITEUX, L. S.; LOPES, C. A.; SILVA, G. O. da. Identificação de fontes de resistência ao nematóide Meloidogyne mayaguensis em acessos de tomateiro (Solanum secção Lycopersicon). Brasília: Embrapa Hortaliças, 2009, 19 p. Boletim de Pesquisa e Desenvolvimento 56. ISSN 1677-2229. 
RAMALHO, M. A. P.; SANTOS, J. B. dos; PINTO, C. A. B. P. Genética na agropecuária. 4. ed. Lavras: UFLA, 2008. 464 p.

RAMAN, K. V.; ALLEYNE, E. H. Biology and management of the West Indian sweet potato weevil, Euscepes postfasciatus. In: JANSSON, R.K.; RAMAN, K.V. (Eds). Sweet potato pest management: a global perspective. San Francisco: Westview Press, 1991. p. 263-281.

RITZINGER, C.; FANCELLI, M. Manejo integrado de nematóides na cultura da bananeira. Revista Brasileira de Fruticultura, Jaboticabal, v. 28, n. 2, p. 331-338, 2006.

RODRÍGUEZ, M. G.; GÓMEZ, L.; PETEIRA, B. Meloidogyne mayaguensis Rammah y Hirschmann, plaga emergente para la agricultura tropical y subtropical. Revista de Protección Vegetal, v. 22, n. 3, p. 183-198, 2007.

ROESLER, P. V. S. O.; GOMES, S. D.; MORO, E.; KUMMER, A. C. B.; CEREDA, M. P. Produção e qualidade de raiz tuberosa de cultivares de batata-doce no Oeste do Paraná. Acta Scientiarum. Agronomy, v. 30, n. 1, p. 117-122, 2008.

ROSE, I.; VASANTHAKAALAM, H. Comparison of the nutrient composition of four sweet potato varieties cultivated in Rwanda. American Journal of Food and Nutrition, v. 1, n. 1, p. 34-38, jan. 2011.

ROSSMANN, H. Estimativas de parâmetros genéticos e fenotípicos de uma população de soja avaliada em quatro anos. 2001. 91 f. Dissertação (Mestrado em Agronomia)- Escola Superior de Agricultura "Luiz de Queiroz”, Universidade de São Paulo, Piracicaba, 2001.

RUKUNDO, P.; SHIMELIS, H.; LAING, M.; GAHAKWA, D. Storage root formation, dry matter synthesis, accumulation and genetics in sweetpotato. Australian Journal of Crop Science, v. 7, n. 13, p. 2054-2061, 2013.

RULES, T. IUPAC Commission on the nomenclature of organic chemistry and IUPAC-IUB comission on biochemical nomenclature: tentative rules for the nomenclature of hte carotenoids. The Journal of Biological Chemistry, v. 247, p. 2633-2643, 1972.

SAN-SAN-YI; JATOI, S. A.; FUJIMURA, T.; YAMANAKA， S.; WATANABE, J.; WATANABE, K. N. Potential loss of unique genetic diversity in tomato landraces by genetic colonization of modern cultivars at a non-center of origin. Plant Breeding, v. 127, n. 2, p. 189-196, abr. 2008.

SCOTT, G. J.; BEST, R.; ROSEGRANT, M.; BOKANGA, M. Roots and Tubers in the Global Food System: A Vision Statement to the Year 2020. Lima, Peru: International Potato Center, 2000. 118p.

SCURRAH, M. I.; NIERE, B.; BRIDGE, J. Nematode parasites of Solanum and sweet potatoes. In: LUC, M.; SIKORA, R. A.; BRIDGE, J. (Ed.). Plant parasitic nematodes in subtropical and tropical agriculture, Cambridge, MA: CABI, 2006. p. 193-220. 
SENANAYAKE, S. A.; RANAWEERA, K. K. D. S.; GUNARATNE, A.; BAMUNUARACHCHI, A. Comparative analysis of nutritional quality of five different cultivars of sweet potatoes (Ipomea batatas (L) Lam) in Sri Lanka. Food Science \& Nutrition, v. 1, n. 4, p. 284-291, 2013.

SHEKHAR, S.; MISHRA, D.; BURAGOHAIN, A. K.; CHAKRABORTY, S.; CHAKRABORTY, N. Comparative analysis of phytochemicals and nutrient availability in two contrasting cultivars of sweet potato (Ipomoea batatas L.). Food Chemistry, v. 173, p. 957-965, 2015.

SHIH, M.-C.; KUO, C.-C.; CHIANG, W. Effects of drying and extrusion on colour, chemical composition, antioxidant activities and mitogenic response of spleen lymphocytes of sweet potatoes. Food Chemistry, v. 117, n. 1, p. 114-121, nov. 2009.

SHIMOJI, Y.; KOHAMA, T. An artificial larval diet for the West Indian Sweet Potato Weevil, Euscepes posfasciatus (FAIRMAIRE) (Coleoptera: Curculionidae). Applied entomology and zoology, v. 31, n. 1, p. 152-154, 1996.

SILVA, J. B. C. da; LOPES, C. A.; MAGALHÃES, J. S. Batata-doce (Ipomoea batatas). Brasília: Embrapa Hortaliças, 2008. Sistemas de Produção, 6. ISSN 1678-880X. Versão Eletrônica. Disponível

$<$ http://sistemasdeproducao.cnptia.embrapa.br/FontesHTML/Batata-doce/Batata-

doce_Ipomoea_batatas/introducao.html>. Acesso em: 19 mar. 2014.

SILVA, J. B. C.; LOPES, C. A.; MAGALHÃES, J. S. Cultura da batata-doce (Ipomoea batatas L.). Brasília: Embrapa Hortaliças, 2004. Sistemas de Produção 6. Disponível em: <http://www.cnph.embrapa.br/sistprod/batatadoce/index.htm>. Acesso em: $10 \mathrm{de}$ fev. 2013.

SILVEIRA, M. A. Batata-doce: uma nova alternativa para a produção de etanol. In: Instituto Euvaldo Lodi. Álcool combustível: Série Indústria em Perspectiva. Brasília: IEL, 2008. p. 109-122.

SILVEIRA, M. DA; MALUF, W. R. Resistência de clones de batata-doce a Meloidogyne spp. Horticultura Brasileira, v. 11, n. 2, p. 131-133, 1993.

SOUZA, A. B. de. Avaliacão de cultivares de batata-doce quanto a atributos agronômicos desejáveis. Ciência e Agrotecnologia, v. 24, n. 4, p. 841-845, 2000.

STRINGHETA, P. C.; BOBBIO, P. A. Copigmentação de antocianinas. Biotecnologia Ciência e Desenvolvimento, v. 14, p. 34-37, 2000.

SUDRÉ, C. P.; RODRIGUES, R.; RIVA, E. M.; KARASAWA, M.; AMARAL JÚNIOR, A. T. Divergência genética entre acessos de pimenta e pimentão utilizando técnicas multivariadas. Horticultura brasileira, v. 23, n. 01, p. 22-27, 2005.

TAYLOR, A. L.; SASSER, J. N. Biology, identification and control of root-knot nematodes (Meloidogyne species). Raleigh: North Carolina State University Graphics, 1978, $111 \mathrm{p}$. 
TEOW, C. C.; TRUONG, V.-D.; McFEETERS, R. F.; THOMPSON, R. L.; PECOTA, K. V.; YENCHO, G. C. Antioxidant activities, phenolic and $\beta$-carotene contents of sweet potato genotypes with varying flesh colours. Food Chemistry, v. 103, n. 3, p. 829-838, 2007.

TERAHARA, N.; SHIMIZU, T.; KATO, Y.; NAKAMURA, M.; MAITANI, T.; YAMAGUCHI, M-A.; GODA, Y. Six diacylated anthocyanins from the storage roots of purple sweet potato, Ipomoea Batatas. Bioscience, Biotechnology, and Biochemistry, v.63, n.8, p.1420-1424, 1999.

TRUONG, V.-D.; DEIGHTON, N.; THOMPSON, R. T.; MCFEETERS, R. F.; DEAN, L. O.; PECOTA, K. V.; YENCHO, G. C. Characterization of anthocyanins and anthocyanidins in purple-fleshed sweetpotatoes by HPLC-DAD/ESI-MS/MS. Journal of Agricultural and Food Chemistry, v. 58, n. 1, p. 404-410, 13 jan. 2010.

UNDERWOOD, B. A. Maternal vitamin A status and its importance in infancy and early childhood. The American journal of clinical nutrition, v. 59, n. 2, p. 517S-522S, 1994.

VAN JAARSVELD, P. J.; FABER, M.; TANUMIHARDJO, S. A.; NESTEL, P.; LOMBARD, C. J.; BENADÉ, A. J. S. $\beta$-Carotene-rich orange-fleshed sweet potato improves the vitamin A status of primary school children assessed with the modified-relative-doseresponse test. The American journal of clinical nutrition, v. 81, n. 5, p. 1080-1087, 2005.

VELIOGLU, Y. S.; MAZZA, G.; GAO, L.; OOMAH, B. D. Antioxidant activity and total phenolics in selected fruits, vegetables, and grain products. Journal of Agricultural and Food Chemistry, v. 46, n. 10, p. 4113-4117, out. 1998.

VIMALA, B.; NAMBISAN, B.; HARIPRAKASH, B. Retention of carotenoids in orangefleshed sweet potato during processing. Journal of Food Science and Technology, v. 48, n. 4, p. 520-524, ago. 2011.

WALTER, Jr., W. M.; COLLINS, W. W.; PURCELL, A. E. Sweet potato protein: A review. Journal of Agricultural and Food Chemistry, v. 32, n. 4, p. 695-699, 1984.

WANDERLEY, P. A.; BOIÇA JÚNIOR, A. L.; WANDERLEY, M. J. A. Resistance of sweet potato cultivars to Euscepes postfasciatus Fairmaire (Coleoptera: Curculionidae). Neotropical Entomology, v. 33, n. 3, p. 371-377, 2004.

WANG, H.; CAO, G.; RONALD, L. Oxygen radical absorbing capacity of anthocyanins. Journal of Agricultural and Food Chemistry, v. 45, n. 2, p. 304-309, 1997.

WANG, L. S.; STONER, G. D. Anthocyanins and their role in cancer prevention. Cancer letters, v. 269, n. 2, p. 281-290, 2008.

XU, J.; SU, X.; LIM, S.; GRIFFIN, J.; CAREY, E.; KATZ, B.; TOMICH, J.; SCOTT SMITH, J.; WANG, W. Characterisation and stability of anthocyanins in purple-fleshed sweet potato P40. Food Chemistry, set. 2014. 
YONEYA, Fernanda. Batata-doce está em plena safra. O Estado de S. Paulo, São Paulo, 12 maio 2010. Disponível em: <http://www.estadao.com.br/noticias/geral,batata-doce-esta-emplena-safra,550589>. Acesso em: 25 mar. 2015.

YOSHIMOTO, M.; OKUNO, S.; YAMAGUCHI, M.; YAMAKAWA, O. Antimutagenicity of deacylated anthocyanins in purple-fleshed sweetpotato. Bioscience, biotechnology, and biochemistry, v. 65, n. 7, p. 1652-1655, 2001.

YOSHINAGA, M.; YAMAKAWA, O.; NAKATANI, M. Genotypic diversity of anthocyanin content and composition in purple-fleshed sweet potato (Ipomoea batatas (L.) Lam). Breeding science, v. 49, n. 1, p. 43-47, 1999.

ZACCARI, F.; GALIETTA, G.; GONZALEZ IDIARTE, H. Caracterización de la pulpa fresca de materiales genéticos de boniato (Ipomoea batata L.) producidos en Uruguay. In: V CONGRESO IBEROAMERICANO DE TECNOLOGÍA POSTCOSECHA Y AGROEXPORTACIONES, 2007, Cartagena- España. Resumenes... Cartagena: AITEP, 2007. p. 552-558. Disponível em: <http://www.horticom.com/pd/imagenes/69/000/69000.pdf >. Acesso em: $10 \mathrm{dez} .2014$.

ZHANG, D.; GHISLAIN, M.; HUAMÁN, Z.; GOLMIRZAIE, A.; HIJMANS, R. RAPD variation in sweetpotato (Ipomoea batatas (L.) Lam) cultivars from South America and Papua New Guinea. Genetic Resources and crop evolution, v. 45, n. 3, p. 271-277, 1998.

ZHANG, K.; WU, Z.-D.; LI, Y.-H.; ZHANG, H.; WANG, L.-P.; ZHOU, Q.-L.; TANG, D.B.; FU, Y.-F.; HE, F.-F.; JIANG, Y.-C.; YANG, H.; WANG, J.-C. ISSR-based molecular characterization of an elite germplasm collection of sweet potato (Ipomoea batatas L.) in China. Journal of Integrative Agriculture, v. 13, n. 11, p. 2346-2361, nov. 2014.

ZIEGLER, R. G. Vegetables, fruits, and carotenoids and the risk of cancer. The American Journal of Clinical Nutrition, v. 53, p. 251S-259S, 1991. 


\section{CAPÍTULO 1}

Divergência genética entre genótipos de batata-doce utilizando descritores morfoagronômicos e físico-químicos das raízes 


\subsection{RESUMO}

O conhecimento da divergência genética disponível em um conjunto de genótipos é de grande importância em programas de melhoramento, por evitar recombinações gênicas semelhantes, com consequente aumento da expressão heterótica em híbridos e de ganhos genéticos em gerações segregantes. O presente trabalho teve como objetivos caracterizar morfoagronômica e físico-químicamente 23 genótipos de batata-doce do banco ativo de germoplasma mantido na Embrapa Hortaliças; utilizar estas características para avaliar a variabilidade genética entre os materiais pela aplicação dos métodos de Análise por Agrupamento Hierárquico (AAH) e Análise por Componentes Principais (PCA) e estimar parâmetros populacionais. O experimento foi conduzido na Fazenda Água Limpa, da UnB, em Brasília - DF. Os materiais foram cultivados em campo no delineamento em blocos ao acaso com quatro repetições. Foram avaliados 17 caracteres de raiz. Os coeficientes de variação genética $\left(\mathrm{CV}_{\mathrm{g}}\right)$ e ambiental $\left(\mathrm{CV}_{\mathrm{e}}\right)$, a herdabilidade no sentido amplo $\left(\mathrm{h}_{\mathrm{a}}{ }^{2}\right)$ e a razão $\mathrm{CV}_{\mathrm{g}} / \mathrm{CV}_{\mathrm{e}}$ indicaram uma situação favorável para a seleção dos caracteres produtividade comercial, diâmetro, comprimento, acidez total, teor de proteína bruta, ratio, teor de cinzas, umidade, conteúdo de amido, $\mathrm{pH}$ e sólidos solúveis totais das raízes. Constatou-se que a maioria dos materiais avaliados é similar com relação aos descritores utilizados. Contudo, os cruzamentos entre genitores de grupos diferentes como o clone CNPH 69, o qual se destacou por suas altas produtividades comercial e total; o clone CNPH 59, que além de suas altas produtividades apresentou altos teores de matéria seca e de sólidos solúveis totais; o clone CNPH 80, que exibiu bom formato e moderada resistência aos insetos de solo; a cultivar Brazlândia Rosada, que apresentou altos teores de amido e de produtividade; os clones CNPH 60 e 56 que tiveram altos rendimentos e teores de fibra e o acesso CNPH 55, que produziu o maior teor de proteína bruta, podem ser indicados para compor programas de intercruzamentos, visando aumentar as chances de obtenção de maior variabilidade genética, ganhos com a heterose e genótipos superiores. A análise de componentes principais revelou que os quatro primeiros componentes explicaram $67,74 \%$ da variabilidade dos dados, demonstrando que os descritores discriminaram satisfatoriamente os genótipos.

Palavras-chave: Ipomoea batatas, dissimilaridade, parâmetros populacionais, melhoramento. 


\subsection{ABSTRACT}

Knowledge of the genetic divergence in a set of genotypes is of great importance in breeding programs to avoid similar genetic recombinations, with consequent increase of heterotic expression in hybrids and genetic gains in segregating generations. The present study aimed to characterize morphoagronomic and physicochemically 23 genotypes of sweet potato belonging to the germplasm bank maintained at Brazilian National Vegetable Research Centre, to use these characteristics to assess the genetic variability among the materials by application of the methods Hierarchical Cluster Analysis (HCA) and Principal Component Analysis (PCA) and to estimate population parameters. The experiment was conducted at Fazenda Água Limpa, owned by UnB, Brasilia - DF. The materials were cultivated in field conditions on a randomized blocks experimental design with four replications. 17 characteristics of the roots were evaluated. The coefficients of genetic $\left(\mathrm{CV}_{\mathrm{g}}\right)$ and environmental $\left(\mathrm{CV}_{\mathrm{e}}\right)$ variation, the broad sense heritability $\left(\mathrm{h}_{\mathrm{a}}{ }^{2}\right)$ and the ratio $\mathrm{CV}_{\mathrm{g}} / \mathrm{CV}_{\mathrm{e}}$ indicated a favorable situation for the selection of the traits marketable yield, diameter, length, titratable acidity, raw protein, ratio, ashes, humidity, starch, $\mathrm{pH}$ and total soluble solids of sweet potato roots. It was found that the most of the genotypes analyzed is similar with respect to the descriptors used. However, crosses between genetically dissimilar parents as the CNPH 69 clone, which stood out for its high marketable and total yield; the CNPH 59 clone, which in addition to its high productivity showed high content of dry matter and total soluble solids; the CNPH 80 clone, which exhibited good shape and moderate resistance to soil insects; the Brazlândia Rosada cultivar, which showed high levels of starch and productivity; the CNPH 60 and CNPH 56 clones, which had high yields and fiber content and the CNPH 55 access; which produced the highest protein content, can be recommended for inclusion in intercross programs aiming to increase the possibilities of obtaining greater genetic variability, gains with the heterosis and superior genotypes. The principal component analysis revealed that the first four components explained $67.74 \%$ of the variability of the data, showing that the descriptors satisfactorily discriminate the genotypes.

Keywords: Ipomoea batatas, dissimilarity, population parameters, breeding. 


\subsection{INTRODUÇÃO}

A batata-doce [Ipomoea batatas (L.) Lam.] pertencente à família Convolvulaceae, é uma espécie hexaplóide com 90 cromossomos $(2 \mathrm{n}=6 \mathrm{x}=90)$, que teve origem na América Tropical e atualmente é cultivada em todas as zonas tropicais, subtropicais e temperadas do mundo (COLLINS et al., 1991; CASTRO et al., 2009; ROESLER et al., 2008).

Esta dicotiledônea é comumente cultivada em países em desenvolvimento, inclusive no Brasil, onde seu cultivo está amplamente distribuído, o que se deve além da riqueza nutricional, à capacidade de produção em solos pobres e degradados, ao baixo custo de produção, ao fácil cultivo e manutenção, à possibilidade de mecanização, à ampla adaptabilidade, à proteção do solo, à resistência à seca, à baixa incidência de pragas ou de doenças limitantes, à pouca resposta à aplicação de fertilizantes, à alta eficiência fotossintética e à baixa exigência em manejo (ANDRADE JÚNIOR et al., 2012; CASTRO et al., 2008; FELTRAN e FABRI, 2010; ROESLER et al., 2008; SILVA et al., 2004).

O Brasil é o $18^{\circ}$ maior produtor mundial de batata-doce, com produção anual em 2013 de 505.350 t, obtida em uma área plantada de 39.393 ha (FAO, 2012; IBGE, 2013). Embora o Nordeste apresente a maior área plantada (15.839 ha) seu rendimento médio de 9,43 $\mathrm{t} \mathrm{ha}^{-1}$ é baixo quando comparado com o da região Sul, com uma produtividade média de 14,36 t ha ${ }^{-1}$, que representa 44,99\% da produção nacional, obtida em uma área plantada de 15.835 ha. Já as regiões Sudeste e Centro-Oeste, apresentam os maiores rendimentos médios por área do pais, com 17,39 $\mathrm{t} \mathrm{ha}^{-1}$ e 31,53 $\mathrm{t} \mathrm{ha}^{-1}$, respectivamente, de acordo com dados do IBGE (2013).

Apesar disto, a produtividade média brasileira de 13,09 t ha ${ }^{-1}$ é considerada baixa, principalmente porque a maioria das cultivares não expressam todo o seu potencial genético; o que está associado a fatores como sistema de plantio inadequado, utilização de variedades com baixo potencial produtivo, uso inadequado de ramas no plantio, plantio em solos de baixa fertilidade natural e baixo nível técnico (CASTRO et al., 2009; FELTRAN e FABRI, 2010).

Adicionalmente, sendo propagada vegetativamente, a cultura tende a aumentar a incidência de plantas infectadas por insetos e doenças durante os sucessivos cultivos, resultando em uma significativa queda na produção, fenômeno referido como degenerescência (KROTH et al., 2004). Para a cultura da batata-doce, o controle fitossanitário é ainda mais relevante, porque a maioria das pragas e doenças importantes causam danos às raízes, depreciando o produto. Este tipo de ataque é geralmente de difícil controle, pois os patógenos 
e os insetos localizados no solo não são facilmente atingidos pelos agrotóxicos (SILVA et al., 2004). Ademais, essa medida de controle não é recomendada por ser antieconômica e requerer cuidados especiais durante a aplicação, devido aos riscos de contaminação do homem e do ambiente, além da inexistência de produtos registrados para a cultura (FREITAS et al., 2001; JACKSON e BOHAC, 2006; MENEZES, 2002).

Contudo, práticas culturais como a rotação de culturas, plantio com material de qualidade fitossanitária, produção de ramas em viveiro, realização de amontoa alta, colheita de toda a área cultivada na época apropriada, emprego de variedades precoces, destruição de restos culturais, utilização de variedades resistentes e irrigação, são práticas importantes na redução da infestação por insetos de solo (FRANÇA e RITSCHEL, 2002; MENEZES, 2002).

O elevado número de variedades de batata-doce com características diferentes é um fator que aumenta a sua potencialidade para uso alimentício e industrial. Enquanto seu teor de proteína é relativamente baixo, a qualidade da proteína é extraordinariamente alta. Ao ser colhida a batata-doce apresenta $85 \%$ de carboidratos, em média, e seu principal componente é o amido. Destaca-se ainda por possuir carotenoides, minerais como potássio, cálcio e ferro e por fornecer altos teores de vitamina $\mathrm{C}$ e quantidades razoáveis de vitaminas do grupo $\mathrm{B}$, incluindo niacina, piridoxina, ácido fólico e riboflavina, fornecendo um enorme potencial para prevenir a desnutrição e aumentar a segurança alimentar em países em desenvolvimento (HORTON e EWELL, 1991; FELTRAN e FABRI, 2010; FONSECA et al., 2008; MOULIN et al., 2012; ZHANG et al., 1998).

Por apresentar grande variabilidade genética, a batata-doce permite a seleção de materiais para inúmeras finalidades, entre elas, a obtenção de materiais mais produtivos e resistentes a pragas e doenças, com melhor qualidade nutricional, maior densidade de raízes e altos teores de matéria seca e amido, que podem proporcionar maior rendimento para produção de álcool e serem desejáveis para a indústria feculeira (GONÇALVES NETO et al., 2011).

A busca por novas variedades atendendo a diversas finalidades de uso (mesa e indústria) é constante. Neste contexto diversos países mantêm programas de melhoramento de batatadoce, inclusive o Brasil, por meio de diversas instituições de ensino e/ou pesquisa públicas (FELTRAN e FABRI, 2010). Contudo, considerando o potencial desta cultura, poucos estudados em termos de melhoramento tem sido realizados no país (SILVEIRA, 2008).

Devido ao seu elevado nível de ploidia, a batata-doce cultivada no território nacional apresenta uma infinidade de formas, com grande diversidade fenotípica e genotípica, que 
precisa ser preservada e estudada para contribuir com futuros programas de melhoramento genético (BORGES et al., 2009; DAROS et al., 2002; FELTRAN e FABRI, 2010).

Estudos de divergência genética entre acessos de uma cultura são importantes para analisar a variabilidade genética existente na coleção do melhorista, identificar materiais genéticos muito próximos ou duplicados e fornecer parâmetros para escolha de genitores geneticamente diferentes, que ao serem cruzados, possibilitem maior efeito heterótico e introgredir genes desejáveis na base genética disponível, aumentando as chances de obtenção de máxima variabilidade genética e genótipos superiores em gerações segregantes (MOHAMMADI e PRASSANA, 2003; MOURA et al., 1999; OLIVEIRA et al., 2000; PAIXÃO et al., 2008).

A caracterização morfológica de um banco de germoplasma é normalmente a forma mais acessível de quantificar sua diversidade genética (RITSCHEL e HUAMÁN, 2002). Esta consiste em fornecer uma identidade para cada entrada através do conhecimento de uma série de dados que permitam estudar a variabilidade genética de cada amostra (DAROS et al., 2002). Já a caracterização agronômica consiste em avaliar características desejáveis pelo agricultor e que atendam ao mercado consumidor (FABRI, 2009).

Quando a caracterização é realizada por meio de dados morfológicos, a quantificação da diversidade entre acessos só terá significado se a divergência fenotípica refletir a divergência genética (BUZAR et al., 2007). Estimativas relativamente altas de herdabilidade de algumas das características utilizadas como descritores de batata-doce aumentam a confiança na utilização dessas variáveis no processo de caracterização (RITSCHEL e HUAMÁN, 2002).

Os três princípios para a definição de herdabilidade são como medida de semelhança entre pai e filho, porção genética no sentido amplo e porção genética no sentido restrito (ROSSMANN, 2001). A herdabilidade no sentido amplo assume maior importância em plantas de propagação vegetativa, nas quais o genótipo é herdado integralmente pelos descendentes (ROSSMANN, 2001; RAMALHO et al., 2008). No caso da batata-doce, a herdabilidade no sentido amplo é importante devido aos efeitos de dominância e epistasia serem mantidos pela propagação vegetativa (GONÇALVES NETO et al., 2012).

Para analisar a diversidade genética e para a seleção dos descritores mais relevantes, encontram-se disponíveis vários procedimentos estatísticos multivariados, em que diversos caracteres avaliados podem ser dimensionados simultaneamente nos genótipos. O estudo de divergência feito por análise de agrupamento tem a finalidade de reunir, por algum critério de 
similaridade ou dissimilaridade, os progenitores em vários grupos, de tal modo que haja maior homogeneidade dentro do grupo e maiores níveis de heterogeneidade entre os grupos (BUZAR et al., 2007).

Métodos de ordenação que permitem reduzir o número original de variáveis em um novo conjunto simplificado são utilizados para o estudo de diferentes espécies cultivadas. A análise de componentes principais é utilizada para a redução de informações de um grande número de variáveis em um conjunto pequeno, perdendo apenas uma pequena quantidade de informação. A principal característica deste método é a redução da dimensionalidade da matriz de distâncias entre os objetos. Para tanto, considera-se um conjunto de $p$ variáveis e encontramse combinações lineares entre elas que produzam índices não correlacionados $Z_{1}, Z_{2}, Z_{3}, \ldots$, $\mathrm{Z}_{\mathrm{P}}$, denominados componentes principais, os quais refletem cada um, uma "dimensão" diferente. As combinações são calculadas de tal maneira que o primeiro componente, que é o principal eixo de um conjunto de pontos no espaço $p$-dimensional, acumula a maior quantidade da variação existente nos dados (PERONI et al., 1999; RAY et al., 2012).

Quanto à verificação da dissimilaridade genética baseada em caracteres fenotípicos da raiz com vistas à obtenção de variabilidade genética para características comerciais visando o melhoramento, há poucos relatos na literatura (SILVA et al., 2012).

Neste contexto, o presente trabalho teve como objetivos caracterizar morfoagronômica e físico-químicamente 23 genótipos de batata-doce pertencentes ao banco de germoplasma mantido na Embrapa Hortaliças; utilizar estas características para avaliar a divergência genética entre os materiais; calcular a importância relativa de cada variável na discriminação mediante uma análise de componentes principais (PCA) e estimar parâmetros genéticos populacionais. 


\subsection{MATERIAL E MÉTODOS}

\subsubsection{Localização da área experimental}

O experimento foi conduzido no período compreendido entre os dias 13 de setembro de 2012 e 14 de fevereiro de 2013 na Fazenda Água Limpa, pertencente à Universidade de Brasília, localizada no Núcleo Rural Vargem Bonita ao Sul de Brasília - DF, a uma altitude de $1.100 \mathrm{~m}$, nas coordenadas $15^{\circ} 56^{\prime}-15^{\circ} 59^{\prime} \mathrm{S}$ e $47^{\circ} 55^{\prime}-47^{\circ} 58^{\prime} \mathrm{WGr}$. O clima da região é do tipo Aw, segundo a classificação de Köppen, com temperaturas médias máxima de $28,5{ }^{\circ} \mathrm{C}$ e mínima de $12{ }^{\circ} \mathrm{C}$, e precipitação média anual de 1.600 mm (FIEDLER et al., 2004).

\subsubsection{Preparo da área}

O solo da área experimental foi classificado como Latossolo Vermelho e a análise química do mesmo apresentou: $\mathrm{pH}$ (água)=6,4; $\mathrm{P}=4,8 \mathrm{mg} \mathrm{dm}^{-3} ; \mathrm{Ca}=2,8 \mathrm{cmol}_{\mathrm{c}} \mathrm{dm}^{-3} ; \mathrm{Mg}=$ $1,8 \mathrm{cmol}_{\mathrm{c}} \mathrm{dm}^{-3} ; \mathrm{K}=0,27 \mathrm{cmol}_{\mathrm{c}} \mathrm{dm}^{-3} ; \mathrm{Na}=0,03 \mathrm{cmol}_{\mathrm{c}} \mathrm{dm}^{-3} ; \mathrm{Al}=0 \mathrm{cmol}_{\mathrm{c}} \mathrm{dm}^{-3} ; \mathrm{H}+\mathrm{Al}=2,7$ $\mathrm{cmol}_{\mathrm{C}} \mathrm{dm}^{-3} ; \mathrm{SB}=4,9 \mathrm{cmol}_{\mathrm{c}} \mathrm{dm}^{-3} ; \mathrm{T}=8 \mathrm{cmol}_{\mathrm{c}} \mathrm{dm}^{-3} ; \mathrm{V}=64 \% ; \mathrm{m}=0 \% ; \mathrm{ISNa}=0,4 \% ; \mathrm{C}=25,8 \mathrm{~g}$ $\mathrm{Kg}^{-1} ; \mathrm{MO}=44,4 \mathrm{~g} \mathrm{Kg}^{-1}$. Os teores de argila, areia e silte determinados pela análise granulométrica foram de 400; 475 e $125 \mathrm{~g} \mathrm{~kg}^{-1}$, respectivamente. Posteriormente, procedeu-se ao preparo da área, onde foi realizada inicialmente uma aração profunda $(25 \mathrm{~cm})$. Após sete dias, foi feita uma nova aração seguida de uma gradagem. Não foi aplicado fertilizante, visto que o solo apresentou uma boa fertilidade natural e também para melhor caracterizar o cultivo na região.

\subsubsection{Delineamento experimental}

Foram estudados 23 genótipos de batata-doce do Banco de Germoplasma mantido na Embrapa Hortaliças. O delineamento experimental utilizado foi em blocos casualizados, com 23 tratamentos e 4 repetições. As unidades experimentais foram constituídas de camalhões de 3,2 m de comprimento x 1,0 m de largura cada, com 8 plantas por parcela, utilizando-se o espaçamento de 0,4 m entre plantas e de 1,0 m entre camalhões. Empregaram-se bordaduras nas laterais do experimento, onde foram plantadas variedades comerciais de batata-doce. Os tratamentos constituíram-se dos clones relacionados na Tabela 1.1. 
Tabela 1.1 Denominação e origem dos clones de batata-doce avaliados

\begin{tabular}{|cc}
\hline Clone & Origem \\
\hline CNPH 02 & Brazlândia-DF \\
CNPH 08 & Brasília-DF \\
CNPH 12 & Felixlândia-MG \\
CNPH 28 & Viçosa-MG \\
CNPH 29 & Brasília-DF \\
CNPH 35 & Piranga-MG \\
CNPH 41 & Brasília-DF \\
CNPH 46 & Manaus-AM \\
CNPH 55 & Pompeu-MG \\
CNPH 56 & Pompeu-MG \\
CNPH 59 & Brasília-DF \\
CNPH 60 & Argentina \\
CNPH 61 & Argentina \\
CNPH 62 & Origem desconhecida \\
CNPH 69 & Brasília-DF \\
CNPH 71 & Não-Me-Toque-RS \\
CNPH 80 & Canguçu-RS \\
CNPH 87 & Campo Grande-MS \\
CNPH 90 & Bandeirantes-MS \\
CNPH 1796 & Palmeira-SC \\
Brazlândia Rosada & Brazlândia-DF \\
Coquinho & Brazlândia-DF \\
Princesa & Brazlândia-DF \\
\hline
\end{tabular}

Foram utilizadas ramas sadias, com 3 a 4 entrenós, dos quais 2 foram enterrados no topo da leira. Durante o desenvolvimento utilizou-se irrigação por aspersão convencional na ausência de chuvas, com aplicação de uma lâmina de água entre 4 e $6 \mathrm{~mm}$ com turno de rega de um dia. Foi efetuada adubação de cobertura 20 dias após o plantio, com sulfato de amônio, na dose de $20 \mathrm{~g}_{\text {planta }}{ }^{-1}$, e o controle de plantas daninhas foi feito por meio de capinas manuais com enxada. Não foram utilizados agroquímicos para o controle de pragas e doenças.

\subsubsection{Caracterização morfoagronômica}

\subsubsection{Produção total de raízes frescas}

A produtividade total (PT) foi calculada pela pesagem de todas as raízes de cada parcela em balança digital, com precisão de três casas decimais. O peso total foi extrapolado para tonelada por hectare $\left(\mathrm{t} \mathrm{ha}^{-1}\right)$. 


\subsubsection{Produção de raízes comerciais}

A produtividade comercial (PC) foi obtida segundo Resende (2000), selecionando-se de cada parcela todas as raízes tuberosas com peso entre 100 e 800 g, com ausência de danos e bom aspecto visual. A produtividade das raízes comercializáveis foi extrapolada para $\mathrm{tha}^{-1}$.

\subsubsection{Incidência de danos e grau de resistência}

Para a estimativa dos danos causados por insetos de solo, foram tomadas aleatoriamente de 4 a 12 raízes em cada parcela e avaliada a incidência de danos (ID) segundo a escala de notas empregada por França et al. (1983), citados por Azevedo et al. (2000) e Andrade Júnior et al. (2012).

Foram atribuídas notas em uma escala variável de 1 a 5, na qual 1= raízes livres de danos, com aspecto comercial desejável; 2 = raízes com poucos danos, mas com presença de alguns furos e galerias; $3=$ raízes com danos verificados sem muito esforço visual, com aspecto comercial objecionável (muitos furos e galerias); 4= obedeceu a raízes muito danificadas, praticamente inadequadas para comercialização (presença de muitas galerias, furos e início de apodrecimento); 5= raízes completamente inadequadas para comercialização (repletas de galerias, furos e apodrecimento mais avançado). As notas foram dadas por dois avaliadores, sendo o valor final expresso pela média das duas notas.

De acordo com a escala de notas para a incidência de danos, classificaram-se os genótipos segundo o seu grau de resistência aos insetos de solo (GR), considerando-se como resistentes $=$ os clones com nota $\leq 1$; moderadamente resistentes $=$ os genótipos com notas $>1$ $\mathrm{e} \leq 2$; moderadamente suscetíveis $=$ os materiais com nota $>2 \mathrm{e} \leq 3$; suscetíveis $=$ os clones com notas $>3$ e $\leq 4$ e altamente suscetíveis $=$ os materiais com notas $>4$ e $\leq 5$.

\subsubsection{Características gerais}

O diâmetro médio da raiz (DR) foi obtido pela mensuração transversal da parte central da raiz, utilizando um paquímetro digital (Digimess $\left.{ }^{\circledR}\right)$. O comprimento médio da raiz (CR) foi obtido medindo-se o eixo longitudinal da raiz com o uso de uma régua plástica graduada. A espessura média do córtex da raiz (EC) foi calculada pela medição da casca na porção mediana das raízes cortadas, com o auxilio de um paquímetro digital. A avaliação destas variáveis foi realizada escolhendo-se ao acaso entre 4 e 12 raízes em cada parcela e as leituras foram expressas em milímetros ( $\mathrm{mm})$. 


\subsubsection{Formato das raízes tuberosas}

O formato das raízes (FTO) foi obtido por meio de uma escala de notas entre 1 e 5 , estabelecida por França et al. (1983) e empregada por Azevedo et al. (2000) e Andrade Júnior et al. (2012), descrita da seguinte forma: 1= raízes com formato fusiforme, regular, sem veias ou quaisquer rachaduras; 2 = raízes com formato considerado bom, próximo do fusiforme, mas com algumas desuniformidades, com possível presença de veias ou curvaturas nas raízes; $3=$ raízes com formato irregular, não fusiformes, com algumas veias e/ou rachaduras, mas comercialmente aceitáveis; 4= raízes muito grandes, com formato muito irregular, com veias e rachaduras, indesejáveis comercialmente; $5=$ raízes totalmente fora dos padrões comerciais, muito irregulares, deformadas, curvas e com muitas veias e rachaduras.

Foram avaliadas entre 4 e 12 raízes tomadas aleatoriamente em cada parcela, considerando-se como nota a média das raízes avaliadas. As notas foram dadas por dois avaliadores, sendo o valor final expresso pela média das duas notas.

\subsubsection{Caracterização físico-química}

Para a caracterização físico-química foram escolhidas ao acaso seis raízes de batata-doce comerciais de cada parcela, que foram lavadas, secas, descascadas manualmente, cortadas em rodelas e trituradas em um miniprocessador de alimentos Philips Walita HR2939/00. Os teores de umidade, cinzas, carotenoides e antocianinas totais foram determinados após o término do processamento das raízes tuberosas. Uma parte de todas as amostras foi acondicionada em recipientes plásticos, identificados e congelados em freezer, a temperatura aproximada de $-18{ }^{\circ} \mathrm{C}$, para execução das demais análises. Todas as análises laboratoriais foram realizadas em triplicata, e com exceção da umidade, os resultados foram expressos em base seca (b.s.).

\subsubsection{Umidade}

A umidade das raízes tuberosas (UM) foi determinada gravimetricamente, pela secagem de $2 \mathrm{~g}$ de amostra em estufa com circulação de ar a $105^{\circ} \mathrm{C}$ durante 2 horas (BRIDGERS et al., 2010). Transcorrido este tempo, as amostras foram resfriadas em dessecador, por aproximadamente $1 \mathrm{~h}$, para a sua pesagem. Esta operação de aquecimento e resfriamento foi repetida até as amostras atingirem peso constante. Os resultados foram expressos em percentual de umidade em base úmida. 


\subsubsection{Cinzas}

O teor de cinzas (CZ) nas amostras de batata-doce foi determinado segundo a metodologia descrita por Lebot et al. (2011). Pesaram-se 2 g de amostra em cápsula de porcelana, previamente tarada, que foram incineradas em mufla a $550{ }^{\circ} \mathrm{C}$ durante $2 \mathrm{~h}$.

\subsubsection{Proteína bruta}

A avaliação do teor de proteína bruta (PTN) foi realizada a partir de 0,3 g de amostra, utilizando-se destilador micro-Kjeldahl e bloco digestor e quantificando-se a porcentagem de nitrogênio na amostra. O conteúdo de proteína bruta foi calculado a partir do teor de nitrogênio multiplicado pelo fator de conversão 6,25 (AOAC, 1980).

\subsubsection{Fração de fibra bruta}

A análise do teor de fibra bruta (FB) foi feita através de digestão exaustiva ácida de 1,5 $\mathrm{g}$ de amostra em solução de $\mathrm{H}_{2} \mathrm{SO}_{4}$ a 1,25\% p/v durante 30 minutos, seguida de digestão básica com $\mathrm{NaOH}$ a $1,25 \% \mathrm{p} / \mathrm{v}$ por mais 30 minutos (AOAC, 1980).

\subsubsection{5 pH e acidez total titulável}

$\mathrm{O}$ pH $(\mathrm{PH})$ e a acidez total titulável (AT) foram determinados a partir de um extrato contendo $10 \mathrm{~g}$ de amostra e $50 \mathrm{~mL}$ de água destilada, segundo a metodologia recomendada pelo Instituto Adolfo Lutz (1985).

\subsubsection{Sólidos solúveis totais}

O teor de sólidos solúveis totais (SS) foi quantificado a partir de $1 \mathrm{~g}$ de polpa de batatadoce. A amostra foi embrulhada em papel de filtro qualitativo de $11 \mu \mathrm{m}$ de diâmetro de poro, sobre o qual exerceu-se uma leve pressão manual até serem extraídas de 1 a 2 gotas de amostra, que foram colocadas diretamente no prisma do refratômetro de Abbé, com leitura imediata da amostra, sendo os dados expressos em graus Brix.

\subsubsection{Ratio}

O valor da relação SS/ AT (ratio) foi obtido através da divisão dos resultados dos teores de sólidos solúveis totais e da acidez total titulável. 


\subsubsection{Rendimento de amido}

A extração e quantificação de amido (AM) foram feitas de acordo com o protocolo proposto por Zavareze et al. (2009) com algumas modificações.

Pesou-se em balança analítica $100 \mathrm{~g}$ de polpa, que foram trituradas, em baixa velocidade, em um liquidificador contendo água destilada na proporção de 1:2 (batata-doce:água), durante 2 min. A massa obtida foi filtrada em saco de algodão e o resíduo foi repetidamente molhado, triturado e filtrado durante três vezes. A suspensão final resultante foi mantida em repouso durante 24 horas para decantação do amido (Figura 4a). Após decantação, descartou-se o sobrenadante e o amido, decantado, foi centrifugado com cerca de $40 \mathrm{ml}$ de água destilada durante 5 vezes a $3.000 \mathrm{rpm} / 10 \mathrm{~min}$ (Figura 4b). Finalmente, o amido foi seco em estufa com circulação de ar a $40{ }^{\circ} \mathrm{C}$ até atingir peso constante e o resultado expresso em \% de amido.
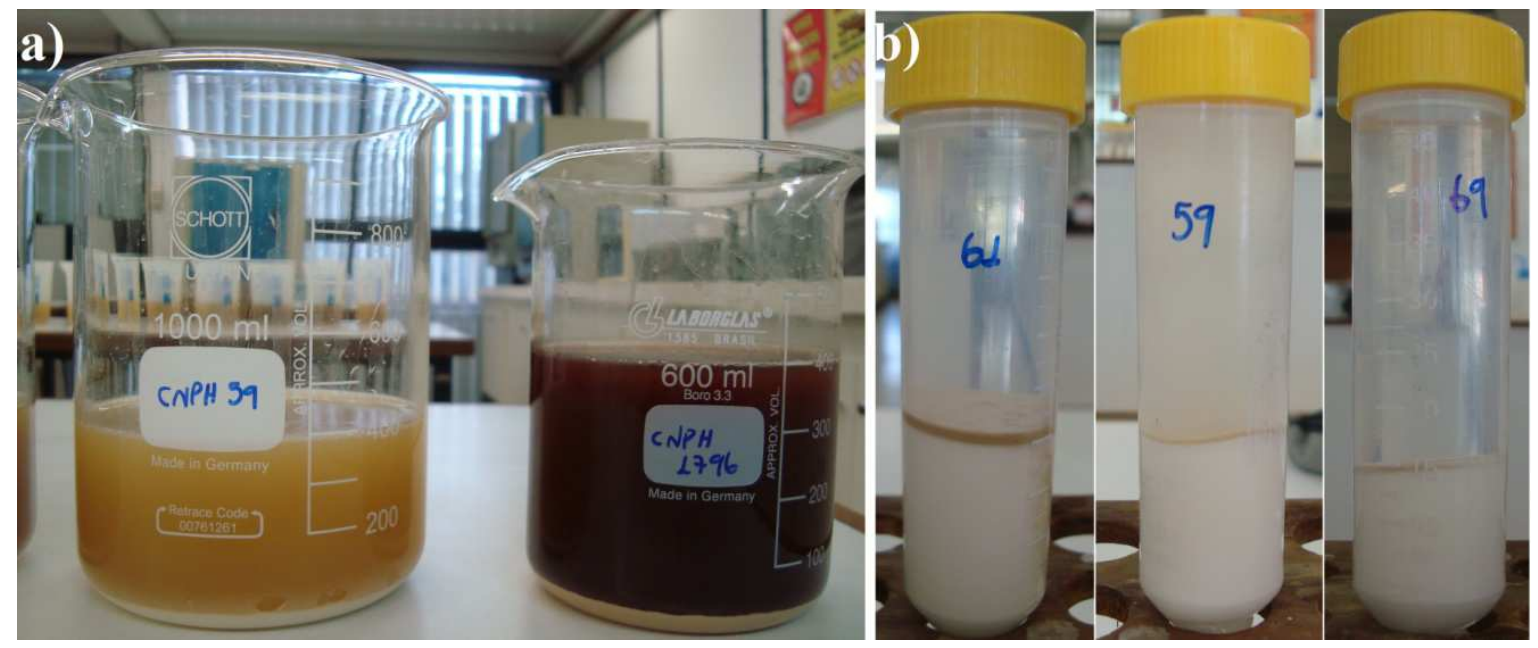

Figura 4 Decantação de amido a partir de extrato de polpa de raízes de batata-doce: a) após trituração; b) após primeira centrifugação.

\subsubsection{Análise estatística}

Com exceção das características diâmetro, formato, teor de fibra, acidez total, cinzas, umidade e conteúdo de amido das raízes de batata-doce, todos os dados foram transformados em $\sqrt{x+1}$, para atender à pressuposição de distribuição normal e homocedasticidade dos dados, sendo apresentados os valores originais.

Os dados foram submetidos à análise de variância para cada caráter e as médias foram agrupadas por meio do teste de Scott-Knott a 5\% de probabilidade. As análises de correlação linear de Pearson, entre todas as variáveis, basearam-se na significância de seus coeficientes. A classificação de intensidade da correlação para $p \leq 0,05$ foi: muito forte $(r \pm 0,91$ a $\pm 1,00)$, 
forte $(r \pm 0,71$ a $\pm 0,9)$, média $(r \pm 0,51$ a $\pm 0,70)$, fraca $(r \pm 0,31$ a $\pm 0,50)$ e muito fraca $(r \leq \pm$ 0,30) (CARVALHO et al., 2004).

Com a utilização dos caracteres quantitativos foram efetuadas análises de diversidade entre os acessos por meio de medidas baseadas na distância Euclidiana. Para o agrupamento hierárquico $(\mathrm{AAH})$ foi obtido o dendrograma para os pares ordenados pela média aritmética não ponderada (UPGMA). Posteriormente, foi realizada uma análise de componentes principais (PCA) sobre uma matriz de correlação. As análises estatísticas descritas anteriormente foram realizadas utilizando-se o software R Core Team (2013).

A partir dos componentes da variância foram estimados os parâmetros genéticos de herdabilidade no sentido amplo $\left(\mathrm{ha}^{2}\right)$, os coeficientes de variação genética $\left(\mathrm{CV}_{\mathrm{g}}\right)$, ambiental $\left(\mathrm{CV}_{\mathrm{e}}\right)$ e a razão entre os coeficientes de variação genética e ambiental $\left(\mathrm{CV}_{\mathrm{g}} / \mathrm{CV}_{\mathrm{e}}\right)$ para os caracteres estudados, utilizando-se o programa GENES (CRUZ, 2013). 


\subsection{RESULTADOS E DISCUSSÃO}

As raízes tuberosas foram caracterizadas morfoagronomicamente quanto às produtividades comercial e total, diâmetro, comprimento, espessura do córtex, número de furos, incidência de danos causados por insetos do solo e formato. A análise de variância indicou a existência de diferenças significativas entre os genótipos a $1 \%$ de probabilidade, pelo teste F, para os caracteres em estudo, o que possibilitou diferenciá-los (Tabela 1.2).

Tabela 1.2 Valores médios do diâmetro, comprimento, espessura do córtex, formato, número de furos causados por insetos de solo, incidência de danos, produtividade comercializável e produtividade total de raízes de batata-doce

\begin{tabular}{|c|c|c|c|c|c|c|c|c|c|}
\hline Genótipo & $\begin{array}{c}\text { DR } \\
(\mathbf{m m})\end{array}$ & $\begin{array}{c}\mathbf{C R} \\
(\mathbf{m m})\end{array}$ & $\begin{array}{c}\mathbf{E C} \\
(\mathbf{m m})\end{array}$ & FTO & NF & ID & GR & $\begin{array}{c}\text { PC } \\
\left(t \text { ha }^{-1}\right)\end{array}$ & $\begin{array}{c}\text { PT } \\
\left(t \text { ha }^{-1}\right)\end{array}$ \\
\hline CNPH 69 & $37,71 \mathrm{c}$ & $383,03 \mathrm{a}$ & $2,97 \mathrm{c}$ & $2,06 \mathrm{~b}$ & $20,65 \mathrm{a}$ & $1,78 \mathrm{a}$ & MR & $47,12 \mathrm{a}$ & $47,54 \mathrm{a}$ \\
\hline CNPH 46 & $39 \mathrm{~b}$ & $244,12 \mathrm{~b}$ & $2,91 \mathrm{c}$ & $3,83 \mathrm{a}$ & $19,99 \mathrm{a}$ & $1,96 \mathrm{a}$ & MR & $29,36 \mathrm{a}$ & $38,36 \mathrm{a}$ \\
\hline &, $48 \mathrm{~b}$ & $173,91 \mathrm{c}$ & $3,29 \mathrm{~b}$ & & & & MR & $36,22 \mathrm{a}$ & $36,56 \mathrm{a}$ \\
\hline CNPH 59 & $57,59 \mathrm{~b}$ & $178,06 \mathrm{c}$ & $2,21 \mathrm{~d}$ & $2,46 \mathrm{~b}$ & $17,40 \mathrm{a}$ & & MR & $32,91 \mathrm{a}$ & $33,54 \mathrm{a}$ \\
\hline Brazlândia Rosada & $57,71 \mathrm{~b}$ & $153,98 \mathrm{c}$ & $2,57 \mathrm{c}$ & $2,37 \mathrm{~b}$ & $14,97 \mathrm{a}$ & $1,89 \mathrm{a}$ & MR & $27,28 \mathrm{a}$ & $28,57 \mathrm{a}$ \\
\hline CNPH 56 & $90,33 \mathrm{a}$ & $194,21 \mathrm{c}$ & $3,40 \mathrm{~b}$ & $3,01 \mathrm{a}$ & $12,13 \mathrm{a}$ & & MR & $24,06 \mathrm{~b}$ & $25,71 \mathrm{a}$ \\
\hline & $55,18 \mathrm{~b}$ & $171,27 \mathrm{c}$ & $2,79 \mathrm{c}$ & & & & MR & $19,65 \mathrm{~b}$ & $25,03 \mathrm{a}$ \\
\hline CNPH 80 & $50,87 \mathrm{c}$ & $169,42 \mathrm{c}$ & $2,58 \mathrm{c}$ & $1,94 \mathrm{~b}$ & $9,19 \mathrm{~b}$ & $1,32 \mathrm{~b}$ & MR & $20,09 \mathrm{~b}$ & $23,69 \mathrm{a}$ \\
\hline $\mathrm{CNPH}$ & $59,26 \mathrm{~b}$ & $114,02 \mathrm{~d}$ & $2,80 \mathrm{c}$ & $2,56 \mathrm{~b}$ & $10,25 \mathrm{~b}$ & & MR & $16,84 \mathrm{~b}$ & $17,53 \mathrm{a}$ \\
\hline Prince & $54,41 \mathrm{~b}$ & $191,53 \mathrm{c}$ & $4,20 \mathrm{a}$ & $2,93 \mathrm{a}$ & & & & $12,47 \mathrm{c}$ & $17,45 \mathrm{a}$ \\
\hline CNPH & $48,21 \mathrm{c}$ & $146,98 \mathrm{c}$ & $2,42 \mathrm{~d}$ & $2,68 \mathrm{~b}$ & $4,76 \mathrm{~b}$ & $1,13 \mathrm{~b}$ & MR & $14,06 \mathrm{c}$ & $14,81 \mathrm{~b}$ \\
\hline CNPH 35 & $82,64 \mathrm{a}$ & $217,66 \mathrm{c}$ & $3,99 \mathrm{a}$ & $2,51 \mathrm{~b}$ & & & & & $13,63 \mathrm{~b}$ \\
\hline CNPH 1796 & $40,21 \mathrm{c}$ & $116,76 \mathrm{~d}$ & $2,07 \mathrm{~d}$ & $1,77 \mathrm{~b}$ & $7,35 \mathrm{~b}$ & $1,26 \mathrm{~b}$ & MR & $7,84 \mathrm{c}$ & $11,51 \mathrm{~b}$ \\
\hline & $57,65 \mathrm{~b}$ & $76,61 \mathrm{~d}$ & $2,72 \mathrm{c}$ & & & & & $10,69 \mathrm{c}$ & $11,22 \mathrm{~b}$ \\
\hline & $55,11 \mathrm{~b}$ & $104,8 \mathrm{~d}$ & $2,76 \mathrm{c}$ & $2,37 \mathrm{~b}$ & $15,67 \mathrm{a}$ & $1,54 \mathrm{~b}$ & MR & $8,20 \mathrm{c}$ & $10,76 \mathrm{~b}$ \\
\hline CNPH 41 & $60,94 \mathrm{~b}$ & $94,37 \mathrm{~d}$ & $2,99 \mathrm{c}$ & $2,33 \mathrm{~b}$ & $6,56 \mathrm{~b}$ & $1,22 \mathrm{~b}$ & MR & $9,39 \mathrm{c}$ & $10,02 \mathrm{~b}$ \\
\hline CNPH 28 & $46,55 \mathrm{c}$ & $111,47 d$ & $2,36 \mathrm{~d}$ & 3,44 a & $16,71 \mathrm{a}$ & $2,34 \mathrm{a}$ & MS & $6,64 c$ & $7,87 \mathrm{~b}$ \\
\hline CNPH 87 & $39,68 \mathrm{c}$ & $111,74 \mathrm{~d}$ & $2,39 d$ & $2,69 \mathrm{~b}$ & $8,25 \mathrm{~b}$ & $1,31 \mathrm{~b}$ & MR & $6,80 \mathrm{c}$ & $7,72 \mathrm{~b}$ \\
\hline CNPH 61 & $52,54 \mathrm{c}$ & $88,84 \mathrm{~d}$ & $2,86 \mathrm{c}$ & $3,17 \mathrm{a}$ & $18,10 \mathrm{a}$ & $1,78 \mathrm{a}$ & MR & $1,31 \mathrm{c}$ & $6,69 \mathrm{~b}$ \\
\hline CNPH 29 & $38,08 \mathrm{c}$ & $194,83 \mathrm{c}$ & $1,97 \mathrm{~d}$ & $2,69 \mathrm{~b}$ & $7,11 \mathrm{~b}$ & $1,29 \mathrm{~b}$ & MR & $5,63 \mathrm{c}$ & $6,23 \mathrm{~b}$ \\
\hline & $34,26 \mathrm{c}$ & $116,71 d$ & $2,29 d$ & $2,31 \mathrm{~b}$ & $3,44 \mathrm{~b}$ & $1,09 \mathrm{~b}$ & MR & $4,13 \mathrm{c}$ & $6,22 b$ \\
\hline & $39,66 \mathrm{c}$ & $67,50 \mathrm{~d}$ & $2,40 \mathrm{~d}$ & $2,00 \mathrm{~b}$ & $19,10 \mathrm{a}$ & $2,14 \mathrm{a}$ & MS & $2,81 \mathrm{c}$ & $4,44 \mathrm{~b}$ \\
\hline CNPH 12 & $64,86 \mathrm{~b}$ & $170,33 \mathrm{c}$ & $3,19 \mathrm{~b}$ & $3,12 \mathrm{a}$ & $19,33 \mathrm{a}$ & $2,37 \mathrm{a}$ & MS & $0,00 \mathrm{c}$ & $0,78 \mathrm{~b}$ \\
\hline $\mathrm{QM}_{\text {(tratamento) }}$ & $764,16^{* *}$ & $23,57 * *$ & $0,08 * *$ & $1,01 * *$ & $2,47 * *$ & $0,06^{* *}$ & - & $9,93 * *$ & 7,96 ** \\
\hline & & & 2,79 & & & 1,66 & - & 15,20 & 17,65 \\
\hline C.V. (\%) & 19,39 & 15,24 & 6,62 & 19,28 & 28,04 & 9,04 & - & 37,80 & 34,11 \\
\hline
\end{tabular}

Médias com a mesma letra na coluna não diferem entre si, pelo teste de Scott-Knott a 5\% de probabilidade; QM: quadrado médio dos tratamentos; **Significativo a $1 \%$ de probabilidade pelo teste F, C.V.: coeficiente de variação. DR: diâmetro; CR: comprimento; EC: espessura do córtex; FT: formato; NF: número de furos causados por insetos de solo por raiz; ID: incidência de danos; GR: grau de resistência; PC: produtividade comercializável; PT: produtividade total, das raízes de batata-doce. 
De acordo com a Tabela 1.2 foi observada grande amplitude de variação na produtividade comercial ( 0 a 47,12 $\mathrm{t} \mathrm{ha}^{-1}$ ), sendo que o clone CNPH 12 não apresentou raízes comerciais. A cultivar Brazlândia Rosada $\left(27,28 \mathrm{t} \mathrm{ha}^{-1}\right)$ e os clones CNPH $46\left(29,36 \mathrm{t} \mathrm{ha}^{-1}\right)$, CNPH $59\left(32,91 \mathrm{t} \mathrm{ha}^{-1}\right)$, CNPH $60\left(36,22 \mathrm{t} \mathrm{ha}^{-1}\right)$ e CNPH $69\left(47,12 \mathrm{t} \mathrm{ha}^{-1}\right)$ apresentaram as maiores produtividades comerciais. As cultivares Coquinho e Princesa apresentaram produtividades comerciais de 4,13 e 12,47 t ha-1, respectivamente. Peixoto et al. (1999) observaram uma produtividade comercial semelhante para a cultivar Coquinho de $4,83 \mathrm{t} \mathrm{ha}^{-1}$. Já o valor obtido para a produtividade média da cultivar Princesa foi superior à produtividade atingida por Viana (2009), com colheita realizada aos cinco meses (11,96 t ha $\left.{ }^{-1}\right)$. Com relação à cultivar Brazlândia Rosada, Figueiredo (2010), avaliando 12 clones de batata-doce em Diamantina-MG, obteve uma produtividade comercial média de raízes na faixa de 11,52 a 28,85 t ha ${ }^{-1}$, sendo que a cultivar Brazlândia Rosada apresentou 24,52 t ha ${ }^{-1}$, valor este condizente, ao observado no presente estudo.

Os clones com maior produção total de raízes frescas foram CNPH 69 (47,54 t ha $\left.{ }^{-1}\right)$, CNPH 46 (38,36 t ha $\left.{ }^{-1}\right)$, CNPH 60 (36,56 t ha $\left.{ }^{-1}\right)$ e CNPH 59 (33,54 t ha'). Contudo, não foram observadas diferenças estatisticamente significativas entre estes materiais e as cultivares Princesa e Brazlândia Rosada (17,45 e 28,57 t ha ${ }^{-1}$, respectivamente) e os clones CNPH 80, CNPH 02 e CNPH $56\left(23,69 ; 25,03\right.$ e 25,71 $\mathrm{t} \mathrm{ha}^{-1}$, respectivamente). A produtividade média total $\left(17,65 \mathrm{t} \mathrm{ha}^{-1}\right)$ foi superior à produtividade média brasileira de 13,09 $\mathrm{t} \mathrm{ha}^{-1}$ (IBGE, 2013) e às produtividades atingidas por Cavalcante et al. (2009), com colheita aos 130 dias $\left(6,29 \mathrm{t} \mathrm{ha}^{-1}\right)$ e às alcançadas por Cardoso et al. (2005) e Massaroto et al. (2014), com colheita aos 6 meses (15,22 e 14,59 t ha ${ }^{-1}$, respectivamente). Além da duração do ciclo dos materiais, das condições edafoclimáticas do local de cultivo, da época de plantio, da qualidade das ramas utilizadas e do tempo de permanência da cultura no campo, constituintes genéticos das cultivares e fatores como a temperatura, fotoperíodo e radiação solar incidente, que resultam na interação entre genótipos e ambientes, afetam diretamente o crescimento, desenvolvimento e tamanho das raízes e, consequentemente, o rendimento das cultivares (BARRETO et al., 2011; ERPEN et al., 2013).

A média geral do diâmetro de raízes para os genótipos estudados foi de $54,45 \mathrm{~mm}$. A cultivar Coquinho $(34,26 \mathrm{~mm})$ apresentou o menor diâmetro; porém, não diferiu estatisticamente dos materiais CNPH 69, CNPH 29, CNPH 71, CNPH 87, CNPH 1796, CNPH 28, CNPH 90, CNPH 80 e CNPH 61 (37,71; 38,08; 39,66; 39,68; 40,21; 46,55; 48,21; 
50,87 e 52,54 mm, respectivamente). Já o maior diâmetro foi verificado nos clones CNPH 35 (82,64 mm) e CNPH 56 (90,33 mm) (Tabela 1.2). Resultados semelhantes foram obtidos por Silva et al. (2012), que observaram diâmetros entre 56,2 (acesso 345-B) e 97,7 mm (acesso 1270) seis meses após o plantio. Ainda segundo Miranda et al. (1995), as raízes de batatadoce do tipo extra A (melhor classificação) devem apresentar diâmetro entre 50 e $80 \mathrm{~mm}$. No presente trabalho $56,52 \%$ dos materiais estudados mostraram valores na faixa ideal, sendo, portanto, promissores. Contudo, segundo Cavalcante et al. (2009) a classificação da batatadoce no mercado atacadista é caracterizada pela cor de sua casca, polpa, pela sua massa e pela sua qualidade, e não são levados em consideração nem o comprimento nem o diâmetro da raiz.

O comprimento das raízes variou entre 67,50 (clone CNPH 71) e 383,03 mm (clone CNPH 69). Apenas o clone CNPH 90 (146,98 mm) e a cultivar Brazlândia Rosada (153,98 mm) se enquadraram no comprimento ideal de raízes de batata-doce (classificação extra A) proposto por Miranda et al. (1995), o qual deve variar entre 120 e $160 \mathrm{~mm}$. Contudo, estes genótipos não apresentaram diferença significativa com os clones CNPH 80 (169,42 mm), CNPH 12 (170,33 mm), CNPH 02 (171,27 mm), CNPH 60 (173,91 mm), CNPH 59 (178,06 mm), CNPH 56 (194,21 mm), CNPH 29 (194,83 mm), CNPH 35 (217,66 mm) e a cultivar Princesa $(191,53 \mathrm{~mm})$, que mostraram valores de comprimento muito próximos à classificação extra A.

A espessura do córtex das raízes de batata-doce variou de $1,97 \mathrm{~mm}$, para o clone CNPH 29, a 4,20 mm, para a cultivar Princesa (Tabela 1.2). Estes valores encontram-se próximos dos observados por Cavalcante et al. (2009), que obtiveram espessuras do córtex entre 2,00 e 4,67 mm, para os clones CL-06 e CL-09, respectivamente. De acordo com estes autores, é possível que raízes que apresentem espessura de córtex mais grossa sejam favorecidas na ocasião do transporte e armazenamento, porém o rendimento da polpa da raiz (massa da polpa sem o córtex) é reduzido.

Com exceção dos clones CNPH 46, CNPH 28, CNPH 61, CNPH 55, CNPH 12 e CNPH 56 , todos os genótipos apresentaram nota de formato inferior a 3,0 (73,91\% dos materiais analisados), variando de 1,77 (CNPH 1796) a 2,93 (Princesa), sendo considerados bastante promissores, especialmente aqueles que mais se aproximaram do formato ideal fusiforme (notas de 1 a 2). Apesar do bom rendimento total do clone CNPH $46\left(38,36 \mathrm{t} \mathrm{ha}^{-1}\right)$, o mesmo apresentou formato ruim $(3,84)$ podendo ser empregado para procesamento industrial ou 
alimentação animal. De acordo com Azevedo et al. (2000), o formato é uma das características importantes estudadas em programas de melhoramento de batata-doce. As cultivares Brazlândia Rosada $(2,38)$ e Coquinho $(2,31)$ apresentaram formatos semelhantes, porém melhores, aos reportados por Azevedo (1995) quem obteve notas de 2,57 e 2,93, respectivamente.

Aproximadamente $35 \%$ dos materiais apresentaram em média menos de 10 furos por raiz, sendo que a cultivar Coquinho apresentou apenas 3,4 furos (Tabela 1.2). Já os clones CNPH 69 e CNPH 35, foram os mais furados pelos insetos de solo apresentando em média 20,65 e 20,06 furos por raiz, respectivamente. Apenas os clones CNPH 35, CNPH 12, CNPH 28 e CNPH 71 apresentaram notas de incidência de danos superiores a 2, sendo considerados moderadamente suscetíveis. Contudo, não houve diferença significativa com relação à incidência de danos e número de furos, entre estes materiais e os genótipos $\mathrm{CNPH} 46, \mathrm{CNPH}$ 02, Princesa, CNPH 61, Brazlândia Rosada, CNPH 69 e CNPH 59, que foram classificados como moderadamente resistentes. Isto pode ser explicado pelo fato da incidência de danos não estar apenas corelacionada com o número de furos. A infecção secundária por outros patógenos pode resultar em degradação extensa dos tecidos previamente furados, afetando não só o aspecto comercial das raízes, mas também o seu grau de resistência.

A cultivar Brazlândia Rosada, empregada como testemunha e cultivada no DF, foi moderadamente resistente aos insetos de solo com 14,97 furos em média por raiz e uma incidência de danos de 1,89, valor semelhante ao relatado por Andrade Júnior et al. (2012) quanto à avaliação de resistência para esta cultivar $(1,8)$. As cultivares Princesa e Coquinho, também foram moderadamente resistentes aos insetos de solo com uma incidência de danos de 1,93 e 1,09, respectivamente. Viana (2009) aos 150 dias do plantio verificou também uma moderada resistência das cultivares Brazlândia Rosada e Princesa, com incidência de danos média entre os dois locais avaliados de 1,57 e 1,19, respectivamente. Resultados contrastantes foram reportados por Peixoto et al. (1999) em seu estudo de resistência a insetos de solo de clones de batata-doce, os quais constataram maiores índices de incidência de danos para as cultivares Brazlândia Rosada e Coquinho (3,00 e 2,68, respectivamente). Azevedo (1995) também verificou a suscetibilidade das cultivares Brazlândia Rosada e Coquinho, com notas 2,10 e 2,37, respectivamente. Segundo o último autor, as notas menores resultam da baixa incidência de insetos de solo na cultura durante a condução do experimento, que está relacionada à prática da irrigação aplicada com frequência. 
As raízes tuberosas também foram caracterizados fisico-quimicamente quanto ao teor de umidade, cinzas, proteína, fibra, $\mathrm{pH}$, acidez total titulável, sólidos solúveis totais, ratio e amido (Tabela 1.3). Diferenças significativas foram apontadas pelo teste de Scott-Knott a 5\% de probabilidade entre as médias dos 23 genótipos para cada característica analisada, indicando grande diversidade genética.

Tabela 1.3 Teores de umidade, cinzas, proteína bruta, fibra bruta, $\mathrm{pH}$, acidez total titulável, sólidos solúveis totais, ratio e amido de raízes tuberosas de batata-doce

\begin{tabular}{|c|c|c|c|c|c|c|c|c|c|}
\hline Genótipo & $\begin{array}{c}\% \text { UM } \\
\text { (b.u.) }\end{array}$ & $\begin{array}{c}\% \mathrm{CZ} \\
\text { (b.s.) }\end{array}$ & $\begin{array}{c}\text { \% PTN } \\
\text { (b.s.) }\end{array}$ & $\begin{array}{c}\% \text { FB } \\
\text { (b.s.) }\end{array}$ & $\mathbf{P H}$ & $\begin{array}{c}\% \text { AT } \\
\text { (b.s.) }\end{array}$ & $\begin{array}{c}\text { SS } \\
\left({ }^{(} \mathbf{B r i x}\right)\end{array}$ & RT & $\begin{array}{c}\% \text { AM } \\
\text { (b.s.) }\end{array}$ \\
\hline CNPH 12 & $68,75 \mathrm{~b}$ & $4,53 \mathrm{a}$ & $5,10 \mathrm{c}$ & $3,00 \mathrm{~b}$ & $5,20 \mathrm{~d}$ & $5,87 \mathrm{c}$ & $8,47 \mathrm{c}$ & $1,46 \mathrm{~d}$ & $52,13 \mathrm{a}$ \\
\hline CNPH 61 & $65 \mathrm{~b}$ & $4,32 \mathrm{a}$ & $14 \mathrm{~b}$ & $3,59 \mathrm{a}$ & ,60 b & $2,00 \mathrm{e}$ & $9,77 \mathrm{~b}$ & $4,97 \mathrm{a}$ & $49,07 \mathrm{a}$ \\
\hline Brazlândia Rosada & $9,03 \mathrm{~b}$ & $3,57 \mathrm{~b}$ & $3,29 \mathrm{~d}$ & $2,91 \mathrm{~b}$ & $5,83 \mathrm{a}$ & $6,88 \mathrm{~b}$ & $9,90 \mathrm{~b}$ & $1,79 \mathrm{c}$ & $47,60 \mathrm{a}$ \\
\hline CNPH 71 & $67,42 \mathrm{~b}$ & $3,47 \mathrm{~b}$ & $6,60 \mathrm{~b}$ & $3,74 \mathrm{a}$ & $50 \mathrm{c}$ & $4,69 \mathrm{~d}$ & $12,13 \mathrm{a}$ & $2,59 \mathrm{~b}$ & $45,48 \mathrm{~b}$ \\
\hline $\mathrm{CNPI}$ &, $70 \mathrm{~b}$ & $4,04 \mathrm{a}$ & $43 \mathrm{~d}$ & $63 \mathrm{~b}$ & $a$ & $5,85 \mathrm{c}$ & $10,08 \mathrm{~b}$ & $1,76 \mathrm{c}$ & $45,22 \mathrm{~b}$ \\
\hline CNPH 1 & $3,81 \mathrm{~b}$ & $4,12 \mathrm{a}$ & $76 \mathrm{c}$ & $16 \mathrm{~b}$ & $63 \mathrm{~b}$ & $6,41 \mathrm{c}$ & $8,13 \mathrm{c}$ & $1,36 \mathrm{~d}$ & $44,37 \mathrm{~b}$ \\
\hline &, $55 \mathrm{a}$ & $3,43 \mathrm{~b}$ & $4,33 \mathrm{~d}$ & $3,02 \mathrm{~b}$ & $\mathrm{c}$ & $5,51 \mathrm{c}$ & $9,03 \mathrm{c}$ & $1,70 \mathrm{c}$ & $44,12 \mathrm{~b}$ \\
\hline & $38 \mathrm{a}$ & $4,45 \mathrm{a}$ & $10,29 \mathrm{a}$ & $4,30 \mathrm{a}$ & $25 \mathrm{~d}$ & $10,10 \mathrm{a}$ & $7,61 \mathrm{c}$ & $0,76 \mathrm{~d}$ & $43,19 \mathrm{~b}$ \\
\hline &, $33 \mathrm{a}$ & $4,12 \mathrm{a}$ & $61 \mathrm{c}$ & $3,26 \mathrm{~b}$ & $5,38 \mathrm{c}$ & $6,08 \mathrm{c}$ & $8,49 \mathrm{c}$ & $1,43 \mathrm{~d}$ & $42,34 \mathrm{c}$ \\
\hline & $5,64 \mathrm{~b}$ & $2,84 \mathrm{c}$ & $95 \mathrm{~d}$ & $2,71 \mathrm{~b}$ & $40 \mathrm{c}$ & $4,14 \mathrm{~d}$ & $8,87 \mathrm{c}$ & 2,1 & $41,81 \mathrm{c}$ \\
\hline & $12 \mathrm{a}$ & $3,78 \mathrm{~b}$ & $47 \mathrm{~d}$ & $3,48 \mathrm{a}$ & $5,40 \mathrm{c}$ & $5,92 \mathrm{c}$ & $8,64 \mathrm{c}$ & $1,46 \mathrm{~d}$ & $41,05 \mathrm{c}$ \\
\hline & $03 \mathrm{~b}$ & $3,54 \mathrm{~b}$ & $43 \mathrm{c}$ & $2,93 \mathrm{~b}$ & $10 \mathrm{c}$ & $4,75 \mathrm{~d}$ & $10,93 \mathrm{a}$ & $2,42 \mathrm{~b}$ & $41,04 \mathrm{c}$ \\
\hline &, $91 \mathrm{a}$ & $3,87 \mathrm{a}$ & $33 \mathrm{~d}$ & $3,15 \mathrm{~b}$ & $5,50 \mathrm{c}$ & $5,10 \mathrm{c}$ & $8,92 \mathrm{c}$ & $2,06 \mathrm{c}$ & $40,28 \mathrm{c}$ \\
\hline & ,63 a & $3,45 \mathrm{~b}$ & $53 \mathrm{~b}$ & $3,39 \mathrm{~b}$ & $5,60 \mathrm{~b}$ & $6,50 \mathrm{c}$ & $10,44 \mathrm{~b}$ & $1,61 \mathrm{c}$ & $40,12 \mathrm{c}$ \\
\hline &, $03 \mathrm{~b}$ & $3,13 \mathrm{c}$ & $4,92 \mathrm{c}$ & $10 \mathrm{a}$ & & $3,78 \mathrm{~d}$ & $9,45 \mathrm{~b}$ & 2,9 & $40,10 \mathrm{c}$ \\
\hline & $69,48 \mathrm{~b}$ & $3,68 \mathrm{~b}$ & $6,51 \mathrm{~b}$ & $4,35 \mathrm{a}$ & $5,48 \mathrm{c}$ & $5,76 \mathrm{c}$ & $10,00 \mathrm{~b}$ & $1,80 \mathrm{c}$ & $39,99 \mathrm{c}$ \\
\hline & $72,58 \mathrm{a}$ & $3,69 \mathrm{~b}$ & $20 d$ & $17 \mathrm{~b}$ & $45 \mathrm{c}$ & $6,63 \mathrm{c}$ & $8,01 \mathrm{c}$ & $1,30 \mathrm{~d}$ & $39,88 \mathrm{c}$ \\
\hline &, $57 \mathrm{~b}$ & $2,99 \mathrm{c}$ & $98 \mathrm{~d}$ & $3,64 \mathrm{a}$ & $5,65 \mathrm{~b}$ & $9,49 \mathrm{a}$ & $9,63 \mathrm{~b}$ & $1,03 \mathrm{~d}$ & $38,92 \mathrm{c}$ \\
\hline & ,64 a & $3,72 \mathrm{~b}$ & $4,38 \mathrm{~d}$ & $3,33 \mathrm{~b}$ & & $7,74 \mathrm{~b}$ & $9,82 \mathrm{~b}$ & $1,34 \mathrm{~d}$ & $63 \mathrm{c}$ \\
\hline & $71,03 \mathrm{a}$ & $3,65 \mathrm{~b}$ & $5,18 \mathrm{c}$ & $3,59 \mathrm{a}$ & $5,55 \mathrm{~b}$ & $7,51 \mathrm{~b}$ & $8,39 \mathrm{c}$ & $1,16 \mathrm{~d}$ & $38,21 \mathrm{c}$ \\
\hline & b & $3,06 \mathrm{c}$ & $3,93 \mathrm{~d}$ & $3,50 \mathrm{a}$ & $5,45 \mathrm{c}$ & $5,64 \mathrm{c}$ & $7,71 \mathrm{c}$ & $1,36 \mathrm{~d}$ & $37,99 \mathrm{c}$ \\
\hline & $71,10 \mathrm{a}$ & $4,09 \mathrm{a}$ & $3,66 \mathrm{~d}$ & $3,53 \mathrm{a}$ & $5,48 \mathrm{c}$ & $5,89 \mathrm{c}$ & $8,22 \mathrm{c}$ & $1,48 \mathrm{~d}$ & $36,29 \mathrm{c}$ \\
\hline CNPH 46 & $72,71 \mathrm{a}$ & $4,83 \mathrm{a}$ & $5,64 \mathrm{c}$ & $3,92 \mathrm{a}$ & $5,43 \mathrm{c}$ & $7,02 \mathrm{~b}$ & $9,22 \mathrm{c}$ & $1,32 \mathrm{~d}$ & $35,39 \mathrm{c}$ \\
\hline $\mathrm{QM}_{\text {(tratamento) }}$ & $27,77 * *$ & $1,04 * *$ & $0,38 * *$ & $0,87 * *$ & $0,004 * *$ & $11,96^{* *}$ & $0,11 * *$ & 0,21 ** & $66,51 * *$ \\
\hline Média & 69,83 & 3,76 & 5,16 & 3,41 & 5,51 & 6,05 & 9,21 & 1,79 & 41,88 \\
\hline C.V. $(\%)$ & 3,13 & 11,68 & 8,43 & 18,65 & 0,97 & 23,85 & 4,66 & 8,56 & 7,96 \\
\hline
\end{tabular}

Médias com a mesma letra na coluna não diferem entre si, pelo teste de Scott-Knott a $5 \%$ de probabilidade; QM: quadrado médio dos tratamentos; **Significativo a $1 \%$ de probabilidade pelo teste F; C.V.: coeficiente de variação. UM: umidade; CZ: cinzas; PTN: proteína bruta; FB: fibra bruta; PH: pH; AT: acidez total titulável; SS: sólidos solúveis totais; RT: ratio; AM: amido, das raízes de batata-doce.

De acordo com a Tabela 1.3, o conteúdo de umidade oscilou entre 65,03 e 75,38\% para os clones CNPH 59 e CNPH 55, respectivamente. Os genótipos CNPH 59, Coquinho, CNPH 35, CNPH 61, CNPH 60, CNPH 71, CNPH 08, CNPH 12, CNPH 1796, Brazlândia Rosada, 
CNPH 62 e CNPH 41 (65,03; 66,57; 66,64; 66,65; 66,91; 67,42; 68,70; 68,75; 68,81; 69,03; 69,03 e 69,48\%, respectivamente), apresentaram teores de umidade abaixo de $70 \%$.

Resultados semelhantes foram observados por Tomlins et al. (2012), que estudando onze variedades de batata-doce com cor de polpa variando do branco ao alaranjado, verificaram teores de umidade na faixa de 60,6 (var. Dimbuka) a 73,2\% (var. SPK004/6/6). Bengtsson et al. (2008) estudando sete variedades de batata-doce de polpa alaranjada na Uganda, reportaram teores de umidade na faixa de 65 (SPK004) a 69,7\% (SPK004/6/6). A cultivar Brazlândia Rosada $(69,03 \%)$ apresentou percentual de umidade similar ao observado por Roesler et al. (2008), que 183 dias após o plantio, reportou 74,20\% de umidade para tal cultivar. Conforme Senanayake et al. (2013) a batata-doce contém cerca de $25 \%$ de matéria seca e os valores exatos dependem das variações genéticas, do nível de água no solo, de fatores fisiológicos, do tempo e das condições de armazenamento. Ainda de acordo com Rukundo et al. (2013) o acúmulo de matéria seca está associado com a capacidade da raiz para atrair produtos fotoassimilados a partir de órgãos fotossintetizantes. Segundo estes últimos autores, o teor de matéria seca é uma característica importante para as indústrias e os consumidores, sendo que para utilização industrial são requeridas variedades de batata-doce com teores acima de 30\% de peso fresco. Neste contexto, destacam-se os genótipos CNPH 41, Brazlândia Rosada, CNPH 62, CNPH 1796, CNPH 12, CNPH 08, CNPH 71, CNPH 60, CNPH 61, CNPH 35, Coquinho e CNPH 59 com teores de matéria seca de 30,52; 30,97; 30,$97 ; 31,19 ; 31,25 ; 31,3 ; 32,58 ; 33,09 ; 33,35 ; 33,36 ; 33,43$ e 34,97\%, respectivamente.

A determinação de umidade é uma das medidas mais importantes e utilizadas na análise de alimentos, pois está relacionada com sua estabilidade, qualidade e composição, e pode afetar características do produto como processamento, estocagem e embalagem. A umidade é o principal fator para os processos microbiológicos, como o desenvolvimento de fungos, leveduras e bactérias, e também para o desenvolvimento de insetos. O conhecimento do teor de umidade das matérias primas é de fundamental importância na conservação e armazenamento, na manutenção da sua qualidade e no processo de comercialização (PARK e ANTONIO, 2006). Adicionalmente, a presença de água nos alimentos e sua concentração são determinantes em seu sabor e digestibilidade, assim como na estrutura física e a capacidade de manejo do material (CORRALES, 2008).

O teor de cinzas médio foi de 3,76\%, sendo que os clones CNPH 46 (4,83\%), CNPH 12 (4,53\%), CNPH 55 (4,45\%), CNPH 61 (4,32\%), CNPH 02 (4,12\%), CNPH 1796 (4,12\%), 
CNPH 08 (4,04\%), CNPH 90 (3,87\%) e a cultivar Princesa (4,09\%) apresentaram os maiores percentuais (Tabela 1.3). Viana (2009) avaliando oito clones de batata-doce em dois ambientes diferentes de cultivo reportou teores médios de cinzas de 2,88 e 3,34\%, respectivamente. Este autor observou para a cultivar Princesa $(2,18 \%)$ um teor de cinzas bem inferior ao encontrado no presente estudo, que foi de 4,09\%; enquanto o teor da cultivar Brazlândia Rosada, de 3,35\%, foi semelhante (3,57\%). Andrade Júnior et al. (2012) analisando 12 clones de batata-doce em Diamantina - MG, observaram que os teores de cinzas oscilaram entre 2,3 (cv. Cambraia) e 3,7\% (clone BD-67).

O teor de cinzas de um alimento é o resíduo inorgânico que permanece após a queima da matéria orgânica. A cinza é constituída principalmente de grandes quantidades de K, Na, Ca e $\mathrm{Mg}$; pequenas quantidades de $\mathrm{Al}, \mathrm{Fe}, \mathrm{Cu}, \mathrm{Mn}$ e $\mathrm{Zn}$ e traços de $\mathrm{Ar}$, I, F e outros elementos (PARK e ANTONIO, 2006) e representa o conteúdo de minerais do alimento.

Os teores de proteína bruta nas raízes dos genótipos avaliados (Tabela 1.3) oscilaram entre 2,95\% (CNPH 35) e 10,29\% (CNPH 55), apresentando teores médios de 5,16\%. Estes resultados são condizentes com os encontrados por Shao e Huang (2008), que avaliando cinco genótipos de batata-doce em Taiwan reportaram teores de proteína variando de 3,53 (WP) a 8,87\% (TNG57). Já os teores médios de proteína foram superiores aos relatados por Miranda et al. (1988), de 1,81\%; Azevedo et al. (2014), de 3,87\% e Senanayake et al. (2013), de 2,3\%. Menezes et al. (1976) estudando o teor de proteína bruta nas raízes tuberosas de seis variedades de batata-doce, em diferentes épocas de colheita (4, 6 e 8 meses), verificaram que a proteína bruta na raiz variou, em média, de 2,65 (var. Moranguinha, com colheita aos 6 meses) a 5,83\% (var. Roxa, com colheita aos 4 meses), sendo os maiores conteúdos atingidos com colheita realizada aos 8 meses (4,92\%). De acordo com estes autores houve influência das variedades e das épocas de colheita sobre os teores de proteína. Ainda, segundo Chakraborty et al. (2010) e Agrawal et al. (2013), o aumento na biossíntese de proteína é uma consequência do aumento da taxa de fotossíntese, que é, eventualmente, um fator crucial para a obtenção de maiores rendimentos.

As proteínas desempenham funções biológicas no organismo humano, dentre as quais destacam-se a regeneração e a formação de tecidos, a síntese de enzimas, anticorpos e hormônios e como constitutivo do sangue; e formam parte dos tecidos muscular e conjuntivo em animais. Os órgãos humanos são compostos principalmente por proteínas e estima-se que 
existem cerca de cinco milhões de tipos com propriedades e características muito específicas (DERGAL, 1999).

Os clones com os menores conteúdos de fibras foram o CNPH 08, CNPH 35, Brazlândia Rosada, CNPH 59, CNPH 12, CNPH 69, CNPH 90, CNPH 1796, CNPH 80, CNPH 02, CNPH 29 e CNPH 87 (2,63; 2,71; 2,91; 2,93; 3,00; 3,02; 3,15; 3,16; 3,17; 3,26; 3,33 e 3,39\%, respectivamente) e o genótipo com o maior teor foi o CNPH 41 (4,35\%). Shekhar et al. (2015) identificaram teores de fibra de 2,31 e 2,35\% para uma variedade de polpa branca e uma de polpa alaranjada, respectivamente, apesar de não ter sido observadas diferenças significativas entre estes materiais. O teor médio de fibras de 3,41\% foi superior ao valor médio obtido por Roesler et al. (2008), de 2,70\%, seis meses após o plantio e inferior aos teores reportados por Viana (2009), de 6,62\% e Andrade Júnior et al. (2012), de 7,88\%.

As fibras alimentares regularizam o funcionamento intestinal, o que as torna relevantes para o bem-estar das pessoas saudáveis e para o tratamento dietético de várias patologias. Pesquisas têm evidenciado os efeitos benéficos destas substâncias para prevenir e tratar a doença diverticular do cólon, reduzir o risco de câncer e melhorar o controle do diabetes mellitus (MATTOS e MARTINS, 2000).

Os menores valores de $\mathrm{pH}$ foram apresentados pelos clones CNPH $12(5,20)$ e CNPH 55 $(5,25)$ e os maiores pela cultivar Brazlândia Rosada $(5,83)$ e pelo clone CNPH $08(5,93)$. Estes valores estiveram dentro dos intervalos observados previamente por Yoshinaga et al. (1999), que avaliando 19 clones de batata-doce de polpa roxa, reportaram teores de pH na faixa de 5 a 6,2, 150 dias após o plantio. Leonel e Cereda (2002) constataram um pH médio de 6,29, sete meses após o plantio, valor inferior ao encontrado neste estudo que foi de 5,5, cinco meses após o plantio. Esta diferença pode estar associada com a época da colheita, pois quanto maior o tempo de permanência das raízes no campo, maior será o pH. De acordo com Franco et al. (2001), o aumento de pH pode ser decorrente da transformação de açúcares por enzimas sintetases de amido, as quais originam o grânulo de amido.

A acidez titulável das raízes dos genótipos de batata-doce (Tabela 1.3) variou de 2,00 (CNPH 61) a 10,10\% (CNPH 55), apresentando teores médios de 6,05\%. Este valor é menor ao verificado por Roesler et al. (2008), os quais seis meses após o plantio, obtiveram teores médios de acidez de $0,73 \%$. Tal diferença pode ser explicada pelo tempo de permanência das raízes no campo, que é inversamente proporcional à acidez das raízes tuberosas. Os ácidos 
orgânicos presentes em alimentos influenciam o sabor, o odor, a cor, a estabilidade e a manutenção de qualidade dos alimentos (CECCHI, 2003).

O clone CNPH 55 (7,61 ${ }^{\circ}$ Brix) apresentou o menor teor de sólidos solúveis entre os genótipos avaliados, enquanto o maior conteúdo foi verificado no material CNPH 71 (12,13 ${ }^{\circ}$ Brix). Estes resultados são compatíveis com os reportados por Miranda et al. (1988) e Silveira et al. (2011), que observaram teores de sólidos solúveis oscilando entre 8,20 (cv. 10) e $12{ }^{\circ}$ Brix (cv. 9) e 6 (clones BD\#02 e LA\#23) e $12{ }^{\circ}$ Brix (clone BD\#09), respectivamente. Os teores de sólidos solúveis totais são utilizados como uma determinação aproximada do teor de açúcares e, muitas vezes, como índice de maturação, além de serem decisivos na manutenção do sabor e aroma de frutos e hortaliças (MANICA et al., 1998).

Os clones CNPH 61, CNPH 62, CNPH 71 e CNPH 59 apresentaram a maior relação entre as variáveis sólidos solúveis totais e acidez (ratio) (4,97; 2,95; 2,59 e 2,42, respectivamente). Estes genótipos podem ser considerados como os mais precoces, pois, segundo Chitarra e Chitarra (1990) durante o processo de maturação o valor do ratio tende a aumentar em função da hidrólise do amido, que resulta no aumento do teor de açúcares solúveis: redutores (glicose, frutose) e não redutores (sacarose) e devido à diminuição durante esse período da acidez. Já o clone CNPH 55, que apresentou o menor ratio $(0,76)$, pode ser considerado como um material mais tardio, pois na época da colheita apresentou baixo teor de sólidos solúveis $\left(7,61^{\circ}\right.$ Brix $)$, e, em contrapartida, como mostrado na Tabela 1.3, alto teor de ácidos orgânicos $(10,10 \%)$.

O teor médio de amido encontrado nas raízes de batata-doce foi de $41,88 \%$. O clone CNPH 12 apresentou o maior conteúdo (52,13\%), sem diferir da cultivar Brazlândia Rosada $(47,60 \%)$ e do clone CNPH 61 (49,07\%) (Tabela 1.3). Estes valores são inferiores aos atingidos por Ahmed et al. (2010), que avaliando o efeito da secagem $\left(55-65^{\circ} \mathrm{C}\right)$ de farinha de batata-doce da cultivar Sinhwangmi sobre as propriedades físico-químicas, reportaram teores de amido em torno de 64,81 (60 $\left.{ }^{\circ} \mathrm{C}\right)$ e $65,31 \%$ b.s. $\left(55\right.$ e $\left.65^{\circ} \mathrm{C}\right)$. Martins et al. (2012) e Viana (2009) reportaram teores médios de amido de 58,36 e 52,68\%, respectivamente. Este último autor constatou teores de amido de 50,78\% para a cultivar Brazlândia Rosada e de $56,74 \%$ para a cultivar Princesa, valores estes superiores aos observados no presente trabalho que foram de 47,60 e 36,29\%, respectivamente. Já Andrade Júnior et al. (2012) registraram para a cultivar Brazlândia Roxa um teor de amido aproximadamente 3 vezes menor $(18,4 \%)$ ao obtido neste pesquisa (55,9\%). Segundo Braun et al. (2010) o amido corresponde a 60- 
$80 \%$ da matéria seca e os açúcares, glicose, frutose e sacarose são os principais carboidratos presentes nas raízes tuberosas. Ao atingir a maturação fisiológica, as raízes de batata-doce apresentam grânulos de amido e quantidades variáveis desses açúcares, dependendo das condições ambientais e de cultivo, da cultivar e da interação entre essas variáveis. Menezes et al. (1999) na avaliação do comportamento de genótipos de batata (Solanum tuberosum L.) nas safras "das águas" e de inverno, no Sul de Minas Gerais, quanto à produção de tubérculos e seus componentes, observaram que o comportamento da maioria dos caracteres foi dependente do genótipo, da safra e da interação entre estas duas variáveis. Em condições de temperaturas altas, que eventualmente ocorrem na safra "das águas", ocorreu atraso no início da tuberização e menor translocação de fotoassimilados para os tubérculos $(24,7 \%)$, que foram particionados principalmente para a parte aérea das plantas, resultando na redução de 25,5\% na produção de tubérculos/planta. Esta pesquisa justifica os baixos teores médios de amido nas raízes observados no presente estudo, pois o experimento foi instalado em setembro, época de chuva e altas temperaturas. Adicionalmente, diferenças entre as metodologias empregadas pelos diversos autores, para a quantificação desta variável, podem conduzir a resultados divergentes.

Devido à suas propriedades físico-químicas e funcionais exclusivas, o amido tem grande importância nos mais diversos setores industriais. $\mathrm{Na}$ indústria de alimentos nacional e na internacional o amido é utilizado como ingrediente, podendo, entre outras funções, facilitar o processamento, fornecer textura, servir como espessante, fornecer sólidos em suspensão ou proteger os alimentos durante o processamento. Pode ser utilizado na sua forma natural ou, por intermédio de processamentos adicionais, dar origem a produtos como amidos modificados, xaropes de glicose, maltose ou frutose e maltodextrinas, entre outros (ROCHA et al., 2008).

Na Tabela 1.4 e Tabela 1.5 são apresentadas as estimativas da herdabilidade no sentido amplo $\left(\mathrm{h}_{\mathrm{a}}{ }^{2}\right)$, os coeficientes de variação genética $\left(\mathrm{CV}_{\mathrm{g}}\right)$, ambiental $\left(\mathrm{CV}_{\mathrm{e}}\right)$ e a razão entre os coeficientes de variação genética e ambiental $\left(\mathrm{CV}_{\mathrm{g}} / \mathrm{CV}_{\mathrm{e}}\right)$ para os caracteres estudados.

Os coeficientes de variação experimental $\left(\mathrm{CV}_{\mathrm{e}}\right)$ para a maioria das variáveis analisadas estiveram abaixo de 18\%, mostrando existir uma boa precisão experimental na avaliação dessas características. Ravindran et al. (1995) na avaliação de dezesseis cultivares de batatadoce quatro meses após o plantio, verificaram para os caracteres umidade, proteína, fibra, cinzas e amido coeficientes de variação de 5,84; 31,29; 20,76; 15,09 e 5,72\%, 
respectivamente, que são congruentes com os verificados nesta pesquisa $(3,12 ; 8,44 ; 18,57$; 11,66 e 7,94\%, respectivamente).

Já os maiores $\mathrm{CV}_{\mathrm{e}}$ obtidos para a produtividade comercial, produtividade total e número de furos causados por insetos de solo $(37,84 ; 34,04$ e 28,03\%, respectivamente) (Tabela 1.4), enquadram-se dentro da faixa encontrada para estes caracteres na batata-doce. Neiva et al. (2011) reportaram $\mathrm{CV}_{\text {e }}$ para a resistência a insetos do solo de 25,73\%. Cardoso et al. (2005) constataram $\mathrm{CV}_{\mathrm{e}}$ para a produtividade de raízes tuberosas de $46,64 \%$ e para a produtividade comercial de 59,02\%. Ainda, Queiroga et al. (2007) observaram para a produtividade total de raízes e a produtividade de raízes comerciais $\mathrm{CV}_{\mathrm{e}}$ de 36,06 e 40,12\%, respectivamente.

De acordo com Cavalcante et al. (2012) é comum encontrar valores de coeficientes de variação elevados em variáveis relacionadas a órgãos ou estruturas subterrâneas, pois o controle do ambiente é dificultado. O coeficiente de variação genética $\left(\mathrm{CV}_{\mathrm{g}}\right)$ foi de alta magnitude para as variáveis PC $(39,73 \%)$, PT $(31,66 \%)$, AT $(25,95 \%)$, DR $(23,46 \%)$ e CR $(18,38 \%)$, indicando alta variabilidade entre os genótipos, com grandes possibilidades de ganhos na seleção (Tabela 1.4 e Tabela 1.5).

Tabela 1.4 Parâmetros populacionais de caracteres morfoagronômicos das raízes tuberosas

\begin{tabular}{ccccccccc}
\hline Parâmetros & PC & PT & NF & ID & DR & CR & EC & FTO \\
\hline $\mathbf{h}_{\mathbf{a}}{ }^{2}(\%)$ & 81,55 & 77,5 & 59 & 65,76 & 85,42 & 85,34 & 78,62 & 74,77 \\
$\mathbf{C V}_{\mathbf{g}}(\boldsymbol{\%})$ & 39,73 & 31,66 & 16,82 & 6,27 & 23,46 & 18,38 & 6,34 & 16,6 \\
$\mathbf{C V}_{\mathbf{e}}(\boldsymbol{\%})$ & 37,84 & 34,04 & 28,03 & 9,09 & 19,39 & 15,19 & 6,6 & 19,3 \\
$\mathbf{C V}_{\mathbf{g}} / \mathbf{C V}_{\mathbf{e}}$ & 1,05 & 0,93 & 0,6 & 0,69 & 1,21 & 1,21 & 0,96 & 0,86 \\
\hline
\end{tabular}

PC: produtividade comercializável $\left(\mathrm{t} \mathrm{ha}^{-1}\right)$; PT: produtividade total $\left(\mathrm{t} \mathrm{ha}^{-1}\right)$; NF: número de furos causados por insetos do solo; ID: incidência de danos; DR: diâmetro (mm); CR: comprimento (mm); EC: espessura do córtex (mm); FTO: formato, das raízes de batata-doce.

Tabela 1.5 Parâmetros populacionais de caracteres físico-químicos das raízes tuberosas

\begin{tabular}{cccccccccc}
\hline Parâmetros & FB & AT & PTN & RT & CZ & UM & AM & PH & SS \\
\hline $\mathbf{h}_{\mathbf{a}}{ }^{2}(\%)$ & 53,63 & 82,56 & 88,71 & 90,37 & 81,45 & 82,78 & 83,3 & 83,72 & 80,71 \\
$\mathbf{C V}_{\mathbf{g}}(\mathbf{\%})$ & 10,03 & 25,95 & 11,81 & 13,12 & 12,24 & 3,43 & 8,89 & 1,13 & 4,77 \\
$\mathbf{C V}_{\mathbf{e}}(\mathbf{\%})$ & 18,57 & 23,81 & 8,44 & 8,58 & 11,66 & 3,12 & 7,94 & 1,00 & 4,68 \\
$\mathbf{C V}_{\mathbf{g}} / \mathbf{C V}_{\mathbf{e}}$ & 0,54 & 1,09 & 1,4 & 1,53 & 1,05 & 1,1 & 1,12 & 1,13 & 1,02 \\
\hline
\end{tabular}

FB: teor de fibra bruta (\%b.s.); AT: acidez total titulável (\%b.s.); PTN: proteína bruta (\%b.s.); RT: ratio; CZ: cinzas (\%b.s.); UM: umidade (\%b.u.); AM: amido (\%b.s.); PH: pH; SS: sólidos solúveis totais, das raízes de batata-doce.

Os valores da herdabilidade no sentido amplo $\left(\mathrm{h}_{\mathrm{a}}{ }^{2}\right)$ entre as médias dos genótipos estudados evidenciaram grandes possibilidades de sucesso com a seleção em ordem decrescente para as variáveis: RT (90,37\%), PTN (88,71\%), DR (85,42\%), CR (85,34\%), PH (83,72\%), AM (83,30\%), UM (82,78\%), AT (82,56\%), PC (81,55\%), CZ (81,45\%) e SS 
$(80,71 \%)$. Estes valores de alta magnitude refletem considerável presença do componente genético na expressão destes caracteres. As outras variáveis apresentaram valores de $h_{a}{ }^{2}$ baixos, pois, segundo Cavalcante et al. (2009), é necessário o mínimo de 80,0\% para obter ganhos genéticos satisfatórios com a seleção. Adicionalmente, o quociente entre o $\mathrm{CV}_{\mathrm{g}} / \mathrm{CV}_{\mathrm{e}}$ (Tabela 1.4 e Tabela 1.5) apresentou valores superiores à unidade para as características PC (1,05), DR (1,21), CR (1,21), AT (1,09), PTN (1,4), RT (1,53), CZ (1,05), UM (1,1), AM $(1,12)$, PH $(1,13)$ e SS $(1,02)$, demonstrando que o controle genético destas variáveis foi elevado e uma situação bastante favorável em termos de seleção nessa população.

Com base nas médias dos dados morfoagronômicos e físico-químicos construiu-se a matriz de distâncias euclidianas, a partir da qual gerou-se o dendrograma, que permitiu constatar similaridade entre os clones (Figura 5). Os acessos mais semelhantes foram o CNPH 80 e o CNPH 02 (distância de ligação de 2,55), que foram os mais divergentes em relação ao clone CNPH 61 (distâncias de ligação de 7,71 e 6,79, respectivamente). Os materiais mais dissimilares foram o CNPH 35 e CNPH 55 (distância de ligação de 9,65).

Foi observado um genótipo com morfologia única (CNPH 55) e a formação de 3 grupos morfológicos discriminados da seguinte forma: dois grupos com dois materiais cada (CNPH 61 e CNPH 71 e CNPH 12 e CNPH 35, respectivamente) e outro grupo com dezoito genótipos (CNPH 46, CNPH 28, CNPH 41, CNPH 62, Coquinho, CNPH 1796, CNPH 90, CNPH 29, CNPH 87, CNPH 59, Brazlândia Rosada, CNPH 08, CNPH 69, CNPH 60, CNPH 02, CNPH 80, CNPH 56 e Princesa).

Dentro do grupo com 18 materiais, detectou-se certa coincidência entre similaridade genética e origem geográfica dos clones, pois alguns destes, provenientes da mesma localidade, apresentaram distâncias de ligação muito curtas, como é o caso, por exemplo, do clone CNPH 08 e a cultivar Brazlândia Rosada $(2,73)$ coletados na região de Brazlândia-DF. Segundo Manifesto et al. (2010) uma possível explicação para duplicatas é a natureza de propagação e a plasticidade fenotípica dos clones. Os materiais são comumente intercambiados entre os agricultores e o mesmo genótipo pode expressar-se diferencialmente em função das condições ambientais e do solo, perdendo sua identidade. Adicionalmente, diferentes agricultores, por vezes, dão nomes diferentes ao material, que fazem referência a um determinado atributo morfológico, localidade ou nome da pessoa que o introduziu.

No entanto, de acordo com Oliveira et al. (2000) a associação entre origem geográfica e similaridade genética de culturas propagadas assexuadamente, como a batata-doce, não é 
muito comum, pois os acessos são deslocados de uma localidade para outra sem haver intercâmbio de genes, pelo processo sexual, entre materiais exógenos e locais.

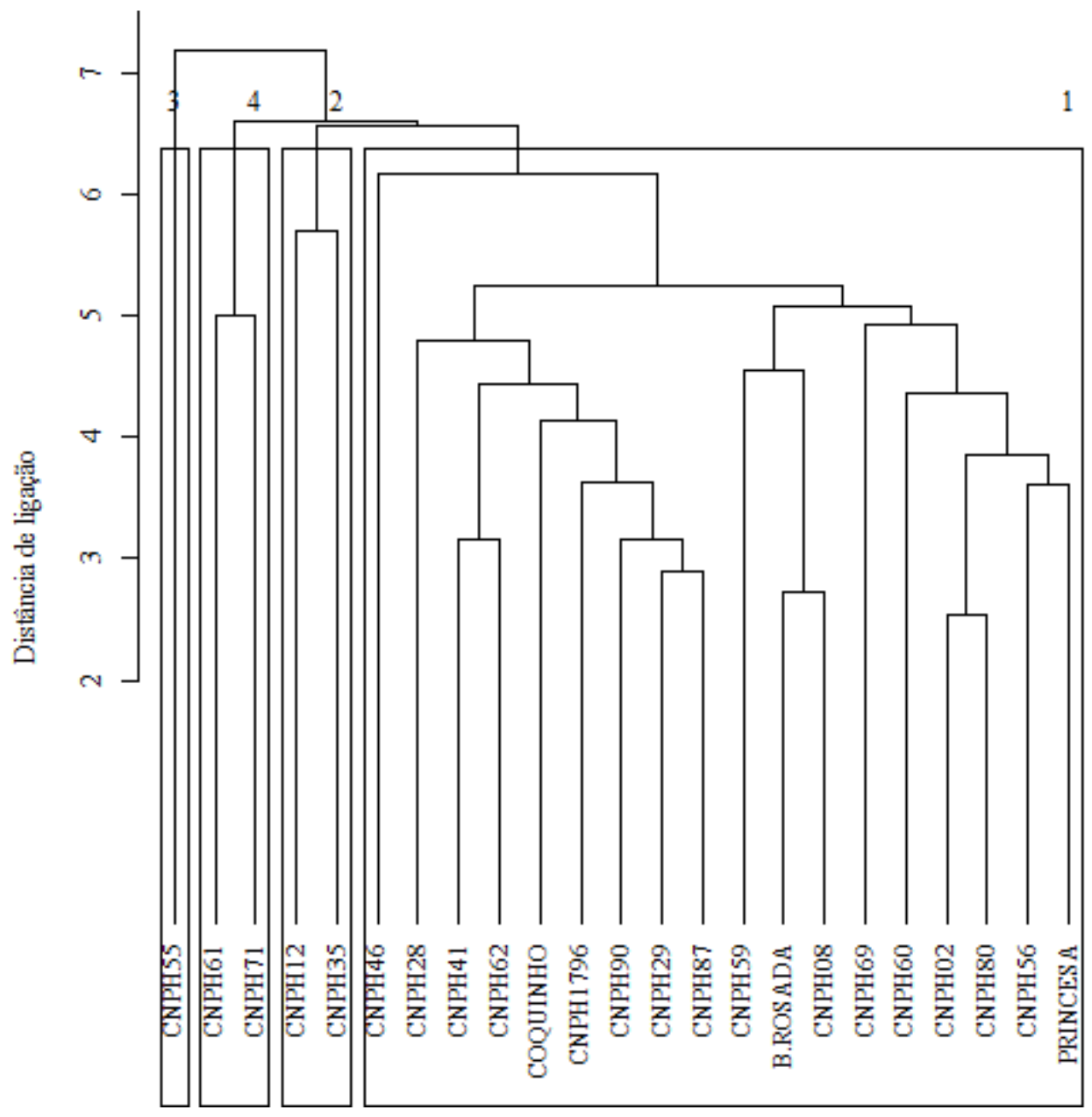

Figura 5 Dendrograma de dissimilaridade de 23 clones de batata-doce, estabelecido pelo método UPGMA utilizando-se a distância Euclidiana, com base em 17 descritores morfoagronômicos e físico-químicos das raízes.

A presença de mais de um clone no mesmo grupo (Figura 5) infere a possibilidade de ocorrência de acessos duplicados entre o conjunto de materiais (OLIVEIRA et al., 2000). Portanto, cruzamentos entre estes genótipos provavelmente não seriam efetivos na obtenção de variabilidade genética para os caracteres quantitativos avaliados (SILVA et al., 2012). Já os clones reunidos em grupos mais distantes dão um indicativo de serem dissimilares, podendo ser considerados promissores na escolha de progenitores para cruzamentos artificiais, com grande possibilidade de obter populações segregantes superiores. Porém, além da divergência, os clones selecionados devem apresentar complementação gênica, associada com média elevada e variabilidade para os caracteres avaliados (MARTINS et al., 2012). 
Ritschel e Huamán (2002) avaliando 324 acessos nativos de batata-doce pertencentes à coleção reunida pelo $\mathrm{CNPH}$, coletados em todas as regiões brasileiras, identificaram a formação de 33 grupos morfológicos, 223 acessos com morfologia única e 68 acessos com morfologia duplicada. Silva et al. (2012) na avaliação da divergência genética entre 11 acessos de batata-doce utilizando caracteres fenotípicos de raiz, observaram a formação de três agrupamentos, sendo que a maioria dos acessos apresentou níveis elevados de similaridade para as características avaliadas. Já Neiva et al. (2011) estudando 69 materiais de batata-doce quanto sua caracterização morfológica, constataram a formação de dois grupos distintos com subdivisões, verificando alta variabilidade morfológica entre os clones, com ausências de fenótipos iguais. Martins et al. (2012) analisando a variabilidade fenotípica e a divergência genética em 50 clones de batata doce no estado do Tocantins, identificaram oito grupos geneticamente disjuntos.

Na Tabela 1.6 é apresentada a matriz de correlação entre as variáveis analisadas e as dimensões da análise de componentes principais.

Tabela 1.6 Matriz de correlação entre as variáveis analisadas e as dimensões da análise de componentes principais

\begin{tabular}{lccccc}
\hline Variáveis & CP1 & CP2 & CP3 & CP4 & CP5 \\
\hline Produção de raízes comerciais & $-0,63$ & n.s. & 0,50 & 0,50 & n.s. \\
Produção total de raízes frescas & $-0,66$ & n.s. & 0,49 & 0,49 & n.s. \\
Número de furos causados por insetos do solo & $-0,50$ & 0,54 & $-0,44$ & n.s. & n.s. \\
Incidência de danos & n.s. & 0,56 & $-0,47$ & n.s. & n.s. \\
Diâmetro médio da raiz & $-0,60$ & n.s. & n.s. & n.s. & n.s. \\
Comprimento médio da raiz & $-0,81$ & n.s. & n.s. & n.s. & n.s. \\
Espessura média do córtex & $-0,65$ & n.s. & n.s. & n.s. & n.s. \\
Formato das raízes tuberosas & n.s. & n.s. & $-0,61$ & n.s. & n.s. \\
Teor de umidade & n.s. & $-0,68$ & n.s. & n.s. & n.s. \\
Teor de cinzas & n.s. & n.s. & $-0,63$ & 0,43 & n.s. \\
Teor de proteína bruta & 0,41 & n.s. & $-0,62$ & n.s. & n.s. \\
Fração de fibra bruta & n.s. & $-0,46$ & $-0,45$ & n.s. & 0,59 \\
Teor de amido & n.s. & 0,53 & n.s. & n.s. & $-0,49$ \\
pH & 0,42 & n.s. & 0,51 & n.s. & n.s. \\
Acidez total titulável & n.s. & $-0,82$ & n.s. & n.s. & n.s. \\
Teor de sólidos solúveis totais & 0,53 & 0,45 & n.s. & n.s. & n.s. \\
Ratio & n.s. & 0,76 & n.s. & n.s. & n.s. \\
\hline Autovalores & 3,75 & 3,41 & 2,94 & 1,41 & 1,38 \\
Variância explicada (\%) & 22,05 & 20,06 & 17,32 & 8,31 & 8,10 \\
Variância acumulativa & 22,05 & 42,12 & 59,44 & 67,74 & 75,85 \\
\hline
\end{tabular}

CP1, CP2, CP3, CP4 e CP5: primeiro, segundo, terceiro, quarto e quinto componente principal, respectivamente; n.s.: não significativo a $5 \%$ de probabilidade. 
A PCA revelou que os quatro primeiros componentes principais explicaram o 22,05\%, $20,06 \%, 17,32 \%$ e 8,31\% da variância, acumulando o 67,74\% da variabilidade total existente. Isto demonstra que os descritores empregados discriminaram satisfatoriamente os genótipos analisados. Observou-se que para o primeiro componente principal, os descritores de maior contribuição na discriminação dos genótipos foram o comprimento médio das raízes $(-0,81)$, a produção total e comercial das raízes (-0,66 e -0,63, respectivamente) e a espessura do córtex $(-0,65)$; no segundo componente, destacaram-se a acidez total $(-0,82)$ e o ratio $(0,76)$; no terceiro componente sobressaíram as variáveis teor de cinzas $(-0,63)$, proteína bruta $(-0,62)$ e o formato das raízes tuberosas $(-0,61)$ e no quarto componente a produção de raízes comerciais $(0,50)$ foi a característica que mais contribuiu para a variabilidade dos clones.

Na Figura 6a encontra-se a representação gráfica dos materiais no sistema de eixos, com base nos três primeiros componentes principais. De acordo com a dispersão espacial dos clones no plano multidimensional e com suas características, foi observada a formação de quatro grupos, como previamente confirmado pela análise de agrupamento dos clones.

Através do dendrograma e do gráfico dos scores e loadings dos componentes principais 1 e 2 (Figura 6a), é possível verificar que o clone CNPH 55, que apresentou morfologia única, encontra-se deslocado em relação aos demais materiais. O primeiro componente principal, que descreveu 22,05\% da variância total dos dados, foi responsável pelo agrupamento dos genótipos CNPH 71 e CNPH 61, os quais mostraram os menores comprimentos de raízes junto com o clone CNPH 55 (67,50; 88,84 e 76,61 mm, respectivamente) e dos clones CNPH 12 e CNPH 35, que apresentaram raízes tuberosas com grande espessura de córtex $(3,19$ e 3,99 mm, respectivamente). Por sua vez, os clones CNPH 12 e CNPH 71 proporcionaram as menores produtividades comerciais $\left(0\right.$ e $2,81 \mathrm{t} \mathrm{ha}^{-1}$, respectivamente) e totais $\left(0,78 \mathrm{e} 4,44 \mathrm{t} \mathrm{ha}^{-}\right.$ ${ }^{1}$, respectivamente), enquanto as maiores produtividades foram verificadas nos clones CNPH 60 e CNPH 69 (36,56 e 47,54 t ha ${ }^{-1}$, respectivamente). Ainda o segundo componente principal, que descreveu 20,06\% da variabilidade existente, o clone CNPH 55 exibiu a maior acidez total $(10,10 \%)$ e o menor teor de sólidos solúveis $\left(7,61^{\circ}\right.$ Brix $)$ e ratio $(0,76)$ sendo, portanto, um material mais tardio quando comparado aos outros genótipos. De acordo com este componente os clones CNPH 61 e CNPH 35 apresentaram os menores teores de acidez (2 e 4,14\%, respectivamente) e elevados ratios (4,97 e 2,15, respectivamente), podendo ser considerados como materiais mais precoces; os acessos CNPH 12 e CNPH 61 e a cultivar Brazlândia Rosada mostraram os maiores teores de amido (52,13; 49,07 e 47,6\%, 
respectivamente) e os genótipos Coquinho, CNPH 90 e CNPH 60 apresentaram menor número de furos e consequentemente, baixa incidência de danos causados por insetos do solo $(1,09 ; 1,13$ e 1,17 , respectivamente).

Através do gráfico dos componentes principais 1 e 3 (Figura 6b), é possível visualizar que o terceiro componente principal contribuiu para separar o genótipo CNPH 55, devido a seu maior conteúdo de proteína bruta $(10,29 \%)$. Ainda, segundo este componente os clones CNPH 61, CNPH 55 e CNPH 12, apresentaram altos teores de cinzas $(4,32 ; 4,45$ e 4,53\%, respectivamente) e os genótipos CNPH 55, CNPH 12, CNPH 61, CNPH 28 e CNPH 46 proporcionaram os piores formatos $(3,12 ; 3,12 ; 3,17 ; 3,44$ e 3,83 , respectivamente).
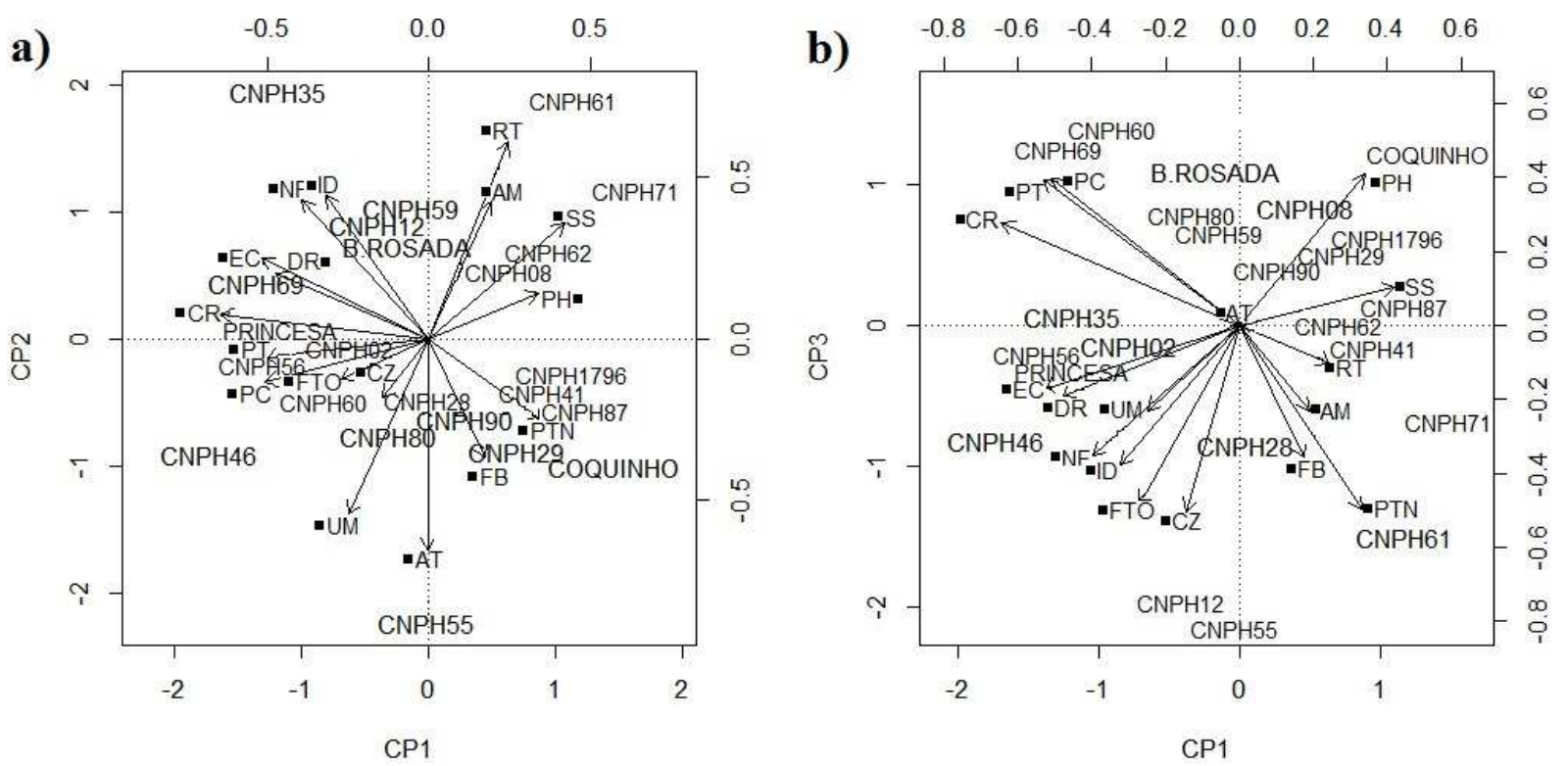

Figura 6 Gráfico biplot da PCA com as características estudadas: a) CP1 versus CP2; b) CP1 versus $\mathrm{CP} 3$, de acordo com os três primeiros componentes principais. PC: produtividade comercializável $\left(\mathrm{t} \mathrm{ha}^{-1}\right)$; PT: produtividade total $\left(\mathrm{t} \mathrm{ha}^{-1}\right)$; $\mathrm{NF}$ : número de furos causados por insetos do solo; ID: incidência de danos; DR: diâmetro (mm); CR: comprimento (mm); EC: espessura do córtex (mm); FT: formato; UM: umidade (\%b.s.); CZ: cinzas (\%b.s.); PTN: teor de proteína bruta (\%b.s.); FB: fração de fibra bruta (\%b.s.); AM: amido (\%b.s.); PH: pH; AT: acidez total titulável (\%b.s.); SS: sólidos solúveis totais; RT: ratio, das raízes de batata-doce.

Na Tabela 1.7 é apresentada a matriz de correlação de Pearson entre as variáveis morfoagronômicas e físico-químicas estudadas.

Verificou-se que houve correlação muito forte entre algumas variáveis como, por exemplo, a produtividade comercializável e a produtividade total $(0,98)$ e o número de furos e a incidência de danos causados por insetos do solo $(0,91)$, indicando que altas produtividades comercializáveis aumentam a produtividade total das raízes e que, quanto maior o número de 
furos ocasionados por insetos do solo, maiores as incidências de danos. A correlação foi forte entre a acidez titulável e o ratio $(-0,87)$, sugerindo que materiais com maiores teores de acidez titulável são mais precoces, pois estas variáveis foram inversamente proporcionais entre si.

Uma estimativa de correlação positiva e alta entre caracteres demonstra que na prática existe a necessidade da avaliação apenas da característica de mais fácil mensuração, pois a seleção estará sendo realizada de forma indireta também para a outra variável; podendo-se inferir com as altas estimativas que os genes que controlam uma característica podem ser os mesmos que controlam a outra (pleiotropia), ou esses, por sua vez, estão ligados no mesmo cromossomo (GONÇALVES NETO et al., 2012; RAMALHO et al., 2008).

A produtividade comercial e total das raízes frescas incrementou com o aumento do comprimento das raízes $(0,63$ e 0,65 , respectivamente). Também, constatou-se correlação média e positiva entre o teor de proteína e fibra bruta $(0,59)$ e o diâmetro das raízes e a espessura do córtex $(0,69)$, o que indica que raízes tuberosas com maiores teores de proteína apresentam maiores conteúdos de fibra e raízes com maior espessura de córtex, apresentam maior diâmetro.

Finalmente, não foi verificada correlação entre a espessura do córtex das raízes e a incidência de danos ocasionados por insetos de solo. 
Tabela 1.7 Matriz de correlação de Pearson entre as variáveis morfoagronômicas e físico-químicas estudadas

\begin{tabular}{|c|c|c|c|c|c|c|c|c|c|c|c|c|c|c|c|c|}
\hline & CR & EC & FTO & NF & ID & PC & PT & FB & AT & PTN & RT & $\mathrm{CZ}$ & UM & $\mathbf{A M}$ & PH & SS \\
\hline DR & $0,231^{\mathrm{ns}}$ & $0,688 * *$ & $0,355^{\mathrm{ns}}$ & $0,302^{\mathrm{ns}}$ & $0,306^{\mathrm{ns}}$ & $0,184^{\mathrm{ns}}$ & $0,205^{\mathrm{ns}}$ & $-0,075^{\mathrm{ns}}$ & $-0,245^{\mathrm{ns}}$ & $-0,202^{\mathrm{ns}}$ & $0,037^{\mathrm{ns}}$ & $0,072^{\mathrm{ns}}$ & $0,010^{\mathrm{ns}}$ & $0,034^{\mathrm{ns}}$ & $-0,295^{\mathrm{ns}}$ & $-0,269^{\mathrm{ns}}$ \\
\hline CR & & $0,367^{\mathrm{ns}}$ & $0,065^{\mathrm{ns}}$ & $0,323^{\mathrm{ns}}$ & $0,227^{\mathrm{ns}}$ & $0,625 * *$ & $0,649 * *$ & $-0,449 *$ & $-0,050^{\mathrm{ns}}$ & $-0,584 * *$ & $-0,219^{\mathrm{ns}}$ & $-0,032^{\mathrm{ns}}$ & $0,103^{\mathrm{ns}}$ & $-0,205^{\mathrm{ns}}$ & $-0,267^{\mathrm{ns}}$ & $-0,275^{\mathrm{ns}}$ \\
\hline EC & & & $0,264^{\mathrm{ns}}$ & $0,425^{*}$ & $0,394^{\mathrm{ns}}$ & $0,112^{\mathrm{ns}}$ & $0,190^{\mathrm{ns}}$ & $-0,017^{\mathrm{ns}}$ & $-0,308^{\mathrm{ns}}$ & $-0,300^{\mathrm{ns}}$ & $0,064^{\mathrm{ns}}$ & $0,001^{\mathrm{ns}}$ & $0,001^{\mathrm{ns}}$ & $-0,040^{\mathrm{ns}}$ & $-0,275^{\mathrm{ns}}$ & $-0,356^{\mathrm{ns}}$ \\
\hline FTO & & & & $0,249^{\mathrm{ns}}$ & $0,314^{\mathrm{ns}}$ & $-0,038^{\mathrm{ns}}$ & $-0,052^{\mathrm{ns}}$ & $0,272^{\mathrm{ns}}$ & $0,122^{\mathrm{ns}}$ & $0,224^{\mathrm{ns}}$ & $-0,050^{\mathrm{ns}}$ & $0,505^{*}$ & $0,286^{\mathrm{ns}}$ & $-0,175^{\mathrm{ns}}$ & $-0,268^{\mathrm{ns}}$ & $-0,210^{\mathrm{ns}}$ \\
\hline NF & & & & & $0,907 * *$ & $0,097^{\mathrm{ns}}$ & $0,161^{\mathrm{ns}}$ & $-0,133^{\mathrm{ns}}$ & $-0,338^{\mathrm{ns}}$ & $-0,016^{\mathrm{ns}}$ & $0,261^{\mathrm{ns}}$ & $0,247^{\mathrm{ns}}$ & $-0,032^{\mathrm{ns}}$ & $0,289^{\mathrm{ns}}$ & $-0,311^{\mathrm{ns}}$ & $0,037^{\mathrm{ns}}$ \\
\hline ID & & & & & & $-0,12^{\mathrm{ns}}$ & $-0,068^{\mathrm{ns}}$ & $-0,199^{\mathrm{ns}}$ & $-0,259^{\mathrm{ns}}$ & $-0,119^{\mathrm{ns}}$ & $0,173^{\mathrm{ns}}$ & $0,165^{\mathrm{ns}}$ & $-0,120^{\mathrm{ns}}$ & $0,303^{\mathrm{ns}}$ & $-0,283^{\mathrm{ns}}$ & $0,066^{\mathrm{ns}}$ \\
\hline PC & & & & & & & $0,981 * *$ & $-0,150^{\mathrm{ns}}$ & $0,073^{\mathrm{ns}}$ & $-0,256^{\mathrm{ns}}$ & $-0,243^{\mathrm{ns}}$ & $-0,015^{\mathrm{ns}}$ & $0,193^{\mathrm{ns}}$ & $-0,326^{\mathrm{ns}}$ & $0,024^{\mathrm{ns}}$ & $-0,153^{\mathrm{ns}}$ \\
\hline PT & & & & & & & & $-0,184^{\mathrm{ns}}$ & $-0,027^{\mathrm{ns}}$ & $-0,299^{\mathrm{ns}}$ & $-0,140^{\mathrm{ns}}$ & $-0,015^{\mathrm{ns}}$ & $0,141^{\mathrm{ns}}$ & $-0,303^{\mathrm{ns}}$ & $0,038^{\mathrm{ns}}$ & $-0,178^{\mathrm{ns}}$ \\
\hline FB & & & & & & & & & $0,221^{\mathrm{ns}}$ & $0,592 * *$ & $-0,039^{\mathrm{ns}}$ & $0,142^{\mathrm{ns}}$ & $0,287^{\mathrm{ns}}$ & $-0,352^{\mathrm{ns}}$ & $-0,233^{\mathrm{ns}}$ & $-0,040^{\mathrm{ns}}$ \\
\hline $\mathbf{A T}$ & & & & & & & & & & $0,144^{\mathrm{ns}}$ & $-0,873 * *$ & $0,129^{\mathrm{ns}}$ & $0,453^{*}$ & $-0,298^{\mathrm{ns}}$ & $-0,101^{\mathrm{ns}}$ & $-0,312^{\mathrm{ns}}$ \\
\hline PTN & & & & & & & & & & & $0,099^{\mathrm{ns}}$ & $0,432 *$ & $0,243^{\mathrm{ns}}$ & $0,176^{\mathrm{ns}}$ & $-0,240^{\mathrm{ns}}$ & $0,126^{\mathrm{ns}}$ \\
\hline RT & & & & & & & & & & & & $-0,079^{\mathrm{ns}}$ & $-0,493 *$ & $0,390^{\mathrm{ns}}$ & $0,234^{\mathrm{ns}}$ & $0,501 *$ \\
\hline $\mathrm{CZ}$ & & & & & & & & & & & & & $0,491 *$ & $0,233^{\mathrm{ns}}$ & $-0,250^{\mathrm{ns}}$ & $-0,225^{\mathrm{ns}}$ \\
\hline UM & & & & & & & & & & & & & & $-0,272^{\mathrm{ns}}$ & $-0,293^{\mathrm{ns}}$ & $-0,479 *$ \\
\hline $\mathbf{A M}$ & & & & & & & & & & & & & & & $0,069^{\mathrm{ns}}$ & $0,180^{\mathrm{ns}}$ \\
\hline $\mathbf{P H}$ & & & & & & & & & & & & & & & & $0,378^{\mathrm{ns}}$ \\
\hline
\end{tabular}

PH

". Significativo a 1 e $5 \%$ de probabilidade pelo teste t; ns: não significativo. DR: diâmetro (mm); CR: comprimento (mm); EC: espessura do córtex (mm); FTO: formato; NF: número de furos causados por insetos do solo; ID: incidência de danos; PC: produtividade comercializável (t ha ${ }^{-1}$ ); PT: produtividade total (t ha ${ }^{-1}$ ); FB: fração de fibra bruta (\%b.s.); AT: acidez total titulável (\%b.s.); PTN: teor de proteína bruta (\%b.s.); RT: ratio; CZ: cinzas (\%b.s.); UM: umidade (\%b.u.); AM: amido (\%b.s.); PH: pH; SS: sólidos solúveis totais, das raízes de batata-doce. 


\subsection{CONCLUSÕES}

As estimativas dos parâmetros genéticos das variáveis produtividade comercial, diâmetro, comprimento, acidez total titulável, proteína, ratio, cinzas, umidade, amido, $\mathrm{pH}$ e sólidos solúveis totais das raízes de batata-doce indicaram que os genótipos analisados apresentam condição favorável em termos de seleção nessa população, devido à considerável presença do componente genético.

Constatou-se que a maioria dos materiais genéticos avaliados é semelhante com relação aos descritores morfoagronômicos e físico-químicos das raízes utilizados.

Os cruzamentos entre genitores de grupos diferentes como o clone CNPH 69, o qual se destacou por suas altas produtividades comercial e total; o clone CNPH 59, que além de suas altas produtividades apresentou altos teores de matéria seca e de sólidos solúveis totais; o clone CNPH 80, que exibiu bom formato e moderada resistência aos insetos de solo; a cultivar Brazlândia Rosada, que apresentou altos teores de amido e de produtividade; os clones CNPH 60 e 56 que proporcionaram altos rendimentos e teores de fibra e o acesso CNPH 55, que mostrou o maior teor de proteína bruta, podem ser indicados para compor programas de intercruzamentos, visando aumentar as chances de obtenção de maior variabilidade genética, ganhos com a heterose e genótipos superiores.

A análise de componentes principais revelou que os quatro primeiros componentes explicaram $67,74 \%$ da variabilidade total dos dados, demonstrando que os descritores morfoagronômicos e físico-químicos discriminaram satisfatoriamente os genótipos. Nos dois

primeiros componentes principais os descritores de maior contribuição na discriminação dos genótipos foram o comprimento, a produção total e a espessura do córtex e a acidez total titulável e a umidade das raízes, respectivamente. 


\subsection{REFERÊNCIAS BIBLIOGRÁFICAS}

AGRAWAL, L.; NARULA, K.; BASU, S.; SHEKHAR, S.; GHOSH, S.; DATTA, A.; CHAKRABORTY, N.; CHAKRABORTY, S. Comparative proteomics reveals a role for seed storage protein AmA1 in cellular growth, development, and nutrient accumulation. Journal of Proteome Research, v. 12, n. 11, p. 4904-4930, 2013.

AHMED, M.; AKTER, M. S.; EUN, J.-B. Peeling, drying temperatures, and sulphitetreatment affect physicochemical properties and nutritional quality of sweet potato flour. Food Chemistry, v. 121, n. 1, p. 112-118, 2010.

ANDRADE JÚNIOR, V. C.; VIANA, D. J. S.; PINTO, N. A. V. D.; RIBEIRO, K. G.; PEREIRA, R. C.; NEIVA, I. P.; AZEVEDO, A. M.; ANDRADE, P. C. R. 2012. Productive and qualitative characteristics of the vines and roots of sweet potato. Horticultura Brasileira, v. 30, n. 4, p. 584-589, 2012.

AOAC- Association of Official Analytical Chemists. Official methods of analysis. 13. ed. Washington, DC, 1980. 109 p.

AZEVEDO, S. M. de. Avaliação de famílias de meios-irmaos de batata-doce [Ipomoea batatas (L.) Lam.] quanto à resistência aos nematoides do gênero Meloidogyne e aos insetos de solo. 1995. 91 f. Dissertação (Mestrado) - Universidade Federal de Lavras, Lavras 1995.

AZEVEDO, S. M. de; FREITAS, J. A.; MALUF, W. R.; SILVEIRA, M. A. Desempenho de clones e métodos de plantio de batata-doce. Acta Scientiarum. Agronomy, v. 22, n. 4, p. 901-905, 2000.

AZEVEDO, A. M.; ANDRADE JÚNIOR, V. C.; VIANA, D. J. S.; ELSAYED, A. Y. A. M.; PEDROSA, C. E.; NEIVA, I. P.; FIGUEIREDO, J. A. Influence of harvest time and cultivation sites on the productivity and quality of sweet potato. Horticultura Brasileira, v. 32, n. 1, p. 21-27, 2014.

BARRETO, H. G.; SANTOS, L. B. dos; OLIVEIRA, G. I. S. de; SANTOS, G. R. dos; FIDELIS, R. R.; SILVEIRA, M. A. da; NASCIMENTO, I. R. do. Estabilidade e adaptabilidade da produtividade e da reação a insetos de solo em genótipos experimentais e comerciais de batata-doce. Bioscience Journal, v. 27, n. 5, p. 739-747, 2011.

BENGTSSON, A.; NAMUTEBI, A.; ALMINGER, M. L.; SVANBERG, U. Effects of various traditional processing methods on the all-trans- $\beta$-carotene content of orange-fleshed sweet potato. Journal of Food Composition and Analysis, v. 21, n. 2, p. 134-143, 2008.

BORGES, A; ROSA, M. S.; RECCHIA, G. H.; QUEIROZ-SILVA, J. R.; BRESSAN, E. A.; VEASEY, E. A. CTAB methods for DNA extraction of sweetpotato for microsatellite analysis. Scientia Agricola, v. 66, n. 4, p. 529-534, 2009. 
BRAUN, H.; FONTES, P. C. R.; FINGER, F. L.; BUSATO, C.; CECON, P. R. Carbohydrates and dry matter in tubers of potato cultivars as affected by nitrogen doses. Ciência e Agrotecnologia, v. 34, n. 2, p. 285-293, 2010.

BRIDGERS, E. N.; CHINN, M. S.; TRUONG, V. D. Extraction of anthocyanins from industrial purple-fleshed sweetpotatoes and enzymatic hydrolysis of residues for fermentable sugars. Industrial Crops and Products, v. 32, n. 3, p. 613-620, 2010.

BUZAR, A. G. R.; OLIVEIRA, V. R.; BOITEUX, L. S. Estimativa da diversidade genética de germoplasma de cebola via descritores morfológicos, agronômicos e bioquímicos. Horticultura Brasileira, v. 25, n. 4, p. 513-518, 2007.

CARDOSO, A. D.; VIANA, A. E. S.; RAMOS, P. A. S.; MATSUMOTO, S. N.; AMARAL, C. L. F.; SEDIYAMA, T.; MORAIS, O. M. Avaliação de clones de batata-doce em Vitória da Conquista. Horticultura Brasileira, v. 23, n. 4, p. 911-914, 2005.

CARVALHO, F. I. F.; LORENCETTI, C.; BENIN, G. Estimativas e implicações da correlação no melhoramento vegetal. Pelotas: Universitárias da UFPel, 2004.

CASTRO, L. A. S. de; TREPTOW, R. O.; CAMPOS, A. D.; CHOER, E.; THÜRMER, L. Acessos de batata-doce do banco ativo de germoplasma da Embrapa Clima Temperado recomendados para mesa e processamento industrial. Pelotas: Embrapa Clima Temperado, 2009, 26 p. Documentos 289.

CASTRO, L. A. S. de; ROCHA, N. E. M.; ABRANTES, V. L. Avaliação biológica de biroses em plantas matrizes e mudas de batata-doce (Ipomoea batatas). Pelotas: Embrapa Clima Temperado, 2008, 12 p. Circular Técnica 75. ISSN 1981-5999.

CAVALCANTE, J. T.; FERREIRA, P. V.; SOARES, L. Correlações fenotípicas, genotípicas e de ambiente em clones de batata-doce (Ipomoea batatas (L.) Lam.). Revista Ciência Agrícola, v. 10, n. 1, p. 1-7, 2012.

CAVALCANTE, M.; FERREIRA, P. V.; PAIXÃO, S. L.; COSTA, J. G.; PEREIRA, R. G.; MADALENA, J. A. S. Potenciais produtivo e genético de clones de batata-doce. Acta Scientiarum. Agronomy, v. 31, n. 3, p. 421-426, 2009.

CECCHI, H. M. Fundamentos teóricos e práticos em análise de alimentos. Editora da UNICAMP: $2^{\circ}$ Ed. rev., Campinas, SP, 207p., 2003.

CHAKRABORTY, S.; CHAKRABORTY, N.; AGRAWAL, L.; GHOSH, S.; NARULA, K.; SHEKHAR, S.; NAIK, P. S.; PANDE, P. C.; CHAKRBORTI, S. K.; DATTA, A. Nextgeneration protein-rich potato expressing the seed protein gene AmA1 is a result of proteome rebalancing in transgenic tuber. Proceedings of the National Academy of Sciences, v. 107, n. 41, p. $17533-17538,2010$.

CHITARRA, M. I. F.; CHITARRA, A. B. Pós-colheita de frutos e hortaliças. Lavras: ESAL-FAEPE, 1990. 320p. 
COLlinS, W. W.; JONES, A.; MULLEN, M. A.; TALEKAR, N.S.; MARTIN, F. W. Breeding sweet potato for insect resistance: a global overview. In: JANSSON, R. K.; RAMAN, K.V. (Ed.). Sweet potato pest management: a global perspective. San Francisco: Westview Press, 1991. p. 379-397.

CORRALES, A. V. D. Folleto químico de alimentos. Sede regional en Estelí - Universidad Nacional de Ingeniería, 2008.

CRUZ C, D. GENES - a software package for analysis in experimental statistics and quantitative genetics. Acta Scientiarum, v. 35, n. 3, p. 271-276, 2013.

DAROS, M.; AMARAL JÚNIOR, A. T.; PEREIRA, T. N. S.; LEAL, N. R.; FREITAS, S. P.; SEDIYAMA, T. Caracterização morfológica de acessos de batata-doce. Horticultura Brasileira, v. 20, n. 1, p. 43-47, 2002.

DERGAL, S. B. Química de los alimentos. México: Pearson Educación, 1990. 648 p.

ERPEN, L.; STRECK, N. A.; UHLMANN, L. O.; LANGNER, J. A.; WINCK, J. E. M.; GABRIEL, L. F. Estimating cardinal temperatures and modeling the vegetative development of sweet potato. Revista Brasileira de Engenharia Agrícola e Ambiental, v. 17, n. 11, p. 1230-1238, 2013.

FABRI, E. G. Diversidade genética entre acessos de batata-doce (Ipomoea batatas L. Lam.) avaliada através de marcadores microssatélites e descritores morfoagronômicos. 2009. 173 f. Tese (Doutorado em Agronomia)-Escola Superior de Agricultura "Luiz de Queiroz", Universidade de São Paulo, Piracicaba, 2009.

FAO- Food and Agriculture Organization of the United Nations. FAOSTAT: estadísticas de producción de alimentos. 2012. Disponível em: 〈http://faostat3.fao.org/browse/Q/QC/S〉. Acesso em: 20 abr. 2013.

FELTRAN, J. C.; FABRI, E. G. Batata-doce uma cultura versátil, porém sub-utilizada. Nosso Alho, n. 6, p. 28-31, 2010.

FIEDLER, N. C.; AZEVEDO, I. N. C.; RESENDE, A. V.; MEDEIROS, M. B.; VENTUROLI, F. Efeito de incêndios florestais na estrutura e composição florística de uma área de cerrado sensu strictona Fazenda Água Limpa-DF. Revista Árvore, v. 28, p. 129-138, 2004.

FIGUEIREDO, J. A. Seleção de clones de batata-doce com potencial de utilização na alimentação humana e animal. 2010. 55 f. Dissertação (Mestrado em Produção Vegetal)Faculdade de Ciências Agrárias, Universidade Federal dos Vales do Jequitinhonha e Mucuri, Diamantina, 2010.

FONSECA, M. J. O.; SOARES, A. G.; FREIRE JUNIOR, M.; ALMEIDA, D. J.; ASCHERI, J. L. R. Effect of extrusion-cooking in total carotenoids content in cream and orange flesh sweet potato cultivars. Horticultura Brasileira, v. 26, n. 1, p. 112-115, 2008. 
FRANÇA, F. H.; MIRANDA, J. E. C.; FERREIRA, P. E.; MALUF, W.R. Comparação de dois métodos de avaliação de germoplasma de batata-doce visando resistência a pragas do solo. In: CONGRESSO BRASILEIRO DE OLERICULTURA, 23., 1983, Rio de Janeiro. Anais... Rio de Janeiro: SOB, 1983. p.176.

FRANÇA, F. H.; RITSCHEL, P. S. Avaliação de acessos de batata-doce para resistência à broca-da-raiz, crisomelídeos e elaterídeos. Horticultura Brasileira, v. 20, n. 1, p. 79-85, 2002.

FRANCO, C. M. L.; DAIUTO, E. R.; DEMIATE, I. M.; CARVALHO, L. J. C. B.; LEONEL, M.; CEREDA, M. P.; VILPOUX, O. F.; SARMENTO, S. B. S. Propriedades gerais do amido: série culturas de tuberosas amiláceas latinoamericanas. São Paulo: Fundação Cargill, 2001. 224p.

FREITAS, J. A. de; SANTOS, G. C. dos; SOUZA, V. S.; AZEVEDO, S. M. de. Resistência de clones de batata-doce, Ipomoea batatas L., aos nematóides causadores de galhas. Acta Scientiarum. Agronomy, v. 23, n. 5, p. 1257-1261, 2001.

GONÇALVES NETO, Á. C.; MALUF, W. R.; GOMES, L. A. A.; GONÇALVES, R. J. S.; SILVA, V. F.; LASMAR, A. Aptidões de genótipos de batata-doce para consumo humano, produção de etanol e alimentação animal. Pesquisa Agropecuária Brasileira, v. 46, n. 11, p. 1513-1520, 2011.

GONÇALVES NETO, Á. C.; MALUF, W. R.; GOMES, L. A. A.; MACIEL, G. M.; FERREIRA, R. P. D.; CARVALHO, R.C. Correlação entre caracteres e estimação de parâmetros populacionais para batata-doce. Horticultura Brasileira, v. 30, n. 4, p. 713-719, 2012.

HORTON, D. E.; EWELL, P. T. Sweet potato pest management: a social science perspective. In: JANSSON, R. K.; RAMAN, K. V. (Ed.). Sweet Potato Pest Management: a global perspective. San Francisco: Westview Press, 1991. p. 407-427.

IBGE- Instituto Brasileiro de Geografia e Estatística. Produção agrícola municipal: culturas temporárias e permanentes. 2013. Disponível em: <http://loja.ibge.gov.br/produco-da-pecuaria-municipal-2013.html>. Acesso em: 01 jan. 2014.

INSTITUTO ADOLFO LUTZ. Normas Analíticas do Instituto Adolfo Lutz: métodos químicos e físicos para análise de alimentos. 3. ed. São Paulo: IMESP, 1985. 533 p.

JACKSON, D.M.; BOHAC, J.R. Improved dry-fleshed sweetpotato genotypes resistant to insect pests. Journal of Economic Entomology, v. 99, n. 5, p. 1877-1883, 2006.

KROTH, L, L.; DANIELS, J.; PIEROBOM, C. R. Degenerescência da batata-doce no Rio Grande do Sul. Revista Brasileira de Agrociência, v. 10, n. 1, p. 79-82, 2004.

LEBOT, V.; NDIAYE, A.; MALAPA, R. Phenotypic characterization of sweet potato [Ipomoea batatas (L.) Lam.] genotypes in relation to prediction of chemical quality constituents by NIRS equations. Plant Breeding, v. 130, n. 4, p. 457-463, 2011. 
LEONEL, M.; CEREDA, M. P. Caracterização físico-química de algumas tuberosas amiláceas. Ciência e Tecnologia de Alimentos, v. 22, n. 1, p. 65-69, 2002.

MANICA, I.; KIST, H.; MICHELETTO, E. L.; KRAUSE, C. A. Competição entre quatro cultivares e duas seleções de goiabeira. Pesquisa Agropecuária Brasileira, v. 33, n. 8, p. 1305-1313, 1998.

MANIFESTO, M. M.; COSTA TÁRTARA, S. M.; ARIZIO, C. M.; ALVAREZ, M. A.; HOMPANERA, N.R. Analysis of the morphological attributes of a sweetpotato collection. Annals of Applied Biology, v. 157, n. 2, p. 273-281, 2010.

MARTINS, E. C. A.; PELUZIO, J. M.; COIMBRA, R. R.; JUNIOR, W. P. O. Variabilidade fenotípica e divergência genética em clones de batata doce no estado do Tocantins. Revista Ciência Agronômica, v. 43, n. 4, p. 691-697, 2012.

MASSAROTO, J. A.; MALUF, W. R.; GOMES, L. A. A.; FRANCO, H. D.; GASPARINO, C. F. Behavior of roots of sweet potato clones. Ambiência, v. 10, n. 1, p. 73-81, 2014.

MATTOS, L. L. de; MARTINS, I. S. Consumo de fibras alimentares em população adulta. Revista de Saúde Pública, v. 34, n. 1, p. 50-55, 2000.

MENEZES, D. M. de; REGO, M. M. do.; NOBRE, A.; MENEGUELLI, C. A. Influência da época de colheita sobre os teores de açúcar e proteína em batata-doce. Pesquisa Agropecuária Brasileira, v. 11, n. 12, p. 49-52, 1976.

MENEZES, C. B. de; PINTO, C. A. B. P.; NURMBERG, P. L.; LAMBERT, E. de S. Avaliação de genótipos de batata (Solanum tuberosum L.) nas safras "das águas" e de inverno no Sul de Minas Gerais. Ciência e Agrotecnologia, v. 23, n. 4, p. 776-783, 1999.

MENEZES, E. de L. A. A broca da batata-boce (Euscepes postfasciatus): descrição, bionomia e controle. Rio de Janeiro: Embrapa Agrobiologia, 2002, 12 p. Circular Técnica 6.

MIRANDA, J. E. C.; FRANÇA, F. H.; CARRIJO, O. A.; SOUZA, A. F.; PEREIRA, W.; LOPES, C. A.; SILVA, J. B. C. A cultura da batata-doce. Brasília: Embrapa Hortaliças, 1995, 89 p. Serviço de Produção de Informação - SPI.

MIRANDA, J. E. C.; CRUZ, C. D.; PEREIRA, A. S. Análise de trilha e divergência genética de cultivares e clones de batata-doce. Revista Brasileira de Genética, v. 11, n. 4, p. 881-892, 1988.

MOHAMMADI, S. A.; PRASANNA, B. M. Analysis of genetic diversity in crop plantssalient statistical tools and considerations. Crop Science, v. 43, n. 4, p. 1235-1248, 2003.

MOULIN, M. M.; RODRIGUES, R.; GONÇALVES, L. S. A.; SUDRÉ, C. P.; PEREIRA, M. G. A comparison of RAPD and ISSR markers reveals genetic diversity among sweet potato landraces (Ipomoea batatas (L.) Lam.). Acta Scientiarum. Agronomy, v. 34, n. 2, p. 139$147,2012$. 
MOURA, W. de M.; CASALI, V. W. D.; CRUZ, C. D.; LIMA P. C. de. Divergência genética em linhagens de pimentão em relação à eficiência nutricional de fósforo. Pesquisa Agropecuária Brasileira, v. 34, n. 2, p. 217-224, 1999.

NEIVA, I. P.; ANDRADE JÚNIOR, V. C.; VIANA, D. J. S.; FIGUEIREDO, J. A.; MENDONÇA FILHO, C. V.; PARRELlA, R. A. C.; SANTOS, J. B. Caracterização morfológica de acessos de batata-doce do banco de germoplasma da UFVJM, Diamantina. Horticultura Brasileira, v. 29, p. 537-541, 2011.

OLIVEIRA, A. C. B. de; SEDIYAMA, M. A. N.; SEDIYAMA, T.; CRUZ, C. D. Avaliação da divergência genética em batata-doce por procedimentos multivariados. Acta Scientiarum. Agronomy, v. 22, p. 895-900, 2000.

PAIXÃO, S. L.; CAVALCANTE, M.; FERREIRA, P. V.; MADALENA, J. A. S.; PEREIRA, R. G. Divergência genética e avaliação de populações de milho em diferentes ambientes no estado de Alagoas. Revista Caatinga, v. 21, n. 4, p. 191-195, 2008.

PARK, K. J.; ANTONIO, G. C. Analises de materiais biológicos. Faculdade de Engenharia Agrícola - Universidade Estadual de Campinas, 2006.

PEIXOTO, J. R.; SANTOS, L. C.; RODRIGUES, F. A.; JULIATTI, F.C.; LYRA, J. R. M. Seleção de clones de batata-doce resistentes a insetos de solo. Pesquisa Agropecuária Brasileira, v. 34, n. 3, p. 385-389, 1999.

PERONI, N.; MARTINS, P. S.; ANDO, A. Inter- and intraspecific diversity and use of multivariate analysis for the morphology of cassava (Manihot esculenta Crantz): a case study. Scientia Agricola, v. 56, n. 3, p. 587-595, jul. 1999.

QUEIROGA, R. C. F.; SANTOS, M. A.; MENEZES, M. A.; VIEIRA, C. P. G.; SILVA, M. C. Fisiologia e produção de cultivares de batata-doce em função da época de colheita. Horticultura Brasileira, v. 25, n. 3, p. 371-374, 2007.

R Core Team. R: A language and environment for statistical computing. R Foundation for Statistical Computing, Vienna, Austria. 2013. Disponível em: 〈http://www.R-project.org/>. Acesso em: 26 dez. 2013.

RAMALHO, M. A. P.; SANTOS, J. B. dos; PINTO, C. A. B. P. Genética na agropecuária. 4. ed. Lavras: Editora UFLA, 2008. 463p.

RAVINDRAN, V.; RAVINDRAN, G.; SIVAKANESAN, R.; RAJAGURU, S. B. Biochemical and nutritional assessment of tubers from 16 cultivars of sweet potato (Ipomoea batatas L.). Journal of agricultural and food chemistry, v. 43, n. 10, p. 2646-2651, 1995.

RAY, R. C.; PANDA, S. K.; SWAIN, M. R.; SIVAKUMAR, P. S. Proximate composition and sensory evaluation of anthocyanin-rich purple sweet potato (Ipomoea batatas L.) wine. International Journal of Food Science \& Technology, v. 47, p. 452-458, 2012. 
RESENDE, G. M. de. Características produtivas de cultivares de batata-doce em duas épocas de colheita, em Porteirinha-MG. Horticultura Brasileira, v. 18, n. 1, p. 68-71, 2000.

RITSCHEL, P. S.; HUAMÁN, Z. Variabilidade morfológica da coleção de germoplasma de batata-doce da Embrapa - Centro Nacional de Pesquisa de Hortaliças. Pesquisa Agropecuária Brasileira, v. 37, n. 4, p. 485-492, 2002.

ROCHA, T. S.; DEMIATE, I. M.; FRANCO, C. M. L. Características estruturais e físicoquímicas de amidos de mandioquinha-salsa (Arracacia xanthorrhiza). Ciência e Tecnologia de Alimentos, v. 28, n. 3, p. 620-628, 2008.

ROESLER, P. V. S. O.; GOMES, S. D.; MORO, E.; KUMMER, A. C. B.; CEREDA, M. P. Produção e qualidade de raiz tuberosa de cultivares de batata-doce no Oeste do Paraná. Acta Scientiarum. Agronomy, v. 30, n. 1, p. 117-122, 2008.

ROSSMANN, H. Estimativas de parâmetros genéticos e fenotípicos de uma população de soja avaliada em quatro anos. 2001. 91 f. Dissertação (Mestrado em Agronomia)- Escola Superior de Agricultura “Luiz de Queiroz”, Universidade de São Paulo, Piracicaba, 2001.

RUKUNDO, P.; SHIMELIS, H.; LAING, M.; GAHAKWA, D. Storage root formation, dry matter synthesis, accumulation and genetics in sweetpotato. Australian Journal of Crop Science, v. 7, n. 13, p. 2054-2061, 2013.

SENANAYAKE, S. A.; RANAWEERA, K. K. D. S.; GUNARATNE, A.; BAMUNUARACHCHI, A. Comparative analysis of nutritional quality of five different cultivars of sweet potatoes (Ipomea batatas (L) Lam) in Sri Lanka. Food Science \& Nutrition, v. 1, n. 4, p. 284-291, 2013.

SHAO, Y.-Y.; HUANG, Y.-C. Effects of steaming and kneading with presteaming treatments on the physicochemical properties of various genotypes of sweet potato ( Ipomoea batatas L.). Journal of Food Process Engineering, v. 31, n. 6, p. 739-753, 2008.

SHEKHAR, S.; MISHRA, D.; BURAGOHAIN, A. K.; CHAKRABORTY, S.; CHAKRABORTY, N. Comparative analysis of phytochemicals and nutrient availability in two contrasting cultivars of sweet potato (Ipomoea batatas L.). Food Chemistry, v. 173, p. 957-965, 2015.

SILVA, G. O.; PONIJALEKI, R.; SUINAGA, F. A. Genetic divergence among sweet potato accessions based on root traits. Horticultura Brasileira, v. 30, n. 4, p. 595-599, 2012.

SILVA, J. B. C.; LOPES, C. A.; MAGALHÃES, J. S. Cultura da batata-doce (Ipomoea batatas L.). Brasília: Embrapa Hortaliças, 2004. Sistemas de Produção 6. Disponível em: <http://www.cnph.embrapa.br/sistprod/batatadoce/index.htm>. Acesso em: 10 de fev. 2013.

SILVEIRA, L. R.; CHIESA, V. B.; TAVARES, I. B.; SOUZA, R. C.; SILVEIRA, M. A.; ALVES, D. G.; JUNIOR, W. P. O. Caracterização físico-química e clones de batata-doce de polpa alaranjada nas condições de Palmas - To. Estudos, v. 38, n. 2, p. 365-380, 2011. 
SILVEIRA, M. A. Batata-doce: uma nova alternativa para a produção de etanol. In: Instituto Euvaldo Lodi. Álcool combustível: Série Indústria em Perspectiva. Brasília: IEL, 2008. p. 109-122.

TOMLINS, K.; OWORI, C.; BECHOFF, A.; MENYA, G.; WESTBY, A. Relationship among the carotenoid content, dry matter content and sensory attributes of sweet potato. Food Chemistry, v. 131, n. 1, p. 14-21, 2012.

VIANA, D. J. S. Produção e qualidade de raízes, ramas e silagem de ramas de clones de batata-doce em diferentes locais e épocas de colheita. 2009. 69 f. Dissertação (Mestrado em Produção Vegetal)- Faculdade de Ciências Agrárias, Universidade Federal dos Vales do Jequitinhonha e Mucuri, Diamantina, 2009.

YOSHINAGA, M.; YAMAKAWA, O.; NAKATANI, M. Genotypic diversity of anthocyanin content and composition in purple-fleshed sweet potato (Ipomoea batatas (L.) Lam). Breeding science, v. 49, n. 1, p. 43-47, 1999.

ZAVAREZE, E. R.; STORCK, C. R.; PEREIRA, J. M.; GULARTE, M. A.; DIAS, A. R. G. Elaboração de pão de queijo com substituição do amido de mandioca por amido de batatadoce (Ipomoea batatas) submetido a diferentes processos de secagem. Brazilian Journal of Food Technology, v. 12, n. 1, p. 68-76, 2009.

ZHANG, D.; GHISLAIN, M.; HUAMÁN, Z.; GOLMIRZAIE, A.; HIJMANS, R. RAPD variation in sweetpotato (Ipomoea batatas (L.) Lam) cultivars from South America and Papua New Guinea. Genetic Resources and crop evolution, v. 45, n. 3, p. 271-277, 1998. 


\section{CAPÍTULO 2}

Caracterização morfoagronômica, físico-química e quantificação dos teores de carotenoides e de antocianinas totais em genótipos de batata-doce 


\subsection{RESUMO}

A batata-doce (Ipomea batatas) é uma cultura extremamente importante em muitas partes do mundo, sendo cultivada em mais de 100 países. Esta tuberosa produz antioxidantes de baixo peso molecular, como os carotenoides e as antocianinas, que são pigmentos orgânicos encontrados em várias partes das plantas e têm recebido atenção recentemente devido às suas variedades de arranjos estruturais que induzem diferentes funções fisiológicas. Foi desenvolvido um experimento em condições de campo, no delineamento em blocos casualizados, com quatro repetições, com o objetivo de caracterizar morfoagronomicamente 26 genótipos de batata-doce. Posteriormente visou-se avaliar as características físico-químicas de 13 materiais; estimar medidas colorimétricas como um rápido método de triagem do conteúdo de carotenoides totais nas raízes; quantificar o teor de antocianinas totais dos genótipos de polpa roxa e estimar a correlação entre as variáveis físico-químicas estudadas. As cultivares Brazlândia Roxa, Beauregard, BRS Rubissol, Princesa e Brazlândia Branca e os clones CNPH 60, CNPH 46, CNPH 1796 e CNPH 08, atingiram mais de 80\% de raízes comerciais. Os clones CNPH 62, CNPH 53 e CNPH 1190 apresentaram baixa produtividade, não sendo indicados para cultivo independente de sua finalidade. Os clones CNPH 1796, CNPH 80, CNPH 08 e CNPH 05 mostraram aptidão para mesa. Os acessos CNPH 69 e CNPH 66 podem ser boas alternativas para a alimentação animal ou o processamento industrial. Os clones CNPH 05, CNPH 1232 e a cultivar Beauregard proporcionaram os maiores teores de fibra bruta. Os genótipos CNPH 05, BRS Rubissol, Beauregard e CNPH 1796, destacaram-se com relação aos conteúdos mais elevados de proteína bruta. A cultivar Brazlândia Roxa mostrou o maior rendimento de amido. $\mathrm{O}$ valor de croma calculado para a polpa das raízes tuberosas foi o mais adequado para a estimativa do teor de carotenoides totais, cujas maiores concentrações foram verificadas nos genótipos Beauregard, BRS Amélia e CNPH 1232. Não foram observadas diferenças significativas entre os clones CNPH 1796, CNPH 80 e CNPH 05 com relação ao conteúdo de antocianinas totais.

Palavras-chave: carotenoides, antocianinas, características morfoagronômicas e físicoquímicas, parâmetros colorimétricos, correlação. 


\subsection{ABSTRACT}

Sweet potato (Ipomoea batatas) is an extremely important crop in many parts of the world, being cultivated in more than 100 countries. This tuberous root produce low molecular weight antioxidants, such as carotenoids and anthocyanins which are organic pigments found in various parts of plants and has recently received attention due to their variety of structural arrangements which induce different physiological functions. An experiment was conducted in field conditions on a randomized blocks experimental design with four replications, in order to characterize morpho-agronomically 26 sweet potato genotypes. Posteriorly, it was aimed to evaluate the physicochemical characteristics of 13 materials; estimate colorimetric measures as a quick screening method of the total carotenoids content in the roots; quantify the total anthocyanins content of the purple flesh genotypes and estimate the correlation between the physicochemical variables studied. The Brazlândia Roxa, Beauregard, BRS Rubissol, Princesa and Brazlândia Branca cultivars and the CNPH 60, CNPH 46, CNPH 1796 and CNPH 08 clones, reached more than $80 \%$ of marketable roots. The CNPH 62, CNPH 53 and CNPH 1190 clones showed low total yield and are not suitable for cultivation independent of its purpose. The CNPH 1796, CNPH 80, CNPH 08 and CNPH 05 clones showed suitability for human consumption. The CNPH 69 and CNPH 66 accessions can be good alternatives for animal feed or industrial processing. The CNPH 05, CNPH 1232 clones and the Beauregard cultivar provided the highest crude fiber contents. The CNPH 05, BRS Rubissol, Beauregard and CNPH 1796 genotypes, stood out in relation to the highest crude protein contents. The Brazlândia Roxa cultivar showed the highest yield of starch. The chroma value calculated for the flesh of tuberous roots was the most appropriate to estimate the total carotenoids content, whose highest concentrations were verified in the Beauregard, BRS Amélia and CNPH 1232 genotypes. No significant differences were observed between the CNPH 1796, CNPH 80 and CNPH 05 clones regarding the total anthocyanins content.

Keywords: carotenoids, anthocyanins, morphoagronomic and physicochemical characteristics, colorimetric parameters, correlation. 


\subsection{INTRODUÇÃO}

Em anos recentes, a população mundial adquiriu a visão de que alimentos não são apenas para nutrir, mas oferecem também compostos ou elementos biologicamente ativos, que proporcionam benefícios adicionais à saúde (SENTANIN e RODRIGUEZ-AMAYA, 2007).

Os carotenoides formam parte destes compostos bioativos e como o principal grupo de pigmentos que ocorrem na natureza são responsáveis pela cor vermelha, alaranjada e amarela de frutas e hortaliças. Estes compostos têm sido objeto de muitas pesquisas devido às suas atividades biológicas, pois desempenham papel importante na oxidação lipídica, apresentam propriedades anticancerígenas e alguns agem como pró-vitamina A; e à sua importância tecnológica, já que oferecem propriedades comercialmente desejáveis, tais como a sua origem natural, toxicidade nula e alta versatilidade, proporcionando corantes lipossolúveis e hidrossolúveis (ALMEIDA e PENTEADO, 1988; ÇINAR, 2004).

Os carotenoides também protegem a maquinaria fotossintética contra danos fotooxidativos causados pelo excesso de luz e são nutrientes essenciais e compostos importantes para a saúde, uma vez que os animais e os humanos são incapazes de sintetizar vitamina A, um micronutriente essencial para a função imune normal do corpo (KIM et al., 2012).

Vitamina A é a expressão genérica usada para descrever o retinol e todos os carotenoides dietéticos que têm atividade biológica de transretinol. A vitamina A natural usualmente apresenta-se na forma de ésteres de retinil de cadeia longa. As formas metabolicamente ativas incluem os correspondentes aldeído (retinal) e ácido (ácido retinóico) (GOMES et al., 2005).

A deficiência de vitamina A é considerada um problema grave de saúde pública em mais de 70 países, pode levar à cegueira e é uma das principais causas de morte infantil e um importante fator de risco para as mulheres grávidas e lactantes (CHAMPAGNE et al., 2010; TOMLINS et al., 2012; VIMALA et al., 2011). Embora o Brasil seja um país com uma alta produção de hortaliças que são fontes de carotenoides, apresenta, em algumas regiões, problemas de hipovitaminose A (ALMEIDA e PENTEADO, 1988). A deficiência de vitamina A é causada por uma dieta habitual que oferece baixas quantidades de vitamina $\mathrm{A}$ biodisponível para cobrir as necessidades fisiológicas (VAN JAARSVELD et al., 2005).

As fontes alimentares de vitamina A são a vitamina A pré-formada (comumente encontrada em alimentos de origem animal) e os carotenoides pró-vitamínicos A (encontrados 
em frutas e vegetais de polpa amarela e alaranjada e em vegetais de folhas verde-escuras) (VAN JAARSVELD et al., 2005).

Os principais carotenoides ingeridos em dietas normais são o $\alpha$-caroteno, o $\beta$-caroteno, a luteína, a zeaxantina, a neoxantina, a violaxantina e o licopeno. Dentre estes o $\beta$-caroteno é o principal carotenoide pró-vitamínico A, que desempenha um papel crucial na promoção da saúde visual humana (KAO et al., 2014). Adicionalmente, uma grande variedade de carotenoides ativos não pró-vitamínicos $\mathrm{A}$ também trazem benefícios à saúde humana. A luteína e a zeaxantina são os componentes primários de pigmentos humanos encontrados na lente e na área macular da retina humana, que atuam como poderosos antioxidantes e sequestradores da luz visível e estão associados com a redução do risco de problemas visuais relacionados à idade, como a degeneração macular e cataratas (LANDRUM e BONE, 2001; MARES et al., 2006).

Os carotenoides também desempenham papel importante na proteção das células e organismos, pois são importantes sequestradores de radicais livres e oxigênio singlete, sendo reconhecidos pela sua alta capacidade antioxidante (BAYDAS et al., 2002; MASCIO et al., 1991; PAIVA e RUSSELL, 1999). Os carotenoides como o licopeno e o $\beta$-caroteno são importantes compostos biológicos que podem inativar as moléculas excitadas eletronicamente. O oxigênio molecular singlete é um exemplo de um composto excitado que é gerado por reações fotoquímicas ou enzimaticamente, ou por processos de peroxidação lipídica das biomembranas (MASCIO et al., 1991).

Os radicais livres são gerados no corpo humano através da respiração aeróbica e existem em diferentes formas, incluindo os radicais superóxido, hidroxilo, hidroperoxilo, peroxilo e alcoxilo. No entanto, os antioxidantes alimentares são úteis para ajudar ao corpo a neutralizar estes radicais livres (TEOW et al., 2007). O $\beta$-caroteno é também reconhecido como varredor de radicais peroxil, especialmente em condições de baixa tensão de oxigênio (PAIVA e RUSSELL, 1999). Por exemplo, o $\beta$-caroteno diminui a taxa de formação de hidroperóxidos de linoleato de metilo (AMES, 1983).

Os antioxidantes são compostos essenciais necessários para controlar reações de oxidação degenerativas causadas por espécies reativas de oxigênio e de nitrogênio em tecidos vivos, bem como a inibição da peroxidação lipídica em alimentos. Estas espécies de radicais livres estão associadas com o envelhecimento e com doenças relacionadas ao envelhecimento, como o câncer e a aterosclerose. A peroxidação lipídica envolve reações de deterioração nos 
alimentos que ocorrem durante o processamento e o armazenamento (CEVALLOS-CASALS e CISNEROS-ZEVALLOS, 2003).

Os antioxidantes não agem apenas como sequestrantes de espécies reativas de oxigênio e nitrogenadas, denominadas oxidantes, evitando danos oxidativos a lipídios, proteínas e ADN, eles também são moléculas de sinalização celular. Tanto o sequestro de radicais livres, como a atividade de sinalização celular dos antioxidantes, podem contribuir para seus potenciais efeitos benéficos na prevenção da aterogénese, carcinogénese e neurodegeneração (RIMBACH e DE PASCUAL-TERESA, 2005).

O teor de compostos fenólicos totais encontrados em vários vegetais, incluindo frutos, folhas, sementes e plantas medicinas, também está correlacionado positiva e significativamente com a atividade antioxidante das plantas (VELIOGLU et al., 1998).

Dentre os compostos fenólicos com propriedade antioxidante, destacam-se os flavonoides, que quimicamente englobam as antocianinas e os flavonóis (LIMA et al., 2002). Os pigmentos antociânicos são responsáveis pelas cores vermelha, roxa e azul de muitas frutas, vegetais, grãos de cereais e flores (BRIDGERS et al., 2010). Estes compostos possuem propriedades antioxidantes, uma vez que minimizam a peroxidação lipídica e o efeito dos radicais livres, ajudando assim a reduzir o risco de doenças cardiovasculares (HERTOG et al., 1993). Além das suas propriedades antioxidantes, as antocianinas apresentam funções fisiológicas, tais como potencial antimutagênico, atividade hepatoprotetora e ação antihipertensiva e anti-hiperglicêmica (ESPÍN et al., 2000; HOU et al., 2010; WANG et al., 1997).

As antocianinas são caracterizadas como tendo uma deficiência de elétrons devido à sua estrutura química particular, que as torna muito reativas com os radicais livres presentes no organismo, permitindo-lhes agir como poderosos antioxidantes naturais (GALVANO et al., 2004; GALVANO, 2005). De fato, variando as posições e os tipos de grupos químicos sobre os anéis aromáticos das antocianinas, a capacidade de aceitar elétrons desemparelhados de moléculas de radicais é variada (SATUÉ-GRACIA et al., 1997; WANG et al., 1997).

De acordo com Bengtsson et al. (2008) a batata-doce (Ipomoea batatas) é uma das principais culturas alimentares em países em desenvolvimento, sendo consumida principalmente cozida.

Enquanto a batata-doce de polpa roxa acumula grandes quantidades de antocianinas nas raízes tuberosas (BRIDGERS et al., 2010), o $\beta$-caroteno constitui o principal carotenoide 
provitamina A encontrado nas raízes de batata-doce de polpa amarela e alaranjada (BENGTSSON et al., 2008, KIDMOSE et al., 2007). Outros constitutivos da cultura incluem amido, açúcares, fibras, proteínas, minerais, vitaminas (especialmente vitaminas $\mathrm{C}_{2} \mathrm{~B}_{6} \mathrm{e}$ folato), bem como antioxidantes, tais como ácidos fenólicos e tocoferol (WU et al., 2008).

A qualidade nutricional e a produtividade agrícola são as duas questões-chave para a produção sustentável de alimentos no mundo (AGRAWAL et al., 2013). Para aumentar o potencial nutritivo de cultivares é necessária a caracterização físico-química de seus órgãos de armazenamento (CHAMPAGNE et al., 2010).

Estratégias de controle da deficiência de vitamina incluem a diversificação da dieta, a fortificação de alimentos e a suplementação de vitamina A. A diversificação da dieta inclui a produção de culturas ricas em $\beta$-caroteno, tais como a batata doce de polpa alaranjada (VAN JAARSVELD et al., 2005), pois alimentos como produtos lácteos e carnes, que contém vitamina A pré-formada, são muito caros para a maioria das pessoas em países em desenvolvimento (K'OSAMBO et al. 1999).

O melhoramento genético é a seleção de fenótipos com base no seu valor "per se". O objetivo é a alteração de características das cultivares, de modo que os novos materiais obtidos possibilitem aumento na produtividade e qualidade do produto final. A identificação de parentais com características complementares, a sua recombinação e a triagem posterior das progênies são necessárias para identificar os híbridos com características desejáveis (CRISÓSTOMO et al., 1999; CHAMPAGNE et al., 2010).

O valor nutricional das espécies cultivadas tem sido um dos principais objetivos em longo prazo dos programas de melhoramento de plantas. Os seres humanos necessitam de uma dieta diversificada e nutricionalmente equilibrada para a manutenção da saúde ideal. Portanto a pesquisa científica global está focada em melhorar a qualidade nutricional dos alimentos, havendo necessidade de explorar o potencial existente disponível no germoplasma de batata-doce (SHEKHAR et al., 2015).

Por conseguinte, os objetivos do presente estudo foram caracterizar morfoagronômicamente 26 genótipos de batata-doce pertencentes ao banco de germoplasma mantido na Embrapa Hortaliças; avaliar físico-químicamente 13 materiais genéticos; estimar medidas de cor das cultivares como um rápido método de triagem do conteúdo de carotenoides totais nas raízes e quantificar o teor de antocianinas totais dos materiais de polpa roxa. 


\subsection{MATERIAL E MÉTODOS}

\subsubsection{Localização da área experimental}

O experimento foi conduzido no período compreendido entre os dias 13 de fevereiro de 2014 e 4 de agosto de 2014, na Embrapa Hortaliças, Brasília - DF, em Latossolo VermelhoAmarelo com textura média, no sistema convencional e com adubações conforme recomendado por Fontes (1999). O preparo do solo realizou-se por meio de uma aração profunda e duas gradagens, após as quais foi feito o enleiramento com aproximadamente 0,4 m de altura.

\subsubsection{Delineamento experimental}

Foram estudados 26 genótipos de batata-doce do Banco de Germoplasma mantido na Embrapa Hortaliças. O delineamento experimental utilizado foi em blocos casualizados, com 26 tratamentos e 4 repetições. As unidades experimentais foram constituídas de camalhões de $4 \mathrm{~m}$ de comprimento $\times 1,0 \mathrm{~m}$ de largura cada, com 10 plantas por parcela, utilizando-se o espaçamento de 0,4 m entre plantas e de 1,0 m entre camalhões. Empregaram-se bordaduras nas laterais do experimento, onde foram plantadas ramas da cultivar Beauregard. Os tratamentos constituíram-se dos clones CNPH 02, CNPH 05, CNPH 08, CNPH 41, CNPH 46, CNPH 53, CNPH 55, CNPH 56, CNPH 60, CNPH 62, CNPH 66, CNPH 69, CNPH 80, CNPH 90, CNPH 1190 e CNPH 1796, da variedade Rainha e das cultivares Beauregard, Brazlândia Branca, Brazlândia Rosada, Brazlândia Roxa, Coquinho, BRS Amélia, BRS Cuia, BRS Rubissol e Princesa.

Foram utilizadas ramas sadias, com 3 a 4 entrenós, dos quais 2 foram enterrados no topo da leira. Quinze dias após o plantio foi realizado o replantio nos locais onde ocorreram falhas. Durante o desenvolvimento, na ausência de chuvas, utilizou-se irrigação por aspersão convencional, por meio da aplicação de uma lâmina de água de aproximadamente $25 \mathrm{~mm}$, com turno de rega de sete dias. Com base nos resultados da análise de solo, realizou-se uma adubação mineral de plantio com a formulação NPK 4-30-16, na dose de $600 \mathrm{~kg} \mathrm{ha}^{-1}$. Foi efetuada adubação de cobertura 20 dias após o plantio, com sulfato de amônio, na dose de 20 g planta ${ }^{-1}$. O controle de plantas daninhas foi realizado por meio de capinas manuais com enxada e da aplicação dos herbicidas Metribuzim, em pré-plantio, na dose de 1,2 $\mathrm{L} \mathrm{ha}^{-1}$ do produto comercial e Paraquat, nas entrelinhas, trinta dias após o plantio, na dose de $1 \mathrm{~L} \mathrm{ha}^{-1}$ do 
produto comercial. Não foi realizado nenhum tratamento fitossanitário quanto a pragas e doenças. Após a colheita foram avaliadas as características morfoagronômicas e físicoquímicas das raízes e quantificaram-se os teores de carotenoides e de antocianinas totais na polpa das raízes de batata-doce.

\subsubsection{Caracterização morfoagronômica}

\subsubsection{Produção total de raízes frescas}

A produtividade total (PT) foi calculada pela pesagem de todas as raízes de cada parcela em balança digital, com precisão de três casas decimais. $\mathrm{O}$ peso total foi extrapolado para tonelada por hectare $\left(\mathrm{t} \mathrm{ha}^{-1}\right)$.

\subsubsection{Número total de raízes por planta}

O número total de raízes por planta (NTRPP) foi obtido dividindo-se o número total de raízes em cada parcela pelo número de plantas úteis colhidas na parcela.

\subsubsection{Produção de raízes comerciais}

Devido à inexistência no Brasil de uma norma oficial para a padronização de batata-doce (MIRANDA et al., 1995), foram classificadas como raízes comercializáveis aquelas que apresentaram pesos entre 150 e 2000 g, com ausência de danos e bom aspecto visual. A produtividade das raízes comercializáveis (PC) foi extrapolada para $\mathrm{tha}^{-1}$.

\subsubsection{Número de raízes comerciais por planta}

O número de raízes com padrão comercial por planta (NRCPP) foi obtido pela divisão do número de raízes aptas à comercialização pelo número de plantas úteis colhidas na parcela.

\subsubsection{Peso médio das raízes comercializáveis}

O peso médio das raízes comercializáveis (PMRC) foi determinado dividindo-se a massa das raízes comerciais pelo número de raízes comerciais produzidas na parcela, sendo o valor final expresso em gramas $(\mathrm{g})$.

\subsubsection{Características gerais}

O diâmetro médio da raiz (DR) foi obtido pela medição transversal da parte central da raiz, com a ajuda de um paquímetro digital (Digimess $\left.{ }^{\circledR}\right)$. O comprimento médio da raiz $(\mathrm{CR})$ 
foi obtido medindo-se o eixo longitudinal da raiz com o uso de uma régua plástica graduada. A espessura média do córtex da raiz (EC) foi calculada pela medição da casca na porção mediana das raízes cortadas, com o auxilio de um paquímetro digital. A avaliação destas variáveis foi realizada escolhendo-se ao acaso entre 4 e 12 raízes em cada parcela e as leituras foram expressas em milímetros (mm).

\subsubsection{Incidência de danos e grau de resistência}

Para a estimativa dos danos causados por insetos de solo, foram tomadas aleatoriamente de 4 a 12 raízes em cada parcela e avaliada a incidência de danos (ID) segundo a escala de notas empregada por França et al. (1983), citados por Azevedo et al. (2000) e Andrade Júnior et al. (2012).

Foram atribuídas notas em uma escala variável de 1 a 5, na qual 1= raízes livres de danos, com aspecto comercial desejável; 2= raízes com poucos danos, mas com presença de alguns furos e galerias; $3=$ raízes com danos verificados sem muito esforço visual, com aspecto comercial objecionável (muitos furos e galerias); 4= obedeceu a raízes muito danificadas, praticamente inadequadas para comercialização (presença de muitas galerias, furos e início de apodrecimento); 5= raízes completamente inadequadas para comercialização (repletas de galerias, furos e apodrecimento mais avançado). As notas foram dadas por dois avaliadores, sendo o valor final expresso pela média das duas notas.

De acordo com a escala de notas para a incidência de danos, classificaram-se os genótipos segundo o seu grau de resistência aos insetos de solo (GR), considerando-se como resistentes $=$ os clones com nota $\leq 1$; moderadamente resistentes $=$ os genótipos com notas $>1$ $\mathrm{e} \leq 2$; moderadamente suscetíveis $=$ os materiais com nota $>2 \mathrm{e} \leq 3$; suscetíveis $=$ os clones com notas $>3$ e $\leq 4$ e altamente suscetíveis $=$ os materiais com notas $>4$ e $\leq 5$.

\subsubsection{Formato das raízes tuberosas}

O formato das raízes (FTO) foi obtido por meio de uma escala de notas entre 1 e 5, estabelecida por França et al. (1983) e empregada por Azevedo et al. (2000) e Andrade Júnior et al. (2012), descrita da seguinte forma: 1= raízes com formato fusiforme, regular, sem veias ou quaisquer rachaduras; $2=$ raízes com formato considerado bom, próximo do fusiforme, mas com algumas desuniformidades, com possível presença de veias ou curvaturas nas raízes; $3=$ raízes com formato irregular, não fusiformes, com algumas veias e/ou rachaduras, mas comercialmente aceitáveis; 4= raízes muito grandes, com formato muito irregular, com veias 
e rachaduras, indesejáveis comercialmente; $5=$ raízes totalmente fora dos padrões comerciais, muito irregulares, deformadas, curvas e com muitas veias e rachaduras.

Foram avaliadas entre 4 e 12 raízes tomadas aleatoriamente em cada parcela, considerando-se como nota a média das raízes avaliadas. As notas foram dadas por dois avaliadores, sendo o valor final expresso pela média das duas notas.

\subsubsection{Porcentagem de raízes comercializáveis}

A porcentagem de raízes comerciáveis (RC) foi determinada dividindo-se a produtividade comercial pela produtividade total de cada parcela, e multiplicando o valor resultante por 100 .

\subsubsection{Caracterização físico-química}

Para a caracterização físico-química foram escolhidas ao acaso seis raízes de batata-doce comerciais de cada parcela, que foram lavadas, secas, descascadas manualmente, cortadas em rodelas e trituradas em um miniprocessador de alimentos Philips Walita HR2939/00. Os teores de umidade, cinzas, carotenoides e antocianinas totais foram determinados após o término do processamento das raízes tuberosas. Uma parte de todas as amostras foi acondicionada em recipientes plásticos, identificados e congelados em freezer, a temperatura aproximada de $-18{ }^{\circ} \mathrm{C}$, para execução das demais análises. Todas as análises laboratoriais foram realizadas em triplicata, e com exceção da umidade, os resultados foram expressos em base seca (b.s.).

\subsubsection{Umidade}

A umidade das raízes tuberosas (UM) foi determinada gravimetricamente, pela secagem de $2 \mathrm{~g}$ de amostra em estufa com circulação de ar a $105{ }^{\circ} \mathrm{C}$ durante 2 horas (BRIDGERS et al., 2010). Transcorrido este tempo, as amostras foram resfriadas em dessecador, por aproximadamente $1 \mathrm{~h}$, para a sua pesagem. Esta operação de aquecimento e resfriamento foi repetida até as amostras atingirem peso constante. Os resultados foram expressos em percentual de umidade em base úmida (b.u.). 


\subsubsection{Cinzas}

O teor de cinzas (CZ) nas amostras de batata-doce foi determinado segundo a metodologia descrita por Lebot et al. (2011). Pesaram-se 2 g de amostra em cápsula de porcelana, previamente tarada, que foram incineradas em mufla a $550{ }^{\circ} \mathrm{C}$ durante $2 \mathrm{~h}$.

\subsubsection{Proteína bruta}

A avaliação do teor de proteína bruta (PTN) foi realizada a partir de 0,3 $\mathrm{g}$ de amostra, utilizando-se destilador micro-Kjeldahl e bloco digestor e quantificando-se a porcentagem de nitrogênio na amostra. O conteúdo de proteína bruta foi calculado a partir do teor de nitrogênio multiplicado pelo fator de conversão 6,25 (AOAC, 1980).

\subsubsection{Fração de fibra bruta}

A análise do teor de fibra bruta (FB) foi feita através de digestão exaustiva ácida de 1,5 g de amostra em solução de $\mathrm{H}_{2} \mathrm{SO}_{4}$ a 1,25\% p/v durante 30 minutos, seguida de digestão básica com $\mathrm{NaOH}$ a $1,25 \% \mathrm{p} / \mathrm{v}$ por mais 30 minutos (AOAC, 1980).

\subsubsection{Rendimento de amido}

A extração e quantificação de amido (AM) foram feitas de acordo com o protocolo proposto por Zavareze et al. (2009) com algumas modificações.

Pesou-se em balança analítica $100 \mathrm{~g}$ de polpa, que foram trituradas, em baixa velocidade, em um liquidificador contendo água destilada na proporção de 1:2 (batata-doce:água), durante 2 min. A massa obtida foi filtrada em saco de algodão e o resíduo foi repetidamente molhado, triturado e filtrado por três vezes. A suspensão final resultante foi mantida em repouso durante 24 horas para decantação do amido. Após decantação, descartou-se o sobrenadante e o amido, decantado, foi centrifugado com cerca de $40 \mathrm{ml}$ de água destilada durante 5 vezes a 3.000 rpm/ 10 min. Finalmente, o amido foi seco em estufa com circulação de ar a $40{ }^{\circ} \mathrm{C}$ até atingir peso constante e o resultado expresso em \% de amido.

\subsubsection{6 pH e acidez total titulável}

As medidas de $\mathrm{pH}(\mathrm{PH})$ e a acidez total titulável (AT) foram realizadas com um titulador automático marca SI Analytics, modelo TitroLine Easy. Cerga de $10 \mathrm{~g}$ de amostra fresca foram homogeneizadas em $50 \mathrm{~mL}$ de água destilada e realizada a leitura direta do $\mathrm{pH}$. Para a 
acidez titulável, foi utilizada a metodologia da AOAC (1980). Após a leitura do pH, a amostra foi titulada com hidróxido de sódio $(\mathrm{NaOH})$ a $0,1 \mathrm{~N}$.

\subsubsection{Sólidos solúveis totais}

O teor de sólidos solúveis totais (SS) foi quantificado a partir de $1 \mathrm{~g}$ de polpa de batatadoce, retirando o suco da polpa com o auxílio de um espremedor, colocando-se de 1 a 2 gotas de amostra diretamente no prisma do refratômetro Atago, modelo PAL-1, com leitura imediata, sendo os dados expressos em graus Brix.

\subsubsection{Ratio}

O valor da relação SS/ AT (ratio) foi obtido através da divisão dos resultados dos teores de sólidos solúveis totais e da acidez total titulável.

\subsubsection{Quantificação da concentração de carotenoides totais na polpa das raízes}

Foram coletadas aleatoriamente 15 raízes com padrão comercial, de diferentes plantas, por parcela no campo. Posteriormente escolheram-se seis raízes tuberosas ao acaso, os quais foram lavados, secos com papel absorvente, descascados e cortados transversalmente em três locais diferentes: parte superior, central e inferior. As partes centrais das raízes foram reunidas, cortadas manualmente em pedaços menores, misturadas e trituradas em um miniprocessador de alimentos Philips Walita HR2939/00. Após o processamento das amostras, as mesmas foram embaladas e fechadas em recipientes de vidro e congeladas para a análise de carotenoides totais, realizada no dia seguinte.

A extração dos carotenoides totais foi realizada de acordo com a metodologia proposta por Rodriguez-Amaya (2001) com modificações. Pesaram-se de 1,5 a 30 g de amostra triturada (conforme a intensidade de cor da polpa) em um tubo de extração, ao qual foram adicionados $50 \mathrm{~mL}$ de acetona gelada $\left(10{ }^{\circ} \mathrm{C} / 2 \mathrm{~h}\right)$. Em seguida, o tecido foi homogeneizado com o auxílio de um microtriturador do tipo turrax (Marconi®, MA-102), durante um minuto. O extrato foi filtrado a vácuo através de um funil de Büchner com papel de filtro Whatman $\mathrm{n}^{\circ} 1$, recolhendo-se o filtrado em um kitasato de $500 \mathrm{~mL}$. A extração foi repetida até o resíduo ficar branco. O extrato foi transferido para um funil de separação, ao qual foram acrescentados aproximadamente $40 \mathrm{~mL}$ de éter de petróleo (o volume foi dependente da cor do extrato) e $300 \mathrm{~mL}$ de água destilada. Após a separação das fases, descartou-se a fase aquosa inferior e repetiu-se a lavagem durante aproximadamente três vezes até a remoção 
total da acetona. Finalmente, o extrato foi filtrado através de um funil com lã de vidro, contendo $15 \mathrm{~g}$ de sulfato de sódio anidro para remoção da água residual, sendo coletada a fase etérea em um balão volumétrico de 25 ou $50 \mathrm{~mL}$ (o volume foi dependente da cor do extrato), coberto com papel alumínio. O volume do balão volumétrico foi completado com éter de petróleo e o teor de carotenoides totais foi quantificado através da leitura da absorbância a um comprimento de onda de $450 \mathrm{~nm}$ em espectrofotômetro de UV-visível (Micronal®, B442). Durante o processo de extração as amostras foram protegidas contra a luz e evitaram-se temperaturas acima de $35^{\circ} \mathrm{C}$, visando prevenir perdas e alterações na composição dos carotenoides durante a análise.

As concentrações dos carotenoides totais foram determinadas a partir da equação (2.4.1).

$$
\text { Carotenoides totais }(\mu \mathrm{g} / \mathrm{g})=\frac{A_{450 \mathrm{~nm}} * y(\mathrm{~mL}) * 10^{4}}{A_{1 \mathrm{~cm}}^{1 \%} * m(\mathrm{~g})}
$$

Onde: $A$ é a absorbância no pico máximo de absorção; $y$ é o volume da solução que deu uma absorbância $A$ a $450 \mathrm{~nm} ; A_{1 c m}^{1 \%}$ é o coeficiente de absorção do $\beta$-caroteno em éter de petróleo (2592) e $m$ é o peso da amostra.

\subsubsection{Determinação dos parâmetros colorimétricos $L^{*}, a^{*}, b^{*}, C^{*} \mathbf{e} h^{*}$}

Foram coletadas aleatoriamente 15 raízes comerciais de diferentes plantas, por parcela no campo. Posteriormente tomaram-se seis raízes tuberosas ao acaso. Para a determinação dos valores de cor na película externa realizaram-se três leituras na região mediana, no sentido transversal, no córtex das raízes de batata-doce previamente lavadas e secas. Já para a quantificação dos parâmetros de cor na polpa, as raízes foram lavadas, secas com papel absorvente, descascadas e cortadas transversalmente em três locais diferentes: parte superior, central e inferior, sendo realizadas duas leituras na parte central das raízes tuberosas.

A cor foi medida com colorímetro Konica Minolta®, modelo CR-400, com 8 mm de diâmetro da área de medida do aparelho e com iluminação difusa (iluminante D65, ângulo de visão $0^{\circ}$ e espaço cromático CIELAB). $\mathrm{O}$ aparelho foi calibrado no sistema $\mathrm{L}^{*}, \mathrm{a}^{*}, \mathrm{~b}^{*}$ com uma placa branca padrão de cerâmica $\left(\mathrm{L}^{*}=84,2 ; \mathrm{a}^{*}=10,1 ; \mathrm{b}^{*}=14,6\right)$.

As colorações foram descritas com base nos valores $\mathrm{L}^{*}, \mathrm{C}^{*}$ e $\mathrm{H}^{*}$, onde $\mathrm{L}^{*}$ indica a luminosidade; $\mathrm{C}^{*}$ indica o croma: saturação da cor $\left(\mathrm{a}^{*^{2}}+\mathrm{b}^{*^{2}}\right)^{1 / 2}$ e $\mathrm{H}^{*}$ define o ângulo Hue $\left(\tan ^{-1} b^{*} / a^{*}\right)$. 


\subsubsection{Quantificação do teor de antocianinas totais na polpa das raízes}

O teor de antocianinas totais foi determinado de acordo com os procedimentos descritos por Fuleki e Francia (1968) com algumas modificações. Aproximadamente 2 g de raízes de batata-doce previamente lavadas, descascadas e trituradas foram homogeneizadas com $38 \mathrm{ml}$ de metanol acidificado $(0,5 \% \mathrm{v} / \mathrm{v} \mathrm{HCl})$, sob nitrogênio gasoso, usando-se um microtriturador do tipo turrax (Marconi ${ }^{\circledR}$, MA-102), à velocidade de $4000 \mathrm{rpm}$ durante $1 \mathrm{~min}$. O extrato foi deixado em repouso por $1 \mathrm{~h}$ a $4{ }^{\circ} \mathrm{C}$, ao abrigo da luz, com agitação ocasional. Findado o período, o extrato foi filtrado a vácuo através de um funil de Büchner com papel de filtro Whatman $\mathrm{n}^{\circ} 1$. As amostras foram então centrifugadas a $17600 \times \mathrm{g}$ durante 15 min a $4{ }^{\circ} \mathrm{C}$. $\mathrm{O}$ sobrenadante foi recuperado e diluído, quando necessário, até uma concentração apropriada. A absorbância foi lida a $515 \mathrm{~nm}$ e as antocianinas totais foram estimadas utilizando-se a equação (2.4.2):

Antocianin as totais $\left(\mathrm{mg} / \mathrm{g}_{\text {cianidina }=3=\text { gli } \cos \text { ideo }}\right)=\frac{A * P M_{\text {cianidina }-3-\text { gli } \cos \text { ideo }} * F D * 1000}{\varepsilon}$

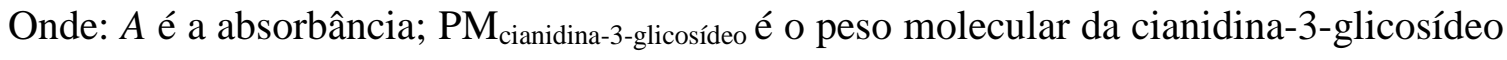
(449,2 g/mol); FD é o fator de diluição (dado pela razão volume de diluição (L) por massa da amostra $(\mathrm{g}))$ e $\varepsilon$ é o coeficiente de extinção molar da cianidina-3-glicosídeo $\left(26900 \mathrm{Lcm}^{-1} \mathrm{~mol}^{-}\right.$ $\left.{ }^{1}\right)$.

\subsubsection{Análise estatística}

Com exceção das características comprimento, diâmetro, espessura do córtex, umidade, sólidos solúveis totais, acidez total titulável, teores de fibra, proteína e amido das raízes de batata-doce, todos os dados foram transformados em $\sqrt{x+1}$, para atender à pressuposição de distribuição normal e homocedasticidade, sendo apresentados os valores originais.

Os dados foram submetidos à análise de variância para cada caráter e as médias foram agrupadas por meio do teste de Scott-Knott a $5 \%$ de probabilidade. As análises de correlação linear de Pearson, entre as variáveis, basearam-se na significância de seus coeficientes. A classificação de intensidade da correlação para $p \leq 0,05$ foi: muito forte $(r \pm 0,91$ a $\pm 1,00)$, forte $(r \pm 0,71$ a $\pm 0,9)$, média $(r \pm 0,51$ a $\pm 0,70)$, fraca $(r \pm 0,31$ a $\pm 0,50)$ e muito fraca $(r \leq \pm$ 0,30) (CARVALHO et al., 2004).

As análises estatísticas descritas anteriormente foram realizadas utilizando-se o software R Core Team (2013). 


\subsection{RESULTADOS E DISCUSSÃO}

Foi observada diferença estatisticamente significativa entre os genótipos avaliados para as características produtivas das raízes (Tabela 2.1).

Tabela 2.1 Comparação de valores médios pelo teste de Scott-Knott para caracteres produtivos de raízes de batata-doce

\begin{tabular}{|c|c|c|c|c|c|}
\hline Genótipo & PT $\left(\mathrm{t} \mathrm{ha}^{-1}\right)$ & NTRPP & $\mathrm{PC}\left(\mathrm{t} \mathrm{ha}^{-1}\right)$ & NRCPP & $\operatorname{PMRC}(\mathrm{g})$ \\
\hline CNPH 62 & $7,13 \mathrm{c}$ & $2,17 \mathrm{~b}$ & $4,02 \mathrm{c}$ & $0,59 \mathrm{~b}$ & $205,17 \mathrm{~b}$ \\
\hline CNPH 53 & $8,32 \mathrm{c}$ & $3,18 \mathrm{~b}$ & $3,10 \mathrm{c}$ & $0,41 \mathrm{~b}$ & $229,01 \mathrm{~b}$ \\
\hline CNPH 02 & $22,52 \mathrm{~b}$ & $2,45 \mathrm{~b}$ & $6,49 \mathrm{c}$ & $0,68 \mathrm{~b}$ & $253,28 \mathrm{~b}$ \\
\hline CNPH 41 & $12,39 \mathrm{c}$ & $3,19 \mathrm{~b}$ & $7,52 \mathrm{c}$ & $1,19 \mathrm{~b}$ & $254,81 \mathrm{~b}$ \\
\hline CNPH 80 & $28,08 \mathrm{~b}$ & $6,02 \mathrm{a}$ & $20,24 \mathrm{c}$ & $2,23 \mathrm{a}$ & $269,80 \mathrm{~b}$ \\
\hline CNPH 90 & $13,56 \mathrm{c}$ & $1,96 \mathrm{~b}$ & $11,67 \mathrm{c}$ & $1,05 \mathrm{~b}$ & $278,59 \mathrm{~b}$ \\
\hline Coquinho & $17,21 \mathrm{~b}$ & $3,87 \mathrm{~b}$ & $12,75 \mathrm{c}$ & $1,71 \mathrm{a}$ & $295,26 \mathrm{~b}$ \\
\hline CNPH 05 & $33,94 \mathrm{a}$ & $6,64 \mathrm{a}$ & $24,7 \mathrm{~b}$ & $2,72 \mathrm{a}$ & $307,60 \mathrm{~b}$ \\
\hline CNPH 08 & $28,09 \mathrm{~b}$ & $5,25 \mathrm{a}$ & $23,69 \mathrm{~b}$ & $2,88 \mathrm{a}$ & $315,71 \mathrm{~b}$ \\
\hline CNPH 1190 & $6,14 \mathrm{c}$ & $1,63 \mathrm{~b}$ & $3,78 \mathrm{c}$ & $0,52 \mathrm{~b}$ & $343,65 \mathrm{~b}$ \\
\hline CNPH 1796 & $30,51 \mathrm{a}$ & $5,04 \mathrm{a}$ & $25,37 \mathrm{~b}$ & $2,93 \mathrm{a}$ & $345,95 \mathrm{~b}$ \\
\hline CNPH 69 & $30,93 \mathrm{a}$ & $4,54 \mathrm{a}$ & $23,97 \mathrm{~b}$ & $2,71 \mathrm{a}$ & $362,12 \mathrm{~b}$ \\
\hline CNPH 55 & $27,14 b$ & $2,24 \mathrm{~b}$ & $6,82 \mathrm{c}$ & $0,64 \mathrm{~b}$ & $369,71 \mathrm{~b}$ \\
\hline CNPH 56 & $24,49 \mathrm{~b}$ & $2,83 \mathrm{~b}$ & $19,84 \mathrm{c}$ & $2,17 \mathrm{a}$ & $378,17 \mathrm{~b}$ \\
\hline BRS Amélia & $40,91 \mathrm{a}$ & $4,90 \mathrm{a}$ & $29,86 b$ & $2,99 \mathrm{a}$ & $387,31 \mathrm{~b}$ \\
\hline CNPH 66 & $29,51 \mathrm{~b}$ & $4,17 \mathrm{~b}$ & $23,25 \mathrm{c}$ & $2,37 \mathrm{a}$ & $389,81 \mathrm{~b}$ \\
\hline BRS Rubissol & $46,79 \mathrm{a}$ & $6,24 \mathrm{a}$ & 39,89 a & $4,05 \mathrm{a}$ & $390,33 \mathrm{~b}$ \\
\hline Brazlândia Roxa & $50,44 \mathrm{a}$ & $6,74 \mathrm{a}$ & $45,39 \mathrm{a}$ & $4,33 \mathrm{a}$ & $421,73 \mathrm{a}$ \\
\hline CNPH 46 & $33,94 \mathrm{a}$ & $3,76 \mathrm{~b}$ & $28,98 \mathrm{~b}$ & $2,35 \mathrm{a}$ & $488,14 \mathrm{a}$ \\
\hline CNPH 60 & $31,97 \mathrm{a}$ & $3,28 \mathrm{~b}$ & $27,61 \mathrm{~b}$ & $2,23 \mathrm{a}$ & $490,59 \mathrm{a}$ \\
\hline Princesa & $40,83 \mathrm{a}$ & $3,65 \mathrm{~b}$ & $32,59 \mathrm{~b}$ & $2,43 \mathrm{a}$ & $527,83 \mathrm{a}$ \\
\hline Brazlândia Branca & $50,67 \mathrm{a}$ & $4,69 \mathrm{a}$ & $41,52 \mathrm{a}$ & $3,22 \mathrm{a}$ & $538,64 \mathrm{a}$ \\
\hline Rainha & $38,65 \mathrm{a}$ & $2,96 \mathrm{~b}$ & $30,33 \mathrm{~b}$ & $2,08 \mathrm{a}$ & $557,32 \mathrm{a}$ \\
\hline Beauregard & $65,68 \mathrm{a}$ & $5,71 \mathrm{a}$ & $56,58 \mathrm{a}$ & $4,11 \mathrm{a}$ & $565,84 \mathrm{a}$ \\
\hline Brazlândia Rosada & $48,59 \mathrm{a}$ & $2,87 \mathrm{~b}$ & $27,84 \mathrm{~b}$ & $1,79 \mathrm{a}$ & $575,39 \mathrm{a}$ \\
\hline BRS Cuia & $65,20 \mathrm{a}$ & 5,15 a & $50,05 \mathrm{a}$ & $3,01 \mathrm{a}$ & $692,30 \mathrm{a}$ \\
\hline $\mathrm{QM}_{\text {(tratamento) }}$ & $9,35 * *$ & $0,43 * *$ & $10,43^{* *}$ & $0,42 * *$ & $52,70 * *$ \\
\hline Média & 31,18 & 3,95 & 23,4 & 2,14 & 391,09 \\
\hline C.V. $(\%)$ & 28,15 & 19,77 & 30,5 & 18,33 & 24,13 \\
\hline
\end{tabular}

Médias com a mesma letra na coluna não diferem entre si, pelo teste de Scott-Knott a 5\% de probabilidade; QM: quadrado médio dos tratamentos; **Significativo a $1 \%$ de probabilidade pelo teste F; C.V.: coeficiente de variação. PT: produtividade total; NTRPP: número total de raízes por planta; PC: produtividade comercializável; NRCPP: número de raízes comerciais por planta; PMRC: peso médio de raízes comerciáveis de batata-doce.

As cultivares Beauregard e BRS Cuia apresentaram as maiores produtividades totais (65,68 e 65,20 $\mathrm{t} \mathrm{ha}^{-1}$, respectivamente), porém foram estatisticamente equivalentes aos materiais Brazlândia Branca, Brazlândia Roxa, Brazlândia Rosada, BRS Rubissol, BRS 
Amélia, Princesa, Rainha, CNPH 46, CNPH 05, CNPH 60, CNPH 69 e CNPH 1796 (50,67; 50,$44 ; 48,59 ; 46,79 ; 40,91 ; 40,83 ; 38,65 ; 33,94 ; 33,94 ; 31,97 ; 30,93$ e $30,51 \mathrm{t} \mathrm{ha}^{-1}$, respectivamente). Com exceção da cultivar Coquinho, todas as cultivares apresentaram produtividades de raízes superiores às produtividades totais atingidas pelos clones. Este resultado pode ser explicado pela origem das mudas utilizadas para a condução do experimento. Os clones são mantidos em campo, multiplicados convencionalmente, e suas mudas não passaram pela limpeza clonal, já as cultivares são mantidas em viveiro e suas mudas foram submetidas previamente à limpeza clonal conforme Fernandes (2013). De acordo com Câmara et al. (2013) a limpeza clonal por meio da propagação in vitro possibilita a obtenção de mudas livres de vírus e outros patógenos, viabilizando a produção de grande número de plantas que podem ser utilizadas para a formação de matrizes com todo o potencial genético, com consequente aumento do rendimento e da melhoria da qualidade das raízes da batata-doce.

Segundo Silva et al. (1995) a cultivar Brazlândia Branca apresenta produtividade média entre 30 e 66 t ha $^{-1}$, em ciclo de 4 a 5 meses e as cultivares Brazlândia Roxa e Brazlândia Rosada apresentam produtividades em torno de 25 (ciclo de 165 dias) e $30 \mathrm{t} \mathrm{ha}^{-1}$ (ciclo de 120 a 150 dias), respectivamente. No presente estudo, apenas a cultivar Brazlândia Branca (50,67 t $\mathrm{ha}^{-1}$ ) apresentou produtividade condizente com estes valores; já as cultivares Brazlândia Roxa $\left(50,44 \mathrm{t} \mathrm{ha}^{-1}\right)$ e Brazlândia Rosada (48,59 $\left.\mathrm{t} \mathrm{ha}^{-1}\right)$ apresentaram produtividades muito superiores, 101,76 e 61,97\%, respectivamente, aos dados citados anteriormente. A produtividade média total $\left(31,18 \mathrm{t} \mathrm{ha}^{-1}\right)$ foi superior à produtividade média atingida por Souza (2000); Azevedo et al. (2000) e Ankumah et al. (2003) (17,2; 18,48 e 29,23, respectivamente). No entanto, foi inferior à produtividade média encontrada por Cecílio Filho et al. (1996) com colheita aos seis meses $\left(33,24 \mathrm{t} \mathrm{ha}^{-1}\right)$ e por Ozturk et al. (2012) com colheita aos 5 meses $\left(42,84 \mathrm{t} \mathrm{ha}^{-1}\right)$. Essa grande variação nas produtividades pode ser decorrente, entre outras causas, do material genético, da qualidade das estacas utilizadas, do local de cultivo, das diferenças na fertilidade do solo entre as estações experimentais, da época de plantio, da adubação e do tempo de permanência da cultura no campo (Andrade Júnior et al., 2012; Kalkmann, 2011).

O número total de raízes por planta oscilou entre 1,63 e 6,74 (Tabela 2.1), sendo que a cultivar Brazlândia Roxa apresentou o maior número de raízes por planta, juntamente com os genótipos CNPH 05, BRS Rubissol, CNPH 80, Beauregard, CNPH 08, BRS Cuia, CNPH 
1796, BRS Amélia, Brazlândia Branca e CNPH 69 (6,74; 6,64; 6,24; 6,02; 5,71; 5,25; 5,15; 5,04; 4,90; 4,69 e 4,54, respectivamente). Estes valores são condizentes, porém superiores, aos reportados por Câmara et al. (2013), que obtiveram um número total de raízes por planta na faixa de 1,25 a 4,75, para as variedades ESAM 1 e Califórnia, respectivamente.

A produtividade de raízes com padrão comercial oscilou entre 3,10, para o clone CNPH 53 e $56,58 \mathrm{t} \mathrm{ha}^{-1}$, para a cultivar Beauregard (Tabela 2.1). As maiores produtividades comercializáveis foram verificadas nas cultivares BRS Rubissol, Brazlândia Branca, Brazlândia Roxa, BRS Cuia e Beauregard (39,89; 41,52; 45,39; 50,05 e 56,58 t ha-1, respectivamente). Estes resultados são congruentes com os reportados por Gonçalves Neto et al. (2012), que na avaliação de 39 genótipos de batata-doce, observaram uma produção de raízes comerciais na faixa de 0 a 51,35 $\mathrm{t} \mathrm{ha}^{-1}$, para os clones UFLA 07-48 e UFLA 07-12, respectivamente. Avaliando 13 clones em Ijaci - MG, Azevedo et al. (2000) encontraram uma produtividade comercial mínima de 2,25 t ha ${ }^{-1}$, com o clone 92619 e máxima de 19,55 $\mathrm{t} \mathrm{ha}^{-1}$, com o clone 92010. Andrade Júnior et al. (2012) na análise de 12 clones de batata-doce em Diamantina - MG, seis meses após o plantio, constataram produtividades comerciais entre $8 \mathrm{t}$ $\mathrm{ha}^{-1}$, com a variedade Batata Mandioca e 29,5 $\mathrm{t} \mathrm{ha}^{-1}$, com o clone BD-45. As cultivares Brazlândia Rosada, Brazlândia Branca e Brazlândia Roxa proporcionaram produtividades comerciais de 27,84; 41,52 e 45,39 $\mathrm{t} \mathrm{ha}^{-1}$, respectivamente, que foram superiores às atingidas por Massaroto (2008) com colheita realizada aos seis meses $\left(10,9 ; 11,9\right.$ e 10,6 t ha ${ }^{-1}$, respectivamente) e às observadas por Resende (2000) 150 dias após o plantio $(16,93 ; 22,84$ e $14,33 \mathrm{tha}^{-1}$, respectivamente).

O número médio de raízes comerciais por planta para os genótipos avaliados foi de 2,14 (Tabela 2.1). A cultivar Brazlândia Roxa (4,33) apresentou a maior quantidade; porém, não diferiu estatisticamente dos materiais Coquinho, Brazlândia Rosada, Rainha, CNPH 56, CNPH 60, CNPH 80, CNPH 46, CNPH 66, Princesa, CNPH 69, CNPH 05, CNPH 08, CNPH 1796, BRS Amélia, BRS Cuia, Brazlândia Branca, BRS Rubissol e Beauregard, que apresentaram entre 1,71 e 4,11 raízes tuberosas comerciais por planta. Já o menor número de raízes comerciais por planta foi verificado nos clones CNPH 53, CNPH 1190, CNPH 62, CNPH 55, CNPH 02, CNPH 90 e CNPH 41 (0,41;0,52;0,59;0,64;0,68; 1,05 e 1,19, respectivamente). Silva et al. (1991) verificaram que as variedades Jacaré e Peçanha Branca apresentaram o menor e o maior números de raízes tuberosas comerciais por parcela $(3,11$ e 9,18, respectivamente), quatro meses após o plantio. Já Câmara et al. (2013) avaliando 
também variedades de batata-doce, quatro meses após o plantio, em Mossoró - RN, encontraram número médio de raízes comerciais por planta variando entre 1 e 3,75 (variedades ESAM 1 e Califórnia, respectivamente).

Com relação ao peso das raízes comerciais, verificou-se uma variação entre 205,17 (clone CNPH 62) e 692,30 g (cv. BRS Cuia), com peso médio de 391,09 g (Tabela 2.1). Estes resultados são congruentes com os obtidos por Massaroto et al. (2014) que na avaliação de 25 materiais de batata-doce cultivados no município de Ijaci - MG, seis meses após o plantio, reportaram peso médio de raízes comerciais entre 233,7 e 889 g (clones UFT-10-AL e UFT112, respectivamente). Já Resende (1999) estudando oito cultivares de batata-doce, com colheita aos cinco meses, registrou peso médio de raízes comerciais de 265,2 e 182 g em condições de irrigação suplementar e de sequeiro, respectivamente, em Porteirinha - MG. Os pesos médios das cultivares Brazlândia Rosada, Brazlândia Branca, Princesa e Brazlândia Roxa $(575,39 ; 538,64 ; 527,83$ e 421,73 g, respectivamente) foram quase duas vezes superiores aos obtidos por Resende (2000) colhendo aos 150 dias após o plantio (319,46; 278,43; 256,35 e 220,12 g, respectivamente). Porém, estes autores obtiveram resultados compatíveis quanto ao maior peso da cultivar Brazlândia Rosada, seguida em ordem decrescente pelas cultivares Brazlândia Branca, Princesa e Brazlândia Roxa.

Segundo Miranda et al. (1995) embora no Brasil não existe uma norma oficial para a padronização de batata-doce, nos principais mercados brasileiros (Rio de Janeiro e São Paulo), vigoram normas não oficiais, que são aceitas pelos produtores e atacadistas e incluem as seguintes classes: extra A, para raízes tuberosas entre 301 e 400 g; extra B, para raízes entre 201 e 300 g; especial, para raízes entre 151 e 200 g e diversos, para raízes tuberosas com pesos entre 80 e $150 \mathrm{~g}$ ou maiores que $400 \mathrm{~g}$. De acordo com esta classificação os materiais CNPH 62, CNPH 53, CNPH 02, CNPH 41, CNPH 80, CNPH 90 e Coquinho, com peso médio entre 205,17 e 295,26 g, exibiram raízes comerciais com padrão extra B; enquanto os genótipos CNPH 05, CNPH 08, CNPH 1190, CNPH 1796, CNPH 69, CNPH 55, CNPH 56, BRS Amélia, CNPH 66 e BRS Rubissol, com peso médio entre 307,60 e 390,33 g, proporcionaram raízes comercias do tipo extra A, que é o tamanho ideal para a comercialização. Já os genótipos BRS Cuia, Brazlândia Rosada, Beauregard, Rainha, Brazlândia Branca, Princesa, CNPH 60, CNPH 46 e Brazlândia Roxa (692,30; 575,39; 565,$84 ; 557,32 ; 538,64 ; 527,83 ; 490,59 ; 488,14$ e $421,73 \mathrm{~g}$, respectivamente), que apresentaram as raízes comerciais com maiores pesos, com valores para a característica acima 
de 400 g, enquadraram-se na classificação como diversos. É prezumível que estes materiais apresentem ciclos mais precoces, que proporcionaram maior tuberização.

Os resultados referentes às características morfoagronômicas das raízes podem ser visualizados na Tabela 2.2.

Tabela 2.2 Comparação de valores médios pelo teste de Scott-Knott para as variáveis comprimento, diâmetro, espessura de córtex, incidência de danos ocasionados por insetos de solo, formato e percentagem de raízes comerciais de 26 genótipos de batata-doce

\begin{tabular}{|c|c|c|c|c|c|c|c|}
\hline Genótipo & CR (mm) & DR (mm) & EC (mm) & ID & GR & FTO & $\mathrm{RC}(\%)$ \\
\hline Brazlândia Roxa & $188,76 \mathrm{~b}$ & $65,07 \mathrm{~b}$ & $2,67 \mathrm{a}$ & $1,10 \mathrm{~b}$ & MR & $1,33 \mathrm{~d}$ & $90,05 \mathrm{a}$ \\
\hline Beauregard & $176,74 \mathrm{~b}$ & $82,41 \mathrm{a}$ & $2,82 \mathrm{a}$ & $1,38 \mathrm{~b}$ & MR & $1,37 \mathrm{~d}$ & 86,36 a \\
\hline CNPH 60 & $198,65 \mathrm{~b}$ & $52,24 \mathrm{c}$ & $2,58 \mathrm{a}$ & $1,27 \mathrm{~b}$ & MR & $2,06 \mathrm{c}$ & 86,01 a \\
\hline CNPH 46 & $182,99 \mathrm{~b}$ & $53,92 \mathrm{c}$ & $2,46 \mathrm{a}$ & $1,48 \mathrm{~b}$ & MR & $2,77 \mathrm{~b}$ & $84,41 \mathrm{a}$ \\
\hline BRS Rubissol & $171,82 \mathrm{~b}$ & $69,77 \mathrm{~b}$ & $2,34 \mathrm{~b}$ & $1,33 \mathrm{~b}$ & MR & $1,73 \mathrm{~d}$ & 84,36 a \\
\hline CNPH 1796 & $179,70 \mathrm{~b}$ & $63,30 \mathrm{~b}$ & $1,84 \mathrm{~b}$ & $1,29 \mathrm{~b}$ & MR & $2,79 \mathrm{~b}$ & $82,77 \mathrm{a}$ \\
\hline Princesa & $236,19 a$ & $59,98 \mathrm{c}$ & $2,85 \mathrm{a}$ & $1,52 \mathrm{~b}$ & MR & $2,25 \mathrm{c}$ & 81,86 a \\
\hline CNPH 08 & $139,29 \mathrm{c}$ & $68,65 \mathrm{~b}$ & $2,13 \mathrm{~b}$ & $1,48 \mathrm{~b}$ & MR & $1,96 \mathrm{c}$ & $81,54 \mathrm{a}$ \\
\hline Brazlândia Branca & $188,79 \mathrm{~b}$ & $72,83 \mathrm{~b}$ & $2,66 \mathrm{a}$ & $1,54 \mathrm{~b}$ & MR & $2,19 \mathrm{c}$ & $81,48 \mathrm{a}$ \\
\hline CNPH 56 & $127,60 \mathrm{c}$ & $39,84 \mathrm{~d}$ & $1,97 \mathrm{~b}$ & $1,98 \mathrm{a}$ & MR & $2,69 \mathrm{~b}$ & 80,36 a \\
\hline CNPH 69 & $167,49 \mathrm{~b}$ & $33,70 \mathrm{~d}$ & $2,09 \mathrm{~b}$ & $1,17 \mathrm{~b}$ & MR & $3,25 \mathrm{~b}$ & $77,42 \mathrm{a}$ \\
\hline BRS Cuia & $154,89 \mathrm{c}$ & 81,16 a & $2,20 \mathrm{~b}$ & $1,40 \mathrm{~b}$ & MR & $2,33 \mathrm{c}$ & $77,41 \mathrm{a}$ \\
\hline Rainha & $161,95 \mathrm{c}$ & $74,30 \mathrm{a}$ & $2,91 \mathrm{a}$ & $1,63 \mathrm{a}$ & MR & $2,40 \mathrm{c}$ & $75,46 \mathrm{a}$ \\
\hline Coquinho & $112,94 \mathrm{c}$ & $70,28 \mathrm{~b}$ & $2,00 \mathrm{~b}$ & $1,54 \mathrm{~b}$ & MR & $2,77 \mathrm{~b}$ & 73,89 a \\
\hline BRS Amélia & $178,71 \mathrm{~b}$ & $69,30 \mathrm{~b}$ & $2,43 \mathrm{a}$ & $1,67 \mathrm{a}$ & MR & $2,65 \mathrm{~b}$ & $72,54 \mathrm{a}$ \\
\hline CNPH 66 & $161,65 \mathrm{c}$ & $68,10 \mathrm{~b}$ & $2,64 \mathrm{a}$ & $1,80 \mathrm{a}$ & MR & $4,13 \mathrm{a}$ & $66,66 \mathrm{a}$ \\
\hline CNPH 05 & $151,14 \mathrm{c}$ & $49,19 \mathrm{c}$ & $1,66 \mathrm{~b}$ & $1,21 \mathrm{~b}$ & MR & $2,32 \mathrm{c}$ & $65,44 \mathrm{a}$ \\
\hline CNPH 1190 & $131,37 \mathrm{c}$ & $50,99 \mathrm{c}$ & $2,17 \mathrm{~b}$ & $1,49 \mathrm{~b}$ & MR & $2,63 \mathrm{~b}$ & $62,09 \mathrm{a}$ \\
\hline CNPH 41 & $141,85 \mathrm{c}$ & $57,93 \mathrm{c}$ & $3,20 \mathrm{a}$ & $1,75 \mathrm{a}$ & MR & $2,19 \mathrm{c}$ & $60,86 \mathrm{a}$ \\
\hline CNPH 90 & $138,63 \mathrm{c}$ & $42,86 \mathrm{~d}$ & $2,00 \mathrm{~b}$ & $1,75 \mathrm{a}$ & MR & $2,54 \mathrm{~b}$ & $60,37 \mathrm{~b}$ \\
\hline CNPH 80 & $147,32 \mathrm{c}$ & $58,10 \mathrm{c}$ & $1,78 \mathrm{~b}$ & $1,25 \mathrm{~b}$ & MR & $2,38 \mathrm{c}$ & $55,72 \mathrm{~b}$ \\
\hline Brazlândia Rosada & $219,30 \mathrm{a}$ & $77,24 \mathrm{a}$ & $2,64 \mathrm{a}$ & $1,69 \mathrm{a}$ & MR & $2,48 \mathrm{c}$ & $53,21 \mathrm{~b}$ \\
\hline CNPH 62 & $138,08 \mathrm{c}$ & $50,76 \mathrm{c}$ & $2,51 \mathrm{a}$ & $1,79 \mathrm{a}$ & MR & $2,57 \mathrm{~b}$ & $45,23 \mathrm{~b}$ \\
\hline CNPH 53 & $112,96 \mathrm{c}$ & $43,24 \mathrm{~d}$ & $2,22 \mathrm{~b}$ & $1,44 \mathrm{~b}$ & MR & $2,32 \mathrm{c}$ & $43,20 \mathrm{~b}$ \\
\hline CNPH 55 & $167,82 \mathrm{~b}$ & $56,66 \mathrm{c}$ & $2,20 \mathrm{~b}$ & $1,46 \mathrm{~b}$ & MR & $2,88 \mathrm{~b}$ & $41,59 \mathrm{~b}$ \\
\hline CNPH 02 & $196,62 \mathrm{~b}$ & $53,49 \mathrm{c}$ & $1,82 \mathrm{~b}$ & $1,52 \mathrm{~b}$ & MR & $3,03 \mathrm{~b}$ & $31,32 \mathrm{~b}$ \\
\hline $\mathrm{QM}_{\text {(tratamento) }}$ & $3741,93 * *$ & $671,13 * *$ & $0,63 * *$ & $0,02 * *$ & - & $0,09 * *$ & $6,25^{*}$ \\
\hline Média & 164,56 & 59,93 & 2,36 & 1,52 & - & 2,5 & 68,39 \\
\hline C.V. & 14,84 & 14,15 & 16,4 & 5,91 & - & 7,36 & 22 \\
\hline
\end{tabular}

Médias com a mesma letra na coluna não diferem entre si, pelo teste de Scott-Knott a 5\% de probabilidade; QM: quadrado médio dos tratamentos; $* *$ e * Significativo a 1 e $5 \%$ de probabilidade pelo teste $\mathrm{F}$, respectivamente; C.V.: coeficiente de variação. CR: comprimento; DR: diâmetro; EC: espessura de córtex; ID: incidência de danos ocasionados por insetos de solo; GR: grau de resistência (MR: moderadamente resistente); FTO: formato; RC: percentagem de raízes comerciais.

Houve diferença estatisticamente significativa entre os clones para a característica comprimento de raízes tuberosas (Tabela 2.2). O tamanho médio das raízes tuberosas variou 
entre 112,94 (cv. Coquinho) e 236,19 mm (cv. Princesa). As cultivares Brazlândia Rosada e Princesa apresentaram os maiores comprimentos (219,30 e 236,19 mm, respectivamente). Já as raízes com menores comprimentos foram verificados nos genótipos Coquinho, CNPH 53, CNPH 56, CNPH 1190, CNPH 62, CNPH 90, CNPH 08, CNPH 41, CNPH 80, CNPH 05, BRS Cuia, CNPH 66 e Rainha (112,94; 112,96; 127,60; 131,37; 138,08; 138,63; 139,29; 141,$85 ; 147,32 ; 151,14 ; 154,89 ; 161,65$ e 161,95 mm, respectivamente). Cardoso et al. (2005) obtiveram valores semelhantes, com comprimento de raízes variando entre 131,8 (clone 100) e 206,9 mm (clone 1). Cavalcante et al. (2009) estudando 11 genótipos de batata-doce em Junqueiro - AL, observaram comprimentos de raiz entre 124,5 e 189,2 mm para o clone CL02 e a variedade Rainha Prata, respectivamente.

O diâmetro médio das raízes tuberosas foi 59,93 mm (Tabela 2.2). Os clones CNPH 69, CNPH 56, CNPH 90 e CNPH 53, com 33,70; 39,84; 42,86 e 43,24 mm, respectivamente, exibiram os menores diâmetros de raízes, enquanto os maiores foram constatados nas cultivares Rainha, Brazlândia Rosada, BRS Cuia e Beauregard (74,30; 77,24; 81,16 e 82,41, respectivamente). Cavalcante et al. (2012) estudando 14 clones de batata-doce, encontraram resultados condizentes com os desse trabalho, com médias variando de 36,8 a 70,5 mm, para os clones CL-11 e CL-13, respectivamente. O diâmetro médio das raízes $(59,93 \mathrm{~mm})$ foi superior aos atingidos por Queiroga et al. (2007), com colheita realizada 150 dias após o plantio (51,2 mm) e por Cavalcante et al. (2009), 130 dias após o plantio (57,4 mm), porém inferior ao valor médio reportado por Silva et al. (2012), seis meses após o plantio (72,2 mm).

A espessura do córtex oscilou entre 1,66, para o clone CNPH 05 e 3,20 mm, para o clone CNPH 41 (Tabela 2.2). Estes valores são compatíveis com os encontrados por Kalkmann (2011), quem obteve espessura de córtex mínima com a cultivar Brazlândia Roxa (2,54 mm) e máxima com o clone CNPH $1203(3,77 \mathrm{~mm})$. Espessuras de córtex mais grossas foram verificadas nos materiais BRS Amélia, CNPH 46, CNPH 62, CNPH 60, Brazlândia Rosada, CNPH 66, Brazlândia Branca, Brazlândia Roxa, Beauregard, Princesa, Rainha e CNPH 41 $(2,43 ; 2,46 ; 2,51 ; 2,58 ; 2,64 ; 2,64 ; 2,66 ; 2,67 ; 2,82 ; 2,85 ; 2,91$ e 3,20 , respectivamente), que podem apresentar maior resistência à injúria mecânica durante o transporte.

Todos os materiais apresentaram resistência moderada aos insetos de solo, porém, os genótipos Brazlândia Roxa, CNPH 69, CNPH 05, CNPH 80, CNPH 60, CNPH 1796, BRS Rubissol, Beauregard, BRS Cuia, CNPH 53, CNPH 55, CNPH 46, CNPH 08, CNPH 1190, Princesa, CNPH 02, Brazlândia Branca e Coquinho, com notas entre 1,10 e 1,54, em ordem 
crescente, proporcionaram as menores incidências de danos (Tabela 2.2). As cultivares Brazlândia Roxa, Brazlândia Branca, Coquinho e Brazlândia Rosada, com resistência moderada, apresentaram notas 1,10; 1,54; 1,54 e 1,69, respectivamente. Massaroto et al. (2014) avaliando 25 materiais de batata-doce, seis meses após o plantio, observou para a cultivar Brazlândia Roxa nota de incidência de danos de 1,66, classificando-a também como de resistência alta a moderada. Contudo, resultados divergentes foram observados por estes autores quanto às cultivares Brazlândia Branca e Brazlândia Rosada, que obtiveram notas 2,51 e 2,83, respectivamente, sendo classificadas como suscetíveis aos insetos de solo. Peixoto et al. (1999), seis meses após o plantio, também verificou a suscetibilidade das cultivares Brazlândia Branca e Brazlândia Rosada, com notas 3,13 e 3,00, respectivamente e da cultivar coquinho, com nota 2,68. Já Andrade Júnior et al. (2012), semelhante aos resultados encontrados neste estudo, aos seis meses do plantio, constatou notas de incidência de danos abaixo de dois para as cultivares Brazlândia Roxa e Brazlândia Rosada (1,6 e 1,8, respectivamente).

Azevedo et al. (2000) obtiveram ampla variabilidade para a reação de resistência da batata-doce aos ataques provocados pelos insetos de solo, com notas variando de 1,38 a 2,96, para os clones 92676 e 92798, respectivamente. Silveira et al. (2011) avaliando 10 clones de batata-doce de polpa alaranjada nas condições de Palmas - To, durante as estações seca e chuvosa, cinco meses após o plantio, observaram notas de incidência de danos causados por insetos de solo oscilando entre 1,5 (clone BD\#35) e 3,5 (clone BD\#14), para a estação seca e entre 1 (clones BD\#09, BD\#25 e BD\#35) e 2,67 (clone BD\#14), para a estação chuvosa. Segundo os resultados obtidos por estes últimos autores e de acordo com Fernandes et al. (2009), variáveis ambientais nos agroecossistemas, como maior precipitação pluviométrica, alta radiação solar, elevadas lâminas de irrigação e altas temperaturas e umidades relativas do ar, reduzem a densidade populacional de insetos.

Para a característica formato das raízes, com exceção dos clones CNPH 02, CNPH 69 e CNPH 66 (notas 3,03; 3,25 e 4,13, respectivamente), todos os materiais apresentaram raízes com notas de formato inferiores a 3 (Tabela 2.2). As cultivares Brazlândia Roxa, Beauregard e BRS Rubissol apresentaram raízes com formatos semelhantes ao ideal, com notas 1,33; 1,37 e 1,73, respectivamente. Dentre os clones, o CNPH 08 e o CNPH 60, com notas 1,96 e 2,06, respectivamente, apresentaram o melhor formato, porém, estatisticamente equivalente, ao apresentado pela cultivar Brazlândia Branca $(2,19)$; caracterizando-se como promissores. 
Azevedo et al. (2014) avaliando oito genótipos de batata-doce em dois ambientes de cultivo, 180 dias após o plantio, obtiveram formatos na faixa de 1,70 (clone BD-25) a 2,77 (clone BD-31TO), no campus JK e de 1,53 (clone BD-45) e 3,57 (clone BD-15), na Fazenda Forquilha - MG. Gonçalves Neto et al. (2012) analisando 30 genótipos de batata-doce, sete meses após o plantio, verificou formatos de raízes oscilando entre 1,5 (clones UFLA07-31, UFLA07-49 e UFLA07-53) e 5 (UFLA07-10, UFLA07-18, UFLA07-21 e UFLA07-42). Adicionalmente, este autor obteve nota 3 para os formatos das cultivares Brazlândia Branca e Brazlândia Rosada, que foi superior às encontradas no presente estudo (2,19 e 2,48, respectivamente) e à observada por Andrade Júnior et al. (2012) para a cultivar Brazlândia Rosada (1,8), seis meses após o plantio. Estas divergências podem ser explicadas pelas diferenças do tempo de permanência dos genótipos no campo, pois de acordo com Azevedo et al. (2014) o formato das raízes torna-se mais irregular com o aumento do tempo de colheita, provavelmente, devido à maior exposição a fatores ambientais.

A classificação de raízes comerciais em porcentagem oscilou entre 31,32, paro o clone CNPH 02 e 90,05\%, para a cultivar Brazlândia Roxa (Tabela 2.2). Foi observado que os materiais Brazlândia Roxa, Beauregard, CNPH 60, CNPH 46, BRS Rubissol, CNPH 1796, Princesa, CNPH 08, Brazlândia Branca e CNPH 56, com 90,05; 86,36; 86,01; 84,41; 84,36; 82,$77 ; 81,86 ; 81,54 ; 81,48$ e $80,36 \%$, respectivamente, apresentaram mais de $80 \%$ de raízes comerciais, porém, sem diferir estatisticamente dos genótipos CNPH 69, BRS Cuia, Rainha, Coquinho, BRS Amélia, CNPH 66, CNPH 05, CNPH 1190 e CNPH 41, que mostraram percentagens de raízes comerciais entre 60,86 e 77,42\%. Embora os materiais BRS Cuia, Brazlândia Rosada, BRS Amélia, Rainha, CNPH 69 e CNPH 55 proporcionaram produtividades acima de $27 \mathrm{t} \mathrm{ha}^{-1}, 65,20 ; 48,59 ; 40,91 ; 38,65 ; 30,93$ e 27,14 t ha ${ }^{-1}$, respectivamente, as maiores notas de formato apresentadas por estes genótipos, 2,33; 2,48; 2,$65 ; 2,40 ; 3,25$ e 2,88, respectivamente, prejudicaram suas percentagens de raízes comerciais em relação à produção total. De acordo com Silva et al. (1995) a cultivar Brazlândia Rosada apresenta ciclo de 120 a 150 dias e se colhida muito tarde produz batatas graúdas, de elevado peso médio. Gonçalves Neto et al. (2011) avaliando 39 genótipos de batata-doce, sete meses após o plantio, reportaram percentagens de raízes comerciais na faixa de 0 a 99,45\%, para os clones UFLA07-48 e UFLA07-51, respectivamente. Estes autores atingiram 69,65 e 86,40\% de raízes comerciais para as cultivares Brazlândia Rosada e Brazlândia Branca, 
respectivamente, que foram semelhantes, porém superiores às constatadas na presente pesquisa $(53,21$ e $81,48 \%$, respectivamente).

Fazendo uma análise geral das características morfoagronômicas avaliadas, pode-se afirmar que os acessos CNPH 05 e CNPH 1796, de polpa roxa, que apresentaram produtividades totais superiores a $30 \mathrm{t} \mathrm{ha}^{-1}$ e estatisticamente equivalentes às das cultivares Beauregard, BRS Cuia, Brazlândia Branca, Brazlândia Roxa, Brazlândia Rosada, BRS Rubissol, BRS Amélia e Princesa; e os clones CNPH 80 e CNPH 08, com produtividades acima de $27 \mathrm{t} \mathrm{ha}^{-1}$, superiores, porém proporcionais à da cultivar Coquinho, são promissores visando o consumo humano, pois apresentaram altas produtividades totais. Adicionalmente, os clones CNPH 05, CNPH 08 e CNPH 1796, proporcionaram peso médio de raízes comercializáveis do tipo extra A, ideal para a comercialização. Entretanto, os clones CNPH 1796, 80 e 05, apresentam polpa roxa, tendo que ser avaliado, posteriormente, o grau de aceitação por parte dos consumidores. Os clones CNPH 60 e CNPH 46, também são promissores, tendo apresentado produtividades equivalentes às das cultivares. Contudo, esses acessos apresentaram raízes tuberosas com peso acima de $400 \mathrm{~g}$, sendo classificados como do tipo diversos, de menor valor comercial. É provável que estes clones apresentem ciclo menor que 172 dias, e que a colheita mais precoce favoreça a produção de raízes tuberosas com padrão extra A. Todos os clones citados anteriormente apresentaram moderada resistência aos insetos de solo e notas para formato que os caracterizam como boas alternativas para o consumo humano.

Já os acessos CNPH 69, com produtividade proporcional à das cultivares e CNPH 66, com quase $30 \mathrm{t} \mathrm{ha}^{-1}$, também mostraram resistência moderada aos insetos de solo, porém, formato não desejável para a comercialização, sendo por tanto boas alternativas para a alimentação animal ou o processamento industrial.

Por fim, os clones CNPH 62, CNPH 53 e CNPH 1190 apresentaram baixa produtividade, não sendo indicados para cultivo, independente de sua finalidade.

Dado que os clones CNPH 08, CNPH 60, CNPH 46 e CNPH 69, que mostraram bom desempenho, já tinham sido caracterizados físico-químicante no Capítulo 1, nesta segunda parte do trabalho foram caracterizadas todas as cultivares, os clones CNPH 1796, CNPH 80 e CNPH 05 e o clone CNPH 1232, que apresenta polpa alaranjada. As variáveis analisadas nas raízes tuberosas foram o teor de umidade, o conteúdo de cinzas, os sólidos solúveis totais, a acidez total titulável, o ratio, o $\mathrm{pH}$, os teores de fibra bruta, proteína bruta e amido e as 
concentrações de carotenoides totais. Também foram avaliados os teores de antocianinas totais para os clones CNPH 1796, CNPH 80 e CNPH 05, que apresentam polpa arroxeada.

Com exceção da variável $\mathrm{pH}$, os genótipos de batata-doce apresentaram grande variabilidade para as características analisadas (Tabela 2.3).

Tabela 2.3 Caracterização físico-química de nove cultivares e quatro clones de batata-doce

\begin{tabular}{cccccccccc}
\hline Genótipo & $\begin{array}{c}\text { \% UM } \\
\text { (b.u.) }\end{array}$ & $\begin{array}{c}\text { \% CZ } \\
\text { (b.s.) }\end{array}$ & $\begin{array}{c}\text { SS } \\
\left({ }^{\circ} \mathbf{B r i x}\right)\end{array}$ & $\begin{array}{c}\text { \% AT } \\
\text { (b.s.) }\end{array}$ & RT & PH & $\begin{array}{c}\text { \% FB } \\
\text { (b.s.) }\end{array}$ & $\begin{array}{c}\text { \% PTN } \\
\text { (b.s.) }\end{array}$ & $\begin{array}{c}\text { \% AM } \\
\text { (b.s.) }\end{array}$ \\
\hline Beauregard & $77,97 \mathrm{a}$ & $4,50 \mathrm{~b}$ & $7,97 \mathrm{c}$ & $9,36 \mathrm{a}$ & $0,92 \mathrm{~b}$ & $6,16 \mathrm{a}$ & $4,61 \mathrm{a}$ & $8,73 \mathrm{a}$ & $36,30 \mathrm{~d}$ \\
BRS Amélia & $64,83 \mathrm{~d}$ & $4,41 \mathrm{~b}$ & $9,30 \mathrm{~b}$ & $4,88 \mathrm{c}$ & $1,94 \mathrm{a}$ & $6,40 \mathrm{a}$ & $3,04 \mathrm{~b}$ & $6,58 \mathrm{~b}$ & $49,72 \mathrm{~b}$ \\
CNPH 1232 & $70,66 \mathrm{~b}$ & $4,06 \mathrm{~b}$ & $6,30 \mathrm{~d}$ & $5,06 \mathrm{c}$ & $1,44 \mathrm{~b}$ & $6,35 \mathrm{a}$ & $4,30 \mathrm{a}$ & $4,31 \mathrm{~b}$ & $40,51 \mathrm{c}$ \\
Brazlândia Rosada & $70,87 \mathrm{~b}$ & $5,55 \mathrm{a}$ & $8,93 \mathrm{~b}$ & $6,89 \mathrm{~b}$ & $1,37 \mathrm{~b}$ & $6,42 \mathrm{a}$ & $3,45 \mathrm{~b}$ & $6,45 \mathrm{~b}$ & $42,14 \mathrm{c}$ \\
Brazlândia Roxa & $61,02 \mathrm{~d}$ & $3,41 \mathrm{~b}$ & $10,83 \mathrm{a}$ & $7,16 \mathrm{~b}$ & $1,55 \mathrm{~b}$ & $6,10 \mathrm{a}$ & $3,06 \mathrm{~b}$ & $5,36 \mathrm{~b}$ & $55,90 \mathrm{a}$ \\
BRS Rubissol & $63,66 \mathrm{~d}$ & $3,62 \mathrm{~b}$ & $10,60 \mathrm{a}$ & $6,10 \mathrm{c}$ & $1,74 \mathrm{a}$ & $6,28 \mathrm{a}$ & $3,13 \mathrm{~b}$ & $8,58 \mathrm{a}$ & $47,12 \mathrm{~b}$ \\
\hline CNPH 80 & $67,94 \mathrm{c}$ & $4,40 \mathrm{~b}$ & $7,53 \mathrm{c}$ & $7,78 \mathrm{~b}$ & $0,99 \mathrm{~b}$ & $6,06 \mathrm{a}$ & $3,43 \mathrm{~b}$ & $6,29 \mathrm{~b}$ & $34,53 \mathrm{~d}$ \\
CNPH 05 & $68,08 \mathrm{c}$ & $5,20 \mathrm{a}$ & $8,23 \mathrm{c}$ & $9,74 \mathrm{a}$ & $0,86 \mathrm{~b}$ & $6,09 \mathrm{a}$ & $3,94 \mathrm{a}$ & $7,34 \mathrm{a}$ & $33,37 \mathrm{~d}$ \\
Princesa & $66,71 \mathrm{c}$ & $4,27 \mathrm{~b}$ & $8,43 \mathrm{c}$ & $5,65 \mathrm{c}$ & $1,57 \mathrm{~b}$ & $6,27 \mathrm{a}$ & $3,09 \mathrm{~b}$ & $3,92 \mathrm{~b}$ & $48,49 \mathrm{~b}$ \\
Brazlândia Branca & $71,00 \mathrm{~b}$ & $6,86 \mathrm{a}$ & $8,10 \mathrm{c}$ & $7,25 \mathrm{~b}$ & $1,18 \mathrm{~b}$ & $6,16 \mathrm{a}$ & $3,61 \mathrm{~b}$ & $6,19 \mathrm{~b}$ & $41,02 \mathrm{c}$ \\
\hline BRS Cuia & $61,49 \mathrm{~d}$ & $3,19 \mathrm{~b}$ & $10,07 \mathrm{a}$ & $4,02 \mathrm{c}$ & $2,69 \mathrm{a}$ & $6,40 \mathrm{a}$ & $2,50 \mathrm{~b}$ & $5,01 \mathrm{~b}$ & $42,82 \mathrm{c}$ \\
\hline CNPH 1796 & $65,04 \mathrm{~d}$ & $4,37 \mathrm{~b}$ & $9,17 \mathrm{~b}$ & $7,32 \mathrm{~b}$ & $1,29 \mathrm{~b}$ & $6,29 \mathrm{a}$ & $3,53 \mathrm{~b}$ & $8,79 \mathrm{a}$ & $41,89 \mathrm{c}$ \\
\hline Coquinho & $64,24 \mathrm{~d}$ & $3,50 \mathrm{~b}$ & $9,93 \mathrm{a}$ & $5,13 \mathrm{c}$ & $2,15 \mathrm{a}$ & $6,38 \mathrm{a}$ & $3,28 \mathrm{~b}$ & $6,89 \mathrm{~b}$ & $53,99 \mathrm{a}$ \\
\hline QM $_{\text {(tratamento) }}$ & $64,95 * *$ & $0,13 *$ & $5,02^{* *}$ & $8,88^{* *}$ & $0,07 * *$ & $0,00^{\mathrm{ns}}$ & $0,96^{* *}$ & $7,62^{* *}$ & $148,71^{* *}$ \\
\hline Média & 67,19 & 4,41 & 8,88 & 6,64 & 1,52 & 6,26 & 3,46 & 6,5 & 43,68 \\
\hline C.V. (\%) & 3,19 & 9,13 & 8,77 & 17,60 & 7,26 & 1,18 & 11,55 & 21,85 & 6,66 \\
\hline
\end{tabular}

Médias com a mesma letra na coluna não diferem entre si, pelo teste de Scott-Knott a 5\% de probabilidade; QM: quadrado médio dos tratamentos; $* *$ e * Significativo a 1 e $5 \%$ de probabilidade pelo teste $\mathrm{F}$, respectivamente; C.V.: coeficiente de variação. UM: umidade; CZ: cinzas; SS: sólidos solúveis totais; AT: acidez total titulável; RT: ratio; PH: pH; FB: fibra bruta; PTN: proteína bruta e AM: amido, das raízes de batata-doce.

Os teores de umidade nas raízes variaram de 61,02 a 77,97\%. Os menores teores de umidade foram verificados nas cultivares Brazlândia Roxa, BRS Cuia, BRS Rubissol, Coquinho, BRS Amélia e o clone CNPH 1796 (61,02; 61,49; 63,66; 64,24; 64,83 e 65,04\%, respetivamente). Já o maior teor de umidade foi constatado na cultivar Beauregard (77,97\%), que apresenta cor laranja intenso. Estes resultados são coerentes com os reportados por Zaccari et al. (2007), que avaliando sete variedades de batata-doce, com cores de polpa branca, amarela e alaranjada, produzidas em Uruguai, reportaram teores de umidade na faixa de 60,51 (cv. Morada Blanco) a 78,80\% (cv. Beauregard). Maiores teores de umidade em variedades alaranjadas também foram observados por Grace et al. (2014), que avaliando quatro genótipos de batata-doce, reportaram valores oscilando entre 66,3 e 80,31\%, para os materiais NCPUR06-020 (polpa roxa) e Covington (polpa alaranjada), respectivamente. Shekhar et al. (2015) observaram teores de umidade de 68,93 e 71,42\%, para uma variedade 
de polpa branca e uma de polpa alaranjada, respectivamente. Contudo, estes autores não observaram diferenças estatisticamente significativas entre as variedades.

Resultados contrastantes foram verificados por Liu et al. (2009), que observaram em raízes de batata-doce de polpa alaranjada menores conteúdos de umidade, em relação aos de polpa amarela, com teores de 68,12 (Tainung 66) e 69,43\% (Tainung 57), respectivamente. Rose e Vasanthakaalam (2011) comparando o conteúdo de umidade de quatro variedades, de polpa branca e amarela, cultivadas em Ruanda, reportaram teores na faixa de 62,58 (var. Rutambira4-160) a 64,34\% (var. Mugande). De acordo com este último autor, os diversos teores de umidade entre as variedades podem ser atribuídos à diferença na sua composição genética e às condições agroclimáticas. Ainda, altos teores de umidade são um indicador de baixos teores de matéria seca e de menor qualidade durante o armazenamento das raízes (SHEKHAR et al., 2015). Menores índices de umidade são interessantes para a indústria, pois altos teores de matéria seca proporcionam maiores rendimentos durante a extração de amido (FIGUEIREDO, 2010; SILVEIRA, 2008). Os teores mais baixos de umidade também são desejáveis para as batatas-doces de mesa, uma vez que a preferência do consumidor brasileiro é por raízes que apresentem polpa seca após o cozimento (GONÇALVES NETO, 2011).

Os genótipos avaliados apresentaram teores de cinzas médios na faixa de 3,19 a 6,86\% (Tabela 2.3). O clone CNPH 05 e as cultivares Brazlândia Rosada e Brazlândia Branca apresentaram as maiores médias (5,20; 5,55 e 6,86\%, respectivamente). Estes resultados são superiores aos obtidos por Wosiacki et al. (1988), que encontraram teores de cinzas mínimo de 1,68 e máximo de 3,7\% b.s., para as variedades Santa Sofia e Dohumey, respectivamente e aos verificados por Azevedo et al. (2014), que na avaliação de oito genótipos de batata-doce em dois ambientes de cultivo, reportaram teores de cinzas oscilando entre 2,28 (clone BD-15) e 3,28\% b.s. (clone BD-38), no campus JK e entre 2,71 (clone BD-15) e 3,99\% b.s. (clone BD-31TO), na Fazenda Forquilha - MG. No entanto, Xu et al. (2014), caracterizando a variedade de batata-doce $\mathrm{P} 40$, de polpa roxa, verificaram um teor de cinzas de 4,3\% b.s., que foi condizente com os teores obtidos nesta pesquisa para os clones CNPH 1796, CNPH 80 e CNPH 05, de polpa arroxeada (4,37; 4,40 e 5,20, respectivamente).

As cultivares Coquinho, BRS Cuia, BRS Rubissol e Brazlândia Roxa, com 9,93; 10,07; 10,60 e 10,83 ${ }^{\circ}$ Brix, respectivamente, destacaram-se quanto aos maiores teores de sólidos solúveis totais, não apresentando diferenças estatisticamente significativas entre elas (Tabela 2.3). Já o menor teor de sólidos solúveis foi constatado no clone CNPH 1232 (6,30 ${ }^{\circ}$ Brix). 
Estes resultados são coerentes com os reportados por Zaccari et al. (2007), que encontraram teores de sólidos solúveis totais oscilando entre 6,20 (Morada Blanco) e 12,80 ${ }^{\circ}$ Brix (Clon 19 CRS). Silveira et al. (2011) observaram teores de sólidos solúveis totais na faixa de 9 (clones BD\#19, BD\#04 e BD\#14) a 17,33 ${ }^{\circ}$ Brix (clone BD\#25), na estação seca e de 6 (clones BD\#02 e LA\#23) a $12^{\circ}$ Brix (clone BD\#09), na estação chuvosa. Miranda et al. (1988) reportaram para 18 cultivares de batata-doce de polpa alaranjada teores de sólidos solúveis totais mínimos de 8,20 (cv. 10) e máximos de $12{ }^{\circ}$ Brix (cv. 9). Menezes et al. (1976) estudando o teor de açúcares totais em seis variedades de batata-doce, em diferentes épocas de colheita (4, 6 e 8 meses), observaram que maiores percentagens de açúcares nas raízes $(5,77 \%)$ foram obtidas com colheita realizada aos 6 meses. De acordo com estes autores houve influência das épocas de colheita e das variedades sobre os teores de açúcares, sendo que do sexto para o oitavo mês, o teor de açúcar decresceu numa proporção que vario de 0,35 a 1,43\% entre as variedades avaliadas. Segundo Chitarra e Chitarra (2005), o teor de sólidos solúveis totais é utilizado como uma medida indireta do teor de açúcares, indicando o grau de maturidade, podendo variar de $2 \%$ a $25 \%$ a depender da espécie, dos estádios de maturação e do clima.

De acordo com a Tabela 2.3, o pH das raízes tuberosas oscilou entre 6,06, para o clone CNPH 80 e 6,42, para a cultivar Brazlândia Rosada, com pH médio de 6,26. Contudo, não foram observadas diferenças significativas entre os materiais analisados. Já a acidez total titulável, com teor médio de 6,64\%, variou entre 4,02 (cv. BRS Cuia) e 9,74\% (clone CNPH 05), sendo os menores valores apresentados pelos genótipos BRS Cuia, BRS Amélia, CNPH 1232, Coquinho, Princesa e BRS Rubissol (4,02; 4,88; 5,06; 5,13; 5,65 e 6,10\%, respectivamente). Resultados semelhantes foram observados por Leonel e Cereda (2002), que encontraram teores médios de $\mathrm{pH}$ de 6,29 e de acidez de 7,93\%. Roesler et al. (2008) observaram teores médios de $\mathrm{pH}$ de 6,12, 115 dias após o plantio e de 6,50,183 dias após o plantio. Estes autores também reportaram teores médios de acidez de 2,11\% b.s., com colheita aos 115 dias e de $0,73 \%$ b.s., com colheita aos 183 dias. Ou seja, enquanto o pH incrementa com o aumento do tempo de colheita, o teor de acidez das raízes diminui. Estas variáveis também são dependentes do material genético e do estádio de desenvolvimento das diferentes raízes tuberosas, sendo que os genótipos mais precoces apresentam maiores teores de $\mathrm{pH}$ e consequentemente menores conteúdos de acidez total titulável. 
A maior relação entre as variáveis sólidos solúveis totais e acidez (ratio) foi apresentada pelas cultivares BRS Rubissol, BRS Amélia, Coquinho e BRS Cuia (1,74; 1,94; 2,15 e 2,69, respectivamente) (Tabela 2.3). De acordo com Chitarra e Chitarra (1990) a relação SST/ATT nos vegetais pode ser considerada como um critério de avaliação do "flavor" e um aumento pode significar incremento de sabor, além de ser indicativo de estádios mais avançados de maturação da matéria prima (INSTITUTO ADOLFO LUTZ, 1985). Por tanto, é provável que os materiais citados anteriormente sejam mais precoces, devido aos altos teores de sólidos solúveis totais e menores conteúdos de acidez apresentados na ocasião da colheita.

Verificou-se diferença estatisticamente significativa $(p<0,05)$ entre os genótipos pesquisados com relação ao teor de fibra bruta (Tabela 2.3), que variou entre 2,50 (cv. BRS Cuia) e 4,61\% (cv. Beauregard), sendo os maiores teores apresentados pelos clones CNPH 05, CNPH 1232 e a cultivar Beauregard (3,94; 4,30 e 4,61\% b.s., respectivamente). Estes resultados são proporcionais, porém superiores aos obtidos por Ravindran et al. (1995), que avaliando dezesseis cultivares de batata-doce, quatro meses após o plantio, reportaram teores de fibra na faixa de 1,89 (cv. L5) a 3,48\% (cv. Wariyapola). Wosiacki et al. (1988) em sua avaliação de raízes de 12 variedades de batata-doce na área experimental da Universidade Estadual de Londrina, obtiveram teores de fibra mínimo de 1,37, para a variedade Dohumey e máximo de 2,33\%, para a variedade Peçonha Rosa. Já Shekhar et al. (2015) não observaram diferenças estatisticamente significativas entre uma variedade de polpa alaranjada e uma de polpa branca, que apresentaram teores de fibra de 2,35 e 2,31\%, respectivamente.

De acordo com Franco et al. (2001) sob o ponto de vista tecnológico, as características das cultivares de batata-doce são melhores, quanto menores seus teores de fibras, já que estas retém fécula e dificultam a moagem, podendo interferir durante seu processo de extração, e consequentemente alterar o rendimento final. Roesler et al. (2008) trabalhando com quatro materiais de batata-doce, também constataram que o genótipo CNPH 003, que apresentou um dos menores teores de fibras $(2,4 \%$ b.s.) foi o que proporcionou maiores rendimentos de fécula em duas épocas de colheita $(75,90$ e 74,23\% b.s., 115 e 183 dias após o plantio, respectivamente).

O teor de proteína variou entre 3,92 (cv. Princesa) e 8,79\% (clone CNPH 1796), destacando-se os genótipos CNPH 05, BRS Rubissol, Beauregard e CNPH 1796 (7,34; 8,58; 8,73 e $8,79 \%$ b.s., respectivamente) (Tabela 2.3 ). Estes teores são substancialmente maiores do que os reportados por Almeida-Muradian (1991), que obtiveram conteúdos de proteína na 
faixa de 1,30 (clone CNPH e cv. Morada Inta) a 2,47\% (cv. Centennial). Shekhar et al. (2015) observaram que uma variedade de batata-doce de polpa alaranjada $(4,85 \%)$ apresentou conteúdo de proteína consideravelmente maior em comparação com um material de polpa branca $(2,93 \%)$, sugerindo que tal variedade poderia conter mais substâncias nitrogenadas. No presente estudo foram avaliados 3 genótipos com polpa alaranjada (Beauregard, BRS Amélia e CNPH 1232), contudo, apenas a cultivar Beauregard destacou-se com relação a esta característica, proporcionando um teor de proteína $(8,73 \%)$ estatisticamente equivalente ao do clone CNHP 1796 (8,79\%), com polpa arroxeada, que apresentou o maior valor.

É importante destacar que o teor de proteína bruta de batata-doce $\left(\mathrm{N}_{2}\right.$ Kjeldahl $\left.* 6,25\right)$ inclui todos os compostos nitrogenados presentes na amostra. Na colheita, a batata-doce apresenta de 15 a 35\% de nitrogênio não-protéico (WALTER et al., 1984). O nitrogênio nãoprotéico é definido como o nitrogênio contido em compostos solúveis em ácido tricloroacético a $12 \%$. Essa classificação inclui pequenos peptídeos que não precipitam, aminoácidos livres, amidas e outros compostos nitrogenados não poliméricos. Os principais constitutivos do nitrogênio de origem não-protéica, da cultivar "Jewel", após 107 dias de armazenamento, foram a asparagina (61,48\%), o ácido aspártico (10,79\%), o ácido glutâmico $(3,93 \%)$, a serina $(4,36 \%)$ e a treonina (2,97\%) (PURCELL e WALTER, 1980). Já a esporamina é a principal proteína das raízes de batata-doce (WALTER et al., 1984).

Em geral, a batata doce é considerada como uma cultura de baixo teor de proteína, variando de 1 a menos do que 10\% (SHEKHAR et al., 2015). Contudo, sua qualidade é de valor nutritivo aceitável e níveis apreciáveis do aminoácido lisina, que é deficiente no arroz, também são encontrados em raízes tuberosas de batata-doce (SENANAYAKE et al., 2013).

As variações no teor de proteína em batata-doce têm sido atribuídas à sua origem genética e às condições ambientais (WALTER et al., 1984), sendo que existe uma forte correlação entre a área folhar, a taxa fotossintética e o conteúdo de proteína das raízes de batata-doce (SHEKHAR et al., 2015).

Os maiores conteúdos de amido foram verificados nas cultivares Brazlândia Roxa $(55,90 \%)$ e Coquinho $(53,99 \%)$, que foram estatisticamente equivalentes, enquanto os teores mais baixos foram apresentados pelos clones CNPH 05, CNPH 80 e a cultivar Beauregard (33,37; 34,53 e 36,30\%, respectivamente) (Tabela 2.3). Estes resultados são condizentes com os encontrados por Senanayake et al. (2013), que avaliando os atributos nutricionais de farinhas obtidas a partir de cinco cultivares de batata-doce, observaram teores de amido 
variando de 33,7 (cv. Swp1) a 64,1\% b.s. (cv. Swp7). Zhang et al. (2002) avaliando 6 genótipos de batata-doce 173 dias após o plantio reportaram teores de amido variando de 46,8 (clone Chao1) a 73,6\% b.s. (clone Hi-dry). De acordo com estes autores, o amido foi o principal componente do peso seco das raízes de batata-doce, com um teor médio nos seis genótipos de 55,9\%. O teor médio de amido constatado nas raízes tuberosas $(43,68 \%)$ foi superior ao atingido por Miranda et al. (1988), de 26,54\% e inferior aos teores reportados por Ravindran et al. (1995), de 72,09\%; Azevedo et al. (2014), de 52,68\% e Silveira et al. (2011), de $26,46 \%$.

De acordo com Lebot et al. (2011) a qualidade das raízes de batata-doce está relacionada com a sua composição química, sendo que, para consumo humano, teores de amido demasiado elevados (acima de 75\%) são desfavoráveis, pois estão associados com um sabor considerado farinhento e seco. Já para a produção de álcool e extração de amido, uma variedade industrial deve ter altos teores de matéria seca e amido. Ainda segundo este autor, o teor de amido é determinado pelo efeito aditivo de poligenes.

O processo de biossíntese de amido na batata-doce começa com a produção de glicose através da fotossíntese. A glicose produzida pode ainda ser utilizada para o subsequente metabolismo da planta ou armazenada, dependendo do estado fisiológico e de desenvolvimento das plantas. Já a sacarose (glicose mais frutose), é um sinal regulador chave que determina o metabolismo e a biossíntese de amido (AHN et al., 2010).

$\mathrm{Na}$ Figura 7 encontram-se as fotografias dos genótipos de batata-doce avaliados.

Os dados obtidos pela mensuração objetiva da cor no sistema Hunter e o teor de carotenoides totais das raízes de batata-doce estão expressos na Tabela 2.4. Os valores colorimétricos " $\mathrm{L}^{*}$ ", "C*” e "H*” tanto para a película externa, quanto para a polpa das raízes tuberosas, demonstraram cores distintas para os genótipos de batata-doce, que corroboraram a aparência visual das raízes (Figura 7).

Os clones avaliados apresentaram película externa branca, creme, amarela pálida, marron alaranjada, rosa, vermelha-arroxeada, roxa-avermelhada, roxa e roxa-escura (Figura 7). Silveira (2008) verificaram em cultivares de batata-doce selecionadas para a produção de etanol no estado de Tocantins, raízes tuberosas com periderme variando entre branca, rosada e roxa. 


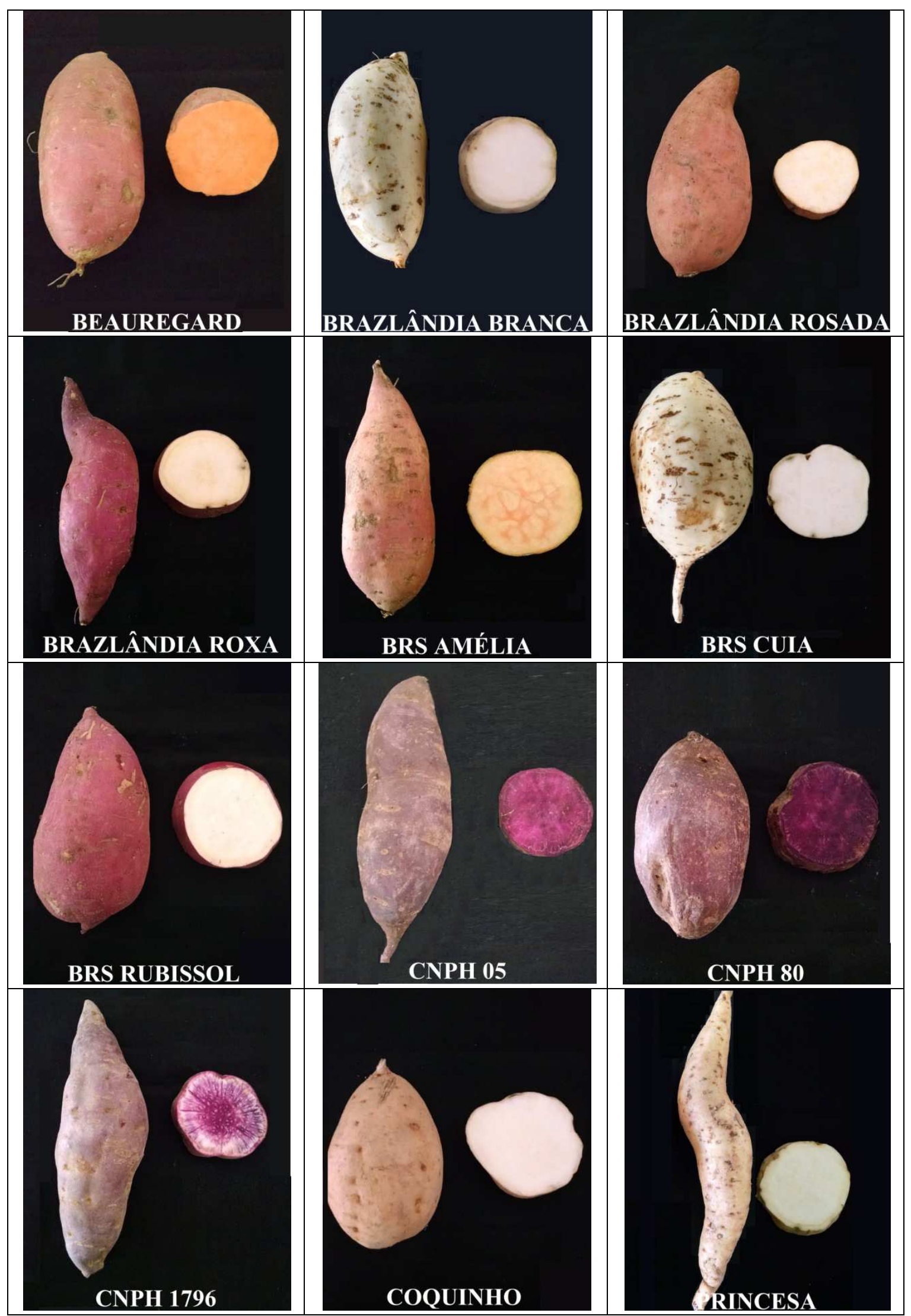

Figura 7 Película externa e polpa das raízes tuberosas dos materiais genéticos de batatadoce avaliados. 
Com relação à película externa das raízes, os valores do componente acromático $\mathrm{L}^{*}$, que define o grau de brilho das amostras, foram maiores nas cultivares Princesa, Brazlândia Branca e BRS Cuia (76,59; 77,82 e 80,29, respectivamente), ou seja, as raízes tuberosas destes genótipos apresentaram peridermes mais claras. Já os clones CNPH 80 e CNPH 05, com valores de 34,60 e 35,32, respectivamente, apresentaram películas externas com colorações mais escuras com relação aos outros materiais genéticos estudados (Tabela 2.4).

Com referência aos valores de croma calculados $\left(\mathrm{C}^{*}\right)$, os genótipos avaliados formaram cinco grupos, sendo que Coquinho, CNPH 1232 e BRS Amélia, proporcionaram os maiores valores médios $(33,67 ; 34,64$ e 34,68, respectivamente) (Tabela 2.4), indicando que estes materiais apresentaram uma coloração de córtex das raízes mais viva. Já os clones CNPH 05 e CNPH 80 (18,32 e 18,39, respectivamente), com os menores valores de saturação, mostraram uma película externa mais opaca.

Com exceção da cultivar BRS Cuia $(117,30)$, os ângulos de tom da periderme de todos os genótipos enquadraram-se no primeiro quadrante (vermelho/amarelo) do sólido de cor Hunter, variando de 13,54, no clone CNPH 1796, que foi estatisticamente equivalente com os genótipos Brazlândia Roxa, BRS Rubissol, CNPH 80, CNPH 05 e Beauregard (17,72; 18,36; 19,$49 ; 22,50$ e 36,05 , respectivamente) a 79,98, na cultivar Coquinho, juntamente com as cultivares BRS Amélia, Brazlândia Branca, Princesa (58,03; 63,60 e 66,67, respectivamente) e o clone CNPH $1232(60,14)$; indicando uma mudança na direção do vermelho para o amarelo vivo, respectivamente (Tabela 2.4).

Os genótipos proporcionaram raízes com cor de polpa branca, creme, creme escura, laranja pálida, laranja intenso, roxa-avermelhada e vermelha púrpura. As raízes com polpa branca foram mais claras, cujos valores de luminosidade $\left(\mathrm{L}^{*}\right)$ variaram de 86,34, na cultivar Brazlândia Branca até 88,43, na cultivar Princesa (Tabela 2.4); enquanto nas raízes com polpa arroxeada e alaranjada os valores de $\mathrm{L}^{*}$ oscilaram entre 28,20, no clone CNPH 05 e 78,65, na cultivar BRS Amélia. Estes resultados são condizentes com os obtidos por Shekhar et al. (2015), que verificaram valores significativamente superiores de $L^{*}$ para uma variedade de polpa branca $(82,51)$ com relação a uma de polpa alaranjada $(77,31)$.

A cultivar Beauregard proporcionou o maior croma $\left(C^{*}\right), 58,80$, que indica que este material apresentou uma polpa com cor mais saturada (alaranjada intenso) (Tabela 2.4). 
Tabela 2.4 Resumo das análises de variância e do agrupamento de médias dos teores de carotenoides totais e dos valores da determinação dos parâmetros colorimétricos da película externa e da polpa das raízes tuberosas de batata-doce

\begin{tabular}{|c|c|c|c|c|c|c|c|c|c|}
\hline Genótipo & $\mathbf{L}_{\mathbf{c}}$ & $\mathrm{C}_{\mathrm{c}}$ & $\mathbf{H}_{\mathrm{c}}$ & Coloração externa & $\mathbf{L}_{\mathbf{p}}$ & $\mathrm{C}_{\mathrm{p}}^{*}$ & $\mathbf{H} *_{\mathrm{p}}$ & Coloração interna & CTN ( $\mu \mathrm{g} \mathrm{g}^{-1}$ b.s. $)$ \\
\hline Beauregard & $50,60 \mathrm{~d}$ & $31,88 \mathrm{~b}$ & $36,05 \mathrm{c}$ & Vermelha-arroxeada & $71,63 \mathrm{c}$ & $58,80 \mathrm{a}$ & $64,34 \mathrm{e}$ & Laranja intenso & $490,53 \mathrm{a}$ \\
\hline BRS Amélia & $64,28 \mathrm{c}$ & $34,68 \mathrm{a}$ & $58,03 \mathrm{~b}$ & Marron alaranjada & $78,65 \mathrm{~b}$ & $45,76 b$ & $72,04 \mathrm{~d}$ & Laranja pálida & $166,06 \mathrm{~b}$ \\
\hline CNPH 1232 & $63,27 \mathrm{c}$ & $34,64 \mathrm{a}$ & $60,14 b$ & Marron alaranjada & $77,15 \mathrm{~b}$ & $43,38 \mathrm{~b}$ & $70,33 \mathrm{~d}$ & Laranja pálida & $130,34 \mathrm{c}$ \\
\hline Brazlândia Rosada & $58,87 \mathrm{c}$ & $30,17 \mathrm{c}$ & $63,92 \mathrm{~b}$ & Rosa & $86,70 \mathrm{a}$ & $30,11 \mathrm{~d}$ & $98,95 \mathrm{c}$ & Creme & $6,02 \mathrm{~d}$ \\
\hline Brazlândia Roxa & $40,64 \mathrm{e}$ & $29,66 \mathrm{c}$ & $17,72 \mathrm{c}$ & Roxa-avermelhada & $87,75 \mathrm{a}$ & $26,76 \mathrm{e}$ & $98,98 \mathrm{c}$ & Creme escura & $3,14 \mathrm{~d}$ \\
\hline BRS Rubissol & $46,63 \mathrm{~d}$ & $30,47 \mathrm{c}$ & $18,36 \mathrm{c}$ & Roxa-avermelhada & $87,75 \mathrm{a}$ & $25,37 \mathrm{e}$ & $97,83 \mathrm{c}$ & Branca & $2,89 \mathrm{~d}$ \\
\hline CNPH 80 & $34,60 \mathrm{f}$ & $18,39 \mathrm{e}$ & $19,49 \mathrm{c}$ & Roxa escura & $28,59 \mathrm{e}$ & $36,60 \mathrm{c}$ & $356,10 \mathrm{a}$ & Roxa-avermelhada & $2,55 \mathrm{~d}$ \\
\hline CNPH 05 & $35,32 \mathrm{f}$ & $18,32 \mathrm{e}$ & $22,50 \mathrm{c}$ & Roxa & $28,20 \mathrm{e}$ & $36,55 \mathrm{c}$ & $356,82 \mathrm{a}$ & Roxa-avermelhada & $2,22 \mathrm{~d}$ \\
\hline Princesa & $76,59 \mathrm{a}$ & $29,96 \mathrm{c}$ & $66,67 \mathrm{~b}$ & Creme & $88,43 \mathrm{a}$ & $20,80 \mathrm{f}$ & $99,17 \mathrm{c}$ & Branca & $2,09 \mathrm{~d}$ \\
\hline Brazlândia Branca & $77,82 \mathrm{a}$ & $29,31 \mathrm{c}$ & $63,60 \mathrm{~b}$ & Branca & $86,34 \mathrm{a}$ & $20,41 \mathrm{f}$ & $100,93 \mathrm{c}$ & Branca & $1,96 \mathrm{~d}$ \\
\hline BRS Cuia & $80,29 \mathrm{a}$ & $30,32 \mathrm{c}$ & $117,30 \mathrm{a}$ & Branca & $87,55 \mathrm{a}$ & $21,52 \mathrm{f}$ & $98,87 \mathrm{c}$ & Creme & $1,61 \mathrm{~d}$ \\
\hline CNPH 1796 & $46,75 \mathrm{~d}$ & $25,48 d$ & $13,54 \mathrm{c}$ & Roxa & $48,00 \mathrm{~d}$ & $30,38 \mathrm{~d}$ & $353,25 \mathrm{~b}$ & Vermelha púrpura & $1,10 \mathrm{~d}$ \\
\hline Coquinho & $71,07 \mathrm{~b}$ & $33,67 \mathrm{a}$ & $79,98 \mathrm{~b}$ & Amarela pálida & $87,51 \mathrm{a}$ & $17,67 \mathrm{f}$ & $96,97 \mathrm{c}$ & Branca & $1,04 \mathrm{~d}$ \\
\hline $\mathrm{QM}_{\text {(tratamento) }}$ & $786,01 * *$ & $84,94 * *$ & $2873,28 * *$ & - & $1528,62 * *$ & $432,80 * *$ & $41163,82^{* *}$ & - & $124,40 * *$ \\
\hline Média & 57,44 & 29 & 49,02 & - & 72,64 & 31,85 & 151,12 & - & 62,43 \\
\hline C.V. (\%) & 5,16 & 4,17 & 46,83 & - & 2,31 & 6,26 & 1,32 & - & 16,18 \\
\hline
\end{tabular}

Médias com a mesma letra na coluna não diferem entre si, pelo teste de Scott-Knott a 5\% de probabilidade; QM: quadrado médio dos tratamentos; **: Significativo a 1\% de probabilidade pelo teste F; C.V.: coeficiente de variação. $\mathrm{L}_{\mathrm{c}}^{*}, \mathrm{C}^{*}{ }_{\mathrm{c}}$ e $\mathrm{H}_{\mathrm{c}}^{*}$ : valores da determinação de cor da película externa; $\mathrm{L}_{\mathrm{p}}^{*}$, $\mathrm{C}^{*}{ }_{\mathrm{p}}$ e $\mathrm{H}_{\mathrm{p}}$ : valores da determinação de cor da polpa; CTN: teores médios de carotenoides totais da polpa das raízes tuberosas. 
Resultados semelhantes foram observados por Zaccari et al. (2007), que avaliando sete genótipos de batata-doce, constataram o maior croma na polpa da cultivar Beauregard $(51,78)$.

Os ângulos de tom dos genótipos com polpa alaranjada, Beauregard, CNPH 1232 e BRS Amélia $(64,34 ; 70,33$ e 72,04, respectivamente) encontraram-se no primeiro quadrante do sólido de cor Hunter (vermelho/amarelo). Os valores menores do ângulo Hue, aliados à alta saturação destes materiais $(58,80 ; 43,38$ e 45,76, respectivamente), apontaram uma cor alaranjada, variando de pálida a intensa, que é condizente com a cor de polpa característica observada nestes genótipos (Figura 7). As cultivares Coquinho, BRS Rubissol, BRS Cuia, Brazlândia Rosada, Brazlândia Roxa, Princesa e Brazlândia Branca (96,97; 97,83; 98,87; 98,95; 98,98; 99,17 e 100,93, respectivamente), corresponderam a polpas com pigmentação variando do amarelo ao verde, como indicado pelos valores do ângulo Hue $\left(\mathrm{H}^{*}\right)$, ubicados no segundo quadrante do sólido de cor Hunter (Tabela 2.4). Já os materiais genéticos com polpa roxa apresentaram ângulos de tom no quarto quadrante, que oscilaram entre 353,25 (clone CNPH 1796) e 356,82 (Clone CNPH 05). Almeida-Muradian (1991) avaliando os parâmetros de cor de seis variedades de batata-doce, com cores de polpa variando do branco ao alaranjado, observaram também que as variedades Centennial, Heart Gold e Vineland Bush (43,1; 52,0 e 58,8, respectivamente), com polpa alaranjada, apresentaram ângulos de tom no primeiro quadrante (vermelho/amarelo); enquanto nas variedades Monalisa, IAC-2-71 e SRT252, com polpa branca, os ângulos se enquadraram no segundo quadrante $(92,5 ; 98,8$ e 99,6, respectivamente), que varia do amarelo ao verde.

Estudos anteriores têm sugerido que a maior saturação e os diferentes ângulos Hue são causados por um aumento do $\mathrm{pH}$, que é conhecido por gerar as cores roxa e azul mais escuras (SUDA et al., 2003). No entanto, as medições de pH para todas as amostras foram em torno de 6,0 (Tabela 2.3), sugerindo que o pH exerce um efeito insignificante sobre a cor da polpa das raízes tuberosas. Estes resultados são condizentes com os previamente reportados por Yoshinaga et al. (1999).

De acordo com a Tabela 2.4, foi observada uma variação estatisticamente significativa no teor de carotenoides totais entre os genótipos avaliados. Esta variação pode ser apreciada pela ampla faixa de cores da polpa dos diferentes materiais (Figura 7). Os genótipos Beauregard, BRS Amélia e CNPH 1232, de polpa alaranjada, apresentaram maiores concentrações de carotenoides totais $\left(490,53 ; 166,06\right.$; e $130,34 \mu \mathrm{g} \mathrm{g}^{-1}$, respectivamente) do que aqueles com polpa branca, creme escura, roxa-avermelhada e vermelha púrpura. As cultivares Coquinho, 
BRS Cuia e Brazlândia Branca (1,04; 1,61 e 1,96 $\mu \mathrm{g} \mathrm{g}^{-1}$, respectivamente), de polpa branca, mostraram os menores teores de carotenoides, juntamente com o clone CNPH $1796(1,10 \mu \mathrm{g}$ $\mathrm{g}^{-1}$ ), de polpa arroxeada. Porém foram estatisticamente equivalentes com os materiais Princesa, CNPH 05, CNPH 80, BRS Rubissol, Brazlândia Roxa e Brazlândia Rosada, com valores na faixa de 2,09 a $6,02 \mu \mathrm{g} \mathrm{g}^{-1}$.

Estes valores são proporcionais, porém superiores, aos reportados por Almeida e Penteado (1988), que verificaram um teor de carotenoides totais de $0,86 \mu \mathrm{g} \mathrm{g}^{-1}$, para variedades de batata-doce de polpa branca adquiridas na CEAGESP-SP e aos encontrados por Tomlins et al. (2012), que estudando onze variedades com cor de polpa variando do branco ao alaranjado, observaram teores de carotenoides na faixa de 1,2 (var. Ndikirya N'omwami) a $216 \mu \mathrm{g} \mathrm{g}^{-1}$ b.s. (var. Ejumula), respectivamente. Shekhar et al. (2015) atingiram teores de carotenoides totais de $6 \mu \mathrm{g} \mathrm{g}^{-1}$, para uma variedade de polpa branca e de $45 \mu \mathrm{g} \mathrm{g}^{-1}$, para uma variedade de polpa alaranjada.

Ameny e Wilson (1997) avaliando quatro cultivares de batata-doce de origem africana, com cor de polpa variando do branco ao amarelo, em Baton Rouge, EUA, reportaram teores de carotenoides totais variando de 0,06 (cv. T3002) a 2,49 $\mu \mathrm{g} \mathrm{g}^{-1}$ b.u. (cv. T1702). Grace et al. (2014) estudando quatro genótipos de batata-doce, obtiveram teores de carotenoides totais oscilando entre 2 e 281,9 $\mu \mathrm{g} \mathrm{g}^{-1}$ b.s., para os materiais NCPUR06-020 (polpa roxa) e Covington (polpa alranjada), respectivamente. Bechoff et al. (2010b) analisando seis cultivares de batata-doce provenientes de duas localidades de Uganda, atingiram teores de carotenoides totais variando de 78,5 (cv. SPK004/1/1) a 300,5 $\mathrm{g} \mathrm{g} \mathrm{g}^{-1}$ b.s. (cv. Ejumula), para as cultivares coletadas em Namulonge, e de 41,7 (cv. SPK004/1/1) a 223,1 $\mu \mathrm{g} \mathrm{g}^{-1}$ b.s. (cv. Ejumula), para as cultivares coletadas no Distrito de Luwero.

Segundo Champagne et al. (2010) e Huang et al. (1999) diferenças no conteúdo de carotenoides totais podem ser explicadas pelos diferentes genótipos e fatores ambientais, como a temperatura e o fotoperíodo, bem como pelos procedimentos de extração utilizados pelos diversos autores.

Almeida-Muradian (1991) observaram que os principais carotenoides encontrados em 10 variedades de batata-doce foram: 5,6,5',6'-diepóxi- $\beta$-caroteno, 5,6-monoepóxi- $\beta$-caroteno, $\beta$ caroteno, luteocromo, $\alpha$-zeacaroteno, $\beta$-zeacaroteno e aurocromo. De acordo com os autores, dentre estes carotenoides, os únicos que possuem atividade pró-vitamínica A são o 5,6- 
monoepóxi- $\beta$-caroteno, com $21 \%$ de atividade, o $\beta$-caroteno, com $100 \%$ e o $\beta$-zeacaroteno, com $25 \%$ de atividade.

A determinação de carotenoides totais tem sido relatada como sendo uma técnica aceitável para se obter uma estimativa aproximada do conteúdo de $\beta$-caroteno em variedades de batata-doce de polpa alaranjada, uma vez que $90 \%$ de seus carotenoides totais são $\beta$ caroteno (BECHOFF et al., 2010; BENGTSSON et al., 2008; GRACE et al., 2014; K'OSAMBO et al., 1999). Com base nestas informações e fazendo-se uma estimativa para os genótipos de polpa alaranjada avaliados, as cultivares Beauregard e BRS Amélia e o clone CNPH 1232, apresentariam concentrações de $\beta$-caroteno em torno de 441,48; 149,45 e 117,31 $\mu \mathrm{g} \mathrm{g}^{-1}$ b.s., respectivamente.

K'osambo et al. (1999) observaram que o teor de $\beta$-caroteno de dezessete cultivares, com cor de polpa variando do branco ao alaranjado, oscilou entre 1 (cvs. Naveto, LM88.002 e TIS2534) e $88 \mu \mathrm{g} \mathrm{g}^{-1}$ b.u. (cv. TIB11), com colheita aos 6 meses. Kidmose et al. (2007) avaliando o conteúdo de $\beta$-caroteno de seis variedades de batata-doce no Quênia, 5 meses após o plantio, encontraram teores na faixa de 12,4 a $108 \mu \mathrm{g} \mathrm{g}^{-1}$ b.u., para as variedades Nyathi Odiewo (amarela clara) e Tainung (alaranjada escura), respectivamente. Bengtsson et al. (2008) verificaram em sete variedades de polpa alaranjada, na Uganda, concentrações de $\beta$-caroteno variando de 108,1 a $314,5 \mu \mathrm{g} \mathrm{g}^{-1}$ b.s. para as variedades SPK004/1 e SPK004/6, respectivamente, 4,5 meses após o plantio. Huang et al. (1999) analisando o teor de $\beta$ caroteno de 18 variedades comercias de batata-doce cultivadas em Havaí, verificaram conteúdos na faixa de 67 a $131 \mu \mathrm{g} \mathrm{g}^{-1}$ b.u., em sete variedades de polpa alaranjada; de <1 a 6 $\mu \mathrm{g} \mathrm{g}^{-1}$ b.u., em sete variedades com polpa amarela e branca e de $<1$ a $5 \mu \mathrm{g} \mathrm{g}^{-1}$ b.u., em quatro variedades de polpa roxa. Wu et al. (2008), 22 semanas após o plantio, na China, observaram teores de $\beta$-caroteno, variando de 6,2 a $231,1 \mu \mathrm{g} \mathrm{g}^{-1}$ b.u., para variedades alaranjadas; de 12,3 a $128,9 \mu \mathrm{g} \mathrm{g}^{-1}$ b.u., para variedades amareladas; de 5,2 a 7,8 $\mu \mathrm{g} \mathrm{g}^{-1}$ b.u., para variedades brancas e de $0,60 \mu \mathrm{g} \mathrm{g}^{-1}$ b.u., para uma variedade de polpa roxa.

De acordo com K'Osambo et al. (1999); Liu et al. (2009); Tomlins et al. (2012) e Wu et al. (2008), fatores como a variedade, condições ambientais (clima, tipo de solo, práticas agrícolas), parte da raiz tuberosa analisada, tamanho da raiz, local de plantio, estágio de maturação, época de colheita, duração do dia, estação do ano, manejo pós-colheita, processamento e armazenamento das raízes de batata-doce, podem ter uma grande influência sobre o conteúdo de $\beta$-caroteno das raízes tuberosas. 
A Tabela 2.5 apresenta a matriz de correlação de Pearson entre os parâmetros de cor e os teores de umidade, amido e carotenoides totais da polpa das raízes tuberosas.

Tabela 2.5 Matriz de correlação de Pearson entre as variáveis colorimétricas da polpa e da película externa, os teores de umidade e as concentrações de carotenoides totais de raízes de batata-doce

\begin{tabular}{|c|c|c|c|c|c|c|c|}
\hline & $C^{*}{ }_{c}$ & $\mathbf{H}^{*}{ }_{\mathrm{c}}$ & $\mathbf{L}^{*}{ }_{\mathrm{p}}$ & $C^{*}{ }_{p}$ & $\mathbf{H}_{\mathrm{p}}^{*}$ & UM & CTN \\
\hline $\mathbf{L}_{\mathrm{c}}$ & $0,640^{*}$ & $0,890^{* * *}$ & $0,697 * *$ & $-0,403^{\mathrm{ns}}$ & $-0,632 *$ & $-0,042^{\mathrm{ns}}$ & $-0,018^{\mathrm{ns}}$ \\
\hline $\mathrm{C}_{\mathrm{c}}^{*}$ & & $0,509^{\mathrm{ns}}$ & $0,862 * *$ & $0,023^{\mathrm{ns}}$ & $-0,909 * *$ & $0,006^{\mathrm{ns}}$ & $0,426^{\mathrm{ns}}$ \\
\hline $\mathbf{H}^{*}$ & & & $0,561^{*}$ & $-0,332^{\mathrm{ns}}$ & $-0,542^{\mathrm{ns}}$ & $-0,098^{\mathrm{ns}}$ & $-0,031^{\mathrm{ns}}$ \\
\hline $\mathbf{L}^{*}$ & & & & $-0,359^{\mathrm{ns}}$ & $-0,924 * *$ & $-0,165^{\mathrm{ns}}$ & $0,059^{\mathrm{ns}}$ \\
\hline$C^{*}{ }_{p}$ & & & & & $0,025^{\mathrm{ns}}$ & $0,624 *$ & $0,881 * *$ \\
\hline $\mathbf{H}^{*}{ }_{p}$ & & & & & & $-0,079^{\mathrm{ns}}$ & $-0,386^{\mathrm{ns}}$ \\
\hline UM & & & & & & & $0,639 *$ \\
\hline
\end{tabular}

** e *: Significativo a 1 e $5 \%$ de probabilidade pelo teste $\mathrm{t}$; ns: não significativo. $\mathrm{L}_{\mathrm{c}}{ }_{\mathrm{c}}, \mathrm{C}_{\mathrm{c}} \mathrm{e} \mathrm{e}^{*}{ }_{\mathrm{c}}$ : valores da determinação de cor da película externa; $\mathrm{L}^{*}, \mathrm{C}_{\mathrm{p}}{ }_{\mathrm{p}}$ e $\mathrm{H}^{*}$ p : valores da determinação de cor da polpa; UM: teor de umidade (\% b.u.) e CTN: concentrações de carotenoides totais ( $\mu \mathrm{g} \mathrm{g}^{-1}$ b.s.) na polpa das raízes de batata-doce.

Verificou-se uma correlação muito forte e negativa $(p<0,01)$ entre o ângulo de tom Hue $\mathrm{H}^{*}$ da polpa das raízes e o croma da periderme $(-0,909)$ e o ângulo de tom Hue $\mathrm{H}^{*}$ e a luminosidade da polpa das raízes tuberosas $(-0,924)$; ou seja, quanto menores a saturação da cor da periderme e a luminosidade da polpa das raízes tuberosas, mais aumentaram os ângulos de tom no sólido de cor Hunter. Já a correlação foi forte e positiva entre a luminosidade $\mathrm{L}^{*}$ e o ângulo de tom Hue $\mathrm{H}^{*}$ da periderme das raízes $(0,890)$ e entre a luminosidade da polpa e o croma da periderme das raízes tuberosas $(0,862)$. Raízes de batata-doce com polpas mais claras também foram obtidas com o incremento da luminosidade e do ângulo Hue da película externa das raízes $(0,697$ e 0,561 , respectivamente); enquanto raízes tuberosas com peridermes mais claras foram atingidas com o aumento da saturação da cor da película externa das raízes $(0,640)$.

O teor de umidade apresentou correlação média e positiva com o valor de croma $C^{*}$ da polpa das raízes $(0,624)$, indicando que polpas com cores mais saturadas apresentaram maiores teores de umidade nas raízes tuberosas (Tabela 2.5).

Estes resultados são condizentes com os constatados por Kidmose et al. (2007), que analisando seis variedades de batata-doce, observaram maiores teores de umidade nas variedades de polpa alaranjada Tainung e Zapallo, com conteúdos de 73,5 e 71,6\%, respectivamente. Maiores teores de umidade em variedades alaranjadas também foram reportados por Grace et al. (2014) e Zaccari et al. (2007). 
A concentração de carotenoides totais correlacionou-se de forma significativa e positiva com o teor de umidade das raízes $(0,639)$, sugerindo que quanto maior o teor de umidade das raízes, maior o conteúdo de carotenoides nas raízes tuberosas (Tabela 2.5). Resultados semelhantes foram constatados por Tomlins et al. (2012), que observaram em variedades de batata-doce uma correlação significativa e negativa $\left(R^{2}=-0,74\right)$ entre o conteúdo de matéria seca e o logaritmo do teor de carotenoides totais.

Os carotenoides totais também correlacionaram-se forte e positivamente com o valor de croma $C^{*}(0,881)$ da polpa das raízes (Tabela 2.5$)$. Na Figura 8 pode ser melhor visualizada esta correlação.

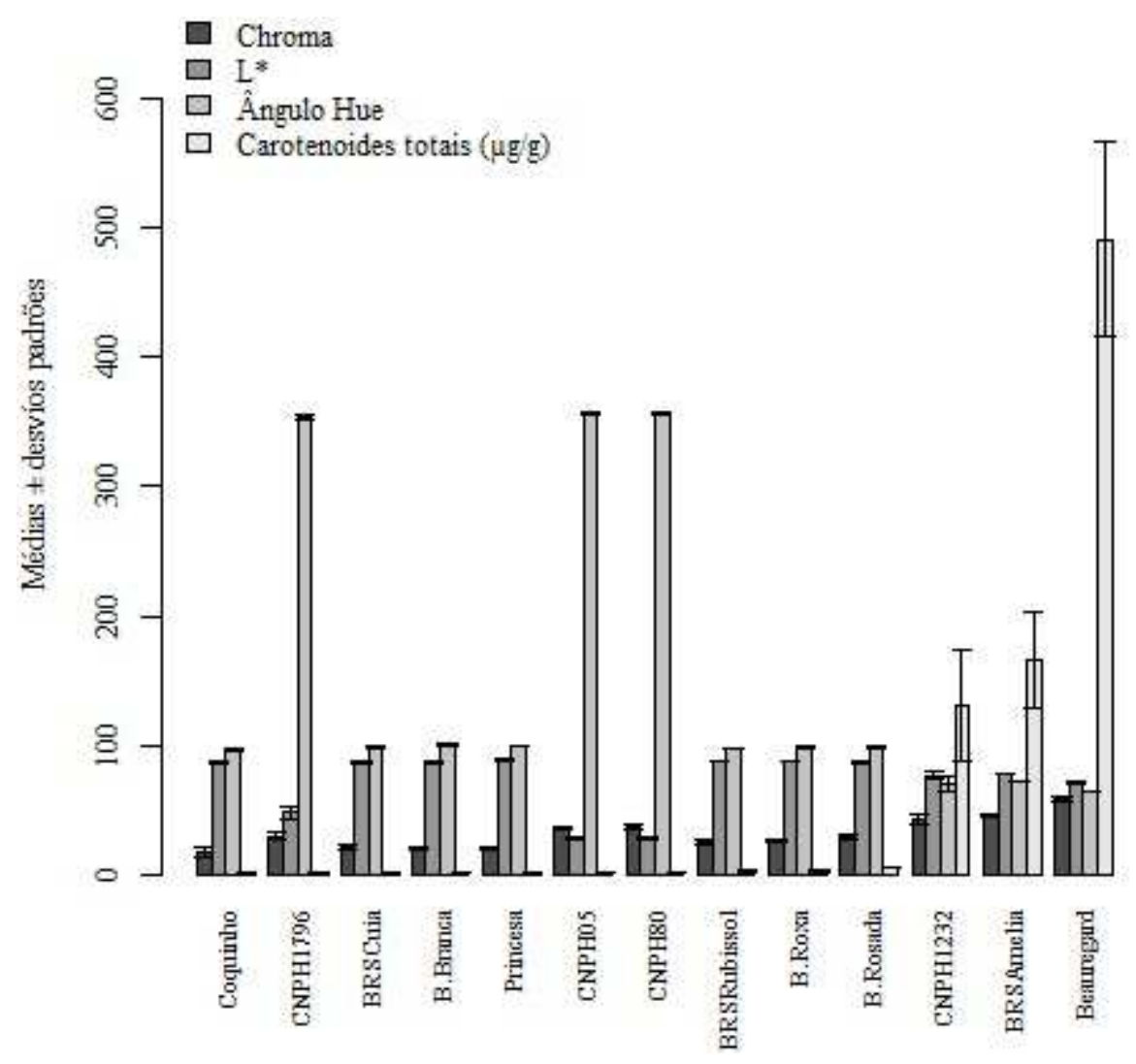

Figura 8 Teor de carotenoides totais e valores das leituras colorimétricas da polpa de treze genótipos de batata-doce.

De acordo com a Figura 8, raízes tuberosas com maiores concentrações de carotenoides apresentaram maiores valores para a saturação (croma) da cor da polpa das raízes. Dessa forma, a utilização da análise colorimétrica, mais rápida e sem resíduos químicos, pode servir como ferramenta para a escolha de genótipos de batata-doce, cujo objetivo seja a seleção de materiais com mais altos teores desse constituinte. 
Estes resultados estão em conformidade com o observado por Almeida-Muradian (1991), que verificou coeficientes de correlação positivos entre o teor de carotenoides totais e os atributos de cor do sistema Hunter $a^{*}, b^{*}$ e croma $C^{*}$ da polpa das raízes $(0,876,0,570$ e 0,950, respectivamente), sendo que os teores mais elevados de carotenoides foram determinados nas amostras com o componente vermelho da cor ( $\mathrm{a}^{*}$ positivo).

Em farinhas de batata-doce de polpa alaranjada, o valor de $a^{*}$ tem sido reportado como a melhor medida de correlação entre a variável cor e o conteúdo de $\beta$-caroteno, como mostrado por um coeficiente de correlação de 0,96 (BENGTSSON et al., 2008). Takahata et al. (1993) também relataram um coeficiente de correlação de 0,90 entre o conteúdo de $\beta$-caroteno e o valor de $a^{*}$ em cultivares de polpa alaranjada, contra 0,81 , que foi a associação com o valor de $b^{*}$.

Resultados contrastantes foram observados por Ameny e Wilson (1997), que verificaram em quatro cultivares de batata-doce de polpa branca uma correlação muito fraca $(0,39)$ entre a concentração de $\beta$-caroteno e o valor de $\mathrm{a}^{*}$ (componente vermelho da cor). Não obstante, estes autores relataram uma correlação significativa e positiva $(0,74)$ entre o valor de cor $b^{*}$ (componente amarelo) e a concentração de $\beta$-caroteno.

Contudo, segundo Hutchings (2002), o estudo da cor utilizando os valores isolados das coordenadas de cromaticidade é incorreto, toda vez que os parâmetros $a^{*}$ e b* não são independentes. No entanto, o ângulo de tonalidade, Hue, e o índice de saturação, croma, são apropriados para a obtenção desta descrição, visto que as duas variáveis são medidas derivadas de $a^{*}$ e $b^{*}$.

Os teores de antocianinas totais e a relação entre os parâmetros colorimétricos $b^{*}$ e a* dos materiais com polpa roxa são apresentados na Tabela 2.6.

Tabela 2.6 Teores médios de antocianinas e relação entre os parâmetros colorimétricos b* e $\mathrm{a}^{*}$ dos clones de batata-doce com polpa roxa

\begin{tabular}{ccc}
\hline Genótipo & Antocianinas totais $\left(\mathbf{m g ~ g}^{\mathbf{- 1}} \mathbf{b . s .}\right)$ & $\mathbf{b}^{* / \mathbf{a}^{*}}$ \\
\hline CNPH 1796 & $0,24 \mathrm{a}$ & $-0,08$ \\
CNPH 80 & $0,52 \mathrm{a}$ & $-0,07$ \\
CNPH 05 & $0,52 \mathrm{a}$ & $-0,06$ \\
\hline QM $_{\text {(tratamento) }}$ & $0,01^{\text {ns }}$ & - \\
\hline Média & 0,43 & - \\
\hline C.V. (\%) & 9,71 & - \\
\hline
\end{tabular}

Médias com a mesma letra na coluna não diferem entre si, pelo teste de Scott-Knott a 5\% de probabilidade; QM: quadrado médio dos tratamentos; ${ }^{\text {ns }}$ Não significativo a $1 \%$ de probabilidade pelo teste F; C.V.: coeficiente de variação. 
Foi observado que o teor de antocianinas totais variou de 0,24, para o clone CNPH 1796 a $0,52 \mathrm{mg} \mathrm{g}^{-1}$ b.s., para os clones CNPH 80 e CNPH 05. Contudo, não foram verificadas diferenças estatisticamente significativas entre estes genótipos (Tabela 2.6). A comparação do conteúdo de antocianinas quantificadas neste estudo com os teores reportados na literatura, indicou que os valores estiveram próximos dos intervalos encontrados previamente por Fu et al. (2008) e Furuta et al. (1998), de 0,132 a 0,851 $\mathrm{mg} \mathrm{g}^{-1}$ b.s. e de 0,053 a 0,536 $\mathrm{mg} \mathrm{g}^{-1}$ b.s., respectivamente. Este último autor, não detectou antocianinas em cultivares com polpa branca, creme, amarela e alaranjada. Teow et al. (2007) reportaram em seis materiais com polpa roxa e dois clones com polpa alaranjada, teores de antocianinas variando entre $0,017 \mathrm{e}$ $0,531 \mathrm{mg} \mathrm{g}^{-1}$ b.u., enquanto na cultivar Beauregard e nos materiais com polpa branca, amarela e alaranjada claro, não foram identificados estes compostos. Já Shekhar et al. (2015) encontraram teores de $0,012 \mathrm{mg} \mathrm{g}^{-1}$, para uma variedade de polpa branca e de $0,016 \mathrm{mg} \mathrm{g}^{-1}$ para uma de polpa alaranjada.

Concentrações de antocianinas superiores às observadas na presente pesquisa, foram atingidas por Cevallos-Casals e Cisneros-Zevallos (2003), Grace et al. (2014), Jiao et al. (2012), Ray et al. (2012), Steed e Truong (2008) e Xu et al. (2014), que observaram valores de $6,18 \mathrm{mg} \mathrm{g}^{-1}$ b.s.; $8,49 \mathrm{mg} \mathrm{g}^{-1}$ b.s.; $1,32 \mathrm{mg} \mathrm{g}^{-1}$ b.s.; $0,755 \mathrm{mg} \mathrm{g}^{-1}$ b.u.; $1,02 \mathrm{mg} \mathrm{g}^{-1}$ b.u. e $13,90 \mathrm{mg} \mathrm{g}^{-1}$ b.s., respectivamente.

Com relação aos tipos de antocianinas presentes em cultivares de batata-doce, Li et al., (2013) identificaram na cultivar "Jihei", de polpa roxa, treze antocianinas, sendo que a cianidina e a peonidina foram as principais agliconas nas antocianinas e a glicose e a soforose foram os glicosilantes. Adicionalmente, quase todas as antocianinas apresentaram resíduos de açúcar acilado com ácido $p$-hidroxibenzóico, ferúlico ou caféico. Xu et al. (2014) analisando a variedade "P40", de polpa roxa, encontraram doze antocianinas, onze das quais foram aciladas com ácidos caféico, ferúlico e/ou $p$-hidroxibenzóico e sete derivadas da cianidina. $66,9 \%$ das antocianinas totais, quantificadas por hidrólise ácida, foram derivadas da cianidina, cujo teor foi $9,3 \mathrm{mg} \mathrm{g}^{-1}$ b.s.. Ainda segundo estes pesquisadores, esta variedade ajudou a prevenir o câncer colorretal em modelos experimentais com camundongos.

Yoshinaga et al. (1999) classificaram 19 clones de batata-doce de polpa roxa em dois principais grupos de cores com base em sua relação $b^{*} / a^{*}$. Clones que apresentaram índices inferiores a $-1,4$, os quais proporcionaram maiores teores de cianidina do que peonidina, foram considerados roxo-azulados; enquanto os clones com proporções superiores a -1,1, que 
apresentaram maiores teores de peonidina, foram classificados como roxo-avermelhados. Com base nesta constatação, as amostras de polpa roxa avaliadas neste estudo, CNPH 1796, CNPH 80 e CNPH 05, cujos valores das relações $b^{*} / a^{*}$ foram $-0,08 ;-0,07$ e $-0,06$, respectivamente, são mais ricas em antocianinas do tipo peonidina, dado que suas proporções $\mathrm{b} * / \mathrm{a} *$ foram superiores a $-1,1$ (Tabela 2.6).

De acordo com Xu et al. (2014) a proporção peonidina/cianidina é um fator importante sobre a cor da polpa das raízes e algumas propriedades funcionais. A batata-doce do tipo peonidina (peonidina/ cianidina > 1) geralmente tem uma cor de polpa variando de rosa a vermelha. Já quando o conteúdo de cianidina é maior, a cor da polpa varia entre roxo e roxo escuro. Segundo estes autores, raízes de batata-doce com maiores teores de cianidina, em relação à peonidina, contém mais grupos hidroxilo, apresentando, portanto, atividade antioxidante mais forte.

Adicionalmente, em estudos anteriores, Yoshimoto et al. (1999) avaliando a antimutagenicidade de antocianinas, na forma desacilada, da variedade Ayamurasaki, de polpa roxa, observaram que a epiderme, com teor de cianidina 1,5 vezes maior em relação à endoderme, apresentou atividade antimutagênica mais elevada.

Na Tabela 2.7 é apresentada a matriz de correlação de Pearson entre o teor de antocianinas totais e os parâmetros colorimétricos dos genótipos com polpa roxa.

Tabela 2.7 Matriz de correlação de Pearson entre os parâmetros de cor e os teores de antocianinas totais em clones de polpa roxa

\begin{tabular}{|c|c|c|c|c|c|c|}
\hline & $\mathbf{C} * \mathbf{c}$ & $\mathbf{H} * \mathbf{c}$ & $\mathbf{L}^{*} \mathbf{p}$ & C*p & $\mathbf{H} * \mathbf{p}$ & ANT \\
\hline $\mathbf{L}^{*} \mathbf{c}$ & $0,998^{*}$ & $-0,925^{\mathrm{ns}}$ & $0,998^{*}$ & $-0,999 *$ & $-0,970^{\mathrm{ns}}$ & $-0,999 *$ \\
\hline C*c & & $-0,946^{\mathrm{ns}}$ & $1,000^{* * *}$ & $-1,000 *$ & $-0,983^{\mathrm{ns}}$ & $-1,000 *$ \\
\hline$H^{*} \mathbf{c}$ & & & $-0,950^{\mathrm{ns}}$ & $0,942^{\text {ns }}$ & $0,990^{\mathrm{ns}}$ & $0,941^{\mathrm{ns}}$ \\
\hline $\mathbf{L}^{*} \mathbf{p}$ & & & & $-1,000 *$ & $-0,985^{\mathrm{ns}}$ & $-1,000 *$ \\
\hline$C^{*} \mathbf{p}$ & & & & & $0,980^{\mathrm{ns}}$ & $1,000 * *$ \\
\hline H*p & & & & & & $0979^{\text {ns }}$ \\
\hline
\end{tabular}

Constatou-se que a luminosidade da polpa correlacionou-se de forma muito forte e positiva com o valor de croma $\mathrm{C}^{*}$ e a luminosidade da película externa das raízes tuberosas (1 e 0,998 , respectivamente); ou seja, quanto mais saturadas e mais claras foram as cores das peridermes, mais claras foram as polpas das raízes tuberosas. A luminosidade da periderme também apresentou uma correlação de magnitude muito forte e positiva com o croma da 
periderme $(0,998)$; porém, inversamente proporcional com o croma da polpa das raízes de batata-doce $(-0,999)$. Já o croma $C^{*}$ da polpa das raízes tuberosas, apresentou uma correlação muito forte e negativa com a luminosidade da polpa (-1) e o parâmetro croma $C^{*}(-1)$ da película externa das raízes. Ou seja, raízes com cores de peridermes menos saturadas e mais escuras, apresentaram polpas com cores mais saturadas.

O teor de antocianinas totais correlacionou-se de forma muito forte e positiva $(p<0,01)$ com o croma $C^{*}$ (1) da polpa das raízes, indicando que raízes com teores de antocianinas mais elevados também apresentaram aumento na saturação da cor da polpa, ou seja, maior $\mathrm{C}^{*}$ (Tabela 2.7). Já a correlação foi muito forte e negativa entre o conteúdo de antocianinas e o croma $C^{*}$ da película externa das raízes $(-1)$, sugerindo que, quanto menor a saturação da cor da periderme das raízes, maior foi o teor de antocianinas na polpa das raízes (Tabela 2.7). Raízes com periderme e polpa mais claras, igualmente apresentaram maiores teores de antocianinas $(-0,999$ e -1 , respectivamente).

Diferenças na composição de nutrientes afetam a cor das raízes de armazenamento de batata-doce. A polpa, que pode ser branca, creme, vermelha, vermelha púrpura, roxaavermelhada, amarela, laranja ou roxa, é coberta por uma pele lisa que pode ser branca, creme, amarela, laranja, vermelha, marrom ou roxa. Por exemplo, as variedades de batatadoce de polpa alaranjada são ricas em $\beta$-caroteno (precursor da vitamina A) (BENGTSSON et al., 2008, KIDMOSE et al., 2007), e poderiam, assim, ajudar a aliviar a deficiência de vitamina A, que é considerada um grave problema de saúde pública em mais de 70 países, especialmente no mundo em desenvolvimento (VIMALA et al., 2011).

As variedades de batata-doce de polpa roxa têm uma cor atrativa roxa-avermelhada e altos níveis de antocianinas, que apresentam atividade antioxidante e fornecem benefícios para a saúde, como a remoção de radicais livres, proteção contra o câncer, potencial antimutagênico, atividade hepatoprotetora e ação anti-hipertensiva e anti-hiperglicêmica (BRIDGERS et al., 2010; ESPÍN et al., 2000; HERTOG et al., 1993; HOU et al., 2010; WANG et al., 1997; XU et al., 2014). Já as variedades de polpa branca, creme ou amarela pálida, são menos doces e úmidas do que aquelas com polpa alaranjada, mas tendem a ter maiores teores de amido e apresentam rendimentos superiores, sendo utilizadas principalmente para a produção de amido (ZHANG et al., 2014).

Fica evidente que a escolha de um material pela coloração de sua polpa depende do objetivo do programa de melhoramento. Se este visa primordialmente a obtenção de uma 
cultivar que atenda à preferência imediata do consumidor, terá que ser observado quais as colorações são mais vendidas na região (KALKMANN, 2011). Entretanto, raízes com maior valor nutracêutico apresentam colorações de polpa alaranjada, mais ricas em $\beta$-caroteno e de polpa roxa, mais ricas em antocianinas.

De acordo com Azevedo et al. (2014) e Grüneberg et al. (2005) a magnitude da interação genótipo $\times$ ambiente para características nutricionais de batata-doce (teores de proteína bruta, fibra bruta, cinzas, matéria seca, amido e $\beta$-caroteno) são pequenas, podendo a seleção para tais características ser praticada em um ou poucos ambientes, mesmo que o melhorista vise o desenvolvimento de materiais para diferentes regiões ecogeográficas. Contudo, as variáveis produtividade comercial e total, peso médio de raízes comerciais e formato das raízes tuberosas, são fortemente influenciadas por esta interação.

A matriz de correlação de Pearson entre as características físico-químicas avaliadas e o teor de carotenoides totais é apresentada na Tabela 2.8 .

Tabela 2.8 Matriz de correlação de Pearson entre as características físico-químicas umidade, cinzas, sólidos solúveis totais, acidez total titulável, $\mathrm{pH}$, carotenoides totais, fibra, proteína, amido e ratio da polpa de treze genótipos de batata-doce

\begin{tabular}{|c|c|c|c|c|c|c|c|c|c|}
\hline & $\mathrm{CZ}$ & SS & $\mathbf{A T}$ & PH & CTN & FB & PTN & AM & RT \\
\hline UM & $0,612^{*}$ & $-0,727 * *$ & $0,540^{\mathrm{ns}}$ & $-0,205^{\mathrm{ns}}$ & $0,639 *$ & $0,854 * *$ & $0,211^{\mathrm{ns}}$ & $-0,631 *$ & $-0,688 * *$ \\
\hline $\mathbf{C Z}$ & & $-0,482^{\mathrm{ns}}$ & $0,484^{\mathrm{ns}}$ & $-0,249^{\mathrm{ns}}$ & $0,030^{\mathrm{ns}}$ & $0,414^{\mathrm{ns}}$ & $0,118^{\mathrm{ns}}$ & $-0,483^{\mathrm{ns}}$ & $-0,619^{*}$ \\
\hline SS & & & $-0,266^{\mathrm{ns}}$ & $0,202^{\mathrm{ns}}$ & $-0,384^{\mathrm{ns}}$ & $-0,715^{* *}$ & $0,219^{\mathrm{ns}}$ & $0,690^{* *}$ & $0,603^{*}$ \\
\hline AT & & & & $-0,771 * *$ & $0,163^{\text {ns }}$ & $0,624 *$ & $0,524^{\mathrm{ns}}$ & $-0,584 *$ & $-0,891 * *$ \\
\hline PH & & & & & $0,058^{\mathrm{ns}}$ & $-0,328^{\mathrm{ns}}$ & $-0,151^{\mathrm{ns}}$ & $0,383^{\text {ns }}$ & $0,709 * *$ \\
\hline CTN & & & & & & $0,615^{*}$ & $0,203^{\text {ns }}$ & $-0,211^{\mathrm{ns}}$ & $-0,222^{\text {ns }}$ \\
\hline FB & & & & & & & $0,307^{\mathrm{ns}}$ & $-0,581^{*}$ & $-0,764 * *$ \\
\hline PTN & & & & & & & & $-0,244^{\mathrm{ns}}$ & $-0,316^{\mathrm{ns}}$ \\
\hline $\mathbf{A M}$ & & & & & & & & & $0,657^{*}$ \\
\hline
\end{tabular}

** e *: Significativo a 1 e $5 \%$ de probabilidade pelo teste $\mathrm{t}$; ns: não significativo. UM: umidade (\%b.u.); CZ: cinzas (\%b.s.); SS: sólidos solúveis totais; AT: acidez total titulável (\%b.s.); PH: pH; CTN: carotenoides totais ( $\mu \mathrm{g} \mathrm{g}^{-1}$ b.s.); FB: fibra (\%b.s.); PTN: proteína (\%b.s.); AM: amido (\%b.s.) e RT: ratio, das raízes de batata-doce.

Verificou-se correlação forte e positiva entre as variáveis $\mathrm{pH}$ e ratio das raízes tuberosas $(0,709)$; indicando que os genótipos mais precoces, com maiores ratios, proporcionaram teores de $\mathrm{pH}$ mais elevados.

As características sólidos solúveis totais e umidade $(-0,727)$ correlacionaram-se de forma forte e negativa, demonstrando que houve uma redução no conteúdo de sólidos solúveis totais com o incremento do teor de umidade, que pode ser atribuída a um efeito de diluição, resultante do aumento do conteúdo de água das raízes. De igual forma, a acidez total titulável 
correlacionou-se forte e inversamente com o $\mathrm{pH}(-0,771)$ e o ratio $(-0,891)$, pois maiores teores de pH são um indicativo do decréscimo da acidez titulável, que é maior em estádios mais avançados de maturação.

Maiores teores de amido foram obtidos com a redução do teor de umidade das raízes tuberosas (-0,631). Estes resultados são condizentes com os observados por Zhang et al. (2002), que verificaram maiores teores de amido em raízes de batata-doce com maiores conteúdos de matéria seca $(\mathrm{r}=0,92 ; p<0,01)$. De forma semelhante ao reportado por Franco et al. (2001), a quantidade de amido nas raízes tuberosas também correlacionou-se negativamente com o teor de fibra bruta $(-0,581)$. Já o amido apresentou correlação média e positiva com o teor de sólidos solúveis totais $(0,690)$ e o ratio $(0,657)$. Isto pode ser explicado pelo fato que uma proporção importante da matéria seca encontra-se na forma de amido, que depois de metabolizado, passa a formar parte dos sólidos solúveis totais, os quais estão presentes em maior proporção nos genótipos mais precoces.

Finalmente, os teores de umidade e cinzas das raízes correlacionaram-se de forma média e positiva $(0,612)$, como previamente constatado por Lebot et al. (2011), que avaliando 240 acessos de bata-doce também observaram aumento no teor de cinzas com a redução do conteúdo de matéria seca das raízes tuberosas.

Analisando-se conjuntamente os dados sobre as características físico-químicas avaliadas, dentre os clones estudados, o CNPH 1796, com teor de matéria seca de 34,96\%, equivalente ao das cultivares Brazlândia Roxa, BRS Cuia, BRS Rubissol, Coquinho e BRS Amélia, é a melhor opção para processamento industrial, visando obter maiores rendimentos de amido ou de etanol biocombustível, e para o consumo humano. Contudo, por ser um material de polpa roxa, haveria que pesquisar-se a aceitabilidade por parte dos consumidores. Quanto à precocidade, destacaram-se as cultivares Coquinho, BRS Cuia e BRS Rubissol, com menores conteúdos de acidez e altos ratios e teores de sólidos solúveis totais. Os clones CNPH 05, CNPH 1232 e a cultivar Beauregard apresentaram os maiores teores de fibra bruta. Porém, sob o ponto de vista tecnológico, estes materiais prejudicariam o processo de extração de fécula. Os genótipos CNPH 05, BRS Rubissol, Beauregard e CNPH 1796, destacaram-se com relação aos maiores teores de proteína bruta, com potencial para aumentar a qualidade nutritiva de raízes de batata-doce através do melhoramento seletivo. As cultivares Brazlândia Roxa e Coquinho sobressaíram-se para a produção de amido. No entanto, a cultivar Coquinho apresentou uma produtividade total baixa. Os genótipos Beauregard, BRS Amélia e CNPH 
1232, de polpa alaranjada, apresentaram as maiores concentrações de carotenoides totais. Dos parâmetros colorimétricos, o valor de croma calculado para a polpa das raízes tuberosas foi o mais adequado para a estimativa do teor de carotenoides totais. 


\subsection{CONCLUSÕES}

Os clones CNPH 1796, CNPH 80, CNPH 08 e CNPH 05 caracterizados por apresentar produtividades totais superiores a $27 \mathrm{t} \mathrm{ha}^{-1}$, bom formato e moderada resistência a insetos de solo mostraram aptidão para mesa.

Os clones CNPH 60 e CNPH 46, também são promissores, porém, para favorecer a produção de raízes tuberosas menores, devem ser colhidos com menos de 172 dias.

Os acessos CNPH 69 e CNPH 66, com boa produtividade, mas com formato não desejável para a comercialização, podem ser boas alternativas para a alimentação animal ou o processamento industrial.

Os clones CNPH 05, CNPH 1232 e a cultivar Beauregard proporcionaram os maiores teores de fibra bruta.

Os genótipos CNPH 05, BRS Rubissol, Beauregard e CNPH 1796, destacaram-se com relação aos maiores conteúdos de proteína bruta.

Para a produção de etanol e a indústria feculeira, a cultivar Brazlândia Roxa mostrou-se a mais indicada dentre os demais materiais avaliados, em função de apresentar baixos teores de fibras na raiz, o maior teor de massa seca, o maior rendimento de amido e alta produtividade.

Os genótipos Beauregard, BRS Amélia e CNPH 1232, de polpa alaranjada, apresentaram as maiores concentrações de carotenoides totais.

O valor de croma calculado para a polpa das raízes tuberosas foi o mais adequado para a estimativa do teor de carotenoides totais, dentre os parâmetros colorimétricos avaliados. 


\subsection{REFRÊNCIAS BIBLIOGRÁFICAS}

AGRAWAL, L.; NARULA, K.; BASU, S.; SHEKHAR, S.; GHOSH, S.; DATTA, A.; CHAKRABORTY, N.; CHAKRABORTY, S. Comparative proteomics reveals a role for seed storage protein AmA1 in cellular growth, development, and nutrient accumulation. Journal of Proteome Research, v. 12, n. 11, p. 4904-4930, 2013.

AHN, Y. O.; KIM, S. H.; KIM, C. Y.; LEE, J.-S.; KWAK, S.-S.; LEE, H.-S. Exogenous sucrose utilization and starch biosynthesis among sweetpotato cultivars. Carbohydrate Research, v. 345, n. 1, p. 55-60, 2010.

ALMEIDA, L. B.; PENTEADO, M. V. C. Carotenoids and pro-vitamin A value of white fleshed Brazilian sweet potatoes (Ipomoea batatas Lam.). Journal of Food Composition and Analysis, v. 1, p. 341-352, 1988.

ALMEIDA-MURADIAN, L. B. Carotenoides de batata-doce (Ipomoea batatas Lam.) e sua relação com a cor das raízes. 1991. $110 \mathrm{f}$. Tese (Doutorado em Ciência dos Alimentos)Faculdade de Ciências Farmacêuticas, Universidade de São Paulo, São Paulo, 1991.

AMENY, M. A.; WILSON, P. W. Relationship between hunter color values and $\beta$-Carotene contents in white-fleshed African sweetpotatoes (Ipomoea batatas Lam). Journal of the Science of Food and Agriculture, v. 73, p. 301-306, 1997.

AMES, B. N. Dietary carcinogens and anticarcinogens oxygen radicals and degenerative diseases. Science, v. 221, n. 4617, p. 1256-1264, 1983.

ANDRADE JÚNIOR, V. C.; VIANA, D. J. S.; PINTO, N. A. V. D.; RIBEIRO, K. G.; PEREIRA, R. C.; NEIVA, I. P.; AZEVEDO, A. M.; ANDRADE, P. C. R. 2012. Productive and qualitative characteristics of the vines and roots of sweet potato. Horticultura Brasileira, v. 30, n. 4, p. 584-589, 2012.

ANKUMAH, R.; KHAN, V.; MWAMBA, K.; KPOMBLEKOU-A, K. The influence of source and timing of nitrogen fertilizers on yield and nitrogen use efficiency of four sweet potato cultivars. Agriculture, Ecosystems and Environment, v. 100, n. 2-3, p. 201-207, 2003.

AOAC- Association of Official Analytical Chemists. Official methods of analysis. 13. ed. Washington, DC, 1980. 109 p.

AZEVEDO, A. M.; ANDRADE JÚNIOR, V. C.; VIANA, D. J. S.; ELSAYED, A. Y. A. M.; PEDROSA, C. E.; NEIVA, I. P.; FIGUEIREDO, J. A. Influence of harvest time and cultivation sites on the productivity and quality of sweet potato. Horticultura Brasileira, v. 32, n. 1, p. 21-27, 2014. 
AZEVEDO, S. M. de; FREITAS, J. A.; MALUF, W. R.; SILVEIRA, M. A. Desempenho de clones e métodos de plantio de batata-doce. Acta Scientiarum. Agronomy, v. 22, n. 4, p. 901-905, 2000.

BAYDAS, G.; KARATAS, F.; GURSU, M. F.; BOZKURT, H. A.; ILHAN, N.; YASAR, A.; CANATAN, H. Antioxidant vitamin levels in term and preterm infants and their relation to maternal vitamin status. Archives of medical research, v. 33, n. 3, p. 276-280, 2002.

BECHOFF, A.; WESTBY, A.; OWORIO, C.; MENYA, G.; DHUIQUE-MAYER, C.; DUFOUR, D.; TOMLINS, K. Effect of drying and storage on the degradation of total carotenoids in orange-fleshed sweetpotato cultivars. Journal of the Science of Food and Agriculture, v. 90, p. 622-629, 2010b.

BECHOFF, A.; DHUIQUE-MAYER, C.; DORNIER, M.; TOMLINS, K. I.; BOULANGER, R.; DUFOUR, D.; WESTBY, A. Relationship between the kinetics of $\beta$-carotene degradation and formation of norisoprenoids in the storage of dried sweet potato chips. Food Chemistry, v. 121, n. 2 , p. $348-357,2010$.

BENGTSSON, A.; NAMUTEBI, A.; ALMINGER, M. L.; SVANBERG, U. Effects of various traditional processing methods on the all-trans- $\beta$-carotene content of orange-fleshed sweet potato. Journal of Food Composition and Analysis, v. 21, n. 2, p. 134-143, 2008.

BRIDGERS, E. N.; CHINN, M. S.; TRUONG, V. D. Extraction of anthocyanins from industrial purple-fleshed sweetpotatoes and enzymatic hydrolysis of residues for fermentable sugars. Industrial Crops and Products, v. 32, n. 3, p. 613-620, 2010.

CÂMARA, F. A. A.; GRANGEIRO, L. C.; DOMBROSKI, J. L. D.; SANTOS, M. A.; FREITAS, R. M. O.; FREITAS, F. C. L. Desempenho agronômico de cultivares de batatadoce oriundas de ramas produzidas de forma convencional e in vitro. Revista Brasileira de Ciências Agrárias, v. 8, n. 3, p. 370-374, 21 set. 2013.

CARDOSO, A. D.; VIANA, A. E. S.; RAMOS, P. A. S.; MATSUMOTO, S. N.; AMARAL, C. L. F.; SEDIYAMA, T.; MORAIS, O. M. Avaliação de clones de batata-doce em Vitória da Conquista. Horticultura Brasileira, v. 23, n. 4, p. 911-914, 2005.

CARVAlHO, F. I. F.; LORENCETTI, C.; BENIN, G. Estimativas e implicações da correlação no melhoramento vegetal. Pelotas: Universitárias da UFPel, 2004.

CAVALCANTE, J. T.; FERREIRA, P. V.; SOARES, L. Correlações fenotípicas, genotípicas e de ambiente em clones de batata-doce (Ipomoea batatas (L.) Lam.). Revista Ciência Agrícola, v. 10, n. 1, p. 1-7, 2012.

CAVALCANTE, M.; FERREIRA, P. V.; PAIXÃO, S. L.; COSTA, J. G.; PEREIRA, R. G.; MADALENA, J. A. S. Potenciais produtivo e genético de clones de batata-doce. Acta Scientiarum. Agronomy, v. 31, n. 3, p. 421-426, 2009.

CECILIO FILHO, A. B.; REIS, M. dos S.; SOUZA, R. J.; PASQUAL, M. Degenerescência em cultivares de batata-doce. Horticultura Brasileira, v. 16, n. 1, p. 82-84, 1996. 
CEVALLOS-CASALS, B. A.; CISNEROS-ZEVALlOS, L. Stoichiometric and kinetic studies of phenolic antioxidants from Andean purple corn and red-fleshed sweetpotato. Journal of agricultural and food chemistry, v. 51, n. 11, p. 3313-3319, 2003.

CHAMPAGNE, A.; BERNILLON, S.; MOING, A.; ROLIN, D.; LEGENDRE, L.; LEBOT, V. Carotenoid profiling of tropical root crop chemotypes from Vanuatu, South Pacific. Journal of Food Composition and Analysis, v. 23, n. 8, p. 763-771, 2010.

CHITARRA, M. I. F.; CHITARRA, A. B. Pós-colheita de frutos e hortaliças. Lavras: ESAL-FAEPE, 1990. 320p.

CHITARRA, M. I. F.; CHITARRA, A. B. Pós-colheita de frutos e hortaliças: fisiologia e manuseio. 2. ed. Lavras: Editora da Universidade Federal de Lavras, 2005. 785p.

ÇINAR, I. Carotenoid pigment loss of freeze-dried plant samples under different storage conditions. LWT - Food Science and Technology, v. 37, n. 3, p. 363-367, 2004.

CRISÓSTOMO, J. R.; BARROS, L. de M.; PAIVA, J. R. de; CAVALCANTI, J. J. V. Melhoramento genético do cajueiro. In: QUEIROZ, M. A.; GOEDERT, C. O.; RAMOS, C. R. R. (Ed.). Recursos genéticos e melhoramento de plantas para o Nordeste brasileiro. Petrolina: Embrapa Semiárido, 1999. Disponível em: <http://www.cpatsa.embrapa.br:8080/catalogo/livrorg/cajumelhoramento.pdf〉. Acesso em: 19 jan. 2015.

ESPÍN, J. C.; SOLER-RIVAS, C.; WICHERS, H. J.; GARCÍA-VIGUERA, C. Anthocyaninbased natural colorants: a new source of antiradical activity for foodstuff. Journal of Agricultural and Food Chemistry, v. 48, n. 5, p. 1588-1592, 2000.

FERNANDES, F. L.; MANTOVANI, E. C.; NETO, H. B.; NUNES, V. de V. Efeitos de variáveis ambientais, irrigação e vespas predadoras sobre Leucoptera coffeella (GuérinMéneville) (Lepidoptera: Lyonetiidae) no cafeeiro. Neotropical Entomology, v. 38, n. 3, p. 410-417, 2009.

FERNANDES, F. R. Limpeza clonal de batata-doce: produção de matrizes com elevada qualidade fitossanitária. Brasília: Embrapa Hortaliças, 2013, 8 p. Circular Técnica 117.

FIGUEIREDO, J. A. Seleção de clones de batata-doce com potencial de utilização na alimentação humana e animal. 2010. 55 f. Dissertação (Mestrado em Produção Vegetal)Faculdade de Ciências Agrárias, Universidade Federal dos Vales do Jequitinhonha e Mucuri, Diamantina, 2010.

FONTES, P. C. R. Sugestões de Adubação para Hortaliças. In: RIBEIRO, A. C.; GUIMARÃES, P. T. G.; ALVAREZ, V. H. V. (Eds). Recomendação para o uso de corretivos e fertilizantes em Minas Gerais: $5^{\text {a }}$ aproximação. Viçosa: Comissão de Fertilidade do Solo do Estado de Minas Gerais, 1999. p. 171-174. 
FRANÇA, F. H.; MIRANDA, J. E. C.; FERREIRA, P. E.; MALUF, W.R. Comparação de dois métodos de avaliação de germoplasma de batata-doce visando resistência a pragas do solo. In: CONGRESSO BRASILEIRO DE OLERICULTURA, 23., 1983, Rio de Janeiro. Anais... Rio de Janeiro: SOB, 1983. p.176.

FRANCO, C. M. L.; DAIUTO, E. R.; DEMIATE, I. M.; CARVALHO, L. J. C. B.; LEONEL, M.; CEREDA, M. P.; VILPOUX, O. F.; SARMENTO, S. B. S. Propriedades gerais do amido: série culturas de tuberosas amiláceas latinoamericanas. São Paulo: Fundação Cargill, 2001. 224p.

FU, Y.-F.; CHEN, M.; YE, X.-L.; ZHANG, Q.-T.; LIAO, Z.-H.; YANG, C.-X.; HE, P. Variation laws of anthocyanin content in roots and their relationships with major economic traits in purple-fleshed sweetpotato [Ipomoea Batatas (L.) Lam]. Agricultural Sciences in China, v. 7, n. 1, p. 32-40, 2008.

FULEKI, T.; FRANCIS, F. J. Quantitative methods for anthocyanins: 1. Extraction and determination of total anthocyanin in Cranberries. Journal of food science, v. 33, n. 1, p. 72 $77,1968$.

FURUTA, S.; SUDA, I.; NISHIBA, Y.; YAMAKAWA, O. High tert-Butylperoxyl radical scavenging activities of sweet potato cultivars with purple flesh. Food Science and Technology International, Tokyo, v. 4, n. 1, p. 33-35, 1998.

GALVANO, F.; FAUCI, L. L.; LAZZARINO, G.; FOGLIANO, V.; RITIENI, A.; CIAPPELLANO, S.; BATTISTINI, N. C.; TAVAZZI, B.; GALVANO, G. Cyanidins: metabolism and biological properties. The Journal of nutritional biochemistry, v. 15, n. 1, p. 2-11, 2004.

GALVANO, F. The chemistry of anthocyanins. Functional Ingredients, jul. 2005. Disponível em: <http://newhope360.com/managing-your-business/chemistry-anthocyanins>. Acesso em : 19 jan. 2015.

GOMES, M. M.; SAUNDERS, C.; ACCIOLY, E. Vitamin A role preventing oxidative stress in newborns. Revista Brasileira de Saúde Materno Infantil, v. 5, n. 3, p. 275-282, 2005.

GONÇALVES NETO, Á. C.; MALUF, W. R.; GOMES, L. A. A.; GONÇALVES, R. J. S.; SILVA, V. F.; LASMAR, A. Aptidões de genótipos de batata-doce para consumo humano, produção de etanol e alimentação animal. Pesquisa Agropecuária Brasileira, v. 46, n. 11, p. 1513-1520, 2011.

GONÇALVES NETO, Á. C. Aptidões para consumo humano, produção de etanol e alimentação animal em clones de batata-doce. 2010. 78 f. Tese (Doutorado em Produção vegetal)- Universidade Federal de Lavras, Lavras, 2010.

GONÇALVES NETO, Á. C.; MALUF, W. R.; GOMES, L. A. A.; MACIEL, G. M.; FERREIRA, R. P. D.; CARVALHO, R.C. Correlação entre caracteres e estimação de parâmetros populacionais para batata-doce. Horticultura Brasileira, v. 30, n. 4, p. 713-719, 2012. 
GRACE, M. H.; YOUSEF, G. G.; GUSTAFSON, S. J.; TRUONG, V.-D.; YENCHO, G. C.; LILA, M. A. Phytochemical changes in phenolics, anthocyanins, ascorbic acid, and carotenoids associated with sweetpotato storage and impacts on bioactive properties. Food Chemistry, v. 145, p. 717-724, 2014.

GRUNEBERG, W. J.; MANRIQUE, K.; ZHANG, D.; HERMANN, M. Genotype × environment interactions for a diverse set of sweetpotato clones evaluated across varying ecogeographic conditions in Peru. Crop Science, v. 45, n. 6, p. 2160-2171, 2005.

HERTOG, M. G. L.; FESKENS, E. J. M.; HOLLMAN, P. C. H.; KATAN, M. B.; KROMHOUT, D. Dietary antioxidant flavonoids and risk of coronary heart disease: the Zutphen Elderly Study. The Lancet, v. 342, n. 8878, p. 1007-1011, 1993.

HOU, F.-Y.; WANG, Q.-M.; DONG, S.-X.; LI, A.-I.; ZHANG, H.-Y.; XIE, B.-T.; ZHANG, L.-M. Accumulation and gene expression of anthocyanin in storage roots of purple-freshed sweet potato [Ipomoea batatas (L.) Lam] under weak light conditions. Agricultural Sciences in China, v. 9, n. 11, p. 1588-1593, 2010.

HUANG, A. S.; TANUDJAJA, L.; LUM, D. Content of alpha-, beta-carotene, and dietary fiber in 18 sweetpotato varieties grown in Hawaii. Journal of Food Composition and Analysis, v. 12, n. 2, p. 147-151, 1999.

HUTCHINGS, J. B. The perception and sensory assessment of colour. In: MACDOUGALL, D. B. (Ed.). Colour in Food. England: Woodhead Publishing Limited, 2002. p. 9-32.

INSTITUTO ADOLFO LUTZ. Normas Analíticas do Instituto Adolfo Lutz: métodos químicos e físicos para análise de alimentos. 3. ed. São Paulo: IMESP, 1985. 533 p.

JIAO, Y.; YANG, Z.; JIANG, Y.; ZHAI, W. Study on chemical constituents and antioxidant activity of anthocyanins from purple sweet potato (Ipomoea batatas L.). International Journal of Food Engineering, v. 8, n. 2, p. 1-16, 2012.

K'OSAMBO, L. M.; CAREY, E. E.; MISRA, A. K.; WILKES, J.; HAGENIMANA, V. Influence of age, farming site, and boiling on pro-vitamin A content in sweet potato (Ipomoea batats (L.) Lam.) storage roots. The Journal of Food Technology in Africa, v. 4, n. 3, p. 77 84, 1999.

KALKMANN, D. C. Produtividade, qualidade de raiz, resistência aos insetos de solo e aos nematóides-das-galhas, e estimativas de parâmetros genéticos em clones de batatadoce cultivados no Distrito Federal. 2011. 144 f. Dissertação (Mestrado em Agronomia)Faculdade de Agronomia e Medicina Veterinária, Universidade de Brasília, Brasília, 2011.

KAO, F.-J.; CHIU, Y.-S.; CHIANG, W.-D. Effect of water cooking on antioxidant capacity of carotenoid-rich vegetables in Taiwan. Journal of Food and Drug Analysis, v. 22, n. 2, p. 202-209, 2014. 
KIDMOSE, U.; CHRISTENSEN, L. P.; AGILI, S. M.; THILSTED, S. H. Effect of home preparation practices on the content of provitamin A carotenoids in coloured sweet potato varieties (Ipomoea batatas Lam.) from Kenya. Innovative Food Science \& Emerging Technologies, v. 8, n. 3, p. 399-406, set. 2007.

KIM, S. H.; AHN, Y. O.; AHN, M.-J.; LEE, H.-S.; KWAK, S.-S. Down-regulation of $\beta$ carotene hydroxylase increases $\beta$-carotene and total carotenoids enhancing salt stress tolerance in transgenic cultured cells of sweetpotato. Phytochemistry, v. 74, p. 69-78, fev. 2012.

LANDRUM, J. T.; BONE, R. A. Lutein, zeaxanthin, and the macular pigment. Archives of Biochemistry and Biophysics, v. 385, n. 1, p. 28-40, jan. 2001.

LEBOT, V.; NDIAYE, A.; MALAPA, R. Phenotypic characterization of sweet potato [Ipomoea batatas (L.) Lam.] genotypes in relation to prediction of chemical quality constituents by NIRS equations. Plant Breeding, v. 130, n. 4, p. 457-463, 2011.

LEONEL, M.; CEREDA, M. P. Caracterizacão físico-química de algumas tuberosas amiláceas. Ciência e Tecnologia de Alimentos, v. 22, n. 1, p. 65-69, 2002.

LI, J.; LI, X.-D.; ZHANG, Y.; ZHENG, Z.-D.; QU, Z.-H.; LIU, M.; ZHU, S.-H.; LIU, S.; WANG, M.; QU, L. Identification and thermal stability of purple-fleshed sweet potato anthocyanins in aqueous solutions with various $\mathrm{pH}$ values and fruit juices. Food Chemistry, v. 136, n. 3-4, p. 1429-1434, fev. 2013.

LIMA, V. L. A. G. de; ALMEIDA MÉLO, E. de; SILVA LIMA, D. E. da. Fenólicos e carotenoides totais em pitanga. Scientia Agrícola, v. 59, n. 3, p. 447-450, 2002.

LIU, S.-C.; LIN, J.-T.; YANG, D.-J. Determination of cis- and trans- $\alpha$ - and $\beta$-carotenoids in Taiwanese sweet potatoes (Ipomoea batatas (L.) Lam.) harvested at various times. Food Chemistry, v. 116, n. 3, p. 605-610, out. 2009.

MARES, J. A.; LaROWE, T. L.; SNODDERLY, D. M.; MOELLER, S. M.; GRUBER, M. J.; KLEIN, M. L.; WOOTEN, B. R.; JOHNSON, E. J.; CHAPPELL, R. J. Predictors of optical density of lutein and zeaxanthin in retinas of older women in the carotenoids in age-related eye disease study, an ancillary study of the women's health initiative. The American journal of clinical nutrition, v. 84, n. 5, p. 1107-1122, 2006.

MASCIO, P., DI; MURPHY, M., E.; SIES, H. Antioxidant defense systems: the role of carotenoids, tocopherols, and thiols. The American Journal of Clinical Nutrition, v. 53, p. 194s-200s, 1991.

MASSAROTO, J. A. Características agronômicas e produção de silagem de clones de batata doce. 2008. 85 f. Tese (Doutorado em Fitotecnia)- Universidade Federal de Lavras, Lavras, 2008.

MASSAROTO, J. A.; MALUF, W. R.; GOMES, L. A. A.; FRANCO, H. D.; GASPARINO, C. F. Behavior of roots of sweet potato clones. Ambiência, v. 10, n. 1, p. 73-81, 2014. 
MENEZES, D. M. de; REGO, M. M. do.; NOBRE, A.; MENEGUELLI, C. A. Influência da época de colheita sobre os teores de açúcar e proteína em batata-doce. Pesquisa Agropecuária Brasileira, v. 11, n. 12, p. 49-52, 1976.

MIRANDA, J. E. C.; CRUZ, C. D.; PEREIRA, A. S. Análise de trilha e divergência genética de cultivares e clones de batata-doce. Revista Brasileira de Genética, v. 11, n. 4, p. 881-892, 1988.

MIRANDA, J. E. C.; FRANÇA, F. H.; CARRIJO, O. A.; SOUZA, A. F.; PEREIRA, W.; LOPES, C. A.; SILVA, J. B. C. A cultura da batata-doce. Brasília: Embrapa Hortaliças, 1995, 89 p. Serviço de Produção de Informação - SPI.

OZTURK, G.; AZERI, F. N.; YILDIRIM, Z. Field performance of in vitro sweet potato [Ipomoea batatas 1.(lam)] plantlets derived from seedstocks. Turkish Journal of Field Crops, v. 17, n. 1, p. 1-4, 2012.

PAIVA, S. A. R.; RUSSELL, R. M. $\beta$-carotene and other carotenoids as antioxidants. Journal of the American College of Nutrition, v. 18, n. 5, p. 426-433, 1999.

PEIXOTO, J. R.; SANTOS, L. C.; RODRIGUES, F. A.; JULIATTI, F.C.; LYRA, J. R. M. Seleção de clones de batata-doce resistentes a insetos de solo. Pesquisa Agropecuária Brasileira, v. 34, n. 3, p. 385-389, 1999.

PURCELL, A. E.; WALTER JR, W. M. Changes in composition of the nonprotein-nitrogen fraction of "jewel" sweet potatoes (Ipomoea batatas (Lam.)) during storage. Journal of agricultural and food chemistry, v. 28, n. 4, p. 842-844, 1980.

QUEIROGA, R. C. F.; SANTOS, M. A.; MENEZES, M. A.; VIEIRA, C. P. G.; SILVA, M. C. Fisiologia e produção de cultivares de batata-doce em função da época de colheita. Horticultura Brasileira, v. 25, n. 3, p. 371-374, 2007.

R Core Team. R: A language and environment for statistical computing. R Foundation for Statistical Computing, Vienna, Austria. 2013. Disponível em: <http://www.R-project.org/>. Acesso em: 26 dez. 2013.

RAVINDRAN, V.; RAVINDRAN, G.; SIVAKANESAN, R.; RAJAGURU, S. B. Biochemical and nutritional assessment of tubers from 16 cultivars of sweet potato (Ipomoea batatas L.). Journal of agricultural and food chemistry, v. 43, n. 10, p. 2646-2651, 1995.

RAY, R. C.; PANDA, S. K.; SWAIN, M. R.; SIVAKUMAR, P. S. Proximate composition and sensory evaluation of anthocyanin-rich purple sweet potato (Ipomoea batatas L.) wine. International Journal of Food Science \& Technology, v. 47, p. 452-458, 2012.

RESENDE, G. M. de. Características produtivas de cultivares de batata-doce sob condições irrigadas e de sequeiro na região norte de Minas Gerais. Horticultura Brasileira, v. 17, n. 2, p. 151-154, 1999. 
RESENDE, G. M. de. Características produtivas de cultivares de batata-doce em duas épocas de colheita, em Porteirinha-MG. Horticultura Brasileira, v. 18, n. 1, p. 68-71, 2000.

RIMBACH, G.; PASCUAL-TERESA, S. de. Application of nutrigenomics tools to analyze the role of oxidants and antioxidants in gene expression. In: RIMBACH, G.; FUCHS, J.; PACKER, L. (Ed.). Nutrigenomics. New York: Boca Raton, 2005. p. 1-12.

RODRIGUEZ-AMAYA, D. B. A guide to carotenoid analysis in foods. Washington: International Life Sciences Institute Press, 2001. 64 p.

ROESLER, P. V. S. O.; GOMES, S. D.; MORO, E.; KUMMER, A. C. B.; CEREDA, M. P. Produção e qualidade de raiz tuberosa de cultivares de batata-doce no Oeste do Paraná. Acta Scientiarum. Agronomy, v. 30, n. 1, p. 117-122, 2008.

ROSE, I.; VASANTHAKAALAM, H. Comparison of the Nutrient composition of four sweet potato varieties cultivated in Rwanda. American Journal of Food and Nutrition, v. 1, n. 1, p. 34-38, jan. 2011.

SATUÉ-GRACIA, M. T.; HEINONEN, M.; FRANKEL, E. N. Anthocyanins as antioxidants on human low-density lipoprotein and lecithin-liposome systems. Journal of agricultural and food chemistry, v. 45, n. 9, p. 3362-3367, 1997.

SENANAYAKE, S. A.; RANAWEERA, K. K. D. S.; GUNARATNE, A.; BAMUNUARACHCHI, A. Comparative analysis of nutritional quality of five different cultivars of sweet potatoes (Ipomea batatas (L) Lam) in Sri Lanka. Food Science \& Nutrition, v. 1, n. 4, p. 284-291, 2013.

SENTANIN, M. A.; RODRIGUEZ-AMAYA, D. B. Teores de carotenóides em mamão e pêssego determinados por cromatografia líquida de alta eficiência. Ciência e Tecnologia de Alimentos, v. 27, n.1, p. 13-19, 2007.

SHEKHAR, S.; MISHRA, D.; BURAGOHAIN, A. K.; CHAKRABORTY, S.; CHAKRABORTY, N. Comparative analysis of phytochemicals and nutrient availability in two contrasting cultivars of sweet potato (Ipomoea batatas L.). Food Chemistry, v. 173, p. 957-965, 2015.

SILVA, G. O. da; PONIJALEKI, R.; SUINAGA, F. A. Genetic divergence among sweet potato accessions based on root traits. Horticultura Brasileira, v. 30, n. 4, p. 595-599, 2012.

SILVA, J. B. C.; LOPES, C. A.; MIRANDA, J. E. C. de; FRANÇA, F. H.; CARRIJO, O. A.; SOUZA, A. F.; PEREIRA, W. Cultivo da batata-doce (Ipomoea batatas (L.) Lam). Brasília: Embrapa Hortaliças, 1995, 18 p. CNPH 7. ISSN 0102-6534.

SILVA, S. de O.; SOUZA, A. da S.; PAZ, O. P. da. Efeito da multiplicação vegetativa in vitro na produtividade da batata-doce (Ipomoea batatas L. Lam.). Revista Brasileira de Fisiologia Vegetal, v. 3, n. 1, p. 47-52, 1991. 
SILVEIRA, L. R.; CHIESA, V. B.; TAVARES, I. B.; SOUZA, R. C.; SILVEIRA, M. A.; ALVES, D. G.; JUNIOR, W. P. O. Caracterização físico-química e clones de batata-doce de polpa alaranjada nas condições de Palmas - To. Estudos, v. 38, n. 2, p. 365-380, 2011.

SILVEIRA, M. A. Batata-doce: uma nova alternativa para a produção de etanol. In: Instituto Euvaldo Lodi. Álcool combustível: Série Indústria em Perspectiva. Brasília: IEL, 2008. p. 109-122.

SOUZA, A. B. de. Avaliacão de cultivares de batata-doce quanto a atributos agronômicos desejáveis. Ciência e Agrotecnologia, v. 24, n. 4, p. 841-845, 2000.

STEED, L. E.; TRUONG, V.-D. Anthocyanin content, antioxidant activity, and selected physical properties of flowable purple-fleshed sweetpotato purees. Journal of Food Science, v. 73, n. 5, p. S215-S221, jun. 2008.

SUDA, I.; OKI, T.; MASUDA, M.; KOBAYASHI, M.; NISHIBA, Y.; FURUTA, S. Physiological functionality of purple-fleshed sweet potatoes containing anthocyanins and their utilization in foods. Japan Agricultural Research Quarterly, v. 37, n. 3, p. 167-173, 2003.

TAKAHATA, Y.; NODA, T.; NAGATA, T. HPLC determination of $\beta$-carotene content of sweet potato cultivars and its relationship with color values. Japanese Journal of Breeding, v. 43, n. 3, p. 421-427, 1993.

TEOW, C. C.; TRUONG, V.-D.; McFEETERS, R. F.; THOMPSON, R. L.; PECOTA, K. V.; YENCHO, G. C. Antioxidant activities, phenolic and $\beta$-carotene contents of sweet potato genotypes with varying flesh colours. Food Chemistry, v. 103, n. 3, p. 829-838, 2007.

TOMLINS, K.; OWORI, C.; BECHOFF, A.; MENYA, G.; WESTBY, A. Relationship among the carotenoid content, dry matter content and sensory attributes of sweet potato. Food Chemistry, v. 131, n. 1, p. 14-21, mar. 2012.

VAN JAARSVELD, P. J.; FABER, M.; TANUMIHARDJO, S. A.; NESTEL, P.; LOMBARD, C. J.; BENADÉ, A. J. S. $\beta$-Carotene-rich orange-fleshed sweet potato improves the vitamin A status of primary school children assessed with the modified-relative-doseresponse test. The American journal of clinical nutrition, v. 81, n. 5, p. 1080-1087, 2005.

VELIOGLU, Y. S.; MAZZA, G.; GAO, L.; OOMAH, B. D. Antioxidant activity and total phenolics in selected fruits, vegetables, and grain products. Journal of Agricultural and Food Chemistry, v. 46, n. 10, p. 4113-4117, out. 1998.

VIMALA, B.; NAMBISAN, B.; HARIPRAKASH, B. Retention of carotenoids in orangefleshed sweet potato during processing. Journal of Food Science and Technology, v. 48, n. 4, p. 520-524, ago. 2011.

WALTER, Jr., W. M.; COLLINS, W. W.; PURCELL, A. E. Sweet potato protein: A review. Journal of Agricultural and Food Chemistry, v. 32, n. 4, p. 695-699, 1984. 
WANG, H.; CAO, G.; RONALD, L. Oxygen radical absorbing capacity of anthocyanins. Journal of Agricultural and Food Chemistry, v. 45, n. 2, p. 304-309, 1997.

WOSIACKI, G.; CEREDA, M. P.; BRITO, O. R.; OLIVEIRA CÉSAR, E. de. Avaliação de doze cultivares de batata-doce (Ipomea batatas, L.) colhidas na área experimental da Universidade de Londrina. Boletim do Centro de Pesquisa de Processamento de Alimentos, v. 6, n. 2, p. 65-72, 1988.

WU, X.; SUN, C.; YANG, L.; ZENG, G.; LIU, Z.; LI, Y. $\beta$-carotene content in sweet potato varieties from China and the effect of preparation on $\beta$-carotene retention in the Yanshu No. 5. Innovative Food Science \& Emerging Technologies, v. 9, n. 4, p. 581-586, out. 2008.

XU, J.; SU, X.; LIM, S.; GRIFFIN, J.; CAREY, E.; KATZ, B.; TOMICH, J.; SCOTT SMITH, J.; WANG, W. Characterisation and stability of anthocyanins in purple-fleshed sweet potato P40. Food Chemistry, set. 2014.

YOSHIMOTO, M.; OKUNO, S.; YOSHINAGA, M.; YAMAKAWA, O.; YAMAGUCHI, M.; YAMADA, J. Antimutagenicity of sweetpotato (Ipomoea batatas) roots. Bioscience, Biotechnology and Biochemistry, v. 63, n. 3, p. 537-541, 1999.

YOSHINAGA, M.; YAMAKAWA, O.; NAKATANI, M. Genotypic diversity of anthocyanin content and composition in purple-fleshed sweet potato (Ipomoea batatas (L.) Lam). Breeding science, v. 49, n. 1, p. 43-47, 1999.

ZACCARI, F.; GALIETTA, G.; GONZALEZ IDIARTE, H. Caracterización de la pulpa fresca de materiales genéticos de boniato (Ipomoea batata L.) producidos en Uruguay. In: V CONGRESO IBEROAMERICANO DE TECNOLOGÍA POSTCOSECHA Y AGROEXPORTACIONES, 2007, Cartagena- España. Resumenes... Cartagena: AITEP, 2007. p. 552-558. Disponível em: <http://www.horticom.com/pd/imagenes/69/000/69000.pdf >. Acesso em: $10 \mathrm{dez} .2014$.

ZAVAREZE, E. R.; STORCK, C. R.; PEREIRA, J. M.; GULARTE, M. A.; DIAS, A. R. G. Elaboração de pão de queijo com substituição do amido de mandioca por amido de batatadoce (Ipomoea batatas) submetido a diferentes processos de secagem. Brazilian Journal of Food Technology, v. 12, n. 1, p. 68-76, 2009.

ZHANG, K.; WU, Z.-D.; LI, Y.-H.; ZHANG, H.; WANG, L.-P.; ZHOU, Q.-L.; TANG, D.B.; FU, Y.-F.; HE, F.-F.; JIANG, Y.-C.; YANG, H.; WANG, J.-C. ISSR-based molecular characterization of an elite germplasm collection of sweet potato (Ipomoea batatas L.) in China. Journal of Integrative Agriculture, v. 13, n. 11, p. 2346-2361, nov. 2014.

ZHANG, Z.; WHEATLEY, C. C.; CORKE, H. Biochemical changes during storage of sweet potato roots differing in dry matter content. Postharvest biology and technology, v. 24, n. 3, p. 317-325, 2002. 


\section{CAPÍTULO 3}

Desempenho morfoagronômico de genótipos de batata-doce avaliados

no Distrito Federal 


\subsection{RESUMO}

No mundo inteiro, a batata-doce (Ipomea batatas) é a sexta cultura alimentícia mais importante. Em países em desenvolvimento, a cultura ocupa a terceira posição em valor de produção e a quinta em contribuição calórica para a dieta humana. É uma hortaliça que se destaca por sua facilidade de cultivo, ampla adaptação a diversas condições edafoclimáticas e versatilidade no uso, porém, a produtividade média brasileira é considerada baixa fazendo-se necessário a adoção de cultivares mais produtivas. Com o objetivo de avaliar o desempenho morfoagronômico de trinta genótipos de batata-doce pertencentes ao banco de germoplasma mantido na Embrapa Hortaliças; avaliar a correlação entre estes caracteres e estimar parâmetros populacionais, conduziu-se um experimento nas condições edafoclimáticas de Brasília - DF, no delineamento em blocos casualizados, com quatro repetições. Verificou-se que as cultivares Beauregard e Brazlândia Branca apresentaram as melhores produtividades totais. Os clones CNPH 1232, CNPH 1357, CNPH 1298, CNPH 1197 e CNPH 1208, também destacaram-se quanto ao rendimento total de raízes. Dentre estes, os clones CNPH 1357 e CNPH 1197 produziram raízes comerciais de batata-doce com peso médio ideal (tipo extra A). Os clones CNPH 1232, CNPH 1298 e CNPH 1208 apresentaram peso médio de raízes com padrão comercial acima de 400 gramas. Aparentemente, são materiais de ciclo menor do que 174 dias. Os clones CNPH 1310 e CNPH 1192, com altas produtividades totais, apresentaram baixas produtividades comerciais, decorrentes de suas suscetibilidades aos insetos de solo e dos piores formatos de suas raízes. As altas estimativas de herdabilidade para as características produtividade comercial, número de raízes comerciais por planta, produtividade total, comprimento, diâmetro, porcentagem de raízes comerciais, formato e número total de raízes por planta, evidenciaram alta presença do componente genético na expressão destes caracteres e grande possibilidade de sucesso com a seleção. A correlação de Pearson foi de magnitude muito forte entre os pares de caracteres peso médio de raízes comerciais e porcentagem de raízes comerciais, produtividade comercial e produtividade total e número de raízes comerciais por planta e produtividade comercializável.

Palavras-chave: Ipomoea batatas, características morfoagronômicas, produtividade, parâmetros populacionais, herdabilidade, correlação de Pearson. 


\subsection{ABSTRACT}

Sweet potato (Ipomoea batatas) ranks as the world's sixth most important food crop. In developing countries, it ranks third in value of production and fifth in caloric contribution to the human diet. It is a vegetable that stands out for its ease of cultivation, wide adaptation to different edaphoclimatic conditions and versatility in use, however, the Brazilian average productivity is considered low making it necessary to adopt more productive cultivars. In order to evaluate the morphoagronomic performance of thirty genotypes of sweet potatoes belonging to the germplasm bank maintained at Brazilian National Vegetable Research Centre; evaluate the correlation between these characteristics and estimate population parameters, an experiment was conducted at edaphoclimatic conditions of Brasília-DF, on a randomized blocks experimental design with four replications. It was found that the Beauregard and Brazlândia Branca cultivars showed the best total yields. The CNPH 1232, CNPH 1357, CNPH 1298, CNPH 1197 and CNPH 1208 clones, also stood out in relation to the total yield of roots. Among these, the CNPH 1357 and CNPH 1197 clones provided marketable roots of sweet potato with average ideal weight (extra A type). The CNPH 1232, CNPH 1298 and CNPH 1208 clones, presented average weight of roots with marketable standard above 400 grams. Apparently, these are materials with cycle shorter than 174 days. The CNPH 1310 and CNPH 1192 clones, with high total yields, showed low marketable yields, due to their susceptibility to soil insects and to the worst shapes of their roots. The high heritability estimates for the characteristics marketable yield, number of marketable roots per plant, total yield, length, diameter, percentage of marketable roots, shape and total number of roots per plant, showed a high presence of the genetic component in the expression of these characteristics and great possibility of successful with the selection. The Pearson's correlation was of a very strong magnitude between the pairs of characteristics average weight of marketable roots and percentage of marketable roots, marketable yield and total yield and number of marketable roots per plant and marketable yield.

Keywords: Ipomoea batatas, morphoagronomic characteristics, yield, population parameters, heritability, Pearson's correlation. 


\subsection{INTRODUÇÃO}

A batata-doce (Ipomoea batatas) é uma espécie dicotiledônea pertencente à família botânica Convolvulaceae, que abrange cerca de 50 a 60 gêneros e entre 1600 e 1700 espécies. Os gêneros Ipomoea e Convolvulus são os maiores dentro dessa família, compreendendo mais do que um terço das espécies, sendo que dentre elas, apenas Ipomea batatas tem cultivo de expressão econômica (STEFANOVIC et al., 2002; SILVA et al., 2008).

Embora a localização exata do centro de domesticação não seja confirmada, com base em caracteres morfológicos da batata-doce e suas espécies relacionadas, a Península de Yucatán, no México e a foz do rio Orinoco, na Venezuela foram postuladas como possíveis origens. A área de dispersão estende-se desde a América Central até o norte da Argentina (AUSTIN, 1988; MANIFESTO et al., 2010).

Mundialmente, a batata-doce é a sexta cultura alimentícia mais importante depois do arroz, o trigo, a batata, o milho e a mandioca, sendo produzidas globalmente a cada ano mais de 105 milhões de toneladas, 95\% das quais são cultivadas em países em desenvolvimento, nos que a cultura ocupa a terceira posição em valor de produção e a quinta em contribuição calórica para a dieta humana (CIP, 2010; SHEKHAR et al., 2015). Hoje, os principais produtores comerciais são China, Indonésia, Vietnã, Japão, Índia e Uganda (SENANAYAKE et al., 2013).

No continente latino-americano, o Brasil é o principal produtor de batata-doce (CAVALCANTE et al., 2009; FELTRAN e FABRI, 2010), com uma produção em 2013 de 505.350 t, obtidas em uma área plantada de 39.393 ha (IBGE, 2013).

É uma cultura perene, que apresenta grande importância na alimentação humana e expressivo potencial para a utilização na produção de ração animal e como matéria-prima em processos industriais, na obtenção de amido e farinhas e na fabricação de álcool combustível (FOLONI et al., 2013). Também proporciona uma contribuição significativa como suplemento de energia e fonte de fitoquímicos. Tanto a parte aérea quanto as raízes tuberosas de quase todas as cultivares de batata-doce são fontes importantes de vitaminas $B_{1}, B_{2}, B_{6}, B_{9}$, $\mathrm{C}, \mathrm{D}$ e E, bem como de fibras e minerais como $\mathrm{K}, \mathrm{P}, \mathrm{Na}, \mathrm{Ca}, \mathrm{Mg}$, e $\mathrm{S}$ e apresentam baixos teores de gordura e colesterol (CIP, 2010; HORTON e EWELL, 1991; KIM et al., 2012; SHEKHAR et al., 2015). 
A batata-doce é considerada uma cultura de fácil cultivo e manejo, pois pode ser cultivada em condições pouco favoráveis e com quantidade mínima de insumos agrícolas. Adicionalmente, a cultura é bem adaptada a condições ambientais extremas e também pode ser cultivada em consórcio com outras culturas (SENANAYAKE et al., 2013).

Esta hortaliça tuberosa tem uma ampla aceitação popular e relevância econômica, pois apesar do baixo custo de produção, quando bem conduzida, oferece retorno relativamente alto, sendo cultivada principalmente por pequenos agricultores (FIGUEIREDO et al., 2012). Seu cultivo está bem difundido em todo o território nacional, principalmente nas regiões Sul e Nordeste. Contudo, são as regiões Sudeste e Centro-Oeste as que apresentam os maiores rendimentos médios por área do país, com 17,39 e 31,53 $\mathrm{t} \mathrm{ha}^{-1}$, respectivamente, de acordo com dados do IBGE (2013).

Apesar destes destaques e do elevado potencial produtivo, a produtividade média brasileira, de 13,09 $\mathrm{t} \mathrm{ha}^{-1}$, é considerada baixa (IBGE, 2013). Esse fato é consequência da utilização de materiais genéticos obsoletos que aliados à forma tradicional de propagação da planta através de ramas-semente ou mesmo de raízes tuberosas obtidas quase sempre na época da colheita, facilitam a disseminação de pragas e doenças, principalmente aquelas provocadas por organismos sistêmicos; comprometem a produtividade e prejudicam a capacidade multiplicativa e a uniformidade dos plantios (KROTH et al., 2004; SILVA et al., 1991). Outros fatores que afetam o rendimento médio da cultura no país são o desconhecimento de práticas culturais apropriadas; o uso de tecnologia de produção inadequada e a baixa atividade de pesquisa visando o desenvolvimento de novas cultivares (CAVALCANTE et al., 2012; FIGUEIREDO et al., 2012), obtendo-se um produto de baixa qualidade, que acarreta perda de receita, desestimulando os produtores e contribuindo para o decréscimo da área plantada com a cultura (SANTOS et al., 2005).

Considerando que o principal produto comercial da batata-doce são as raízes tuberosas, é de fundamental importância que o material genético utilizado para cultivo comercial apresente, além de alta produtividade, formato de raízes comercialmente aceitável e resistência aos insetos de solo, que podem tornar as raízes imprestáveis até mesmo para o consumo animal (MASSAROTO et al., 2014). Apesar de não serem comuns altos níveis de danos, estes podem ser elevados caso a manejo não seja adequado, com perdas entre $60 \% \mathrm{e}$ $100 \%$ da produção (WANDERLEY et al., 2004). 
A batata-doce é uma espécie autohexaplóide, que apresenta 90 cromossomos $(2 \mathrm{n}=6 \mathrm{x}=$ 90) (CHEN et al., 1992). O mecanismo de auto-incompatibilidade presente na espécie conduz à polinização cruzada e, portanto, a um alto grau de heterozigose. A polinização é, normalmente, feita por insetos e a autofecundação raramente ocorre (OLIVEIRA et al., 2002). Devido ao alto grau de heterozigose, as progênies obtidas por via sexual diferem geneticamente das linhagens parentais já na primeira geração (MAROUELLI et al; 2005).

Os cruzamentos naturais da cultura aliados à propagação vegetativa, têm gerado grande diversidade de genótipos cultivados no mundo inteiro (ZHANG et al., 1998), a qual pode também ser decorrente da mutação espontânea; das introduções de plantas provenientes de outras localidades; da seleção e de outros fatores etnográficos, como a heterogeneidade ambiental associada a diversos padrões de consumo (HE at al., 2006). Essa variabilidade genômica, espontânea ou criada, torna as populações locais da espécie um recurso genético importante a ser empregado em programas de melhoramento da cultura (MARTINS et al., 2014). No entanto, há pouca informação disponível sobre a diversidade da batata-doce, especialmente quando se considera o seu cultivo em pequenas propriedades (MOULIN et al., 2012).

O conhecimento da diversidade genética dentro de uma coleção de germoplasma é fundamental para a sua utilização racional. Descritores morfoagronômicos e fenológicos, que são específicos para cada espécie, têm sido amplamente utilizados na caracterização, diferenciação e proteção de culturas (MANIFESTO et al., 2010).

O melhoramento pode ser dirigido para caracteres como resistência a doenças e tolerância a pragas, produtividade, precocidade e alterações na constituição física e química das raízes, de modo que o resultado final seja a maior lucratividade do investidor e a maior satisfação do consumidor (CRISÓSTOMO et al., 1999).

De acordo com Scott et al. (2000) o melhoramento de batata-doce tem sido mais lento do que o de outras culturas devido à sua natureza inerente, incluindo a poliploidia, o pobre florescimento, a pouca produção de sementes, a auto e a inter-incompatibilidade, a heterozigoticidade e o grande número de cromossomos.

Mesmo sendo uma cultura importante para o Brasil, principalmente pela função social, a batata-doce é uma cultura ainda pouco pesquisada, principalmente no que diz respeito ao desenvolvimento de novas cultivares, que sejam mais produtivas e adaptadas para as diferentes regiões do país (MASSAROTO et al., 2014). Em condições adversas de cultivo em 
pequenas propriedades familiares como um alimento básico para as comunidades pobres, é necessário proporcionar recursos alternativos que poderiam desempenhar um papel vital na dieta animal e na alimentação humana (AZEVEDO et al., 2014).

Diante o exposto, em programas de melhoramento envolvendo a seleção de genótipos superiores é necessário dispor de informações a respeito do germoplasma a ser utilizado, de suas potencialidades genéticas e de parâmetros genéticos intrínsecos às características que serão melhoradas (OLIVEIRA et al., 2000).

Neste contexto, o trabalho teve como objetivos avaliar o desempenho morfoagronômico de trinta genótipos de batata-doce pertencentes ao banco de germoplasma mantido na Embrapa Hortaliças, nas condições edafoclimáticas de Brasília - DF; avaliar a correlação entre caracteres morfoagronômicos e estimar parâmetros genéticos populacionais. 


\subsection{MATERIAL E MÉTODOS}

\subsubsection{Localização da área experimental}

O experimento foi conduzido no período compreendido entre os dias 19 de março de 2014 e 9 de setembro de 2014, na Embrapa Hortaliças, Brasília - DF, em Latossolo Vermelho-Amarelo com textura média, no sistema convencional e com adubações conforme recomendado por Fontes (1999). O preparo do solo foi realizado por meio de uma aração profunda e duas gradagens, após as quais foi feito o enleiramento com aproximadamente 0,4 m de altura.

\subsubsection{Delineamento experimental}

Foram estudados 30 genótipos de batata-doce do Banco de Germoplasma mantido na Embrapa Hortaliças. O delineamento experimental utilizado foi em blocos casualizados, com 30 tratamentos e 4 repetições. As unidades experimentais foram constituídas de camalhões de $4 \mathrm{~m}$ de comprimento $\times 1,0 \mathrm{~m}$ de largura cada, com 10 plantas por parcela, utilizando-se o espaçamento de 0,4 m entre plantas e de 1,0 m entre camalhões. Empregaram-se bordaduras nas laterais do experimento, onde foram plantadas ramas da cultivar Princesa. Os tratamentos constituíram-se dos clones CNPH 1192, CNPH 1195, CNPH 1197, CNPH 1200, CNPH 1202 , CNPH 1208, CNPH 1216, CNPH 1219, CNPH 1220, CNPH 1221, CNPH 1232, CNPH 1292, CNPH 1298, CNPH 1310, CNPH 1344, CNPH 1357, CNPH 1358, CNPH 1361, CNPH 1365 , CNPH 1805 e CNPH 1809 e das cultivares Beauregard, Brazlândia Branca, Brazlândia Rosada, Brazlândia Roxa, Coquinho, BRS Amélia, BRS Cuia, BRS Rubissol e Princesa.

Foram utilizadas ramas sadias, com 3 a 4 entrenós, dos quais 2 foram enterrados no topo da leira. Quinze dias após o plantio foi realizado o replantio nos locais onde ocorreram falhas. Durante o desenvolvimento, na ausência de chuvas, utilizou-se irrigação por aspersão convencional, por meio da aplicação de uma lâmina de água de aproximadamente $25 \mathrm{~mm}$, com turno de rega de sete dias. Com base nos resultados da análise de solo, realizou-se uma adubação mineral de plantio com a formulação NPK 4-30-16, na dose de $600 \mathrm{~kg} \mathrm{ha}^{-1}$. Foi efetuada adubação de cobertura 20 dias após o plantio, com sulfato de amônio, na dose de 20 $\mathrm{g}$ planta $^{-1}$. O controle de plantas daninhas foi realizado por meio de capinas manuais com enxada e da aplicação dos herbicidas Metribuzim, em pré-plantio, na dose de $1,2 \mathrm{~L} \mathrm{ha}^{-1}$ do produto comercial e Paraquat, nas entrelinhas, trinta dias após o plantio, na dose de $1 \mathrm{~L} \mathrm{ha}^{-1}$ 
do produto comercial. Não foi realizado nenhum tratamento fitossanitário quanto a pragas e doenças. Por ocasião da colheita, as leiras foram desfeitas com enxada, cuidadosamente, e as raízes colhidas de cada parcela foram colocadas em caixas separadas. Posteriormente avaliaram-se as características morfoagronômicas das raízes tuberosas.

\subsubsection{Caracterização morfoagronômica}

\subsubsection{Produção total de raízes frescas}

A produtividade total (PT) foi calculada pela pesagem de todas as raízes de cada parcela em balança digital, com precisão de três casas decimais. O peso total foi extrapolado para t ha 1

\subsubsection{Número total de raízes por planta}

O número total de raízes por planta (NTRPP) foi obtido pela divisão entre o número total de raízes em cada parcela e o número de plantas úteis colhidas na parcela.

\subsubsection{Produção de raízes comerciais}

Dado que no Brasil não existe uma norma oficial para a padronização de batata-doce (MIRANDA et al., 1995), foram classificadas como raízes comercializáveis aquelas que apresentaram pesos entre 150 e 2000 g, com ausência de danos e bom aspecto visual. A produtividade das raízes comercializáveis (PC) foi extrapolada para $\mathrm{tha}^{-1}$.

\subsubsection{Número de raízes comerciais por planta}

O número de raízes com padrão comercial por planta (NRCPP) foi obtido dividindo o número de raízes aptas à comercialização pelo número de plantas úteis colhidas na parcela.

\subsubsection{Peso médio das raízes comercializáveis}

O peso médio das raízes comercializáveis (PMRC) foi determinado pela divisão entre a massa das raízes comerciais e o número de raízes comerciais produzidas na parcela, sendo o valor final expresso em gramas $(\mathrm{g})$.

\subsubsection{Características gerais}

O diâmetro médio da raiz (DR) foi obtido pela medição transversal da parte central da raiz, com a ajuda de um paquímetro digital (Digimess $\left.{ }^{\circledR}\right)$. O comprimento médio da raiz (CR) 
foi obtido medindo-se o eixo longitudinal da raiz com o uso de uma régua plástica graduada. A espessura média do córtex da raiz (EC) foi calculada pela medição da casca na porção mediana das raízes cortadas, com o auxilio de um paquímetro digital. A avaliação destas variáveis foi realizada com a escolha aleatória de 4 a 12 raízes em cada parcela e as leituras foram expressas em milímetros (mm).

\subsubsection{Incidência de danos e grau de resistência}

Para a estimativa dos danos causados por insetos de solo, foram tomadas aleatoriamente de 4 a 12 raízes em cada parcela e avaliada a incidência de danos (ID) segundo a escala de notas empregada por França et al. (1983), citados por Azevedo et al. (2000) e Andrade Júnior et al. (2012).

Foram atribuídas notas em uma escala variável de 1 a 5, na qual 1= raízes livres de danos, com aspecto comercial desejável; 2= raízes com poucos danos, mas com presença de alguns furos e galerias; $3=$ raízes com danos verificados sem muito esforço visual, com aspecto comercial objecionável (muitos furos e galerias); 4= obedeceu a raízes muito danificadas, praticamente inadequadas para comercialização (presença de muitas galerias, furos e início de apodrecimento); $5=$ raízes completamente inadequadas para comercialização (repletas de galerias, furos e apodrecimento mais avançado). As notas foram dadas por dois avaliadores, sendo o valor final expresso pela média das duas notas.

De acordo com a escala de notas para a incidência de danos, classificaram-se os genótipos segundo o seu grau de resistência aos insetos de solo (GR), considerando-se como resistentes $=$ os clones com nota $\leq 1$; moderadamente resistentes $=$ os genótipos com notas $>1$ $\mathrm{e} \leq 2$; moderadamente suscetíveis $=$ os materiais com nota $>2 \mathrm{e} \leq 3$; suscetíveis $=$ os clones com notas $>3$ e $\leq 4$ e altamente suscetíveis $=$ os materiais com notas $>4$ e $\leq 5$.

\subsubsection{Formato das raízes tuberosas}

O formato das raízes (FTO) foi obtido por meio de uma escala de notas entre 1 e 5, estabelecida por França et al. (1983) e empregada por Azevedo et al. (2000) e Andrade Júnior et al. (2012), descrita da seguinte forma: 1= raízes com formato fusiforme, regular, sem veias ou quaisquer rachaduras; $2=$ raízes com formato considerado bom, próximo do fusiforme, mas com algumas desuniformidades, com possível presença de veias ou curvaturas nas raízes; $3=$ raízes com formato irregular, não fusiformes, com algumas veias e/ou rachaduras, mas comercialmente aceitáveis; 4= raízes muito grandes, com formato muito irregular, com veias 
e rachaduras, indesejáveis comercialmente; 5= raízes totalmente fora dos padrões comerciais, muito irregulares, deformadas, curvas e com muitas veias e rachaduras.

Foram avaliadas entre 4 e 12 raízes tomadas aleatoriamente em cada parcela, considerando-se como nota a média das raízes avaliadas. As notas foram dadas por dois avaliadores, sendo o valor final expresso pela média das duas notas.

\subsubsection{Porcentagem de raízes comercializáveis}

A porcentagem de raízes comerciáveis (RC) foi determinada dividindo-se a produtividade comercial pela produtividade total de cada parcela, e multiplicando o valor resultante por 100 .

\subsubsection{Análise estatística}

Com exceção das características comprimento, diâmetro e espessura do córtex das raízes de batata-doce, todos os dados foram transformados em $\sqrt{x+1}$, para atender à pressuposição de distribuição normal e homocedasticidade dos dados, sendo apresentados os valores originais.

Os dados foram submetidos à análise de variância para cada caráter e as médias foram agrupadas por meio do teste de Scott-Knott a 5\% de probabilidade. As análises de correlação linear de Pearson, entre as variáveis, basearam-se na significância de seus coeficientes. A classificação de intensidade da correlação para $p \leq 0,05$ foi: muito forte $(r \pm 0,91$ a $\pm 1,00)$, forte $(r \pm 0,71$ a $\pm 0,9)$, média $(r \pm 0,51$ a $\pm 0,70)$, fraca $(r \pm 0,31$ a $\pm 0,50)$ e muito fraca $(r \leq \pm$ 0,30) (CARVALHO et al., 2004). As análises estatísticas descritas anteriormente foram realizadas utilizando-se o software R Core Team (2013).

A partir dos componentes da variância foram estimados os parâmetros genéticos de herdabilidade no sentido amplo $\left(\mathrm{h}_{\mathrm{a}}{ }^{2}\right)$, os coeficientes de variação genética $\left(\mathrm{CV}_{\mathrm{g}}\right)$, ambiental $\left(\mathrm{CV}_{\mathrm{e}}\right)$ e a razão entre os coeficientes de variação genética e ambiental $\left(\mathrm{CV}_{\mathrm{g}} / \mathrm{CV}_{\mathrm{e}}\right)$ para os caracteres estudados, utilizando-se o programa GENES (CRUZ, 2013). 


\subsection{RESULTADOS E DISCUSSÃO}

Verificou-se a existência de diferenças significativas entre os genótipos a $1 \%$ de probabilidade pelo teste $\mathrm{F}$ para as características produtividade total, número total de raízes por planta, produtividade comercial, número de raízes com padrão comercial e peso médio das raízes comerciais, indicando a existência de variabilidade genética entre os materiais avaliados para estes caracteres (Tabela 3.1).

Foi observada grande amplitude de variação na produtividade total de raízes. O clone CNPH 1310 e as cultivares Brazlândia Branca e Beauregard apresentaram os melhores desempenhos $\left(77,17 ; 85,84\right.$ e 101,03 $\mathrm{t} \mathrm{ha}^{-1}$, respectivamente), enquanto as menores produtividades foram verificadas nos materiais CNPH 1292, CNPH 1809, CNPH 1200, CNPH 1220, CNPH 1344, CNPH 1365, Coquinho, CNPH 1219 e CNPH 1202 (2,81; 2,91; 5,$93 ; 8,00 ; 9,13 ; 10,16 ; 10,98 ; 11,02$ e 12,83 $\mathrm{t} \mathrm{ha}^{-1}$, respectivamente) (Tabela 3.1). A cultivar Beauregard, rica em $\beta$-caroteno, proporcionou rendimentos 36,44; 38,58; 42,14; 43,33; 45,25; 64,59 e 89,13\% superiores, com relação às cultivares BRS Cuia, Princesa, BRS Amélia, BRS Rubissol, Brazlândia Roxa, Brazlândia Rosada e Coquinho, respectivamente.

De acordo com Schultheis et al. (1999) a cultivar Beauregard além de se destacar pelo seu alto rendimento; tem grande aceitação por parte dos consumidores na Carolina do Norte, EUA e apresenta alta precocidade, com tempo ideal para a colheita entre 100 e 110 dias após o cultivo, podendo se obter rendimentos aceitáveis 90 dias após o plantio. Com espaçamento de $31 \mathrm{~cm}$ entre as plantas, estes autores obtiveram produtividade total para esta cultivar de $25,5 \mathrm{t} \mathrm{ha}^{-1}, 132$ dias após o plantio, valor bem inferior ao obtido no presente trabalho $(101,03 \mathrm{t}$ $\mathrm{ha}^{-1}$ ), que pode ter sido decorrente do menor tempo de permanência da cultura no campo.

Segundo Barreto et al. (2011) as cultivares Brazlândia Branca, Brazlândia Roxa e Brazlândia Rosada têm ciclo de cinco meses e apresentam como característica o elevado potencial produtivo de raízes. O clone CNPH $1310\left(77,17 \mathrm{t} \mathrm{ha}^{-1}\right)$, de polpa alaranjada, embora não apresentou diferença estatisticamente significativa com a cultivar Brazlândia Branca $\left(85,84 \mathrm{t} \mathrm{ha}^{-1}\right)$, proporcionou produtividade estatisticamente superior aos valores médios das cultivares comerciais Brazlândia Rosada e Brazlândia Roxa $\left(35,77\right.$ e 55,31 t ha ${ }^{-1}$, respectivamente), as quais também apresentaram produtividades equivalentes, porém inferiores, às dos clones CNPH 1232 e CNPH 1357 (56,47 e 56,79 t ha ${ }^{-1}$, respectivamente). 
Os clones CNPH 1298, CNPH 1192, CNPH 1197, CNPH 1358 e CNPH 1208, também destacaram-se quanto à produtividade total de raízes, com rendimentos médios superiores a $27 \mathrm{t} \mathrm{ha}^{-1}\left(27,93 ; 28,61 ; 28,77 ; 29,61\right.$ e $31,01 \mathrm{t} \mathrm{ha}^{-1}$, respectivamente) (Tabela 3.1).

Tabela 3.1 Produtividade total, número total de raízes por planta, produtividade comercial, número de raízes comerciais por planta e peso médio de raízes comerciais de trinta genótipos de batata-doce

\begin{tabular}{|c|c|c|c|c|c|}
\hline Genótipo & PT $\left(\right.$ t ha $\left.^{-1}\right)$ & NTRPP & $\mathrm{PC}\left(\mathrm{t} \mathrm{ha}^{-1}\right)$ & NRCPP & PMRC (g) \\
\hline Beauregard & 101,03 a & $7,17 \mathrm{a}$ & 87,39 a & $5,36 \mathrm{a}$ & $657,07 \mathrm{a}$ \\
\hline Princesa & $62,05 \mathrm{~b}$ & $5,39 \mathrm{a}$ & $50,37 \mathrm{~b}$ & $3,61 \mathrm{~b}$ & $604,48 \mathrm{a}$ \\
\hline CNPH 1232 & $56,47 \mathrm{~b}$ & $4,59 \mathrm{a}$ & $44,06 \mathrm{~b}$ & $3,12 \mathrm{~b}$ & 573,39 a \\
\hline Brazlândia Branca & 85,84 a & $7,14 \mathrm{a}$ & 70,66 a & $5,35 \mathrm{a}$ & $561,10 \mathrm{a}$ \\
\hline BRS Cuia & $64,21 \mathrm{~b}$ & $5,38 \mathrm{a}$ & $58,22 \mathrm{~b}$ & $4,23 \mathrm{a}$ & $547,87 \mathrm{a}$ \\
\hline CNPH 1221 & $24,32 \mathrm{c}$ & $2,27 \mathrm{~b}$ & $17,50 \mathrm{~d}$ & $1,22 \mathrm{c}$ & $536,95 \mathrm{a}$ \\
\hline BRS Rubissol & $57,25 \mathrm{~b}$ & $5,54 \mathrm{a}$ & $51,76 \mathrm{~b}$ & $4,02 \mathrm{a}$ & $511,09 \mathrm{a}$ \\
\hline BRS Amélia & $58,46 \mathrm{~b}$ & $5,78 \mathrm{a}$ & $44,47 \mathrm{~b}$ & $3,57 \mathrm{~b}$ & 489,36 a \\
\hline CNPH 1298 & $27,93 \mathrm{c}$ & $3,85 \mathrm{~b}$ & $22,96 \mathrm{c}$ & $2,20 \mathrm{c}$ & $484,32 \mathrm{a}$ \\
\hline CNPH 1310 & 77,17 a & $7,93 \mathrm{a}$ & $16,13 \mathrm{~d}$ & $1,50 \mathrm{c}$ & $482,80 \mathrm{a}$ \\
\hline CNPH 1208 & $31,01 \mathrm{c}$ & $4,15 b$ & $22,93 \mathrm{c}$ & $1,96 \mathrm{c}$ & $457,64 \mathrm{a}$ \\
\hline Brazlândia Rosada & $35,77 \mathrm{~b}$ & $3,51 \mathrm{~b}$ & $27,95 \mathrm{c}$ & $2,51 \mathrm{~b}$ & $440,16 \mathrm{a}$ \\
\hline CNPH 1197 & $28,77 \mathrm{c}$ & $3,86 \mathrm{~b}$ & $25,17 \mathrm{c}$ & $2,54 \mathrm{~b}$ & $395,99 \mathrm{a}$ \\
\hline CNPH 1357 & $56,79 \mathrm{~b}$ & $7,93 \mathrm{a}$ & $39,69 \mathrm{c}$ & $4,04 \mathrm{a}$ & $383,24 \mathrm{a}$ \\
\hline Brazlândia Roxa & $55,31 \mathrm{~b}$ & $7,55 \mathrm{a}$ & $46,51 \mathrm{~b}$ & $4,83 \mathrm{a}$ & $380,14 \mathrm{a}$ \\
\hline CNPH 1358 & $29,61 \mathrm{c}$ & $3,48 \mathrm{~b}$ & $12,72 \mathrm{~d}$ & $1,27 \mathrm{c}$ & $364,67 \mathrm{a}$ \\
\hline CNPH 1216 & $22,10 \mathrm{c}$ & $4,03 \mathrm{~b}$ & $12,66 \mathrm{~d}$ & $1,27 \mathrm{c}$ & $358,19 \mathrm{a}$ \\
\hline CNPH 1344 & $9,13 \mathrm{~d}$ & $2,17 \mathrm{~b}$ & $5,79 \mathrm{e}$ & $0,33 \mathrm{~d}$ & $347,50 \mathrm{a}$ \\
\hline CNPH 1805 & $23,06 \mathrm{c}$ & $3,96 \mathrm{~b}$ & $17,24 \mathrm{~d}$ & $2,12 \mathrm{c}$ & $331,93 \mathrm{a}$ \\
\hline CNPH 1195 & $16,56 \mathrm{c}$ & $3,29 \mathrm{~b}$ & $10,93 \mathrm{~d}$ & $1,41 \mathrm{c}$ & $312,08 \mathrm{a}$ \\
\hline CNPH 1219 & $11,02 \mathrm{~d}$ & $2,99 \mathrm{~b}$ & $7,82 \mathrm{~d}$ & $1,04 \mathrm{c}$ & $298,35 \mathrm{a}$ \\
\hline Coquinho & $10,98 \mathrm{~d}$ & $2,50 \mathrm{~b}$ & $8,43 \mathrm{~d}$ & $1,18 \mathrm{c}$ & $251,36 \mathrm{~b}$ \\
\hline CNPH 1200 & $5,93 \mathrm{~d}$ & $2,81 \mathrm{~b}$ & $2,40 \mathrm{e}$ & $0,40 \mathrm{~d}$ & $215,17 \mathrm{~b}$ \\
\hline CNPH 1202 & $12,83 \mathrm{~d}$ & $4,20 \mathrm{~b}$ & $8,34 \mathrm{~d}$ & $1,16 \mathrm{c}$ & $209,41 \mathrm{~b}$ \\
\hline CNPH 1809 & $2,91 \mathrm{~d}$ & $0,88 \mathrm{~b}$ & $1,61 \mathrm{e}$ & $0,26 \mathrm{~d}$ & $183,33 \mathrm{~b}$ \\
\hline CNPH 1361 & $16,97 \mathrm{c}$ & $2,99 \mathrm{~b}$ & $5,00 \mathrm{e}$ & $0,57 \mathrm{~d}$ & $181,39 \mathrm{~b}$ \\
\hline CNPH 1192 & $28,61 \mathrm{c}$ & $2,16 b$ & $0,73 \mathrm{e}$ & $0,09 \mathrm{~d}$ & $153,75 \mathrm{~b}$ \\
\hline CNPH 1365 & $10,16 \mathrm{~d}$ & $2,99 \mathrm{~b}$ & $2,06 \mathrm{e}$ & $0,27 \mathrm{~d}$ & $145,63 \mathrm{~b}$ \\
\hline CNPH 1220 & $8,00 \mathrm{~d}$ & $2,33 \mathrm{~b}$ & $0,00 \mathrm{e}$ & $0,00 \mathrm{~d}$ & $0,00 \mathrm{c}$ \\
\hline CNPH 1292 & $2,81 \mathrm{~d}$ & $3,00 \mathrm{~b}$ & $0,00 \mathrm{e}$ & $0,00 \mathrm{~d}$ & $0,00 \mathrm{c}$ \\
\hline $\mathrm{QM}_{\text {(tratamento) }}$ & $20,66^{* *}$ & $0,67 * *$ & $22,46 * *$ & $0,90 * *$ & $168,06 * *$ \\
\hline Média & 34,44 & 4,19 & 24,05 & 2,05 & 361,94 \\
\hline C.V. $(\%)$ & 23,49 & 15,9 & 25,74 & 14,54 & 33,87 \\
\hline
\end{tabular}

Médias com a mesma letra na coluna não diferem entre si, pelo teste de Scott-Knott a 5\% de probabilidade; QM: quadrado médio dos tratamentos; **Significativo a $1 \%$ de probabilidade pelo teste F; C.V.: coeficiente de variação. PT: produtividade total; NTRPP: número total de raízes por planta; PC: produtividade comercializável; NRCPP: número de raízes comerciais por planta; PMRC: peso médio de raízes comerciáveis de batata-doce. 
Com exceção da cultivar Coquinho, as produtividades mais elevadas observadas para maioria das cultivares com relação aos rendimentos dos clones, podem ser explicadas, além do material genético, pela origem das mudas, que no caso das cultivares, são mantidas em viveiro e passaram previamente pela limpeza clonal. Já os clones são mantidos em campo e são multiplicados de forma convencional. Ainda, foi observado em campo que as cultivares possuem ramas mais vigorosas que as dos clones, os quais podem ter suas ramas sobrepostas pelas das cultivares quando colocados em parcelas próximas, fato que pode comprometer o desenvolvimento de suas plantas e consequentemente a produtividade de suas raízes.

A produtividade total média atingida no presente estudo $\left(34,44 \mathrm{t} \mathrm{ha}^{-1}\right)$ foi superior aos valores previamente reportados por Silva et al. (1991), Ankumah et al. (2003) e Câmara et al. (2013), com colheita aos quatro meses (14,38; 29,23 e 30,74 $\mathrm{t} \mathrm{ha}^{-1}$, respectivamente); Azevedo et al. (2000) e Queiroga et al. (2007), com colheita aos cinco meses (18,48 e 20,70 t $\mathrm{ha}^{-1}$, respectivamente); Andrade Júnior et al. (2012) e Cecílio Filho et al. (1996), com colheita aos seis meses (19,43 e 33,24 $\mathrm{t} \mathrm{ha}^{-1}$, respectivamente); Cardoso et al. (2005), com colheita aos 7 meses $\left(15,22 \mathrm{t} \mathrm{ha}^{-1}\right)$ e Souza (2000), com colheita aos oito meses (17,2 $\left.\mathrm{t} \mathrm{ha}^{-1}\right)$. No entanto, foi inferior à produtividade média encontrada por Ozturk et al. (2012), com colheita aos 7 meses $\left(42,93 \mathrm{tha}^{-1}\right)$.

A maior produtividade média constatada no presente estudo pode ser atribuída à época de cultivo, com o plantio no mês de março, quando, 102 dias após a implantação da cultura no campo, ou seja, no mês de julho, ocorre aumento do fotoperíodo na região, favorecendo o crescimento da estrutura vegetativa das plantas, que conduz ao maior acúmulo de fotoassimilados nas raízes tuberosas.

Estas diferenças podem também estar associadas com a duração do ciclo da cultura em campo, que têm influência direta sobre a produtividade de batata-doce, como previamente constatado por Azevedo et al. (2014), que reportaram produtividades médias de 11,76; 19,53 e $17,77 \mathrm{t} \mathrm{ha}^{-1}$ com colheita realizada aos 120, 150 e 180 dias após o plantio. De igual forma, segundo Viana (2009), os rendimentos médios dos genótipos também estão condicionados ao local de plantio. Este autor avaliou dois ambientes de cultivo, em Diamantina - MG e observou na Fazenda Forquilha uma produtividade total 113,33\% superior $\left(18,41 \mathrm{t} \mathrm{ha}^{-1}\right)$ com relação à produtividade verificada no Campus II da UFVJM $\left(8,63 \mathrm{t} \mathrm{ha}^{-1}\right)$.

Além da época e do local de plantio, das condições edafoclimáticas do lugar de cultivo, do tempo de permanência da cultura no campo e dos constituintes genéticos dos materiais, 
diferentes cultivares de uma mesma cultura adaptam-se de forma muito diferente em resposta a estímulos ambientais, mesmo que elas estejam acostumadas ao mesmo ambiente (SHEKHAR et al., 2015).

De acordo com Abidin et al. (2005) o desempenho de genótipos em diversos ambientes é quantificado em termos da adaptabilidade ampla e específica e da estabilidade do rendimento, sendo estes conceitos essenciais para a batata-doce, que é uma cultura muito sensível a mudanças ambientais. Segundo este autor a adaptabilidade ampla é geralmente atribuída a variedades que apresentam bom desempenho em diversos locais. Variedades amplamente adaptadas apresentam médias altas em diversos ambientes enquanto as variedades com adaptação específica proporcionam os maiores rendimentos em alguns locais, mas não em outros. Uma variedade é considerada estável quando o rendimento varia relativamente pouco em relação ao rendimento médio para essa variedade, após correção das diferenças médias que sempre existirão entre os ambientes.

Segundo Grüneberg et al. (2005) o conhecimento das interações genótipo × ambiente em batata-doce é necessário antes de se decidir entre desenvolver genótipos amplamente ou especificamente adaptados e como alocar os recursos entre os testes para a produtividade e as características nutricionais. Genótipos que apresentem potencial produtivo devem ser avaliados no maior número possível de locais e anos para verificar sua estabilidade e as interações com o ambiente, visando fazer uma indicação segura antes da liberação de uma nova variedade. Já a magnitude da interação genótipo $\times$ ambiente para características nutricionais de batata-doce são pequenas, podendo a seleção ser praticada em um ou poucos ambientes, mesmo que o melhorista esteja objetivando o desenvolvimento de materiais para diferentes regiões ecogeográficas.

O número total de raízes por planta oscilou entre 0,88 e 7,93 (Tabela 3.1). Os genótipos CNPH 1232, BRS Cuia, Princesa, BRS Rubissol, BRS Amélia, Brazlândia Branca, Beauregard, Brazlândia Roxa, CNPH 1357 e CNPH 1310 produziram as maiores quantidades de raízes por planta $(4,59 ; 5,38 ; 5,39 ; 5,54 ; 5,78 ; 7,14 ; 7,17 ; 7,55 ; 7,93$ e 7,93, respectivamente). A comparação do número total de raízes, quantificado neste estudo, com os reportados na literatura, indicou que os valores estiveram dentro dos intervalos observados previamente por Santos et al. (2005), de 1,98 a 2,37; Cavalcante et al. (2009), de 2,67 a 5 e Câmara et al. (2013), de 2,5 a 5,75. 
As cultivares Beauregard e Brazlândia Branca destacaram-se quanto à produtividade comercial, com rendimentos comerciais médios de 87,39 e $70,66 \mathrm{t} \mathrm{ha}^{-1}$, respectivamente (Tabela 3.1). No outro extremo, os clones CNPH 1192, CNPH 1809, CNPH 1365, CNPH 1200, CNPH 1361 e CNPH 1344, mostraram os piores desempenhos, com produtividades comerciáveis oscilando entre 0,73 e 5,79 $\mathrm{t} \mathrm{ha}^{-1}$, sendo que os clones CNPH1220 e CNPH 1292 não apresentaram raízes comerciais. O clone CNPH $1232\left(44,06 \mathrm{t} \mathrm{ha}^{-1}\right)$, de polpa alaranjada, apresentou produtividade comercial equivalente à das cultivares BRS Amélia, Brazlândia Roxa, Princesa, BRS Rubissol e BRS Cuia (44,47; 46,51; 50,37; 51,76 e 58,22 t $\mathrm{ha}^{-1}$, respectivamente) e superior à das cultivares Coquinho e Brazlândia Rosada (8,43 e 27,95 $\mathrm{t} \mathrm{ha}^{-1}$, respectivamente), sendo por tanto promissor. Os clones CNPH 1208, CNPH 1298, CNPH 1197 e CNPH 1357 com 22,93; 22,96; 25,17 e 39,69 t ha ${ }^{-1}$, respectivamente, também obtiveram boa produtividade comercial, não apresentando diferenças estatisticamente significativas com a cultivar Brazlândia Rosada $\left(27,95 \mathrm{t} \mathrm{ha}^{-1}\right)$.

Cardoso et al. (2005), com colheita aos 7 meses; Massaroto (2008), com colheita aos 6 meses; Gonçalves Neto et al. (2011), com colheita aos 7 meses e Figueiredo (2010), com colheita aos 5,5 meses, reportaram produtividades comercializáveis médias de 10,83; 11,81; 16,50 e 20,87 $\mathrm{t} \mathrm{ha}^{-1}$, respectivamente, as quais foram inferiores às obtidas na presente pesquisa $\left(24,05 \mathrm{t} \mathrm{ha}^{-1}\right)$.

Observou-se diferença estatisticamente significativa entre os materiais estudados com relação ao número de raízes com padrão comercial por planta, que variou de 0 a 5,36, com valor médio de 2,05 (Tabela 3.1). As maiores quantidades foram verificadas nos materiais BRS Rubissol, CNPH 1357, BRS Cuia, Brazlândia Roxa, Brazlândia Branca e Beauregard $(4,02 ; 4,04 ; 4,23 ; 4,83 ; 5,35$ e 5,36, respectivamente). Com relação às cultivares Brazlândia Roxa e Brazlândia Branca, Pozzer et al. (1995) reportaram 1,7 e 2,88 raízes comercias por planta, respectivamente, valores estes inferiores aos obtidos no presente trabalho, que foram de 4,83 e 5,35, respectivamente. O número médio de raízes comerciais por cova $(2,05)$ foi semelhante ao obtido por Queiroga et al. (2007), de 1,80, com plantio em março e colheita aos 155 dias; contudo, foi inferior às quantidades constatadas por Câmara et al. (2013), de 3,75, com plantio em agosto e colheita aos 4 meses e por Silva et al. (1991), de 7,64, com plantio em abril e colheita efetuada aos 4 meses.

Erpen et al., (2013) estudando, em Santa Maria - RS, o efeito de datas de plantio sobre o início de tuberização (IT) da cultivar Princesa, verificaram maior produtividade comercial de 
raízes (21,5 $\left.\mathrm{t} \mathrm{ha}^{-1}\right)$ quando o plantio foi realizado no final do inverno (25/8/2011). Apesar de que nesta data, a fase plantio-IT (70 dias após o plantio) foi superior com relação aos plantios realizados nos meses de novembro, janeiro e fevereiro (58, 55 e 53 dias após o plantio, respectivamente); os meses de novembro a fevereiro apresentaram valores mais altos de radiação solar incidente e coincidiram com o período de acumulação de amido. Com maior disponibilidade de radiação solar e de temperaturas favoráveis ao crescimento e desenvolvimento das plantas, estas foram capazes de produzir maior massa seca total, tanto da parte aérea como das raízes tuberosas, aumentando a produtividade das raízes. Adicionalmente, de acordo com estes autores, o índice de tuberização também foi influenciado pelo fotoperíodo, sendo que fotoperíodos mais curtos e temperaturas amenas $\left(25^{\circ} \mathrm{C}\right)$ aceleram sua ocorrência. Já maior duração do período IT-colheita e alta radiação solar incidente, permitem maior tempo para a acumulação de fotoassimilados nas raízes durante o período de crescimento.

O peso médio das raízes comerciais oscilou entre 145,63, para o clone CNPH 1365 e $657,07 \mathrm{~g}$, para a cultivar Beauregard (Tabela 3.1). O maior peso médio obtido para esta cultivar, reforça a hipótese de que a mesma possui ciclo mais curto, o que contribuiu para um valor superior. No entanto, a cultivar Beauregard apresentou peso médio de raízes com padrão comercial estatisticamente equivalente ao dos genótipos CNPH 1219, CNPH 1195, CNPH 1805, CNPH 1344, CNPH 1216, CNPH 1358, Brazlândia Roxa, CNPH 1357, CNPH 1197, Brazlândia Rosada, CNPH 1208, CNPH 1310, CNPH 1298, BRS Amélia, BRS Rubissol, CNPH 1221, BRS Cuia, Brazlândia Branca, CNPH 1232 e Princesa, com peso médio de raízes comerciais variando entre 298,35 e 604,48 g.

A grande amplitude de variação observada para a massa das raízes com padrão comercial (de 145,63 a 657,07 g), foi superior à corroborada por Azevedo et al. (2000), de 123,26 a 261,43 g; Azevedo et al. (2014) de 114,12 a 520,60 g; Ozturk et al. (2012), de 208,3 a 470,3 g; Queiroga et al. (2007) de 174,86 a 257,03 g; Resende (1999), de 219,9 a 337,6 g e Resende (2000) de 220,12 a 504,94 g; contudo, foi inferior à alcançada por Massaroto et al. (2014), de 233,7 a $889,0 \mathrm{~g}$.

Os clones CNPH 1344, CNPH 1358, CNPH 1216, CNPH 1357, CNPH 1195, CNPH 1805 e CNPH 1197 e a cultivar Brazlândia Roxa, enquadraram-se no peso médio ideal de raízes de batata-doce (tipo extra A), que de acordo com Miranda et al. (1995) deve variar entre 301 e 400g. A cultivar Coquinho e os clones CNPH 1219, CNPH 1202 e CNPH 1200, 
encaixaram-se na classificação Extra B de raízes (entre 201 e 300 g). Já as cultivares BRS Cuia, BRS Rubissol, Beauregard, Brazlândia Branca, Princesa, Brazlândia Rosada, BRS Amélia e os clones CNPH 1232, CNPH 1298, CNPH 1208, CNPH 1221 e CNPH 1310, ajustaram-se na classificação diversos (raízes tuberosas com pesos entre 80 e 150 g ou maiores que $400 \mathrm{~g}$ ). É provável que estes genótipos apresentem ciclos mais precoces, que proporcionaram maior tuberização.

A Tabela 3.2 apresenta os valores médios das variáveis comprimento, diâmetro, espessura de córtex, incidência de danos ocasionados por insetos de solo, grau de resistência, formato e porcentagem de raízes comerciais dos genótipos de batata-doce estudados.

Foram observadas diferenças significativas entre os genótipos para a característica comprimento das raízes tuberosas, que variou de 101,62 a 237,44 mm (Tabela 3.2). As cultivares Brazlândia Branca e Princesa e o clone CNPH 1357 apresentaram os maiores comprimentos (212,15; 235,69 e 237,44 mm, respectivamente). Resultados semelhantes foram encontrados por Cavalcante et al. (2012), que obtiveram comprimentos de raízes tuberosas na faixa de 137,8 (clone CL-13) a 207,8 mm (clone CL-01); Cardoso et al. (2005), que verificaram raízes com comprimentos entre 123,1 e 206,9 mm, para os clones Gurupi e Janaúba, respectivamente e Miranda et al. (1988), que observaram com as cultivares 1 e 9 raízes com comprimento máximo de $110 \mathrm{~mm}$ e mínimo de $240 \mathrm{~mm}$, respectivamente.

O diâmetro das raízes variou de 26,38 a 92,43 mm, para os clones CNPH 1292 e CNPH 1192, respectivamente (Tabela 3.2). Os maiores diâmetros foram verificados nos genótipos BRS Amélia, CNPH 1197, BRS Rubissol, Princesa, Beauregard, CNPH 1221, CNPH 1208, CNPH 1310, CNPH 1805, BRS Cuia, CNPH 1232 e CNPH 1192 (68,53; 70,36; 72,61; 74,07; 74,$63 ; 74,77 ; 75,08 ; 75,21 ; 76,50 ; 80,44 ; 84,30$ e 92,43 mm, respectivamente). Cavalcante et al. (2009), Queiroga et al. (2007) e Silva et al. (2012), encontraram diâmetros de raízes de batata-doce variando entre 50,0 e $66,6 \mathrm{~mm} ; 45,9$ e $52,9 \mathrm{~mm}$ e 56,2 e $97,7 \mathrm{~mm}$, respectivamente. $\mathrm{O}$ menor diâmetro observado no presente estudo $(26,38 \mathrm{~mm})$ esteve abaixo dos limites inferiores reportados pelos autores previamente citados.

A espessura média do córtex foi de 2,32 mm (Tabela 3.2), sendo os maiores valores apresentados pelo clone CNPH 1232 e pelas cultivaras Brazlândia Roxa e Princesa (2,93; 3,04 e 3,50, respectivamente). Cavalcante et al. (2009) observaram para esta característica valor médio de 3,03 mm, que foi superior ao atingido no presente estudo. 
Com referência à incidência de danos ocasionados por insetos de solo, foram observadas notas variando de 1,06 a 2,54 (Tabela 3.2).

Tabela 3.2 Comparação dos valores médios do comprimento, diâmetro, espessura de córtex, incidência de danos ocasionados por insetos de solo, formato e percentagem de raízes comerciais de trinta genótipos de batata-doce

\begin{tabular}{|c|c|c|c|c|c|c|c|}
\hline Genótipo & CR (mm) & DR (mm) & $\mathrm{EC}(\mathrm{mm})$ & ID & GR & FTO & $\mathrm{RC}(\%)$ \\
\hline BRS Cuia & $160,46 \mathrm{c}$ & $80,44 \mathrm{a}$ & $2,15 \mathrm{c}$ & $1,69 \mathrm{~b}$ & MR & $2,25 \mathrm{c}$ & $90,05 \mathrm{a}$ \\
\hline BRS Rubissol & $196,21 \mathrm{~b}$ & $72,61 \mathrm{a}$ & $2,52 \mathrm{~b}$ & $1,94 \mathrm{a}$ & MR & $2,04 \mathrm{c}$ & $89,69 \mathrm{a}$ \\
\hline CNPH 1197 & $150,00 \mathrm{c}$ & $70,36 \mathrm{a}$ & $2,68 \mathrm{~b}$ & $1,81 \mathrm{a}$ & MR & $2,63 \mathrm{~b}$ & $87,60 \mathrm{a}$ \\
\hline Beauregard & $178,04 \mathrm{~b}$ & $74,63 \mathrm{a}$ & $2,37 \mathrm{c}$ & $1,54 \mathrm{~b}$ & MR & $1,13 \mathrm{~d}$ & $86,36 \mathrm{a}$ \\
\hline Brazlândia Roxa & $179,90 \mathrm{~b}$ & $50,37 \mathrm{~b}$ & $3,04 \mathrm{a}$ & $1,35 \mathrm{~b}$ & MR & $1,50 \mathrm{~d}$ & $83,06 \mathrm{a}$ \\
\hline Brazlândia Branca & $212,15 \mathrm{a}$ & $61,38 \mathrm{~b}$ & $2,36 \mathrm{c}$ & $2,21 \mathrm{a}$ & MS & $1,88 \mathrm{c}$ & $82,12 \mathrm{a}$ \\
\hline CNPH 1232 & $162,23 \mathrm{c}$ & $84,30 \mathrm{a}$ & $2,93 \mathrm{a}$ & $1,50 \mathrm{~b}$ & MR & $1,90 \mathrm{c}$ & $80,84 \mathrm{a}$ \\
\hline Princesa & $235,69 \mathrm{a}$ & $74,07 \mathrm{a}$ & $3,50 \mathrm{a}$ & $2,04 \mathrm{a}$ & MS & $2,33 \mathrm{c}$ & $79,40 \mathrm{a}$ \\
\hline Brazlândia Rosada & $194,75 \mathrm{~b}$ & $59,16 \mathrm{~b}$ & $2,39 \mathrm{c}$ & $1,98 \mathrm{a}$ & MR & $1,88 \mathrm{c}$ & $76,87 \mathrm{a}$ \\
\hline CNPH 1805 & $125,50 \mathrm{~d}$ & $76,50 \mathrm{a}$ & $2,81 \mathrm{~b}$ & $1,58 \mathrm{~b}$ & MR & $2,73 \mathrm{~b}$ & $76,62 \mathrm{a}$ \\
\hline BRS Amélia & $190,63 \mathrm{~b}$ & $68,53 \mathrm{a}$ & $2,64 \mathrm{~b}$ & $1,65 \mathrm{~b}$ & MR & $2,00 \mathrm{c}$ & $76,00 \mathrm{a}$ \\
\hline CNPH 1298 & $152,21 \mathrm{c}$ & $60,10 \mathrm{~b}$ & $2,28 \mathrm{c}$ & $1,58 \mathrm{~b}$ & MR & $2,03 \mathrm{c}$ & $74,22 \mathrm{a}$ \\
\hline CNPH 1208 & $149,17 \mathrm{c}$ & $75,08 \mathrm{a}$ & $1,89 \mathrm{c}$ & $1,96 \mathrm{a}$ & MR & $2,71 \mathrm{~b}$ & $73,73 \mathrm{a}$ \\
\hline CNPH 1219 & $134,35 \mathrm{c}$ & $63,36 \mathrm{~b}$ & $2,66 \mathrm{~b}$ & $1,79 \mathrm{a}$ & MR & $2,21 \mathrm{c}$ & $68,70 \mathrm{a}$ \\
\hline CNPH 1195 & $184,04 \mathrm{~b}$ & $55,40 \mathrm{~b}$ & $2,13 \mathrm{c}$ & $1,33 \mathrm{~b}$ & MR & $1,60 \mathrm{~d}$ & $67,49 \mathrm{a}$ \\
\hline CNPH 1221 & $141,63 \mathrm{c}$ & $74,77 \mathrm{a}$ & $2,13 \mathrm{c}$ & $1,9 \mathrm{a}$ & MR & $3,02 \mathrm{~b}$ & $67,44 \mathrm{a}$ \\
\hline CNPH 1357 & $237,44 \mathrm{a}$ & $57,77 \mathrm{~b}$ & $1,89 \mathrm{c}$ & $1,38 \mathrm{~b}$ & MR & $2,79 \mathrm{~b}$ & $67,18 \mathrm{a}$ \\
\hline Coquinho & $101,62 \mathrm{~d}$ & $56,22 \mathrm{~b}$ & $1,46 \mathrm{c}$ & $2,04 \mathrm{a}$ & MS & $2,46 \mathrm{c}$ & $59,94 \mathrm{a}$ \\
\hline CNPH 1216 & $168,58 \mathrm{~b}$ & $56,68 \mathrm{~b}$ & $2,74 \mathrm{~b}$ & $2,08 \mathrm{a}$ & MS & $3,00 \mathrm{~b}$ & $53,28 \mathrm{a}$ \\
\hline CNPH 1809 & $118,97 \mathrm{~d}$ & $38,06 \mathrm{c}$ & $2,03 \mathrm{c}$ & $1,06 \mathrm{~b}$ & MR & $2,88 \mathrm{~b}$ & $50,35 \mathrm{a}$ \\
\hline CNPH 1358 & $147,69 \mathrm{c}$ & $56,80 \mathrm{~b}$ & $2,53 \mathrm{~b}$ & $1,50 \mathrm{~b}$ & MR & $2,65 \mathrm{~b}$ & $46,91 \mathrm{a}$ \\
\hline CNPH 1202 & $144,88 \mathrm{c}$ & $48,59 \mathrm{~b}$ & $1,93 \mathrm{c}$ & $1,65 \mathrm{~b}$ & MR & $2,08 \mathrm{c}$ & $44,80 \mathrm{a}$ \\
\hline CNPH 1344 & $138,27 \mathrm{c}$ & $46,21 \mathrm{~b}$ & $2,03 \mathrm{c}$ & $2,08 \mathrm{a}$ & MS & $2,83 \mathrm{~b}$ & $33,90 \mathrm{~b}$ \\
\hline CNPH 1310 & $159,96 \mathrm{c}$ & $75,21 \mathrm{a}$ & $2,34 \mathrm{c}$ & $2,35 \mathrm{a}$ & MS & $3,54 \mathrm{a}$ & $31,38 \mathrm{~b}$ \\
\hline CNPH 1200 & $121,96 \mathrm{~d}$ & $50,41 \mathrm{~b}$ & $2,04 \mathrm{c}$ & $1,84 \mathrm{a}$ & MR & $2,10 \mathrm{c}$ & $28,93 \mathrm{~b}$ \\
\hline CNPH 1361 & $113,56 \mathrm{~d}$ & $57,87 \mathrm{~b}$ & $1,91 \mathrm{c}$ & $2,53 \mathrm{a}$ & MS & $3,69 \mathrm{a}$ & $18,89 \mathrm{~b}$ \\
\hline CNPH 1365 & $139,73 \mathrm{c}$ & $53,81 \mathrm{~b}$ & $2,52 \mathrm{~b}$ & $1,85 \mathrm{a}$ & MR & $3,44 \mathrm{a}$ & $18,14 \mathrm{~b}$ \\
\hline CNPH 1192 & $119,37 \mathrm{~d}$ & 92,43 a & $1,83 \mathrm{c}$ & $2,54 \mathrm{a}$ & MS & $4,31 \mathrm{a}$ & $1,53 \mathrm{c}$ \\
\hline CNPH 1220 & $145,21 \mathrm{c}$ & $36,36 \mathrm{c}$ & $2,16 \mathrm{c}$ & $1,75 \mathrm{~b}$ & MR & $3,38 \mathrm{a}$ & $0,00 \mathrm{c}$ \\
\hline CNPH 1292 & $101,92 \mathrm{~d}$ & $26,38 \mathrm{c}$ & $1,77 \mathrm{c}$ & $1,77 \mathrm{a}$ & MR & $3,13 \mathrm{~b}$ & $0,00 \mathrm{c}$ \\
\hline $\mathrm{QM}_{\text {(tratamento) }}$ & $5055,27 * *$ & $890,68 * *$ & $0,76^{* *}$ & $0,04 * *$ & - & $0,14 * *$ & $27,84 * *$ \\
\hline Média & 156,87 & 61,8 & 2,32 & 1,81 & - & 2,54 & 57,18 \\
\hline C.V. (\%) & 14,81 & 16,51 & 17,06 & 7,51 & - & 8,08 & 28,28 \\
\hline
\end{tabular}

Médias com a mesma letra na coluna não diferem entre si, pelo teste de Scott-Knott a 5\% de probabilidade; QM: quadrado médio dos tratamentos; **Significativo a $1 \%$ de probabilidade pelo teste F; C.V.: coeficiente de variação. CR: comprimento; DR: diâmetro; EC: espessura de córtex; ID: incidência de danos ocasionados por insetos de solo; GR: grau de resistência (MR: moderadamente resistente; MS: moderadamente suscetível); FTO: formato; $\mathrm{RC}$ : percentagem de raízes comerciais.

Os maiores danos foram constatados nos genótipos Coquinho, Princesa, CNPH 1216, CNPH 1344, Brazlândia Branca, CNPH 1310, CNPH 1361 e CNPH 1192, com notas 
superiores a $2(2,04 ; 2,04 ; 2,08 ; 2,08 ; 2,21 ; 2,35 ; 2,53$ e 2,54 , respectivamente), sendo considerados como moderadamente suscetíveis. Contudo, estes materiais foram estatisticamente equivalentes aos clones CNPH 1292, CNPH 1219, CNPH 1197, CNPH 1200, CNPH 1365, CNPH 1221 e CNPH 1208 e às variedades BRS Rubissol e Brazlândia Rosada, que apresentaram notas variando entre 1,77 e 1,98 e foram classificados como de resistência moderada aos insetos de solo.

Outros genótipos que apresentaram moderada resistência a insetos de solo foram CNPH 1809, CNPH 1195, Brazlândia Roxa, CNPH 1357, CNPH 1358, CNPH 1232, Beauregard, CNPH 1805, CNPH 1298, CNPH 1202, BRS Amélia, BRS Cuia e CNPH 1220, os quais mostraram danos de pequena proporção, com notas 1,$06 ; 1,33 ; 1,35 ; 1,38 ; 1,50 ; 1,50 ; 1,54$; 1,$58 ; 1,58 ; 1,65 ; 1,65 ; 1,69$ e 1,75 , respectivamente.

Apenas os clones CNPH 1310, CNPH 1361 e CNPH 1192 (2,35; 2,53 e 2,54, respectivamente), apresentaram notas superiores a 2,21, que foi o valor obtido pela cultivar Brazlândia Branca, reconhecidamente suscetível a insetos de solo (AZEVEDO et al., 2000; MASSAROTO et al., 2014; PEIXOTO et al., 1999).

Viana (2009) avaliando dois ambientes de cultivo, em Diamantina - MG, observaram que todos os clones apresentaram de alta a moderada resistência, com notas variando de 1,0 a 2,53 .

Peixoto et al. (1999) também verificaram a suscetibilidade a insetos de solo da cultivar Coquinho, com nota 2,68.

Andrade Júnior et al. (2012) avaliando a resistência a insetos de 12 materiais, seis meses após o plantio, observaram notas com uma amplitude de variação de 1,2 a 2,5. Estes autores igualmente conferiram a resistência das cultivares Brazlândia Roxa e Brazlândia Rosada com notas 1,6 e 1,8, respectivamente. Segundo Silva et al. (1995) a cultivar Brazlândia Roxa apresenta boa resistência a insetos de solo.

Massaroto et al. (2014) estudando 25 clones de batata-doce, 6 meses após o plantio, verificaram danos na faixa de 1,42 a 3,74. Estes autores classificaram a cultivar Brazlândia roxa, com nota 1,66, como de resistência alta a moderada. Já as cultivares Brazlândia Branca e Brazlândia Rosada apresentaram notas superiores a 2 (2,51 e 2,83, respectivamente).

Figueiredo (2010) reportaram resistência a insetos de solo variando de 1,10 a 2,56; com as cultivares Brazlândia Branca e Brazlândia Rosada apresentando notas de 2,02 e 2,28, respectivamente. 
Azevedo et al. (2014) estudando 3 épocas de colheita e 2 locais de cultivo, em Diamantina - MG, encontraram que não houve diferenças estatisticamente significativas, com relação à resistência a insetos de solo, entre os locais de plantio e as datas de colheita avaliadas. Cento e oitenta dias após o plantio, no campus JK, estes autores constaram maior ataque dos insetos de solo à cultivar Princesa $(1,83)$ com relação à cultivar Brazlândia Rosada $(1,43)$; já na fazenda Forquilha, foi observado um comportamento oposto $(1,13$ e 1,57, respectivamente).

Silveira et al. (2011) em pesquisa sobre os danos causados por insetos de solo durante duas estações, cinco meses após o plantio, verificaram que na estação seca os danos foram maiores, com notas oscilando entre 1,5 e 3,5, enquanto no período chuvoso, a amplitude da variação dos danos foi mais estreita e menor, de 1 a 2,67.

O formato médio das raízes tuberosas oscilou entre 1,13 e 4,31 (Tabela 3.2). Os melhores formatos foram observados nas cultivares Beauregard, Brazlândia Roxa e no clone CNPH $1195(1,13 ; 1,50$ e 1,60, respectivamente). Contudo, as cultivares Brazlândia Branca, Brazlândia Rosada, BRS Amélia, BRS Rubissol, BRS Cuia, Princesa e Coquinho e os clones CNPH 1232, CNPH 1298, CNPH 1202, CNPH 1200 e CNPH 1219, com notas variando entre 1,88 e 2,46, apresentaram notas de formato inferior a 2,5.

Andrade Júnior et al. (2012) verificaram que todos os clones apresentaram raízes com formato próximo ao ideal para comercialização, com notas inferiores a 3,0. As cultivares Brazlândia Rosada $(1,88)$ e Brazlândia Roxa $(1,50)$ apresentaram formatos semelhantes, aos reportados por estes autores que obtiveram notas de 1,8 e 2,2, respectivamente.

Entre os 29 materiais estudados por Peixoto et al. (1999), todos os clones apresentaram notas de formato inferiores a 3,0, variando de 1,70 (clone Pira 1) a 2,93 (clones 95008 e Rio Doce), sendo considerados bastante promissores. Já as cultivares Brazlândia rosada e Coquinho receberam nota 3,1 , que foi superior às encontradas na presente pesquisa $(1,88 \mathrm{e}$ 2,46, respectivamente).

Massaroto (2008) observou em 25 clones notas de formato entre 2,27 (cv. Brazlândia roxa) e 4,75 (clone UFT-52). O 60\% dos materiais avaliados por este autor apresentou notas superiores a 3,0, que no presente trabalho foram observadas apenas para o 26,67\% dos genótipos estudados. 
Azevedo et al. (2000), cinco meses após o plantio, obtiveram formatos na faixa de 2,17, para os clones 92676 e Surpresa a 4,92, para o clone 92619. A cultivar Brazlândia Branca apresentou nota 3,5 , que foi quase duas vezes maior à obtida nesta pesquisa $(1,88)$.

Gonçalves Neto et al. (2012) avaliando 39 materiais, sete meses após o plantio, verificaram notas de formato variando de 1,5 (clones UFLA07-31, UFLA07-49 e UFLA0753) a 4,5 (clones UFLA07-10, UFLA07-18, UFLA07-21 e UFLA07-42). Já Cardoso et al. (2005), com colheita aos sete meses, não observaram diferenças significativas para o formato de raízes tuberosas entre os 16 clones avaliados, sendo que todos os clones apresentaram notas inferiores a 3,0, variando de 1,63 a 2,27.

Os clones CNPH 1216, CNPH 1221, CNPH 1292, CNPH 1220, CNPH 1365, CNPH 1310, CNPH 1361 e CNPH 1192 apresentaram os piores formatos, com notas variando de 3 a 4,31 .

Os genótipos BRS Cuia, BRS Rubissol, Beauregard, Brazlândia Roxa, Brazlândia Branca e CNPH 1232, com produtividades totais acima de $55 \mathrm{t} \mathrm{ha}^{-1}$, apresentaram percentagens de raízes comerciais superiores a $80 \%(90,05 ; 89,69 ; 86,36 ; 83,06 ; 82,12$ e $80,84 \%$ respectivamente), porém sem diferir estatisticamente dos materiais CNPH 1197, Princesa, Brazlândia Rosada, BRS Amélia, CNPH 1298, CNPH 1208, CNPH 1357 e CNPH 1358 $(87,60 ; 79,40 ; 76,87 ; 76,00 ; 74,22 ; 73,73 ; 67,18$ e $46,91 \%$, respectivamente), que proporcionaram produtividades variando de 27,93 a 62,05 $\mathrm{t} \mathrm{ha}^{-1}$ (Tabela 3.2).

Apesar das altas produtividades totais verificadas nos clones CNPH 1310, de 77,17 t ha ${ }^{-1}$ e CNPH 1192, de 28,61 t ha-1, estes materiais apresentaram baixas produtividades de raízes com padrão comercial (31,38 e 1,53\%, respectivamente). As altas perdas constatadas de 98,47\%, para o clone CNPH 1192 e de 68,62\%, para o clone CNPH 1310, foram decorrentes de suas suscetibilidades aos insetos de solo e dos piores formatos de suas raízes, que foram excessivamente grandes e rachadas, tornando-as indesejáveis para a comercialização.

Os longos fotoperíodos durante a maior parte do período de desenvolvimento da cultura promoveram um ambiente favorável para o aumento da produtividade de batata-doce. No entanto, maiores períodos de permanência da cultura no campo prejudicam os materiais mais precoces, devido à maior vulnerabilidade ao ataque de insetos de solo e a distúrbios fisiológicos e ao crescimento contínuo das raízes tuberosas, que apresentam peso médio excessivo em casos de colheita tardia, comprometendo a qualidade e prejudicando a produtividade de raízes comerciais. 
A porcentagem média de raízes comerciais $(57,18 \%)$ foi condizente com a obtida por Gonçalves Neto et al. (2011), de 57,12\%, sete meses após o plantio.

Na Tabela 3.3 são apresentadas as estimativas da herdabilidade no sentido amplo $\left(\mathrm{h}_{\mathrm{a}}{ }^{2}\right)$, os coeficientes de variação genético $\left(\mathrm{CV}_{\mathrm{g}}\right)$, ambiental $\left(\mathrm{CV}_{\mathrm{e}}\right)$ e a razão entre os coeficientes de variação genético e ambiental $\left(\mathrm{CV}_{\mathrm{g}} / \mathrm{CV}_{\mathrm{e}}\right)$ para as variáveis avaliadas.

Tabela 3.3 Estimativas de parâmetros populacionais das características número de raízes totais e com padrão comercial por planta, produtividade total e comercial, peso médio de raízes comerciais, porcentagem de raízes comerciais, formato, incidência de danos causados por insetos do solo, comprimento, diâmetro e espessura do córtex de raízes de batata-doce

\begin{tabular}{cccccccccccc}
\hline Parâmetros & NTRPP & PT & NRCPP & PC & PMRC & RC & FTO & ID & CR & DR & EC \\
\hline $\mathbf{h}_{\mathbf{a}}{ }^{\mathbf{2}}(\mathbf{\%})$ & 81,35 & 92,2 & 93,42 & 94,48 & 79,71 & 86,03 & 83,86 & 61,93 & 89,33 & 88,31 & 79,43 \\
$\mathbf{C V}_{\mathbf{g}} \mathbf{( \% )}$ & 16,61 & 40,38 & 27,4 & 53,26 & 33,56 & 35,09 & 9,21 & 4,79 & 21,42 & 22,69 & 16,76 \\
$\mathbf{C V}_{\mathbf{e}}(\mathbf{\%})$ & 15,97 & 23,48 & 14,57 & 25,73 & 33,9 & 28,3 & 8,08 & 7,48 & 14,77 & 16,56 & 17,1 \\
$\mathbf{C V}_{\mathbf{g}} / \mathbf{C V}_{\mathbf{e}}$ & 1,04 & 1,72 & 1,88 & 2,07 & 0,99 & 1,24 & 1,14 & 0,64 & 1,45 & 1,37 & 0,98 \\
\hline
\end{tabular}

NTRPP: número total de raízes por planta; PT: produtividade total $\left(\mathrm{t} \mathrm{ha}^{-1}\right)$; NRCPP: número de raízes com padrão comercial por planta; PC: produtividade comercializável $\left(\mathrm{t} \mathrm{ha}^{-1}\right)$; PMRC: peso médio de raízes comerciais (g); RC: porcentagem de raízes comerciais (\%); FTO: formato; ID: incidência de danos causados por insetos do solo; CR: comprimento (mm); DR: diâmetro (mm); EC: espessura do córtex (mm), das raízes de batata-doce.

De acordo com Gonçalves Neto et al. (2012) o coeficiente de variação experimental $\left(\mathrm{CV}_{\mathrm{e}}\right)$ é o parâmetro que indica a magnitude da precisão experimental. As variáveis incidência de danos ocasionados por insetos de solo, formato, número de raízes com padrão comercial por planta, comprimento, número total de raízes por planta, diâmetro e espessura de córtex das raízes, com valores de 7,48; 8,08; 14,57; 14,77; 15,97; 16,56 e 17,1\%, respectivamente, mostraram existir uma boa precisão experimental.

Já os maiores coeficientes de variação experimental observados nas características produtividade total, produtividade comercial, porcentagem de raízes com padrão comercial e peso médio das raízes comerciais $(23,48 ; 25,73 ; 28,3$ e 33,9, respectivamente), são comuns em culturas tuberosas, devido à grande variabilidade existente na formação de raízes tuberosas por planta e a que o controle do ambiente é dificultado (CAVALCANTE et al., 2012; ERPEN et al., 2013). Cardoso et al. (2005) observaram para as variáveis produtividade total e produtividade comercial de raízes tuberosas coeficientes de variação experimental de 46,64 e 59,02\%, respectivamente. Figueiredo (2010) encontraram para os caracteres peso médio de raízes comerciais, produtividade total e produtividade comercial coeficientes de variação experimental de 25,20; 37,60 e 41,36\%, respectivamente. Ainda Viana (2009) 
verificaram coeficientes médios de variação experimental de 43,52 e 44,67\%, para as características produtividade total e comercial de raízes, respectivamente.

As estimativas para o coeficiente de variação genética foram maiores que para o coeficiente de variação ambiental nas variáveis estudadas (Tabela 3.3), exceto para os caracteres incidência de danos ocasionados por insetos de solo, espessura do córtex e peso médio das raízes comerciais $(0,64 ; 0,98$ e 0,99 , respectivamente), demonstrando alta variabilidade entre os genótipos e que o controle genético das variáveis estudadas foi elevado, indicando uma situação bastante favorável em termos de seleção nessa população para as variáveis: número total de raízes por planta $(1,04)$, formato $(1,14)$, porcentagem de raízes comerciais $(1,24)$, diâmetro $(1,37)$, comprimento $(1,45)$, produtividade total $(1,72)$, número de raízes comerciais por planta $(1,88)$ e produtividade comercial $(2,07)$, das raízes tuberosas.

As estimativas de herdabilidade no sentido amplo foram superiores a $80 \%$ em ordem decrescente para as variáveis: produtividade comercial $(94,48 \%)$, número de raízes comerciais por planta $(93,42 \%)$, produtividade total $(92,2 \%)$, comprimento $(89,33 \%)$, diâmetro $(88,31 \%)$, porcentagem de raízes comerciais $(86,03 \%)$, formato $(83,86 \%)$ e número total de raízes por planta $(81,35 \%)$, o que mais uma vez reflete alta presença do componente genético na expressão destes caracteres e evidencia grande possibilidade de sucesso com a seleção.

Cavalcante et al. (2009) observaram valores de herdabilidade de 43,44; 64,37; 66,20 e 95,39\% para o diâmetro, o comprimento, a espessura do córtex e a produtividade total de raízes de batata-doce, respectivamente. Já Gonçalves Neto et al. (2012) encontraram para o formato médio e a produção total de raízes frescas herdabilidades no sentido amplo de 66,86 e $95,72 \%$, respectivamente.

As correlações de Pearson entre todas as características morfoagronômicas avaliadas encontram-se na Tabela 3.4.

De acordo com a matriz de correlação de Pearson para as variáveis estudadas (Tabela 3.4), a magnitude da correlação foi muito forte e significativa $(p<0,01)$ entre os caracteres peso médio de raízes comerciais e porcentagem de raízes comerciais, produtividade comercial e produtividade total e número de raízes comerciais por planta e produtividade comercializável $(0,909 ; 0,919$ e 0,984, respectivamente). Como estas correlações foram positivas, pode ser concluído que o incremento das variáveis peso médio de raízes comerciais, produtividade comercial e número de raízes comerciais por planta, resultaram no aumento da porcentagem de raízes comerciais, produtividade total e produtividade comercializável, 
respectivamente. Uma estimativa de correlação alta e positiva entre caracteres demonstra que na prática há possibilidade de apenas um deles ser avaliado, pois a seleção estará sendo realizada de forma indireta também para o outro caráter.

O peso médio das raízes comerciais correlacionou-se de forma alta e significativa ( $p<$ 0,01) com as características produtividade total, número de raízes comerciais por planta e produtividade comercial $(0,789 ; 0,820$ e 0,854 , respectivamente).

Raízes mais compridas aumentaram o número total de raízes por planta, as produtividades total e comercial e o número de raízes comerciais por planta $(0,732 ; 0,735$; 0,748 e 0,759 , respectivamente). Por sua vez, maiores quantidades do número total de raízes por planta incrementaram a produtividade comercial, o número de raízes com padrão comercial por planta e o rendimento total $(0,815 ; 0,848$ e 0,878 , respectivamente).

Também foram observadas correlações significativas e fortes entre os pares de caracteres número de raízes comerciais por planta e produtividade total $(0,894)$, número de raízes comerciais por planta e porcentagem de raízes comerciais $(0,823)$ e produtividade comercial e porcentagem de raízes comerciais $(0,810)$. Já a correlação forte e inversamente proporcional entre a porcentagem de raízes comerciais e o formato $(-0,707)$, indica que maiores rendimentos de raízes comerciais foram obtidos com notas de formato baixas, próximas ao formato ideal para a comercialização.

O formato também correlacionou-se de forma negativa com as variáveis peso médio das raízes comerciais, produtividade comercial e número de raízes comerciais por planta $(-0,569$; -0,660 e -0,676, respectivamente). Contudo, a magnitude da correlação foi média.

Finalmente, a magnitude da correlação foi média e positiva entre os pares número total de raízes por planta e peso médio das raízes comerciais $(0,630)$, número total de raízes por planta e porcentagem de raízes comerciais $(0,532)$, produtividade total e porcentagem de raízes comerciais $(0,617)$, comprimento e peso médio das raízes comerciais $(0,636)$, comprimento e porcentagem de raízes comerciais $(0,580)$, diâmetro e produtividade total $(0,633)$, diâmetro e produtividade comercial $(0,519)$ e diâmetro e peso médios das raízes com padrão comercial $(0,657)$. As outras correlações, quando significativas, apresentaram associação fraca, pois segundo Skinner et al. (1999) apenas coeficientes de correlação com valores absolutos superiores a 0,71 devem ser considerados biologicamente significativos. Estes autores explicam que somente nestas situações mais do que 50\% da variância de uma característica é predita pela outra. 
Tabela 3.4 Matriz de correlação de Pearson entre as características número total de raízes por planta, produtividade total, número de raízes com padrão comercial por planta, produtividade comercializável, peso médio de raízes comerciais, percentagem de raízes comercias, formato, incidência de danos ocasionados por insetos do solo, comprimento, diâmetro e espessura do córtex, avaliadas em trinta genótipos de batata-doce

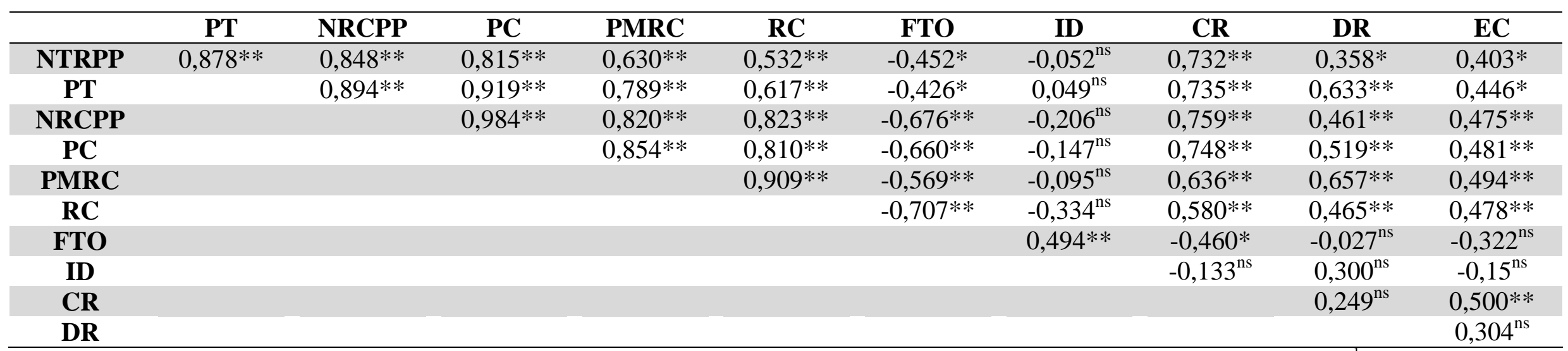

** e *: Significativo a 1 e $5 \%$ de probabilidade pelo teste $\mathrm{t}$; ns: não significativo. NTR: número total de raízes por planta; PT: produtividade total (t ha ${ }^{-1}$ ); NRCPP: número de raízes com padrão comercial por planta; PC: produtividade comercializável ( $\mathrm{t}$ ha ${ }^{-1}$ ); PMRC: peso médio de raízes comerciais ( $\mathrm{g}$ ); $\mathrm{RC}$ : porcentagem de raízes comercias em relação à produtividade total (\%); FTO: formato; ID: incidência de danos ocasionados por insetos do solo; CR: comprimento (mm); DR: diâmetro (mm); EC: espessura do córtex (mm), das raízes de batata-doce. 


\subsection{CONCLUSÕES}

Considerando que as produtividades total e comercial, o formato e a resistência a insetos de solo das raízes tuberosas de batata-doce estão entre os principais objetivos dos programas de melhoramento, os clones com melhor desempenho com relação a estas características foram CNPH 1232, CNPH 1357, CNPH 1298, CNPH 1197 e CNPH 1208. Dentre estes, os clones CNPH 1357 e CNPH 1197 proporcionaram raízes comerciais de batata-doce com peso médio ideal (tipo extra A). Os clones CNPH 1232, CNPH 1298 e CNPH 1208, também são promissores, contudo, apresentaram peso médio de raízes com padrão comercial acima de 400 gramas, sendo classificados como diversos, de menor valor comercial. É prezumível que são materiais de ciclo menor do que 174 dias, com possibilidade de produzir raízes tuberosas do tipo Extra A ou Extra B caso a colheita seja antecipada.

Altas estimativas de herdabilidade para as características produtividade comercial, número de raízes comerciais por planta, produtividade total, comprimento, diâmetro, porcentagem de raízes comerciais, formato e número total de raízes por planta, evidenciaram alta presença do componente genético na expressão destes caracteres e grande possibilidade de sucesso com a seleção.

Apesar das altas produtividades totais dos clones CNPH 1310 e CNPH 1192, estes materiais apresentaram baixas produtividades de raízes com padrão comercial, decorrentes de suas suscetibilidades aos insetos de solo e dos piores formatos de suas raízes.

A correlação de Pearson foi de magnitude muito forte entre os pares de caracteres peso médio de raízes comerciais e porcentagem de raízes comerciais, produtividade comercial e produtividade total e número de raízes comerciais por planta e produtividade comercializável. 


\subsection{REFERÊNCIAS BIBLIOGRÁFICAS}

ABIDIN, P. E.; EEUWIJK, F. A. V.; STAM, P.; STRUIK, P. C.; MALOSETTI, M.; MWANGA, R. O. M.; ODONGO, B.; HERMANN, M.; CAREY, E. E. Adaptation and stability analysis of sweet potato varieties for low-input systems in Uganda. Plant breeding, v. 124, n. 5, p. 491-497, 2005.

ANDRADE JÚNIOR, V. C.; VIANA, D. J. S.; PINTO, N. A. V. D.; RIBEIRO, K. G.; PEREIRA, R. C.; NEIVA, I. P.; AZEVEDO, A. M.; ANDRADE, P. C. R. 2012. Productive and qualitative characteristics of the vines and roots of sweet potato. Horticultura Brasileira, v. 30, n. 4, p. 584-589, 2012.

ANKUMAH, R.; KHAN, V.; MWAMBA, K.; KPOMBLEKOU-A, K. The influence of source and timing of nitrogen fertilizers on yield and nitrogen use efficiency of four sweet potato cultivars. Agriculture, Ecosystems and Environment, v. 100, n. 2-3, p. 201-207, 2003.

AUSTIN, D. F. The taxonomy, evolution and genetic diversity of sweet potatoes and related wild species. In: Exploration, maintenance, and utilization of sweetpotato genetic resources: report of the first sweet potato planning conference, 1987. CIP, Lima, Peru, 1988. p. 27-59.

AZEVEDO, A. M.; ANDRADE JÚNIOR, V. C.; VIANA, D. J. S.; ELSAYED, A. Y. A. M.; PEDROSA, C. E.; NEIVA, I. P.; FIGUEIREDO, J. A. Influence of harvest time and cultivation sites on the productivity and quality of sweet potato. Horticultura Brasileira, v. 32, n. 1, p. 21-27, 2014.

AZEVEDO, S. M. de; FREITAS, J. A.; MALUF, W. R.; SILVEIRA, M. A. Desempenho de clones e métodos de plantio de batata-doce. Acta Scientiarum. Agronomy, v. 22, n. 4, p. 901-905, 2000.

BARRETO, H. G.; SANTOS, L. B. dos; OLIVEIRA, G. I. S. de; SANTOS, G. R. dos; FIDELIS, R. R.; SILVEIRA, M. A. da; NASCIMENTO, I. R. do. Estabilidade e adaptabilidade da produtividade e da reação a insetos de solo em genótipos experimentais e comerciais de batata-doce. Bioscience Journal, v. 27, n. 5, p. 739-747, 2011.

CÂMARA, F. A. A.; GRANGEIRO, L. C.; DOMBROSKI, J. L. D.; SANTOS, M. A.; FREITAS, R. M. O.; FREITAS, F. C. L. Desempenho agronômico de cultivares de batatadoce oriundas de ramas produzidas de forma convencional e in vitro. Revista Brasileira de Ciências Agrárias, v. 8, n. 3, p. 370-374, 21 set. 2013.

CARDOSO, A. D.; VIANA, A. E. S.; RAMOS, P. A. S.; MATSUMOTO, S. N.; AMARAL, C. L. F.; SEDIYAMA, T.; MORAIS, O. M. Avaliação de clones de batata-doce em Vitória da Conquista. Horticultura Brasileira, v. 23, n. 4, p. 911-914, 2005. 
CARVALHO, F. I. F.; LORENCETTI, C.; BENIN, G. Estimativas e implicações da correlação no melhoramento vegetal. Pelotas: Universitárias da UFPel, 2004.

CAVALCANTE, J. T.; FERREIRA, P. V.; SOARES, L. Correlações fenotípicas, genotípicas e de ambiente em clones de batata-doce (Ipomoea batatas (L.) Lam.). Revista Ciência Agrícola, v. 10, n. 1, p. 1-7, 2012.

CAVALCANTE, M.; FERREIRA, P. V.; PAIXÃO, S. L.; COSTA, J. G.; PEREIRA, R. G.; MADALENA, J. A. S. Potenciais produtivo e genético de clones de batata-doce. Acta Scientiarum. Agronomy, v. 31, n. 3, p. 421-426, 2009.

CECILIO FILHO, A. B.; REIS, M. dos S.; SOUZA, R. J.; PASQUAL, M. Degenerescência em cultivares de batata-doce. Horticultura Brasileira, v. 16, n. 1, p. 82-84, 1996.

CHEN, L.-F. O.; LO, H.-F.; CHEN, T.-H.; LEE, L. Peroxidase zymograms of sweet potato (Ipomoea batatas (L.) Lam.) grown under hydroponic culture. Botanical Bulletin of Academia Sinica, v. 33, p. 247-252, 1992.

CIP- Centro Internacional de la Papa. Facts and figures about sweetpotato. 2010. Disponível em: <file:///C:/Users/Paula/Downloads/Temp/005448.pdf〉. Acesso em: 20 jan. 2015.

CRISÓSTOMO, J. R.; BARROS, L. de M.; PAIVA, J. R. de; CAVALCANTI, J. J. V. Melhoramento genético do cajueiro. In: QUEIROZ, M. A.; GOEDERT, C. O.; RAMOS, C. R. R. (Ed.). Recursos genéticos e melhoramento de plantas para o Nordeste brasileiro. Petrolina: Embrapa Semiárido, 1999. Disponível em: <http://www.cpatsa.embrapa.br:8080/catalogo/livrorg/cajumelhoramento.pdf >. Acesso em: 19 jan. 2015.

CRUZ C, D. GENES - a software package for analysis in experimental statistics and quantitative genetics. Acta Scientiarum, v. 35, n. 3, p. 271-276, 2013.

ERPEN, L.; STRECK, N. A.; UHLMANN, L. O.; FREITAS, C. P. O.; ANDRIOLO, J. L. Tuberização e produtividade de batata-doce em função de datas de plantio em clima subtropical. Bragantia, v. 72, n. 4, p. 396-402, 2013.

FELTRAN, J. C.; FABRI, E. G. Batata-doce uma cultura versátil, porém sub-utilizada. Nosso Alho, n. 6, p. 28-31, 2010.

FIGUEIREDO, J. A. Seleção de clones de batata-doce com potencial de utilização na alimentação humana e animal. 2010. 55 f. Dissertação (Mestrado em Produção Vegetal)Faculdade de Ciências Agrárias, Universidade Federal dos Vales do Jequitinhonha e Mucuri, Diamantina, 2010.

FIGUEIREDO, J. A.; ANDRADE JUNIOR, V. C.; PEREIRA, R. C.; RIBEIRO, K. G.; VIANA, D. J. S.; NEIVA, I. P. Avaliação de silagens de ramas de batata-doce. Horticultura Brasileira, v. 30, n. 4, p. 708-712, 2012. 
FOLONI, J. S. S.; CORTE, A. J.; CORTE, J. R. do N.; ECHER, F. R.; TIRITAN, C. S. Adubação de cobertura na batata-doce com doses combinadas de nitrogênio e potássio. Semina: Ciências Agrárias, v. 34, n. 1, p. 117-126, 11 mar. 2013.

FONTES, P. C. R. Sugestões de Adubação para Hortaliças. In: RIBEIRO, A. C.; GUIMARÃES, P. T. G.; ALVAREZ, V. H. V. (Eds). Recomendação para o uso de corretivos e fertilizantes em Minas Gerais: $5^{a}$ aproximação. Viçosa: Comissão de Fertilidade do Solo do Estado de Minas Gerais, 1999. p. 171-174.

FRANÇA, F. H.; MIRANDA, J. E. C.; FERREIRA, P. E.; MALUF, W.R. Comparação de dois métodos de avaliação de germoplasma de batata-doce visando resistência a pragas do solo. In: CONGRESSO BRASILEIRO DE OLERICULTURA, 23., 1983, Rio de Janeiro. Anais... Rio de Janeiro: SOB, 1983. p.176.

GONÇALVES NETO, Á. C.; MALUF, W. R.; GOMES, L. A. A.; GONÇALVES, R. J. S.; SILVA, V. F.; LASMAR, A. Aptidões de genótipos de batata-doce para consumo humano, produção de etanol e alimentação animal. Pesquisa Agropecuária Brasileira, v. 46, n. 11, p. 1513-1520, 2011.

GONÇALVES NETO, Á. C.; MALUF, W. R.; GOMES, L. A. A.; MACIEL, G. M.; FERREIRA, R. P. D.; CARVALHO, R.C. Correlação entre caracteres e estimação de parâmetros populacionais para batata-doce. Horticultura Brasileira, v. 30, n. 4, p. 713-719, 2012.

GRUNEBERG, W. J.; MANRIQUE, K.; ZHANG, D.; HERMANN, M. Genotype $\times$ environment interactions for a diverse set of sweetpotato clones evaluated across varying ecogeographic conditions in Peru. Crop Science, v. 45, n. 6, p. 2160-2171, 2005.

HE, X.-Q.. LIU, Q.-C.; ISHIKI, K.; ZHAI, H.; WANG, Y.-P. Genetic diversity and genetic relationships among Chinese sweetpotato landraces revealed by RAPD and AFLP markers. Breeding science, v. 56, n. 2, p. 201-207, 2006.

HORTON, D. E.; EWELL, P. T. Sweet potato pest management: a social science perspective. In: JANSSON, R. K.; RAMAN, K. V. (Ed.). Sweet Potato Pest Management: a global perspective. San Francisco: Westview Press, 1991. p. 407-427.

IBGE- Instituto Brasileiro de Geografia e Estatística. Produção agrícola municipal: culturas temporárias e permanentes. 2013. Disponível em: <http://loja.ibge.gov.br/produco-da-pecuaria-municipal-2013.html>. Acesso em: 01 jan. 2014.

KIM, H. W.. KIM, J. B.; CHO, S. M.; CHUNG, M. N.; LEE, Y. M.; CHU, S. M.; CHE, J. H.; KIM, S. N.; KIM, S. Y.; CHO, Y. S.; KIM, J. H.; PARK, H. J. Anthocyanin changes in the Korean purple-fleshed sweet potato, Shinzami, as affected by steaming and baking. Food Chemistry, v. 130, n. 4, p. 966-972, 2012.

KROTH, L. L.; DANIELS, J.; PIEROBOM, C. R. Degenerescência da batata-doce no Rio Grande do Sul. Revista Brasileira de Agrosciência, v. 10, n. 1, p. 79-82, 2004. 
MANIFESTO, M. M.; TÁRTARA, S. M. C.; ARIZIO, C.M.; AlVAREZ, M. A.; HOMPANERA, N. R. Analysis of the morphological attributes of a sweetpotato collection. Annals of Applied Biology, v. 157, n. 2, p. 273-281, set. 2010.

MAROUELli, L. P.; BUSO, G. S. C.; MAGALHÃES, J. S.; FERREIRA, C. F.; TORRES, A. C. Estudo da variabilidade genética de plantas oriundas da embriogênese somática de genótipos de batata-doce utilizando marcadores RAPD. Brasília: Embrapa Hortaliças, 2005, 15 p. Boletim de Pesquisa e Desenvolvimento 10. ISSN 1677-2299.

MARTINS, E. C. A.; PELUZIO, J. M.; COIMBRA, R. R.; SILVEIRA, M. A. da; OLIVEIRA, J. das D. D.; OLIVEIRA JUNIOR, W. P. de. Diversidade genética em batatadoce no Tocantins. Bioscience Journal, v. 30, n. 2, p. 429-435, 2014.

MASSAROTO, J. A. Características agronômicas e produção de silagem de clones de batata doce. 2008. 85 f. Tese (Doutorado em Fitotecnia)- Universidade Federal de Lavras, Lavras, 2008.

MASSAROTO, J. A.; MALUF, W. R.; GOMES, L. A. A.; FRANCO, H. D.; GASPARINO, C. F. Behavior of roots of sweet potato clones. Ambiência, v. 10, n. 1, p. 73-81, 2014.

MIRANDA, J. E. C.; CRUZ, C. D.; PEREIRA, A. S. Análise de trilha e divergência genética de cultivares e clones de batata-doce. Revista Brasileira de Genética, v. 11, n. 4, p. 881-892, 1988.

MIRANDA, J. E. C.; FRANÇA, F. H.; CARRIJO, O. A.; SOUZA, A. F.; PEREIRA, W.; LOPES, C. A.; SILVA, J. B. C. A cultura da batata-doce. Brasília: Embrapa Hortaliças, 1995, 89 p. Serviço de Produção de Informação - SPI.

MOULIN, M. M.; RODRIGUES, R.; GONÇALVES, L. S. A.; SUDRÉ, C. P.; PEREIRA, M. G. A comparison of RAPD and ISSR markers reveals genetic diversity among sweet potato landraces (Ipomoea batatas (L.) Lam.). Acta Scientiarum. Agronomy, v. 34, n. 2, 13 mar. 2012.

OLIVEIRA, A. C. B. de; SEDIYAMA, M. A. N.; SEDIYAMA, T.; FINGER, F. L.; CRUZ, C. D. Variabilidade genética em batata-doce com base em marcadores isoenzimáticos. Horticultura Brasileira, v. 20, n. 4, p. 576-582, 2002.

OLIVEIRA, A. C. B. de; SEDIYAMA, M. A. N.; SEDIYAMA, T.; CRUZ, C. D. Avaliação da divergência genética em batata-doce por procedimentos multivariados. Acta Scientiarum. Agronomy, v. 22, n. 4, p. 895-900, 2000.

OZTURK, G.; AZERI, F. N.; YILDIRIM, Z. Field performance of in vitro sweet potato [Ipomoea batatas L.(lam)] plantlets derived from seedstocks. Turkish Journal of Field Crops, v. 17, n. 1, p. 1-4, 2012.

PEIXOTO, J. R.; SANTOS, L. C.; RODRIGUES, F. A.; JULIATTI, F.C.; LYRA, J. R. M. Seleção de clones de batata-doce resistentes a insetos de solo. Pesquisa Agropecuária Brasileira, v. 34, n. 3, p. 385-389, 1999. 
POZZER, L.; SILVA, J. B. C.; DUSI, A. N.; KITAJIMA, E. W. Performance of micropropagated sweet potato plants after two field propagations and rate of reinfection by sweet potato feathery mottle virus. Fitopatologia Brasileira, v. 20, n. 3, p. 464-468, 1995.

QUEIROGA, R. C. F.; SANTOS, M. A.; MENEZES, M. A.; VIEIRA, C. P. G.; SILVA, M. C. Fisiologia e produção de cultivares de batata-doce em função da época de colheita. Horticultura Brasileira, v. 25, n. 3, p. 371-374, 2007.

R Core Team. R: A language and environment for statistical computing. R Foundation for Statistical Computing, Vienna, Austria. 2013. Disponível em: <http://www.R-project.org/>. Acesso em: 26 dez. 2013.

RESENDE, G. M. de. Características produtivas de cultivares de batata-doce sob condições irrigadas e de sequeiro na região norte de Minas Gerais. Horticultura Brasileira, v. 17, n. 2, p. 151-154, 1999.

RESENDE, G. M. de. Características produtivas de cultivares de batata-doce em duas épocas de colheita, em Porteirinha-MG. Horticultura Brasileira, v. 18, n. 1, p. 68-71, 2000.

SANTOS, J. F. dos; BRITO, L. de M. P.; GRANJEIRO, J. I. T.; ALMEIDA, F. de A. C.; OLIVEIRA, M. E. C. de. Componentes de produção e rendimentos de batata-doce, em função de doses de esterco de bovino. Revista Brasileira de Produtos Agroindustriais, v. 7, n. 2, p. 115-121, 2005.

SCHULTHEIS, J. R.; WALTERS, S. A.; ADAMS, D. E.; ESTES, E. A. In-row plant spacing and date of harvest of 'Beauregard' sweetpotato affect yield and return on investment. HortScience, v. 34, n. 7, p. 1229-1233, 1999.

SCOTT, G. J.; BEST, R.; ROSEGRAND, M.; BOKANGA, M. Roots and Tubers in the Global Food System: A Vision Statement to the Year 2020. Lima, Peru: International Potato Center, 2000. 111 p.

SENANAYAKE, S. A.; RANAWEERA, K. K. D. S.; GUNARATNE, A.; BAMUNUARACHCHI, A. Comparative analysis of nutritional quality of five different cultivars of sweet potatoes (Ipomea batatas (L) Lam) in Sri Lanka. Food Science \& Nutrition, v. 1, n. 4, p. 284-291, 2013.

SHEKHAR, S.; MISHRA, D.; BURAGOHAIN, A. K.; CHAKRABORTY, S.; CHAKRABORTY, N. Comparative analysis of phytochemicals and nutrient availability in two contrasting cultivars of sweet potato (Ipomoea batatas L.). Food Chemistry, v. 173, p. 957-965, 2015.

SILVA, G. O. da; PONIJALEKI, R.; SUINAGA, F. A. Genetic divergence among sweet potato accessions based on root traits. Horticultura Brasileira, v. 30, n. 4, p. 595-599, 2012.

SILVA, J. B. C.; LOPES, C. A.; MIRANDA, J. E. C. de; FRANÇA, F. H.; CARRIJO, O. A.; SOUZA, A. F.; PEREIRA, W. Cultivo da batata-doce (Ipomoea batatas (L.) Lam). Brasília: Embrapa Hortaliças, 1995, 18 p. CNPH 7. ISSN 0102-6534. 
SILVA, J. B. C. da; LOPES, C. A.; MAGALHÃES, J. S. Batata-doce (Ipomoea batatas). Brasília: Embrapa Hortaliças, 2008. Sistemas de Produção, 6. ISSN 1678-880X. Versão Eletrônica. Disponível $<$ http://sistemasdeproducao.cnptia.embrapa.br/FontesHTML/Batata-doce/Batatadoce_Ipomoea_batatas/introducao.html>. Acesso em: 19 mar. 2014.

SILVA, S. de O.; SOUZA, A. da S.; PAZ, O. P. da. Efeito da multiplicação vegetativa in vitro na produtividade da batata-doce (Ipomoea batatas L. Lam.). Revista Brasileira de Fisiologia Vegetal, v. 3, n. 1, p. 47-52, 1991.

SILVEIRA, L. R.; CHIESA, V. B.; TAVARES, I. B.; SOUZA, R. C.; SILVEIRA, M. A.; ALVES, D. G.; JUNIOR, W. P. O. Caracterização físico-química e clones de batata-doce de polpa alaranjada nas condições de Palmas - To. Estudos, v. 38, n. 2, p. 365-380, 2011.

SKINNER, D. Z.; BAUCHAN, G. R.; AURICHT, G.; HUGHES, S. A method for the efficient management and utilization of large germplasm collections. Crop science, v. 39, n. 4, p. 1237-1242, 1999.

SOUZA, A. B. de. Avaliacão de cultivares de batata-doce quanto a atributos agronômicos desejáveis. Ciência e Agrotecnologia, v. 24, n. 4, p. 841-845, 2000.

STEFANOVIĆ, S.; KRUEGER, L.; OLMSTEAD, R. G. Monophyly of the Convolvulaceae and circumscription of their major lineages based on DNA sequences of multiple chloroplast loci. American Journal of Botany, v. 89, n. 9, p. 1510-1522, 2002.

VIANA, D. J. S. Produção e qualidade de raízes, ramas e silagem de ramas de clones de batata-doce em diferentes locais e épocas de colheita. 2009. 69 f. Dissertação (Mestrado em Produção Vegetal)- Faculdade de Ciências Agrárias, Universidade Federal dos Vales do Jequitinhonha e Mucuri, Diamantina, 2009

WANDERLEY, P. A.; BOIÇA JÚNIOR, A. L.; WANDERLEY, M. J. A. Resistance of sweet potato cultivars to Euscepes postfasciatus Fairmaire (Coleoptera: Curculionidae). Neotropical Entomology, v. 33, n. 3, p. 371-377, 2004.

ZHANG, D.; GHISLAIN, M.; HUAMÁN, Z.; GOLMIRZAIE, A.; HIJMANS, R. RAPD variation in sweetpotato (Ipomoea batatas (L.) Lam) cultivars from South America and Papua New Guinea. Genetic Resources and crop evolution, v. 45, n. 3, p. 271-277, 1998. 


\section{CAPÍTULO 4}

Reação de genótipos de batata-doce à infecção por $M$. javanica, $M$. incognita raça 1 e M. enterolobii 


\subsection{RESUMO}

Um dos principais obstáculos para a produção de alimentos em muitos países em desenvolvimento é o dano causado pelos fitonematoides, principalmente os formadores de galhas, pertencentes ao gênero Meloidogyne. Além da redução das raízes absorventes, da folhagem, do crescimento da planta e da baixa produtividade, a infecção por esses fitoparasitas afeta negativamente a qualidade das raízes tuberosas, das quais, uma alta proporção torna-se não comercializável. O trabalho teve como objetivo avaliar o nível de resistência de genótipos de batata-doce a $M$. javanica, $M$. incognita raça 1 e $M$. enterolobii. 44 clones foram avaliados entre janeiro e abril de 2014, em casa de vegetação em Brasília - DF. Utilizou-se o delineamento inteiramente casualizado, com seis repetições. A classificação dos níveis de resistência foi realizada de acordo com o fator de reprodução dos nematoides. Também foram estimados parâmetros genéticos populacionais, correlações entre o nível de resistência a $M$. javanica, $M$. incognita raça 1 e $M$. enterolobii e a cor da periderme e da polpa das raízes e correlações entre o índice de galhas, o índice de massas de ovos, o fator de reprodução dos nematoides e o número de ovos $+\mathrm{J} 2$ por grama de raiz, para as três espécies estudadas. M. javanica foi a espécie menos agressiva infectando 9,09\% dos genótipos. A raça 1 de $M$. incognita reproduziu-se exitosamente em $47,73 \%$ dos materiais. $M$. enterolobii foi a espécie mais virulenta tendo como hospedeiros suscetíveis 79,55\% dos clones avaliados. $52,27 \%$ dos materiais foram resistentes a $M$. javanica e $M$. incognita raça $1 ; 18,18 \%$ foram resistentes à infecção por $M$. javanica e $M$. enterolobii e 13,64\% foram resistentes a $M$. incognita raça 1 e $M$. enterolobii e simultaneamente a $M$. javanica, $M$. incognita raça 1 e $M$. enterolobii (CNPH 1200, CNPH 1219, CNPH 1292, CNPH 1392, CNPH 60 e Coquinho); sendo os hospedeiros mais eficientes em inibir a multiplicação das três espécies. As estimativas de herdabilidade no sentido amplo foram superiores a $85 \%$ para as variáveis índice de galhas, índice de massas de ovos, fator de reprodução e número de ovos+J2 por grama de raiz. As correlações entre a resistência à infecção por $M$. javanica, $M$. incognita raça 1 e $M$. enterolobii e as cores da periderme e da polpa das raízes de batata-doce foram não significativas. As populações finais dos nematoides das três espécies incrementaram com o aumento do número de galhas e de massas de ovos nos sistemas radiculares das plantas.

Palavras-chave: Ipomoea batatas, Meloidogyne spp., fator de reprodução, resistência. 


\subsection{ABSTRACT}

One of the main obstacles to food production in many developing countries is the damage caused by phytonematodes, especially those forming galls, belonging to the genus Meloidogyne. In addition to the reduction of fibrous roots, the foliage, the growth of the plant and the low yield, the infection with these plant parasites negatively affects the quality of tubers, of which a high proportion becomes unmarketable. The study aimed to assess the resistance level of sweet potato genotypes to the root-knot nematodes $M$. javanica, $M$. incognita race 1 and M. enterolobii. 44 clones were evaluated between January and April of 2014, under greenhouse conditions in Brasilia - DF. A completely randomized design with six replications was used. The classification of the resistance levels was defined by the nematodes reproduction factors. Population genetic parameters, correlations between the resistance level to the infection by $M$. javanica, $M$. incognita race 1 and $M$. enterolobii and the color of periderm and flesh of tubers and correlations between the gall index, the egg mass index, the nematodes reproduction factor and the number of eggs $+\mathrm{J} 2$ per gram of root for the three species studied, also were estimated. $M$. javanica was the less aggressive specie infecting $9.09 \%$ of the genotypes. $M$. incognita race 1 reproduced successfully on $47.73 \%$ of the materials. M. enterolobii was the most virulent specie, which had as susceptible hosts $79.55 \%$ of the clones. $52.27 \%$ of the sweet potato genotypes were resistant to $M$. javanica and $M$. incognita race $1 ; 18.18 \%$ were resistant to the infection by $M$. javanica and $M$. enterolobii and $13.64 \%$ were resistant to $M$. incognita race 1 and $M$. enterolobii and simultaneously to $M$. javanica, M. incognita race 1 and M. enterolobii (CNPH 1200, CNPH 1219, CNPH 1292, CNPH 1392, CNPH 60 and Coquinho); which were the most efficient hosts to inhibit the multiplication of the three species. Estimates of broad sense heritability were greater than $85 \%$ for the variables gall index, egg mass index, reproduction factor and number of eggs $+\mathrm{J} 2$ per gram of root. Correlations between the resistance to the infection by $M$. javanica, $M$. incognita race 1 and $M$. enterolobii and the colors of periderm and flesh of storage roots were not significant. The final nematode populations of the three species increased with the increase in the number of galls and egg masses on the root systems of plants.

Keywords: Ipomoea batatas, Meloidogyne spp., reproduction factor, resistance. 


\subsection{INTRODUÇÃO}

Entre os mais disseminados fitonematoides que limitam a produtividade agrícola, os formadores de galhas, pertencentes ao gênero Meloidogyne Göldi, 1892, são considerados um dos mais prejudiciais para a agricultura (ROSA, 2010). São patógenos de plantas obrigatórios, altamente adaptados e parasitam quase todas as espécies de plantas superiores (PERRY e MOENS, 2006). Sua ampla distribuição geográfica, grande número de hospedeiras e associação com fungos, bactérias e vírus em doenças complexas, classificá-los entre os principais fitopatógenos que afetam a oferta mundial de alimentos (SASSER, 1980). Contudo, paradoxalmente, grande parte dos danos causados pelo nematoide-das-galhas não são detectados. Adicionalmente, devido à dificuldade e complexidade de associar as perdas de produtividade com estes nematoides, somente algumas estimativas são calculadas (CERVANTES-FLORES, 2000).

O gênero Meloidogyne contém mais de 80 espécies descritas, sendo que poucas $(M$. arenaria, M. hapla, $M$. incognita e $M$. javanica) apresentam ampla variedade de plantas hospedeiras (CARNEIRO e ALMEIDA, 2001a; ROBERTS, 1995). Tem-se demonstrado que populações da mesma espécie de Meloidogyne spp. variam na sua habilidade de parasitar diferentes plantas hospedeiras. Essas populações têm sido referidas como raças fisiológicas, biótipos ou patótipos (CARNEIRO et al., 2003). Segundo Roberts (1995) não existem ainda marcadores moleculares, bioquímicos ou morfológicos para a diferenciação de raças dentro das espécies de Meloidogyne.

Com base em sua capacidade de infectar diferentes hospedeiras, têm sido identificadas quatro raças de $M$. incognita e $M$. javanica e três de $M$. arenaria (CARNEIRO et al., 2003; PIEDRA-BUENA et al., 2011).

A batata-doce (Ipomoea batatas L.), pertencente à família Convolvulaceae, é uma hortaliça de raiz tuberosa, com ampla adaptação, cultivada em condições de clima tropical e subtropical (STEFANOVIĆ et al., 2002). Embora seja bastante rústica, é suscetível aos nematoides do gênero Meloidogyne spp., que são de grande preocupação em relação à produção nos trópicos, subtrópicos e regiões quentes de todo o mundo (JATALA, 1991; SILVEIRA e MALUF, 1993). 
Meloidogyne incognita, apresenta ampla distribuição global e é a espécie mais importante do gênero que ocorre na batata-doce. Meloidogyne arenaria, M. hapla e Meloidogyne javanica também infectam a cultura, embora existam alguns materiais não hospedeiros para certos isolados de $M$. javanica (SCURRAH et al., 2005). Já a distribuição geográfica de $M$. hapla se limita às regiões mais frias, onde a produção da batata-doce é mínima (CERVANTES-FLORES et al., 2000).

No entanto, nos últimos anos, têm sido relatadas algumas espécies que além de apresentar capacidade para quebrar a resistência de várias culturas, estão se dispersando relativamente rápido (RODRÍGUEZ et al., 2007). A espécie Meloidogyne enterolobii (Syn. M. mayaguensis) (YANG e EISENBACK, 1983) é atualmente considerada como uma das mais importantes do gênero, pois suas populações têm atacado plantas resistentes a outras espécies de Meloidogyne, como o tomateiro cv. Rossol (gene Mi), a batata-doce cv. CDH e a soja cv. Forest, cultivares resistentes a $M$. incognita, M. javanica e M. arenaria (CARNEIRO et al., 2006, CARNEIRO et al., 2006; RODRÍGUEZ et al., 2007). Dentre os principais hospedeiros de Meloidogyne enterolobii encontra-se a batata-doce (EPPO, 2014).

No Brasil, as espécies mais importantes em cultivos de batata-doce são $M$. incognita e $M$. javanica (CHARCHAR e RITSCHEL, 2004; CHAVES et al., 2013). De acordo com Cervantes-Flores et al. (2002a) genótipos de batata-doce resistentes a múltiplas espécies de Meloidogyne têm sido raramente reportados.

A maioria dos fitonematoides alimentam-se do tecido radicular das suas hospedeiras, ocasionando-lhes danos severos sobre a fisiologia e crescimento, devido ao comprometimento da capacidade das plantas de absorver água e nutrientes e a que promovem infecções microbianas ou fúngicas através das raízes lesadas e servem como vetores para vírus patogênicos (CERVANTES-FLORES, 2000; PERRY e MOENS, 2006).

Os nematoides do gênero Meloidogyne são os mais abundantes e prejudiciais nematoides fitoparasitas. Eles se reproduzem e se alimentam endoparasiticamente, dentro das raízes das plantas, causando alterações nas células do cilindro vascular e induzindo a formação de galhas, que são a principal característica da ação destes nematoides na planta hospedeira (PERRY e MOENS, 2006). Contudo, em plantas suscetíveis de batata-doce, a presença de inúmeras fêmeas com massas de ovos nas raízes secundárias, imperceptíveis a olho nu, sem formação de galhas, conceituam a cultura como "falsa hospedeira". Adicionalmente, não é 
comum observar galhas nas raízes tuberosas, com exceção de genótipos altamente suscetíveis (CHARCHAR e RITSCHEL, 2004).

Além da redução das raízes absorventes, da folhagem e do crescimento da planta (MONTES et al., 1998) a ocorrência destes nematoides pode predispor a formação de rachaduras longitudinais em raízes de batata-doce, afetando não somente a produtividade, mas também a qualidade e conservação das raízes, e prejudicando o aspecto comercial das batatas, sendo, portanto, de grande importância econômica (PERRY e MOENS, 2006; SASSER, 1980; SILVEIRA e MALUF, 1993). As rachaduras facilitam a penetração e o estabelecimento de muitos organismos secundários e/ou patogênicos, que podem, posteriormente, levar ao apodrecimento das raízes tuberosas. Em adição aos seus efeitos diretos, espécies do gênero Meloidogyne interagem com outros agentes patogênicos para desenvolver doenças complexas (JATALA, 1991).

Os nematoides-das-galhas quebram a resistência monogênica à murcha de Fusarium em cultivares de tomate. Alterações histopatológicas na hospedeira, causadas pela infecção por nematoides, aparentemente, são responsáveis por tornar o(s) gene(s) para a resistência ineficaz(es) e como resultado, a hospedeira não é capaz de expressar a reação de resistência (PERRY e MOENS, 2006).

As respostas da interação planta hospedeira-parasita que estão associadas com a resistência ao nematoide-das-galhas em batata-doce são ausência ou poucas galhas no sistema radicular da hospedeira; necrose moderada ou grave na ponta da raiz; incapacidade dos juvenis para atingir a maturidade; ausência ou baixa taxa de reprodução do nematoide e redução do número de ovos caso a reprodução aconteça (CERVANTES-FLORES, 2000).

Várias estratégias têm sido eficazes no controle do nematoide-das-galhas em batata-doce. Dentre elas, o uso de nematicidas altamente neurotóxicos, em combinação com práticas de controle culturais. Embora os nematicidas sejam eficazes, seu alto custo é proibitivo para os produtores em pequena escala devido ao relativamente baixo valor de mercado da batatadoce. Adicionalmente, a persistência e a toxicidade dos nematicidas são uma séria ameaça para o meio ambiente e a saúde. Com a redução do uso de nematicidas nas últimas décadas, há uma necessidade crescente de desenvolver variedades resistentes (CERVANTESFLORES, 2000). A resistência genética em plantas, sempre que disponível, é o método de controle dos nematoides do gênero Meloidogyne mais eficiente, economicamente sustentável, ambientalmente seguro, não precisa técnicas de aplicação especiais e contribui para reduzir os 
períodos de rotação de culturas (CERVANTES-FLORES et al., 2002b; GOMES, 2014; MELO et al., 2011; MONTES et al., 1998; PIEDRA-BUENA et al., 2011).

O fator mais importante para o desenvolvimento de culturas com resistência ao nematoide-das-galhas é a disponibilidade de material genético resistente dentro de uma espécie de planta. Em batata-doce, há um amplo pool gênico para resistência a doenças e muitas outras características (CERVANTES-FLORES, 2000). O Brasil possui um vasto germoplasma mantido por pequenos agricultores, comunidades indígenas e bancos de germoplasma como o mantido na Embrapa Hortaliças, onde está sediada a maior coleção brasileira de batata-doce (RITSCHEL e HUAMÁN, 2002; SILVEIRA e MALUF, 1993).

Em países em desenvolvimento das regiões tropicais e subtropicais, nos que a batatadoce é uma cultura básica e o sistema de cultivo apresenta baixa entrada de insumos, o uso de cultivares resistentes pode ser uma importante alternativa de manejo economicamente viável, à qual podem ser integradas outras estratégias (ROBERTS, 1992). Adicionalmente, a possibilidade de propagação vegetativa da batata-doce permite a adoção imediata de clones geneticamente superiores, quando identificados em qualquer fase do programa de melhoramento (FREITAS et al., 2001).

Neste contexto, o presente trabalho teve como objetivos avaliar 44 genótipos de batatadoce quanto à resistência a $M$. incognita raça $1, M$. javanica e $M$. enterolobii e identificar materiais que possam ser usados como fontes de genes de resistência ao nematoide-dasgalhas. 


\subsection{MATERIAL E MÉTODOS}

\subsubsection{Localização da área experimental}

Os experimentos foram conduzidos no período compreendido entre os dias 17 de dezembro de 2013 e 14 de abril de 2014, em casa de vegetação pertencente à Embrapa Hortaliças, que está à altitude média de 996 m, entre as coordenadas geográficas 1556'00" de latitude Sul e 4808'00" de longitude Oeste. O clima da região é caracterizado por duas estações típicas; verão chuvoso de outubro a abril e inverno seco de maio a setembro.

\subsubsection{Obtenção, manutenção e preparo do inóculo}

Utilizaram-se como inóculos as espécies Meloidogyne javanica, M. enterolobii e Meloidogyne incognita raça 1, que foram gentilmente cedidas pela Embrapa Recursos Genéticos e Biotecnologia - DF. Todos os inóculos foram fornecidos previamente caracterizados e purificados, sendo realizada a confirmação das espécies pelos fenótipos isoenzimáticos para esterase, seguindo a metodologia proposta por Carneiro e Almeida (2001a); e a determinação da raça 1 de $M$. incognita foi feita pelo teste das plantas hospedeiras diferenciadoras (TAYLOR e SASSER, 1978). As espécies foram multiplicadas e mantidas isoladamente em plantas de tomateiro (Solanum lycopersicum, cv. 'Santa Cruz') em condições de casa de vegetação com umidade e temperatura controladas $\left(25-30{ }^{\circ} \mathrm{C}\right)$ durante 180 dias.

O inóculo foi preparado a partir de raízes com galhas com as espécies Meloidogyne javanica, M. enterolobii e Meloidogyne incognita raça 1, através da extração de ovos e juvenis de segundo estádio (J2) de acordo com o protocolo descrito por Hussey e Baker (1973) modificado por Boneti e Ferraz (1981). As raízes dos tomateiros foram retiradas dos vasos, lavadas cuidadosamente, cortadas em pedaços de aproximadamente $0,5 \mathrm{~cm}$ de comprimento e trituradas em liquidificador com solução de hipoclorito de sódio $(\mathrm{NaOCl})$ $0,5 \%$ por 1 minuto a baixa rotação. A seguir a suspensão foi vertida em peneiras sobrepostas de 150 e 500 mesh de abertura. Os ovos e juvenis de segundo estádio (J2), que ficaram retidos na peneira de 500 mesh, foram lavados com água corrente e coletados em béquer.

A suspensão com os ovos e $\mathbf{J} 2$ foi usada para inocular as plantas de tomateiro, cujas mudas foram obtidas por meio da semeadura de sementes da cultivar 'Santa Cruz', em bandejas de poliestireno tipo speedling com 128 células piramidais invertidas (densidade de 2 
sementes/ célula), contendo substrato artificial à base de vermiculita e casca de Pinus sp. As mudas foram transplantadas com 30 dias após a semeadura, em vasos plásticos com capacidade para $2 \mathrm{~L}$, contendo substrato previamente esterilizado composto de solo:areia, na proporção 2:1. As plântulas de tomate foram inoculadas isoladamente para cada espécie depositando-se a suspensão de ovos e $\mathrm{J} 2$ em três orifícios equidistantes de $3 \mathrm{~cm}$ de profundidade, em torno da planta (BORGES et al., 2009; MENDES e RODRIGUEZ, 2000).

Quando necessário, foram feitas pulverizações com fungicidas e inseticidas para o controle de doenças e pragas. As plantas foram irrigadas periodicamente para manter o nível de umidade adequado.

\subsubsection{Delineamento experimental}

Foram avaliados 44 genótipos de batata-doce do Banco de Germoplasma mantido na Embrapa Hortaliças quanto à resistência a Meloidogyne javanica, Meloidogyne enterolobii e Meloidogyne incognita raça 1. Para cada espécie de nematoide foi instalado um experimento independente, utilizando o delineamento experimental inteiramente casualizado, com 45 tratamentos e 6 repetições. Com o objetivo de verificar a viabilidade do inóculo, também foram inoculadas 6 plantas da cultivar de tomate 'Santa Cruz', suscetível aos nematoides.

Cada experimento foi constituído dos clones CNPH 02, CNPH 05, CNPH 08, CNPH 1192, CNPH 1195, CNPH 1197, CNPH 1200, CNPH 1202, CNPH 1208, CNPH 1216, CNPH 1219, CNPH 1220, CNPH 1221, CNPH 1232, CNPH 1292, CNPH 1298, CNPH 1310, CNPH 1344, CNPH 1357, CNPH 1358, CNPH 1361, CNPH 1365, CNPH 1392, CNPH 1393, CNPH 1394, CNPH 1796, CNPH 1805, CNPH 1809, CNPH 41, CNPH 46, CNPH 53, CNPH 56, CNPH 59, CNPH 60, CNPH 66, CNPH 69, CNPH 80, da variedade Rainha e das cultivares comerciais Brazlândia Rosada (Brazlândia-DF), Brazlândia Branca (Brazlândia-DF), Brazlândia Roxa (Brazlândia-DF), Coquinho (Brasília-DF), Princesa (Brazlândia-DF) e Beauregard.

Com relação a $M$. javanica e $M$. incognita raça 1 , as cultivares de batata-doce Brazlândia Roxa e Brazlândia Branca foram utilizadas como padrões de resistência e suscetibilidade, respectivamente (CHARCHAR e RITSCHEL, 2004; MARCHESE et al., 2010; MASSAROTO et al., 2010). 


\subsubsection{Inoculação em batata-doce}

Um mês antes da inoculação das espécies de nematoides, seis ramas sadias com 4 gemas internodais de cada genótipo foram plantadas individualmente em vasos plásticos com capacidade para $2 \mathrm{~L}$, contendo substrato previamente esterilizado composto de solo de cerrado, areia lavada, esterco de gado e palha de arroz carbonizada, na proporção 1:1:1:1. As plantas foram cultivadas sob estufa plástica, na Embrapa Hortaliças, em Brasília - DF.

O inóculo foi preparado, como anteriormente descrito, a partir de raízes galhadas de tomateiros com as espécies Meloidogyne javanica, M. enterolobii e Meloidogyne incognita raça 1, através da extração de ovos e $\mathbf{J} 2$ de acordo com o protocolo proposto por Hussey e Baker (1973) modificado por Boneti e Ferraz (1981). Os ovos e J2 foram contados em câmara de Peters, sob microscópio óptico.

As inoculações foram realizadas trinta dias após o plantio das ramas (dia 23 de janeiro de 2014), colocando-se, para cada espécie estudada, quantidades de suspensão equivalentes a 5.000 ovos $+\mathrm{J} 2 /$ planta $(\mathrm{Pi}=$ nível de inoculo inicial), que foram distribuídas em pequenos orifícios realizados em torno das ramas e tampados posteriormente. Os vasos de cada espécie foram colocados sobre mesas de forma completamente aleatorizada.

Durante a execução dos experimentos realizaram-se irrigações diárias das plantas até a ocasião das avaliações. Foi efetuada adubação de cobertura no dia 25 de fevereiro, sendo adicionados $3 \mathrm{~g}$ de Osmocote $®$ (19-06-10) por litro de substrato.

\subsubsection{Avaliação do índice de galhas, índice de massas de ovos, população final e fator de reprodução}

Oitenta dias após a inoculação, as plantas foram retiradas cuidadosamente dos vasos e, em seguida, tiveram seus sistemas radiculares lavados em água corrente e coloridos por imersão em solução de floxina $\mathrm{B}$, na concentração de $0,12 \mathrm{~g} / 4 \mathrm{~L}$ de água, durante 15 min (HUSSEY e BAKER, 1973). Posteriormente efetuou-se a avaliação do índice de galhas (IG) e do índice de massas de ovos (IMO) no sistema radicular de cada planta, segundo a escala de notas proposta por Taylor e Sasser (1978), onde: $0=$ sem galhas ou massas de ovos; $1=1-2$ galhas ou massas de ovos; 2= 3-10 galhas ou massas de ovos; 3=11-30 galhas ou massas de ovos; 4= 31-100 galhas ou massas de ovos e 5= mais de 100 galhas ou massas de ovos no sistema radicular de cada planta. 
Determinou-se também a população final dos nematoides no sistema radicular e nas porções das raízes tuberosas com galhas, procedendo-se para a extração, da mesma forma como realizado para as raízes galhadas de tomateiros. As partes das raízes tuberosas que apresentaram galhas, forma removidas cuidadosamente e liquidificadas juntamente com as raízes. A população final (Pf) foi quantificada pela contagem dos ovos e J2 em câmara de Peters, sob microscópio óptico. Os resultados foram divididos pelo peso fresco da raiz e da parte das raízes tuberosas com galhas e expressos como ovos+J2 por grama de raiz.

$\mathrm{O}$ fator de reprodução do nematoide $(\mathrm{FR}=\mathrm{Pf} / \mathrm{Pi})$, foi calculado pela divisão entre as populações final e inicial, sendo considerados resistentes os genótipos com FR menor que 1 e suscetíveis os que apresentaram FR superior ou igual à unidade (Oostenbrink, 1966).

\subsubsection{Determinação dos parâmetros colorimétricos $L^{*}, a^{*}, b^{*}, C^{*}$ e $h^{*}$}

Foram coletadas aleatoriamente 6 raízes, de diferentes plantas, por genótipo. Para a determinação dos valores de cor na película externa, realizaram-se três leituras na região mediana, no sentido transversal, no córtex das raízes tuberosas previamente lavadas e secas. Já para a quantificação dos parâmetros de cor na polpa, as raízes foram lavadas, secas com papel absorvente, descascadas e cortadas transversalmente em três locais diferentes: parte superior, central e inferior, sendo realizadas duas leituras na parte central das raízes tuberosas.

A cor foi medida com colorímetro Konica Minolta®, modelo CR-400, com 8 mm de diâmetro da área de medida do aparelho e com iluminação difusa (iluminante D65, ângulo de visão $0^{\circ}$ e espaço cromático CIELAB). $\mathrm{O}$ aparelho foi calibrado no sistema $\mathrm{L}^{*}, \mathrm{a}^{*}, \mathrm{~b}^{*}$ com uma placa branca padrão de cerâmica $\left(\mathrm{L}^{*}=84,2 ; \mathrm{a}^{*}=10,1 ; \mathrm{b}^{*}=14,6\right)$.

As colorações foram descritas com base nos valores $\mathrm{L}^{*}, \mathrm{C}^{*} \mathrm{e} \mathrm{H}^{*}$, onde $\mathrm{L}^{*}$ indica a luminosidade; $\mathrm{C}^{*}$ indica o croma: saturação da cor $\left(\mathrm{a}^{*^{2}}+\mathrm{b}^{*^{2}}\right)^{1 / 2}$ e $\mathrm{H}^{*}$ define o ângulo Hue $\left(\tan ^{-1} \mathrm{~b}^{*} / \mathrm{a}^{*}\right)$.

\subsubsection{Análise estatística}

Com exceção dos parâmetros de cor, tanto para a película externa, quanto para a polpa, todos os dados foram transformados em $\sqrt{x+1}$, para atender à pressuposição de distribuição normal e homocedasticidade dos dados, sendo apresentados os valores originais.

Os dados foram submetidos à análise de variância para cada caracteristica e as médias foram agrupadas por meio do teste de Scott-Knott com nível de significância de 5\%. 
As análises de correlação linear de Pearson, entre as variáveis, basearam-se na significância de seus coeficientes. A classificação de intensidade da correlação para $p \leq 0,05$ foi: muito forte $(r \pm 0,91$ a $\pm 1,00)$, forte $(r \pm 0,71$ a $\pm 0,9)$, média $(r \pm 0,51$ a $\pm 0,70)$, fraca $(r$ $\pm 0,31$ a $\pm 0,50)$ e muito fraca $(r \leq \pm 0,30)$ (CARVALHO et al., 2004). As análises estatísticas descritas anteriormente foram realizadas utilizando-se o software R Core Team (2013).

A partir dos componentes da variância foram estimados os parâmetros genéticos de herdabilidade no sentido amplo $\left(\mathrm{ha}^{2}\right)$, os coeficientes de variação genética $\left(\mathrm{CV}_{\mathrm{g}}\right)$, ambiental $\left(\mathrm{CV}_{\mathrm{e}}\right)$ e a razão entre os coeficientes de variação genética e ambiental $\left(\mathrm{CV}_{\mathrm{g}} / \mathrm{CV}_{\mathrm{e}}\right)$ para os caracteres estudados, utilizando-se o programa GENES (CRUZ, 2013). 


\subsection{RESULTADOS E DISCUSSÃO}

Na Tabela 4.1 são apresentados os valores médios dos caracteres índice de galhas, índice de massas de ovos, número de ovos $+\mathrm{J} 2$ por grama de raiz e fator de reprodução, que foram utilizadas no estudo de 44 clones de batata-doce quanto à resistência a $M$. javanica .

As notas médias para o índice de galhas nas raízes oscilaram entre 0 e 4 . Os clones CNPH 1361, CNPH 08, CNPH 1393, CNPH 66, CNPH 1197, CNPH 1392, CNPH 1195, CNPH 1292, CNPH 1358, CNPH 1365, CNPH 1220, Rainha, CNPH 1310, CNPH 02 e CNPH 1357 e as cultivares Brazlândia Rosada e Coquinho foram resistentes à formação de galhas no sistema radicular por $M$. javanica. Esta espécie não produziu massas de ovos nos materiais mencionados anteriormente nem no clone CNPH 80 (Tabela 4.1). É importante destacar que o experimento foi conduzido entre os meses de janeiro e abril e as condições prevalecentes durante esta época do ano na região são adequadas e desejáveis para o crescimento e desenvolvimento do nematoide. O clone CNPH 59 (nota 4) demonstrou índice de galhas no sistema radicular estatisticamente equivalente ao apresentado pela cultivar de tomate Santa Cruz (nota 5), considerada testemunha padrão de suscetibilidade a Meloidogyne spp. Segundo Freitas et al. (2001), o maior índice de galhas na cultivar Santa Cruz pode ser explicado pela maior eficiência do inóculo na formação de galhas nas raízes do tomateiro. $M$. javanica produziu o maior número de massas de ovos sobre as cultivares Beauregard e Princesa e os clones CNPH 1809 e CNPH 59 (notas 3; 3,33; 3 e 4, respectivamente), os quais não apresentaram diferenças significativas com o tomateiro (nota 4,17) (Tabela 4.1).

Cervantes-Flores et al. (2002b) avaliaram a resistência de genótipos de batata-doce a $M$. javanica com base no número de massas de ovos produzidos por sistema radicular, sendo que, plantas que proporcionaram um valor médio igual ou superior a 10 foram consideradas boas hospedeiras. Estes autores verificaram a suscetibilidade da cultivar Beauregard a esta espécie, a qual apresentou 24 massas de ovos por sistema radicular. Igualmente, Cervantes-Flores et al. (2002a) constataram que a cv. Beauregard foi suscetível a $M$. javanica, apresentando $20 \%$ de seu sistema radicular galhado por esta espécie. Segundo estes autores a cv. Beauregard deve ser usada em programas de melhoramento preferencialmente em cruzamentos com materiais resistentes. 
Tabela 4.1 Reação de genótipos de batata-doce à infecção por $M$. javanica

\begin{tabular}{|c|c|c|c|c|c|c|c|}
\hline Genótipo & IG & IMO & FR & GR & OMRT & Coloração externa & Coloração interna \\
\hline CNPH 56 & $0,33 \mathrm{e}$ & $0,33 \mathrm{e}$ & $0,00 \mathrm{~d}$ & $\mathrm{R}$ & $0,00 \mathrm{e}$ & Branca & Branca \\
\hline CNPH 1361 & $0,00 \mathrm{e}$ & $0,00 \mathrm{e}$ & $0,00 \mathrm{~d}$ & $\mathrm{R}$ & $0,00 \mathrm{e}$ & Roxa & Branca \\
\hline CNPH 1394 & $0,33 \mathrm{e}$ & $0,17 \mathrm{e}$ & $0,00 \mathrm{~d}$ & $\mathrm{R}$ & $0,00 \mathrm{e}$ & Roxa-avermelhada & Branca \\
\hline CNPH 08 & $0,00 \mathrm{e}$ & $0,00 \mathrm{e}$ & $0,00 \mathrm{~d}$ & $\mathrm{R}$ & $0,00 \mathrm{e}$ & Rosa & Branca \\
\hline CNPH 1393 & $0,00 \mathrm{e}$ & $0,00 \mathrm{e}$ & $0,00 \mathrm{~d}$ & $\mathrm{R}$ & $0,00 \mathrm{e}$ & Branca & Creme \\
\hline CNPH 66 & $0,00 \mathrm{e}$ & $0,00 \mathrm{e}$ & $0,00 \mathrm{~d}$ & $\mathrm{R}$ & $0,00 \mathrm{e}$ & Creme escura & Creme escura \\
\hline B. Rosada & $0,00 \mathrm{e}$ & $0,00 \mathrm{e}$ & $0,00 \mathrm{~d}$ & $\mathrm{R}$ & $0,00 \mathrm{e}$ & Rosa & Creme \\
\hline CNPH 1197 & $0,00 \mathrm{e}$ & $0,00 \mathrm{e}$ & $0,00 \mathrm{~d}$ & $\mathrm{R}$ & $0,00 \mathrm{e}$ & Roxa-avermelhada & Branca \\
\hline CNPH 1392 & $0,00 \mathrm{e}$ & $0,00 \mathrm{e}$ & $0,00 \mathrm{~d}$ & $\mathrm{R}$ & $0,00 \mathrm{e}$ & Marron alaranjada & Laranja pálida \\
\hline CNPH 1195 & $0,00 \mathrm{e}$ & $0,00 \mathrm{e}$ & $0,00 \mathrm{~d}$ & $\mathrm{R}$ & $0,00 \mathrm{e}$ & Rosa & Laranja intenso \\
\hline CNPH 1796 & $0,33 \mathrm{e}$ & $0,33 \mathrm{e}$ & $0,00 \mathrm{~d}$ & $\mathrm{R}$ & $0,00 \mathrm{e}$ & Roxa & Vermelha púrpura \\
\hline CNPH 80 & $0,50 \mathrm{~d}$ & $0,00 \mathrm{e}$ & $0,00 \mathrm{~d}$ & $\mathrm{R}$ & $0,00 \mathrm{e}$ & Roxa-escura & Roxa-avermelhada \\
\hline CNPH 1219 & $0,50 \mathrm{~d}$ & $0,50 \mathrm{e}$ & $0,02 \mathrm{~d}$ & $\mathrm{R}$ & $6,46 \mathrm{e}$ & Roxa-avermelhada & Creme \\
\hline Coquinho & $0,00 \mathrm{e}$ & $0,00 \mathrm{e}$ & $0,02 \mathrm{~d}$ & $\mathrm{R}$ & $12,08 \mathrm{e}$ & Amarela pálida & Branca \\
\hline B. Roxa & $0,67 \mathrm{~d}$ & $0,17 \mathrm{e}$ & $0,02 \mathrm{~d}$ & $\mathrm{R}$ & 0,99 e & Roxa-avermelhada & Creme escura \\
\hline CNPH 1292 & $0,00 \mathrm{e}$ & $0,00 \mathrm{e}$ & $0,02 \mathrm{~d}$ & $\mathrm{R}$ & $6,89 \mathrm{e}$ & Roxa-avermelhada & Laranja avermelhada \\
\hline CNPH 1358 & $0,00 \mathrm{e}$ & $0,00 \mathrm{e}$ & $0,03 \mathrm{~d}$ & $\mathrm{R}$ & $13,48 \mathrm{e}$ & Roxa & Branca \\
\hline CNPH 1805 & $1,00 \mathrm{~d}$ & $1,00 \mathrm{~d}$ & $0,03 \mathrm{~d}$ & $\mathrm{R}$ & $11,57 \mathrm{e}$ & Roxa & Creme \\
\hline CNPH 1365 & $0,00 \mathrm{e}$ & $0,00 \mathrm{e}$ & $0,03 \mathrm{~d}$ & $\mathrm{R}$ & $5,89 \mathrm{e}$ & Marron alaranjada & Laranja intenso \\
\hline CNPH 05 & $0,17 \mathrm{e}$ & $0,17 \mathrm{e}$ & $0,03 \mathrm{~d}$ & $\mathrm{R}$ & 7,96 e & Roxa & Roxa-avermelhada \\
\hline CNPH 1220 & $0,00 \mathrm{e}$ & $0,00 \mathrm{e}$ & $0,05 \mathrm{~d}$ & $\mathrm{R}$ & $68,73 \mathrm{e}$ & Amarela pálida & Laranja intenso \\
\hline CNPH 1298 & $0,17 \mathrm{e}$ & $0,17 \mathrm{e}$ & $0,07 \mathrm{~d}$ & $\mathrm{R}$ & $25,08 \mathrm{e}$ & Roxa & Laranja avermelhada \\
\hline Rainha & $0,00 \mathrm{e}$ & $0,00 \mathrm{e}$ & $0,08 \mathrm{~d}$ & $\mathrm{R}$ & 27,79 e & Rosa & Branca \\
\hline CNPH 1310 & $0,00 \mathrm{e}$ & $0,00 \mathrm{e}$ & $0,08 \mathrm{~d}$ & $\mathrm{R}$ & $20,34 \mathrm{e}$ & Marron alaranjada & Laranja intenso \\
\hline CNPH 02 & $0,00 \mathrm{e}$ & $0,00 \mathrm{e}$ & $0,10 \mathrm{~d}$ & $\mathrm{R}$ & $28,61 \mathrm{e}$ & Creme escura & Creme \\
\hline CNPH 60 & $0,50 \mathrm{~d}$ & $0,50 \mathrm{e}$ & $0,10 \mathrm{~d}$ & $\mathrm{R}$ & $54,35 \mathrm{e}$ & Creme escura & Branca \\
\hline CNPH 1357 & $0,00 \mathrm{e}$ & $0,00 \mathrm{e}$ & $0,12 \mathrm{~d}$ & $\mathrm{R}$ & $145,07 \mathrm{e}$ & Branca & Branca \\
\hline CNPH 1232 & $0,33 \mathrm{e}$ & $0,33 \mathrm{e}$ & $0,12 \mathrm{~d}$ & $\mathrm{R}$ & $38,39 \mathrm{e}$ & Marron alaranjada & Laranja pálida \\
\hline CNPH 46 & $1,83 \mathrm{c}$ & $2,00 \mathrm{~b}$ & $0,15 \mathrm{~d}$ & $\mathrm{R}$ & $53,63 \mathrm{e}$ & Amarela pálida & Creme \\
\hline CNPH 69 & 0,17 e & $0,50 \mathrm{~d}$ & $0,16 \mathrm{~d}$ & $\mathrm{R}$ & $31,15 \mathrm{e}$ & Amarela pálida & Branca \\
\hline CNPH 1221 & $1,33 \mathrm{c}$ & $1,17 \mathrm{~d}$ & $0,17 \mathrm{~d}$ & $\mathrm{R}$ & $25,23 \mathrm{e}$ & Roxa & Creme \\
\hline CNPH 1216 & $0,83 \mathrm{~d}$ & $0,83 \mathrm{~d}$ & $0,22 \mathrm{~d}$ & $\mathrm{R}$ & $53,45 \mathrm{e}$ & Marron alaranjada & Laranja intenso \\
\hline CNPH 1200 & $2,00 \mathrm{c}$ & $2,33 \mathrm{~b}$ & $0,27 \mathrm{~d}$ & $\mathrm{R}$ & $75,66 \mathrm{e}$ & Rosa & Laranja intenso \\
\hline B. Branca & $1,50 \mathrm{c}$ & $1,33 \mathrm{c}$ & $0,37 \mathrm{~d}$ & $\mathrm{R}$ & $104,34 \mathrm{e}$ & Branca & Branca \\
\hline CNPH 1208 & $1,67 \mathrm{c}$ & $1,67 \mathrm{c}$ & $0,40 \mathrm{~d}$ & $\mathrm{R}$ & $220,52 d$ & Roxa & Branca \\
\hline CNPH 41 & $1,67 \mathrm{c}$ & $1,50 \mathrm{c}$ & $0,53 \mathrm{~d}$ & $\mathrm{R}$ & $601,37 \mathrm{c}$ & Branca & Branca \\
\hline CNPH 1344 & $2,00 \mathrm{c}$ & $2,00 \mathrm{~b}$ & $0,58 \mathrm{~d}$ & $\mathrm{R}$ & $469,64 d$ & Rosa & Creme escura \\
\hline CNPH 53 & $1,00 \mathrm{~d}$ & $1,00 \mathrm{~d}$ & $0,63 \mathrm{~d}$ & $\mathrm{R}$ & $262,80 \mathrm{~d}$ & Roxa & Branca \\
\hline CNPH 1202 & $1,50 \mathrm{c}$ & $1,67 \mathrm{c}$ & $0,75 \mathrm{~d}$ & $\mathrm{R}$ & $256,66 \mathrm{~d}$ & Marron alaranjada & Laranja intenso \\
\hline Princesa & $3,33 \mathrm{~b}$ & $3,33 \mathrm{a}$ & $0,85 \mathrm{~d}$ & $\mathrm{R}$ & $268,32 \mathrm{~d}$ & Creme & Branca \\
\hline CNPH 1192 & $2,50 \mathrm{c}$ & $2,50 \mathrm{~b}$ & $1,65 \mathrm{c}$ & $S$ & $712,09 \mathrm{c}$ & Amarela pálida & Laranja pálida \\
\hline Beauregard & $3,00 \mathrm{~b}$ & $3,00 \mathrm{a}$ & $2,30 \mathrm{c}$ & $\mathrm{S}$ & $874,93 \mathrm{c}$ & Vermelha-arroxeada & Laranja intenso \\
\hline CNPH 1809 & $3,00 \mathrm{~b}$ & $3,00 \mathrm{a}$ & $2,78 \mathrm{c}$ & $\mathrm{S}$ & $324,10 \mathrm{~d}$ & Roxa escura & Vermelha púrpura \\
\hline CNPH 59 & $4,00 \mathrm{a}$ & $4,00 \mathrm{a}$ & $17,26 \mathrm{~b}$ & S & $5.298,9 \mathrm{~b}$ & Creme escura & Branca \\
\hline T. Santa Cruz & $5,00 \mathrm{a}$ & $4,17 \mathrm{a}$ & $94,31 \mathrm{a}$ & $S$ & $11.211 \mathrm{a}$ & - & - \\
\hline Média & 0,91 & 0,88 & 2,76 & & 473,72 & - & - \\
\hline C.V. (\%) & 17,24 & 17,1 & 38,07 & & 76,7 & - & - \\
\hline
\end{tabular}

Médias com a mesma letra na coluna não diferem entre si, pelo teste de Scott-Knott a 5\% de probabilidade. IG: índice de galhas; IMO: índice de massas de ovos; FR: fator de reprodução; GR: grau de resistência (R: resistente e S: suscetível); OMRT: ovos $+\mathrm{J}_{2}$ por grama de raiz e parte da raiz tuberosa com galhas. 
Os clones CNPH 56, CNPH 1361, CNPH 1394, CNPH 08, CNPH 1393, CNPH 66, CNPH 1197, CNPH 1392, CNPH 1195, CNPH 1796, CNPH 80, CNPH 1219, CNPH 1292, CNPH 1358, CNPH 1805, CNPH 1365, CNPH 05, CNPH 1220, CNPH 1298, Rainha, CNPH 1310, CNPH 02, CNPH 60, CNPH 1357, CNPH 1232, CNPH 46, CNPH 69, CNPH 1221, CNPH 1216, CNPH 1200, CNPH 1208, CNPH 41, CNPH 1344, CNPH 53 e CNPH 1202 e as cultivares Princesa, Brazlândia Rosada, Coquinho, Brazlândia Roxa e Brazlândia Branca, com valores de fator de reprodução de $M$. javanica inferiores a 1 (totalizando 90,91\% dos genótipos de batata-doce avaliados), foram resistentes a esta espécie. O clone CNPH 59 foi o melhor hospedeiro para a reprodução deste fitoparasita, com fator de reprodução de 17,26. A cultivar Beauregard e os clones CNPH 1192 e CNPH 1809, com fatores de reprodução do nematoide de 2,30; 1,65 e 2,78, respectivamente, também foram suscetíveis à infecção por $M$. javanica.

Gomes (2014) também constatou a resistência da cultivar Brazlândia Branca a $M$. javanica, com fator de reprodução de 0,02 .

Segundo Cervantes-Flores et al. (2002b) o melhoramento para a resistência a $M$. javanica, a segunda espécie de Meloidogyne mais comumente encontrada nas terras cultivadas no mundo inteiro, principalmente nos trópicos, pode junto com $M$. arenaria não ser um problema para a batata-doce, toda vez que existem boas fontes de resistência para estas espécies. Dos 26 genótipos avaliados por estes autores $88,46 \%$ foram resistentes a $M$. javanica. Contudo, as cultivares Beauregard, L86-33 e Nancy Hall foram altamente suscetíveis a esta espécie. Ainda segundo estes autores, as cultivares Beauregard e Nancy Hall têm sido utilizadas amplamente como genitores em muitos programas de melhoramento de batata-doce em diversos países.

Maluf et al. (1996) estudaram uma população de 226 clones de batata-doce quanto à resistência aos nematoides-das-galhas $M$. javanica e $M$. incognita raças 1, 2, 3 e 4, com base no número de massas de ovos por raiz. Estes autores observaram que as frequências de genótipos resistentes foram maiores para M. javanica e menores para $M$. incognita, raça 2.

Silveira e Maluf (1993) igualmente verificaram a relativa facilidade de se encontrar clones resistentes a $M$. javanica com relação às quatro raças de $M$. incognita. Estes autores avaliaram 36 clones de batata-doce quanto à resistência a $M$. javanica, segundo o número médio de massas de ovos presentes no sistema radicular de cada planta, e identificaram 23 materiais resistentes $(63,89 \%)$; sendo também constatado que as cultivares Brazlândia Roxa, 
Brazlândia Rosada e Coquinho, as quais não apresentaram massas de ovos nos sistemas radiculares, foram altamente resistentes. No entanto, as cultivares comerciais Brazlândia Branca e Princesa, classificadas no presente trabalho como resistentes, foram consideradas como suscetíveis por estes pesquisadores.

Charchar e Ritschel (2004) estudaram a resistência de 357 acessos a M. javanica com base na média dos índices de massas de ovos por sistema radicular. 85,99\% dos genótipos foram altamente resistentes a esta espécie, que infectou apenas 50 dos materiais avaliados $(14,01 \%)$, dentre os quais, 19 apresentaram algum grau de resistência, 10 foram suscetíveis e 21 altamente suscetíveis. Os resultados desta pesquisa também corroboraram a resistência das cultivares Brazlândia Roxa e Princesa. Contudo, foram divergentes para a cv. Brazlândia Branca, suscetível e as cvs. Brazlândia Rosada e Coquinho, altamente suscetíveis à espécie.

Entretanto, os resultados dos autores supracitados não podem ser exatamente comparáveis com os obtidos neste estudo, devido ao fato que as metodologias utilizadas por estes para a classificação da resistência apresentam diferenças, pois baseiam-se no número de massas de ovos por sistema radicular. Adicionalmente, o desenvolvimento do nematoide, uma vez que este penetra nas raízes das cultivares é afetado por outros fatores como o genótipo das plantas, a espécie e a raça do nematoide, a variabilidade existente entre os isolados dos nematoides, o local de origem da população, a população inicial de inóculo, a data de plantio, as temperaturas médias do solo e do ambiente durante a condução do experimento, o tipo de solo, o tempo transcorrido durante a inoculação e a avaliação do experimento e o volume de água utilizado durante as irrigações, que são determinantes para a população final do nematoide.

Pilco et al. (2011) ao avaliar a resposta de 4 genótipos de batata-doce a M. javanica, estudando diferentes níveis de inoculo, observaram que as populações finais mais altas foram atingidas com o aumento da população inicial, enquanto os fatores de reprodução mais elevados foram encontrados em plantas inoculadas com populações inicias mais baixas. Estes autores reportaram nos clones TU-111, C-14 e Mariara fatores de reprodução de $M$. javanica variando de 1,5 a 9,3; de 5,3 a 36,8 e de 3,8 a 16,4, para as plantas inoculadas com 64 e 0,5 ovos $+\mathrm{J} 2 / \mathrm{cm}^{3}$ de solo, respectivamente. Já o clone U-013 foi o único resistente/tolerante a esta espécie, pois não apresentou galhas, nem massas de ovos nas raízes, nem alterações nas características agronômicas da planta, independentemente da população inoculada. 
Chaves et al. (2013) na avaliação da reação de 25 materiais a $M$. javanica, observaram que apenas os genótipos experimentais BDFMI-03 e BDFMI-51 foram suscetíveis. Os outros 23 materiais (92\%) apresentaram diversos graus de resistência com base no índice de reprodução do nematoide relativo à cultivar de tomate Santa Clara, sendo que 16; 48 e 28\% dos genótipos avaliados foram classificados como muito resistentes; levemente resistentes e moderadamente resistentes, respectivamente.

Foi constatada grande variação entre os materiais avaliados com relação ao número de ovos $+\mathrm{J} 2$ por grama de raiz, que oscilou entre 0 e 5.298,9 ovos $+\mathrm{J} 2 /$ g. O melhor hospedeiro de M. javanica foi o clone CNPH 59, já que suportou o maior número de nematoides por grama de raiz $(5.298,9)$. Em contrapartida, esta espécie não infectou os genótipos CNPH 56, CNPH 1361, CNPH 1394, CNPH 08, CNPH 1393, CNPH 66, Brazlândia Rosada, CNPH 1197, CNPH 1392, CNPH 1195, CNPH 1796 e CNPH 80, que não apresentaram formação de ovos $+\mathrm{J} 2$, sendo não hospedeiros de M. javanica.

Observou-se que a cv. Princesa foi resistente a M. javanica, embora apresentou índice de massas de ovos estatisticamente equivalente ao dos genótipos Beauregard, CNPH 1809 e CNPH 59 (3,33; 3; 3 e 4, respectivamente), que foram suscetíveis. Considerando o desenvolvimento radicular das plantas, por exemplo, na cv. Princesa o nematoide atingiu um índice de massas de ovos de 3,33 com 268,32 ovos+J2/ g de raízes, enquanto na cv. Beauregard o índice de massa de ovos foi de 3 com 874,93 ovos $+\mathrm{J} 2 / \mathrm{g}$ de raízes, o que indica que a resistência e a população alcançada na cv. Princesa deve-se a um grau superior de tolerância e a uma hospedeira mais eficiente em inibir a multiplicação do nematoide.

Os valores médios dos caracteres índice de galhas, índice de massas de ovos, número de ovos+J2 por grama de raiz e fator de reprodução da espécie Meloidogyne incognita raça 1, bem como os resultados da análise estatística comparativa são apresentados na Tabela 4.2.

Somente os clones CNPH 1358, CNPH 02, CNPH 1361 e CNPH 1202 não apresentaram galhas, nem massas de ovos nos sistemas radiculares. Já os genótipos CNPH 1221, CNPH 1220, CNPH 41, CNPH 1344, CNPH 59, CNPH 1805, CNPH 53, Princesa, Brazlândia Branca, CNPH 1216, CNPH 1298, CNPH 1192 e CNPH 1809 com notas de índice de galhas de 2,$83 ; 3,00 ; 3,00 ; 3,00 ; 3,33 ; 3,33 ; 3,50 ; 3,33 ; 3,50 ; 3,67 ; 3,67 ; 3,67$ e 3,67 e de índices de massas de ovos de 2,83; 3,00; 3,00; 3,00; 3,00; 3,17; 3,33; 3,33; 3,50; 3,67; 3,67; 3,67 e 3,67, respectivamente, foram estatisticamente equivalentes à cv. de tomate Santa Cruz, que apresentou índices médios de galhas e de massas de ovos nas raízes de 5 e 4, respectivamente. 
Tabela 4.2 Reação de genótipos de batata-doce à infecção por $M$. incognita raça 1

\begin{tabular}{|c|c|c|c|c|c|c|c|}
\hline Genótipo & IG & IMO & FR & GR & OMRT & Coloração externa & Coloração interna \\
\hline CNPH 1219 & $0,33 \mathrm{~d}$ & $0,33 \mathrm{~d}$ & $0,00 \mathrm{~d}$ & $\mathrm{R}$ & $0,00 \mathrm{e}$ & Roxa-avermelhada & Creme \\
\hline Coquinho & $0,17 \mathrm{~d}$ & $0,17 \mathrm{~d}$ & $0,00 \mathrm{~d}$ & $\mathrm{R}$ & $0,00 \mathrm{e}$ & Amarela pálida & Branca \\
\hline CNPH 1392 & $0,33 \mathrm{~d}$ & $0,33 \mathrm{~d}$ & $0,00 \mathrm{~d}$ & $\mathrm{R}$ & $0,00 \mathrm{e}$ & Marron alaranjada & Laranja pálida \\
\hline CNPH 1292 & $0,17 \mathrm{~d}$ & $0,17 \mathrm{~d}$ & $0,00 \mathrm{~d}$ & $\mathrm{R}$ & $0,00 \mathrm{e}$ & Roxa-avermelhada & Laranja avermelhada \\
\hline CNPH 1358 & $0,00 \mathrm{~d}$ & $0,00 \mathrm{~d}$ & $0,02 \mathrm{~d}$ & $\mathrm{R}$ & $14,12 \mathrm{e}$ & Roxa & Branca \\
\hline CNPH 69 & $0,17 \mathrm{~d}$ & $0,00 \mathrm{~d}$ & $0,03 \mathrm{~d}$ & $\mathrm{R}$ & $12,89 \mathrm{e}$ & Amarela pálida & Branca \\
\hline CNPH 56 & $0,17 \mathrm{~d}$ & $0,33 \mathrm{~d}$ & $0,04 \mathrm{~d}$ & $\mathrm{R}$ & $35,31 \mathrm{e}$ & Branca & Branca \\
\hline CNPH 02 & $0,00 \mathrm{~d}$ & $0,00 \mathrm{~d}$ & $0,05 \mathrm{~d}$ & $\mathrm{R}$ & $13,41 \mathrm{e}$ & Creme escura & Creme \\
\hline CNPH 1361 & $0,00 \mathrm{~d}$ & $0,00 \mathrm{~d}$ & $0,05 \mathrm{~d}$ & $\mathrm{R}$ & $11,39 \mathrm{e}$ & Roxa & Branca \\
\hline CNPH 1202 & $0,00 \mathrm{~d}$ & $0,00 \mathrm{~d}$ & $0,05 \mathrm{~d}$ & $\mathrm{R}$ & $46,53 \mathrm{e}$ & Marron alaranjada & Laranja intenso \\
\hline CNPH 08 & $0,17 \mathrm{~d}$ & $0,17 \mathrm{~d}$ & $0,08 \mathrm{~d}$ & $\mathrm{R}$ & $20,01 \mathrm{e}$ & Rosa & Branca \\
\hline CNPH 1796 & $0,50 \mathrm{~d}$ & $0,50 \mathrm{~d}$ & $0,10 \mathrm{~d}$ & $\mathrm{R}$ & $90,46 \mathrm{e}$ & Roxa & Vermelha púrpura \\
\hline CNPH 1394 & $0,67 \mathrm{c}$ & $0,67 \mathrm{~d}$ & $0,13 \mathrm{~d}$ & $\mathrm{R}$ & $32,72 \mathrm{e}$ & Roxa-avermelhada & Branca \\
\hline CNPH 1393 & $0,50 \mathrm{~d}$ & $0,50 \mathrm{~d}$ & $0,14 \mathrm{~d}$ & $\mathrm{R}$ & $32,37 \mathrm{e}$ & Branca & Creme \\
\hline B. Roxa & $0,33 \mathrm{~d}$ & $0,33 \mathrm{~d}$ & $0,15 \mathrm{~d}$ & $\mathrm{R}$ & $30,85 \mathrm{e}$ & Roxa-avermelhada & Creme escura \\
\hline CNPH 1197 & $1,17 \mathrm{c}$ & $1,17 \mathrm{c}$ & $0,18 \mathrm{~d}$ & $\mathrm{R}$ & $47,90 \mathrm{e}$ & Roxa-avermelhada & Branca \\
\hline CNPH 1232 & $1,00 \mathrm{c}$ & $1,00 \mathrm{c}$ & $0,37 \mathrm{~d}$ & $\mathrm{R}$ & $89,04 \mathrm{e}$ & Marron alaranjada & Laranja pálida \\
\hline CNPH 05 & $1,00 \mathrm{c}$ & $1,00 \mathrm{c}$ & $0,44 \mathrm{~d}$ & $\mathrm{R}$ & $160,26 \mathrm{e}$ & Roxa & Roxa-avermelhada \\
\hline CNPH 60 & $2,00 \mathrm{~b}$ & $2,00 \mathrm{~b}$ & $0,45 \mathrm{~d}$ & $\mathrm{R}$ & $231,41 \mathrm{~d}$ & Creme escura & Branca \\
\hline Rainha & $2,00 \mathrm{~b}$ & $1,33 \mathrm{c}$ & $0,50 \mathrm{~d}$ & $\mathrm{R}$ & $405,31 \mathrm{~d}$ & Rosa & Branca \\
\hline CNPH 1200 & $0,83 \mathrm{c}$ & $0,83 \mathrm{c}$ & $0,50 \mathrm{~d}$ & $\mathrm{R}$ & $261,43 \mathrm{~d}$ & Rosa & Laranja intenso \\
\hline CNPH 1310 & $2,83 \mathrm{a}$ & $2,83 \mathrm{a}$ & $0,73 \mathrm{~d}$ & $\mathrm{R}$ & $591,50 \mathrm{~d}$ & Marron alaranjada & Laranja intenso \\
\hline B. Rosada & $1,67 \mathrm{~b}$ & $1,17 \mathrm{c}$ & $0,92 \mathrm{~d}$ & $\mathrm{R}$ & $195,23 \mathrm{e}$ & Rosa & Creme \\
\hline CNPH 1220 & $3,00 \mathrm{a}$ & $3,00 \mathrm{a}$ & $1,21 \mathrm{~d}$ & $\mathrm{~S}$ & $2.248,3 \mathrm{c}$ & Amarela pálida & Laranja intenso \\
\hline CNPH 66 & $1,33 \mathrm{c}$ & $1,33 \mathrm{c}$ & $1,43 \mathrm{~d}$ & $\mathrm{~S}$ & $436,24 \mathrm{~d}$ & Creme escura & Creme escura \\
\hline CNPH 46 & $2,17 \mathrm{~b}$ & $2,33 \mathrm{~b}$ & $2,20 \mathrm{~d}$ & $\mathrm{~S}$ & $661,25 \mathrm{~d}$ & Amarela pálida & Creme \\
\hline CNPH 1208 & $2,00 \mathrm{~b}$ & $2,00 \mathrm{~b}$ & $2,28 \mathrm{c}$ & $\mathrm{S}$ & $1.789,7 \mathrm{c}$ & Roxa & Branca \\
\hline CNPH 1195 & $2,33 \mathrm{~b}$ & $2,33 \mathrm{~b}$ & $2,50 \mathrm{c}$ & $\mathrm{S}$ & $1.637,8 \mathrm{c}$ & Rosa & Laranja intenso \\
\hline CNPH 1357 & $2,33 \mathrm{~b}$ & $1,83 \mathrm{~b}$ & $2,74 \mathrm{c}$ & $\mathrm{S}$ & $1.942,2 \mathrm{c}$ & Branca & Branca \\
\hline CNPH 41 & $3,00 \mathrm{a}$ & $3,00 \mathrm{a}$ & $2,74 \mathrm{c}$ & $\mathrm{S}$ & $2.436,8 \mathrm{c}$ & Branca & Branca \\
\hline CNPH 53 & $3,50 \mathrm{a}$ & $3,33 \mathrm{a}$ & $3,10 \mathrm{c}$ & $\mathrm{S}$ & $1.502,2 \mathrm{c}$ & Roxa & Branca \\
\hline CNPH 80 & $2,50 \mathrm{~b}$ & $1,00 \mathrm{c}$ & $3,61 \mathrm{c}$ & $\mathrm{S}$ & $2.456,3 \mathrm{c}$ & Roxa-escura & Roxa-avermelhada \\
\hline Beauregard & $1,83 \mathrm{~b}$ & $1,83 \mathrm{~b}$ & $3,90 \mathrm{c}$ & $\mathrm{S}$ & $982,92 \mathrm{~d}$ & Vermelha-arroxeada & Laranja intenso \\
\hline CNPH 1216 & $3,67 \mathrm{a}$ & $3,67 \mathrm{a}$ & $4,20 \mathrm{c}$ & $\mathrm{S}$ & $3.737,2 \mathrm{~b}$ & Marron alaranjada & Laranja intenso \\
\hline CNPH 1298 & $3,67 \mathrm{a}$ & $3,67 \mathrm{a}$ & $4,25 \mathrm{c}$ & $\mathrm{S}$ & $1.638,2 \mathrm{c}$ & Roxa & Laranja avermelhada \\
\hline CNPH 1344 & $3,00 \mathrm{a}$ & $3,00 \mathrm{a}$ & $4,41 \mathrm{c}$ & $\mathrm{S}$ & $2.359,3 \mathrm{c}$ & Rosa & Creme escura \\
\hline B. Branca & $3,50 \mathrm{a}$ & $3,50 \mathrm{a}$ & $5,40 \mathrm{~b}$ & $\mathrm{~S}$ & $706,58 \mathrm{~d}$ & Branca & Branca \\
\hline Princesa & 3,33 a & $3,33 \mathrm{a}$ & $6,00 \mathrm{~b}$ & $\mathrm{~S}$ & $1.876,9 \mathrm{c}$ & Creme & Branca \\
\hline CNPH 1192 & $3,67 \mathrm{a}$ & $3,67 \mathrm{a}$ & $6,05 \mathrm{~b}$ & $\mathrm{~S}$ & $5.304,3 \mathrm{~b}$ & Amarela pálida & Laranja pálida \\
\hline CNPH 1805 & 3,33 a & $3,17 \mathrm{a}$ & $6,43 \mathrm{~b}$ & $\mathrm{~S}$ & $2.004,0 \mathrm{c}$ & Roxa & Creme \\
\hline CNPH 1221 & $2,83 \mathrm{a}$ & $2,83 \mathrm{a}$ & $6,55 \mathrm{~b}$ & $\mathrm{~S}$ & $1.053,7 \mathrm{c}$ & Roxa & Creme \\
\hline CNPH 1365 & $2,33 \mathrm{~b}$ & $2,33 \mathrm{~b}$ & $9,82 \mathrm{~b}$ & $\mathrm{~S}$ & $2.497,2 \mathrm{c}$ & Marron alaranjada & Laranja intens \\
\hline CNPH 59 & $3,33 \mathrm{a}$ & $3,00 \mathrm{a}$ & $10,08 \mathrm{~b}$ & $\mathrm{~S}$ & $3.478,3 \mathrm{~b}$ & Creme escura & Branca \\
\hline CNPH 1809 & $3,67 \mathrm{a}$ & $3,67 \mathrm{a}$ & $11,02 \mathrm{~b}$ & $\mathrm{~S}$ & $2.128,6 \mathrm{c}$ & Roxa escura & Vermelha púrpura \\
\hline T. Santa Cruz & $5,00 \mathrm{a}$ & $4,00 \mathrm{a}$ & $115,2 \mathrm{a}$ & $\mathrm{S}$ & $18.134 \mathrm{a}$ & - & - \\
\hline Média & 1,81 & 1,7 & 4,89 & & $1.407,4$ & - & - \\
\hline C.V. (\%) & 15,26 & 16,03 & 36,24 & & 60,16 & - & - \\
\hline
\end{tabular}

Médias com a mesma letra na coluna não diferem entre si, pelo teste de Scott-Knott a 5\% de probabilidade. IG: índice de galhas; IMO: índice de massas de ovos; FR: fator de reprodução; GR: grau de resistência (R: resistente e $S$ : suscetível); OMRT: ovos $+\mathrm{J}_{2}$ por grama de raiz e parte da raiz tuberosa com galhas. 
Verificaram-se diferenças estatisticamente significativas entre os genótipos de batatadoce com relação ao fator de reprodução (FR) de $M$. incognita raça 1, indicando a existência de variabilidade genética para esta característica. 52,27\% dos genótipos, com fator de reprodução do nematoide inferior a 1, foram classificados como resistentes, sendo eles CNPH 1219, Coquinho, CNPH 1392, CNPH 1292, CNPH 1358, CNPH 69, CNPH 56, CNPH 02, CNPH 1361, CNPH 1202, CNPH 08, CNPH 1796, CNPH 1394, CNPH 1393, Brazlândia Roxa, CNPH 1197, CNPH 1232, CNPH 05, CNPH 60, Rainha, CNPH 1200, CNPH 1310 e Brazlândia Rosada.

Contudo, estes materiais foram estatisticamente equivalentes aos clones CNPH 1220, CNPH 66 e CNPH 46, que foram apenas ligeiramente infectados, apresentando fatores de reprodução de $M$. incognita raça 1 de 1,21; 1,43 e 2,20, respectivamente, sendo classificados como suscetíveis. O agrupamento dos clones CNPH 1220, CNPH 66 e CNPH 46 no mesmo grupo dos genótipos resistentes, indica que embora estes materiais foram considerados como suscetíveis à multiplicação do nematoide pelo critério de Oostenbrink (1966), podem apresentar algum grau de resistência. As maiores médias para o FR desta espécie foram observadas nos genótipos Brazlândia Branca, Princesa, CNPH 1192, CNPH 1805, CNPH 1221, CNPH 1365, CNPH 59 e CNPH 1809 (5,40; 6,00; 6,05; 6,43; 6,55; 9,82; 10,08 e 11,02, respectivamente), indicando suscetibilidade ao nematoide. $\mathrm{O}$ alto fator de reprodução apresentado pela testemunha, cv. de tomate Santa Cruz $(115,2)$, comprovou a viabilidade do inóculo. A cv. Beauregard com fator de reprodução de 3,9 também foi suscetível a $M$. incognita raça 1.

Cervantes-Flores et al. (2002b) também constataram a suscetibilidade da cultivar Beauregard à raça 1 de $M$. incognita, a qual apresentou 39 massas de ovos por sistema radicular.

Wanderley e Santos (2004) estudaram a resistência de 35 cultivares de batata-doce a Meloidogyne incognita, com base no fator de reprodução. Dentre as 35 cultivares avaliadas, estes autores consideraram 15 resistentes $(42,86 \%)$, as quais apresentaram fatores de reprodução desta espécie variando entre 0,05 (cv. Rama Fina) e 0,98 (cv. Roxa de Bonito). As demais cultivares apresentaram FR do nematoide entre 1,16 e 21,34, sendo classificadas como suscetíveis.

Chaves et al. (2013) avaliaram a reação de 25 genótipos de batata-doce a $M$. incognita raça 2 e observaram, com base no índice de reprodução relativo à cultivar de tomate Santa 
Clara, que $28 \%$ dos materiais foram levemente resistentes; $52 \%$ moderadamente resistentes e $16 \%$ muito resistentes; apenas o genótipo BDFMI-70 foi suscetível.

Massaroto et al. (2010) avaliaram a reação de 50 acessos de batata-doce à infecção por Meloidogyne incognita raça 1, por meio do índice de massas de ovos por sistema radicular, que variou entre 1,12 e 3,82, para os clones UFT-14-AL e UFVJM-04, respectivamente. 15 dos materiais avaliados (30\%) foram altamente resistentes. A cultivar Brazlândia Rosada, como verificado nesta pesquisa, mostrou moderada resistência ao nematoide-das-galhas, com índice de massas de ovos nas raízes de 2,73.

Gomes (2014) avaliaram 63 clones de batata-doce com relação à reação de resistência a Meloidogyne incognita raças 1 e 3 com base no fator de reprodução (FR), que esteve na faixa de 0 a 5,21, para a raça 1 e de 0 a 10,50, para a raça 3 . Dos clones analisados, 77,78 e 79,36\% foram classificados como resistentes às raças 1 e 3, respectivamente. Já 66,66\% dos genótipos apresentaram resistência múltipla às duas raças de $M$. incognita. As cultivares Coquinho, Brazlândia Rosada e Brazlândia Branca, apresentaram-se resistentes a ambas as raças, com FR do nematoide de $0 ; 0,13$ e 0,40, respectivamente, para a raça 1 e de 0,$09 ; 0,14$ e 0,32 , respectivamente, para a raça 3. Já a cultivar Princesa foi classificada como suscetível com FR de 1,58 e 3,40, para as raças 1 e 3 de $M$. incognita, respectivamente. A cultivar Brazlândia Branca foi a única que apresentou resultado divergente ao obtido neste estudo, no que a mesma, com FR de $M$. incognita raça 1 de 5,40, foi considerada suscetível.

Marchese et al. (2010) 60 dias após a inoculação, com 2.065 ovos/planta, avaliaram 123 genótipos de batata-doce quanto à resistência a $M$. incognita raça 1 , com base no fator de reprodução do nematoide, que oscilou entre 0,02 e 37,35. Foram identificados 57 genótipos de batata-doce resistentes (45,97\% dos clones avaliados), dentre eles a cultivar Brazlândia Roxa $(\mathrm{FR}=0,36)$, como constatado nesta pesquisa $(\mathrm{FR}=0,15)$. Estes autores reportaram que a cultivar Brazlândia Rosada, com fator de reprodução de $M$. incognita raça 1 de 9,68, foi suscetível; não obstante, a presente pesquisa indicou que esta cultivar é resistente, dado que o fator de reprodução do nematoide, de 0,92 , foi menor à unidade e significativamente inferior ao da cultivar Brazlândia Branca $(5,40)$, que é reconhecidamente suscetível a esta espécie (MASSAROTO et al., 2010; SILVEIRA e MALUF, 1993). Já as reações de suscetibilidade verificadas para a cultivar comercial Brazlândia Branca e a cultivar de tomate Santa Clara, com fatores de reprodução desta espécie de 17,43 e 3,62, respectivamente, foram congruentes com as observadas neste estudo (5,40 e 115,2 respectivamente). 
Charchar e Ritschel (2004) exploraram 357 acessos quanto à resistência à infecção pelas 4 raças de Meloidogyne incognita, segundo o índice médio de massas de ovos. 77,87\% dos materiais foram altamente resistentes à raça 1 de $M$. incognita, que infectou 79 acessos $(22,13 \%)$, dentre os quais, 20 proporcionaram algum grau de resistência, 22 foram suscetíveis e 37 altamente suscetíveis. M. incognita raças 3, 2 e 4 infectaram 49, 42 e 40 acessos, respectivamente. As cultivares Brazlândia Roxa e Princesa foram altamente resistentes a todas as raças avaliadas. As cultivares Brazlândia Branca, Brazlândia Rosada e Coquinho foram suscetíveis à raça 1 de $M$. incognita. Apenas as cultivares Brazlândia Roxa e Brazlândia Branca apresentaram respostas à infecção pelo nematoide congruentes com os resultados obtidos no presente estudo.

Dentre os 36 clones avaliados por Silveira e Maluf (1993) com relação à infecção pelas raças 1, 2, 3 e 4 de $M$. incognita, foram identificados 7, 1, 9 e 2 materiais resistentes a estas raças, respectivamente. Nenhum dos clones foi simultaneamente resistente às 4 raças de $M$. incognita. Adicionalmente, estes autores verificaram baixos coeficientes de correlação genotípica entre as respostas de resistência às diferentes raças e espécies, indicando independência das fontes de resistência. Com relação à raça 1 de $M$. incognita, estes autores observaram que as cultivares Coquinho, Brazlândia Roxa e Brazlândia Branca foram suscetíveis (9,50; 9,66 e 23,50 massas de ovos por sistema radicular, respectivamente), enquanto a cultivar Princesa, que não apresentou massas de ovos nas raízes, foi resistente. Neste trabalho, apenas a cultivar Brazlândia Branca, suscetível $(\mathrm{FR}=5,40)$, apresentou resultado semelhante aos anteriormente citados.

A temperatura, a cultivar, o tempo de permanência das raízes no solo antes da inoculação, a data de plantio, o ciclo de vida do nematoide e o estádio de desenvolvimento do sistema radicular da batata-doce são fatores importantes que regulam a expressão da resistência em batata-doce a $M$. incognita.

Jatala e Russell (1972) estudaram, em fotoperíodos de 16 h, o efeito da temperatura (24; 28 e $32^{\circ} \mathrm{C}$ durante o dia) sobre o desenvolvimento e ciclo de vida de $M$. incognita nas cultivares de batata-doce Nemagold, resistente e Allgold, suscetível. A taxa de desenvolvimento do nematoide nas raízes das duas cultivares aumentou com o incremento da temperatura, contudo, independentemente da temperatura ou dos dias transcorridos após a inoculação, a cv. Nemagold apresentou menor número de nematoides e fêmeas adultas de menor tamanho do que a cv. Allgold, na que o ciclo de vida do nematoide foi completado 
mais rapidamente. Machos foram recuperados apenas a partir das raízes da cv. Nemagold cultivadas a 24 e $28^{\circ} \mathrm{C}$. Adicionalmente, o desenvolvimento de $M$. incognita nesta cultivar foi retardado em baixas temperaturas, nas que a necrose das células hipersensíveis foi mais elevada.

Jatala e Russell (1972) também observaram correlação estatisticamente significativa e negativa entre o tempo de permanência das raízes no solo antes da inoculação e a taxa de penetração de $M$. incognita na cultivar de batata-doce Nemagold, resistente. De acordo com estes autores os exsudatos desta cultivar são tóxicos ou repelentes, além de persistentes no solo e a acumulação na rizosfera de plantas estabelecidas, pode impedir ou reduzir a penetração larval nas raízes.

Araujo et al. (1982) ao estudar em tomateiro o efeito das temperaturas do solo sobre $M$. incognita raça 1, observaram que todos os genótipos que foram mantidos em altas temperaturas do solo durante o dia e a noite $\left(32,5^{\circ} \mathrm{C}\right)$ exibiram um número significativamente maior de massas de ovos do que quando expostos a mudanças de temperatura do solo (durante o dia $32,5^{\circ} \mathrm{C}$ e durante a noite temperatura ambiente variando de 19 a $25^{\circ} \mathrm{C}$ ). Nesta última condição, os juvenis do segundo estádio foram incapazes de se desenvolver e atingir a maturidade.

Lawrence et al. (1986) estudando em duas datas de plantio o efeito de diferentes densidades populacionais de $M$. incognita raça 1 sobre a resistência de duas cultivares de batata-doce, observaram que a densidade populacional inicial apresentou correlação estatisticamente significativa com a cultivar e a data da instalação do experimento. Estas correlações indicaram que a data de plantio e a cultivar afetaram o número total de nematoides que se desenvolveram em cada planta. Por sua vez, a interação entre a cultivar e a data de plantio influenciou significativamente o crescimento radicular das plantas, como refletido na produtividade. Estes autores também observaram maiores densidades populacionais aproximadamente dois meses após o plantio, que é o tempo requerido por $M$. incognita para completar um ou dois ciclos de vida e o tempo associado com o máximo crescimento radicular da batata-doce; sugerindo que, variações temporais na densidade populacional de nematoides podem estar relacionadas não só com o ciclo de vida do nematoide, mas também com o estádio de desenvolvimento das raízes da batata-doce.

Não foram encontrados ovos nas raízes dos genótipos CNPH 1219, Coquinho, CNPH 1392 e CNPH 1292. Contudo, estes materiais foram estatisticamente equivalentes aos clones 
CNPH 1361, CNPH 69, CNPH 02, CNPH 1358, CNPH 08, Brazlândia Roxa, CNPH 1393, CNPH 1394, CNPH 56, CNPH 1202, CNPH 1197, CNPH 1232, CNPH 1796 e CNPH 05, que apresentaram entre 11,39 e 160,26 ovos+J2/ g de raiz. Os clones mais favoráveis ao nematoide foram CNPH 59, CNPH 1216 e CNPH 1192, que apresentaram 3.478,26; 3.737,18 e 5.304,31 ovos $+\mathrm{J} 2 / \mathrm{g}$ de raiz, respectivamente.

Valores semelhantes foram encontrados por Montes et al. (1998), que avaliando a resposta de 28 clones de batata-doce a $M$. incognita raça 2, 50 dias após a inoculação, inoculando 1.500 ovos+J2, observaram entre 396 (clone UCV-8) e 6.250 (clone E-214) ovos $+\mathrm{J} 2$ por grama de raiz. Adicionalmente, estes autores observaram índices de galhas nas raízes variando de 2,5 (clone UCV-8) a 5 (clone Mariara) e fator de reprodução do nematoide na faixa de 0,9 (clone UCV-8) a 13,5 (clone E-214); sendo que apenas o clone UCV-8, com fator de reprodução de 0,9 , foi resistente.

Komiyama et al. (2006) ao avaliar a infecção de duas raças de $M$. incognita em uma cultivar resistente (Minamiyutaka) e uma suscetível (Kokei No.14) de batata-doce, 40 dias após a inoculação com $500 \mathrm{~J} 2 /$ planta, encontraram 401,2 e 700,9 nematoides por grama de raiz, respectivamente. Estes autores observaram que 3 dias após a inoculação, o nematoide penetrou nos sistemas radiculares de ambas as espécies, independentemente do grau de resistência das plantas. Contudo, no sistema radicular da planta resistente, Minamiyutaka, foram observadas células anormais (60,7\% de necrose) adjacentes aos nematoides penetrados nas raízes, que não foram constatadas na planta suscetível; sugerindo que a reação de hipersensibilidade, é um dos mecanismos de resistência a $M$. incognita. Segundo estes autores, o mecanismo de resistência pode ser governado por dois genes dominantes.

Tradicionalmente, a necrose radicular localizada tem sido associada com a resistência da planta, como uma resposta de hipersensibilidade. Não obstante, Cervantes-Flores et al. (2002a) observaram falta de correlação entre a necrose radicular e a infecção por nematoides, sugerindo que esta variável não é um bom indicador da resistência de batata-doce aos nematoides-das-galhas e que a necrose parece ser uma função do genótipo da planta.

As respostas dos 44 genótipos avaliados com relação à reação pela infecção de $M$. enterolobii estão apresentadas na Tabela 4.3.

Foram constatadas diferenças estatisticamente significativas entre os materiais avaliados com relação aos índices médios de galhas e de massas de ovos nas raízes. 
Tabela 4.3 Reação de genótipos de batata-doce à infecção por M. enterolobii

\begin{tabular}{|c|c|c|c|c|c|c|c|}
\hline Genótipo & IG & IMO & FR & GR & OMRT & Coloracão externa & Coloracão interna \\
\hline CNPH 1392 & $0,00 \mathrm{~d}$ & $0,00 \mathrm{~d}$ & $0,00 \mathrm{e}$ & $\mathrm{R}$ & $0,00 \mathrm{e}$ & Marron alaranjada & Laranja pálida \\
\hline CNPH 1292 & $0,00 \mathrm{~d}$ & $0,00 \mathrm{~d}$ & $0,03 \mathrm{e}$ & $\mathrm{R}$ & $73,21 \mathrm{e}$ & Roxa-avermelhada & Laranja avermelhada \\
\hline CNPH 1219 & $0,83 \mathrm{c}$ & $0,67 \mathrm{c}$ & $0,13 \mathrm{e}$ & $\mathrm{R}$ & $77,62 \mathrm{e}$ & Roxa-avermelhada & Creme \\
\hline CNPH 46 & $0,67 \mathrm{c}$ & $1,00 \mathrm{c}$ & $0,24 \mathrm{e}$ & $\mathrm{R}$ & $27,26 \mathrm{e}$ & Amarela pálida & Creme \\
\hline CNPH 60 & $0,50 \mathrm{c}$ & $0,67 \mathrm{c}$ & $0,28 \mathrm{e}$ & $\mathrm{R}$ & $282,74 \mathrm{e}$ & Creme escura & Branca \\
\hline CNPH 1221 & $0,67 \mathrm{c}$ & $1,17 \mathrm{c}$ & $0,33 \mathrm{e}$ & $\mathrm{R}$ & $112,63 \mathrm{e}$ & Roxa & Creme \\
\hline Coquinho & $3,17 \mathrm{~b}$ & $3,17 \mathrm{~b}$ & $0,40 \mathrm{e}$ & $\mathrm{R}$ & $1.027,5 \mathrm{~d}$ & Amarela pálida & Branca \\
\hline CNPH 1809 & $1,33 \mathrm{c}$ & $2,33 \mathrm{~b}$ & $0,52 \mathrm{e}$ & $\mathrm{R}$ & $144,81 \mathrm{e}$ & Roxa escura & Vermelha púrpura \\
\hline CNPH 1200 & $0,83 \mathrm{c}$ & $1,17 \mathrm{c}$ & $0,83 \mathrm{e}$ & $\mathrm{R}$ & $160,35 \mathrm{e}$ & Rosa & Laranja intenso \\
\hline CNPH 1197 & $3,67 \mathrm{~b}$ & $3,67 \mathrm{~b}$ & $1,16 \mathrm{e}$ & S & $2.672,4 \mathrm{~d}$ & Roxa-avermelhada & Branca \\
\hline CNPH 1202 & $3,33 \mathrm{~b}$ & $3,67 \mathrm{~b}$ & $1,65 \mathrm{e}$ & S & $1.955,7 \mathrm{~d}$ & Marron alaranjada & Laranja intenso \\
\hline Princesa & $2,17 \mathrm{~b}$ & $2,50 \mathrm{~b}$ & $2,53 \mathrm{e}$ & S & $479,18 \mathrm{e}$ & Creme & Branca \\
\hline CNPH 56 & $2,83 \mathrm{~b}$ & $2,83 \mathrm{~b}$ & $3,01 \mathrm{~d}$ & S & $7.830,4 \mathrm{c}$ & Branca & Branca \\
\hline Rainha & $3,83 \mathrm{a}$ & $4,00 \mathrm{a}$ & $4,04 \mathrm{~d}$ & S & $1.896,2 \mathrm{~d}$ & Rosa & Branca \\
\hline CNPH 80 & $3,00 \mathrm{~b}$ & $2,67 \mathrm{~b}$ & $4,65 \mathrm{~d}$ & S & $5.842,8 \mathrm{c}$ & Roxa-escura & Roxa-avermelhada \\
\hline CNPH 1310 & $3,83 \mathrm{a}$ & $3,50 \mathrm{~b}$ & $5,17 \mathrm{~d}$ & S & $3.250,2 \mathrm{~d}$ & Marron alaranjada & Laranja intenso \\
\hline CNPH 1195 & $2,83 \mathrm{~b}$ & $3,67 \mathrm{~b}$ & $5,60 \mathrm{~d}$ & S & $2.765,5 \mathrm{~d}$ & Rosa & Laranja intenso \\
\hline CNPH 1394 & $3,67 \mathrm{a}$ & $3,67 \mathrm{~b}$ & $6,38 \mathrm{~d}$ & S & $4.305,0 \mathrm{c}$ & Roxa-avermelhada & Branca \\
\hline Beauregard & $3,00 \mathrm{~b}$ & $3,33 \mathrm{~b}$ & $6,53 \mathrm{~d}$ & S & $6.293,6 \mathrm{c}$ & Vermelha-arroxeada & Laranja intenso \\
\hline CNPH 02 & $3,83 \mathrm{a}$ & $4,33 \mathrm{a}$ & $6,57 \mathrm{~d}$ & S & $2.195,1 \mathrm{~d}$ & Creme escura & Creme \\
\hline CNPH 66 & $4,33 \mathrm{a}$ & $4,33 \mathrm{a}$ & $6,85 \mathrm{~d}$ & S & $3.612,1 \mathrm{c}$ & Creme & Branca \\
\hline CNPH 1358 & $3,67 \mathrm{a}$ & $4,17 \mathrm{a}$ & $7,18 \mathrm{~d}$ & S & $5.040,1 \mathrm{c}$ & Roxa & Branca \\
\hline B. Roxa & $4,17 \mathrm{a}$ & $4,50 \mathrm{a}$ & $9,55 \mathrm{~d}$ & S & $2.809,0 \mathrm{~d}$ & Roxa-avermelhada & Creme escura \\
\hline CNPH 1393 & $3,33 \mathrm{~b}$ & $3,33 \mathrm{~b}$ & $9,77 \mathrm{~d}$ & S & $13.788,3 \mathrm{c}$ & Branca & Creme \\
\hline CNPH 53 & $3,67 \mathrm{a}$ & $3,67 \mathrm{~b}$ & $9,80 \mathrm{~d}$ & S & $7.135,2 \mathrm{c}$ & Roxa & Branca \\
\hline CNPH 08 & $4,17 \mathrm{a}$ & $4,33 \mathrm{a}$ & $10,50 \mathrm{c}$ & S & $3.129,8 \mathrm{~d}$ & Rosa & Branca \\
\hline CNPH 1805 & $3,83 \mathrm{a}$ & $4,50 \mathrm{a}$ & $11,24 \mathrm{c}$ & S & $5.840,24 \mathrm{c}$ & Roxa & Creme \\
\hline CNPH 1298 & $3,50 \mathrm{~b}$ & $4,17 \mathrm{a}$ & $12,70 \mathrm{c}$ & S & $4.790,5 \mathrm{c}$ & Roxa & Laranja avermelhada \\
\hline CNPH 1216 & $4,67 \mathrm{a}$ & $4,67 \mathrm{a}$ & $14,05 \mathrm{c}$ & S & $5.254,4 \mathrm{c}$ & Marron alaranjada & Laranja intenso \\
\hline CNPH 59 & $4,17 \mathrm{a}$ & $4,00 \mathrm{a}$ & $14,22 \mathrm{c}$ & S & $2.715,3 \mathrm{~d}$ & Creme escura & Branca \\
\hline B. Branca & $4,00 \mathrm{a}$ & $4,00 \mathrm{a}$ & $14,33 \mathrm{c}$ & S & $6.264,2 \mathrm{c}$ & Branca & Branca \\
\hline CNPH 41 & $3,50 \mathrm{~b}$ & $3,67 \mathrm{~b}$ & $15,74 \mathrm{c}$ & S & $8.140,3 \mathrm{c}$ & Branca & Branca \\
\hline CNPH 1208 & $4,33 \mathrm{a}$ & $4,67 \mathrm{a}$ & $15,87 \mathrm{c}$ & S & $5.600,7 \mathrm{c}$ & Roxa & Branca \\
\hline CNPH 69 & $4,33 \mathrm{a}$ & $4,50 \mathrm{a}$ & $15,93 \mathrm{c}$ & S & $4.449,9 \mathrm{c}$ & Amarela pálida & Branca \\
\hline CNPH 1796 & $4,33 \mathrm{a}$ & $4,50 \mathrm{a}$ & $16,17 \mathrm{c}$ & S & $7.400,9 \mathrm{c}$ & Roxa & Vermelha púrpura \\
\hline CNPH 1344 & $4,17 \mathrm{a}$ & $4,33 \mathrm{a}$ & $16,68 \mathrm{c}$ & S & $12.195,1 \mathrm{~b}$ & Rosa & Creme escura \\
\hline B. Rosada & $3,17 \mathrm{~b}$ & $3,50 \mathrm{~b}$ & $21,70 \mathrm{c}$ & S & $6.168,5 \mathrm{c}$ & Rosa & Creme \\
\hline CNPH 1232 & $4,83 \mathrm{a}$ & $5,00 \mathrm{a}$ & $22,57 \mathrm{c}$ & S & $8.995,6 \mathrm{c}$ & Marron alaranjada & Laranja pálida \\
\hline CNPH 1357 & $4,17 \mathrm{a}$ & $3,67 \mathrm{~b}$ & $23,72 \mathrm{c}$ & S & $20.875,3 \mathrm{~b}$ & Branca & Branca \\
\hline CNPH 1192 & $4,17 \mathrm{a}$ & $4,17 \mathrm{a}$ & $27,32 \mathrm{~b}$ & $\mathrm{~S}$ & $15.977,7 \mathrm{~b}$ & Amarela pálida & Laranja pálida \\
\hline CNPH 1365 & $4,50 \mathrm{a}$ & $4,83 \mathrm{a}$ & $30,73 \mathrm{~b}$ & S & $8.672,4 \mathrm{c}$ & Marron alaranjada & Laranja intenso \\
\hline CNPH 05 & $4,67 \mathrm{a}$ & $4,50 \mathrm{a}$ & $34,27 \mathrm{~b}$ & S & $9.531,8 \mathrm{c}$ & Roxa & Roxa-avermelhada \\
\hline CNPH 1361 & $4,83 \mathrm{a}$ & $4,67 \mathrm{a}$ & $39,72 \mathrm{~b}$ & $\mathrm{~S}$ & $14.717,4 \mathrm{~b}$ & Roxa & Branca \\
\hline CNPH 1220 & $4,00 \mathrm{a}$ & $3,33 \mathrm{~b}$ & $45,87 \mathrm{~b}$ & $\mathrm{~S}$ & $40.226,2 \mathrm{a}$ & Amarela pálida & Laranja intenso \\
\hline T. Santa Cruz & $5,00 \mathrm{a}$ & $3,67 \mathrm{~b}$ & $96,07 \mathrm{a}$ & S & $12.592,8 \mathrm{~b}$ & - & - \\
\hline Média & 3,28 & 3,39 & 13,17 & & $6.162,6$ & - & - \\
\hline C.V. (\%) & 11,83 & 12,24 & 51,03 & & 53,94 & - & - \\
\hline
\end{tabular}

Médias com a mesma letra na coluna não diferem entre si, pelo teste de Scott-Knott a 5\% de probabilidade. IG: índice de galhas; IMO: índice de massas de ovos; FR: fator de reprodução; GR: grau de resistência (R: resistente e S: suscetível) e OMRT: ovos $+\mathrm{J}_{2}$ por grama de raiz e parte da raiz tuberosa com galhas. 
Não foram observadas galhas nem massas de ovos nos sistemas radiculares dos clones CNPH 1392 e CNPH 1292. Com exceção dos clones CNPH 60, CNPH 46, CNPH 1221, CNPH 1219, CNPH 1200, CNPH 1809, Princesa e CNPH 56 que apresentaram índices de galhas e de massas de ovos variando entre 0,50 e 2,83 e entre 0,67 e 2,83, respectivamente, todos os genótipos mostraram para estas variáveis índices superiores a 3 (mais de 30 galhas e massas de ovos por sistema radicular). Os genótipos Rainha, CNPH 59, Brazlândia Branca, CNPH 1358, CNPH 1298, CNPH 1192, CNPH 02, CNPH 66, CNPH 08, CNPH 1344, Brazlândia Roxa, CNPH 1805, CNPH 69, CNPH 1796, CNPH 05, CNPH 1216, CNPH 1208, CNPH 1361, CNPH 1365 e CNPH 1232 com índices de massas de ovos oscilando entre 4 e 5, apresentaram para esta variável valores estatisticamente superiores ao índice de massas de ovos obtido pela cultivar de tomate Santa Cruz $(3,67)$.

Com exceção dos genótipos CNPH 1392, CNPH 1292, CNPH 1219, CNPH 46, CNPH 60, CNPH 1221, Coquinho, CNPH 1809 e CNPH 1200, que foram resistentes à multiplicação de $M$. enterolobii (20,45\% dos clones avaliados), com fatores de reprodução na faixa de 0 a 0,83 e dos genótipos CNPH 1197, CNPH 1202 e Princesa, com fatores de reprodução de 1,16; 1,65 e 2,53, respectivamente, que não apresentaram diferença significativa com os materiais resistentes; todos os clones em maior ou menor grau permitiram a multiplicação do patógeno.

O clone CNPH 1809, com fator de reprodução de $M$. enterolobii de 0,52 , foi resistente à infecção por esta espécie, apesar de ter sido suscetível a $M$. javanica e $M$. incognita raça 1.

Os melhores hospedeiros foram os clones CNPH 1192, CNPH 1365, CNPH 05, CNPH 1361 e CNPH 1220, que apresentaram elevados fatores de reprodução de $M$. enterolobii $(27,32 ; 30,73 ; 34,27 ; 39,72$ e 45,87, respectivamente). Contudo, o maior fator de reprodução foi verificado na cultivar de tomate Santa Cruz $(96,07)$. De modo geral, os genótipos com notas de índices de galhas e de massas de ovos superiores a 2, foram suscetíveis a $M$. enterolobii.

As cultivares Brazlândia Roxa e Brazlândia Rosada, que apresentaram resistência a $M$. javanica e $M$. incognita raça 1 , foram suscetíveis a $M$. enterolobii, com fatores de reprodução de 9,55 e 21,70, respectivamente. Já a cultivar Coquinho, com fator de reprodução de $M$. enterolobii de 0,40, foi resistente a esta espécie e também a $M$. javanica e a $M$. incognita raça 1. A cultivar Beauregard foi suscetível a $M$. enterolobii $(\mathrm{FR}=6,53)$, a $M$. javanica e a $M$. incognita raça 1. As cultivares Brazlândia Branca e Princesa, com fatores de reprodução de 
M. enterolobii de 14,33 e 2,53, respectivamente, foram suscetíveis a esta espécie e à raça 1 de M. incognita, porém apresentaram resistência a $M$. javanica.

Melo et al. (2011) avaliaram a resistência de 8 genótipos de batata-doce ao nematoide Meloidogyne enterolobii, com base no fator de reprodução e o índice de reprodução relativo ao tomateiro (Solanum lycopersicum), 60 dias após a inoculação com 2.065 ovos viáveis por plântula. Entre os genótipos estudados, como observado no presente trabalho, as cultivares Brazlândia Rosada, Brazlândia Roxa e Brazlândia Branca, com fatores de reprodução de 4,6; 7,0 e 10,6 e porcentagens de índice de reprodução de 95,9; 144,8 e 220,8, respectivamente, foram suscetíveis a esta espécie. Outros genótipos suscetíveis foram o clone UFLA07-43 e Palmas (FR=3,4 e 9,1, respectivamente). Já os clones de batata-doce UFLA07-53 e UFLA0749 (25\% dos materiais estudados), com fatores de reprodução de 0,1 e 0,2 , respectivamente, foram altamente resistentes a esta espécie. Segundo estes autores, a resistência a $M$. enterolobii aparentemente é mediada por genes diferentes dos que conferem resistência a outras espécies e raças de Meloidogyne.

Gonçalves (2011) pesquisou 142 clones de batata-doce com relação à resistência a $M$. enterolobii, 60 dias após a inoculação com 1.279 ovos por planta. Com base no FR do patógeno, que variou entre 0,04 (genótipos 2007HSF001-21 e 2007HSF027-12) e 31,24 (genótipo Livia), foram classificados como resistentes 30 genótipos (21,13\% dos materiais analisados). As cultivares de batata-doce Brazlândia Rosada, Brazlândia Roxa, Brazlândia Branca e a cultivar de tomate Santa Clara, apresentaram fatores de reprodução de $M$. enterolobii de 4,63; 7,00; 10,66 e 4,84, respectivamente, sendo consideradas suscetíveis. Estes resultados são condizentes com os encontrados na presente pesquisa, na que foi constatada a suscetibilidade desses genótipos com fatores de reprodução de $M$. enterolobii de 21,70; 9,55; 14,33 e 96,07 , respectivamente.

O maior número de ovos e J2 de $M$. enterolobii por grama de raiz foi verificado no clone CNPH 1220 (40.226,19 ovos+J2/g), que foi mais favorável ao nematoide do que a cultivar de tomate Santa Cruz (12.592,76 ovos+J2/ g), utilizada como testemunha suscetível. O sistema radicular do clone CNPH 1392 não apresentou ovos, porém, não diferiu significativamente dos genótipos CNPH 46, CNPH 1292, CNPH 1219, CNPH 1221, CNPH 1809, CNPH 1200, CNPH 60 e Princesa, que obtiveram entre 27,26 e 479,18 ovos+J2 por grama de raiz, respectivamente. 
Estes resultados são semelhantes aos observados em pesquisa similar por Gonçalves (2011), que encontraram em 142 clones de batata-doce número de ovos e J2 de M. enterolobii por grama de raiz oscilando entre 23 (genótipos 2007HSF022-12 e 2007HSF027-12) e 45.112 (genótipo Livia).

Recentemente, Gao et al. (2014) publicaram o primeiro relato de Meloidogyne enterolobii em batata-doce na China. De acordo com estes autores, neste país, a infecção por M. enterolobii já tinha sido reportada em mais de 20 espécies de plantas pertencentes a seis famílias: Fabaceae, Cucurbitaceae, Solanaceae, Myrtaceae, Annonaceae e Marantaceae; entretanto, este foi o primeiro relato de M. enterolobii em um membro da família Convolvulaceae na China.

Na Figura 9 são apresentadas raízes de plantas de batata-doce infectadas por $M$. javanica, M. incognita raça 1 e $M$. enterolobii.

Como verificado na Figura 9a e previamente constatado por Charchar e Ritschel (2004), em plantas suscetíveis de batata-doce a presença de inúmeras fêmeas com massas de ovos nas raízes secundárias e imperceptíveis a olho nu, sem formação de galhas, sem dúvida, passaria despercebida, se não fosse pelo processo de coloração dos sistemas radiculares com floxina B. Contudo, em sistemas radiculares infectados com $M$. enterolobii que atingiram altas populações finais de nematoides (CNPH 1192 e CNPH 1220, com FR= 27,32 e 45,87, respectivamente), foi constatada a formação de galhas tanto nas raízes absorventes quanto nas raízes tuberosas das plantas (Figura 9b), o que ratifica a agressividade desta espécie. Em contrapartida, as três espécies de Meloidogyne avaliadas foram altamente eficientes na formação de galhas nas raízes de tomate (Figura 9c, tomateiro inoculado com M. javanica).

$\mathrm{Na}$ Figura 9d observa-se que os sistemas radiculares infectados por Meloidogyne enterolobii também apresentaram menor abundância de raízes, sendo estas menos ramificadas e com menos pêlos radiculares, quando comparadas a algumas das plantas que foram resistentes às três espécies (Figura 9e). A deformação nas raízes e sua ineficiência para absorver água e nutrientes, com relação às plantas com sistemas radiculares bem desenvolvidos, causam murcha, principalmente em climas secos, paralisação do crescimento e queda no rendimento da planta (TAYLOR e SASSER, 1978).

Nas Figuras 9f observa-se que Meloidogyne enterolobii infectou as raízes tuberosas e causou galhas ou protuberâncias na sua superfície, conferindo-lhes uma aparência verrucosa, afetando a sua qualidade e reduzindo seu valor comercial. Dessas protuberâncias e do interior 
das raízes tuberosas foram extraídas várias fêmeas que apresentaram formato piriforme, em torno das quais foi observada necrose (Figura 9g). Raízes absorventes e tuberosas podem apresentar áreas de tecido morto (necrose), como resultado da atividade do nematoide. Conforme o nematoide se alimenta e migra dentro das raízes, ocorre destrução das células da planta o que dificulta as funções celulares normais, com consequente morte do tecido (COYNE et al., 2007).

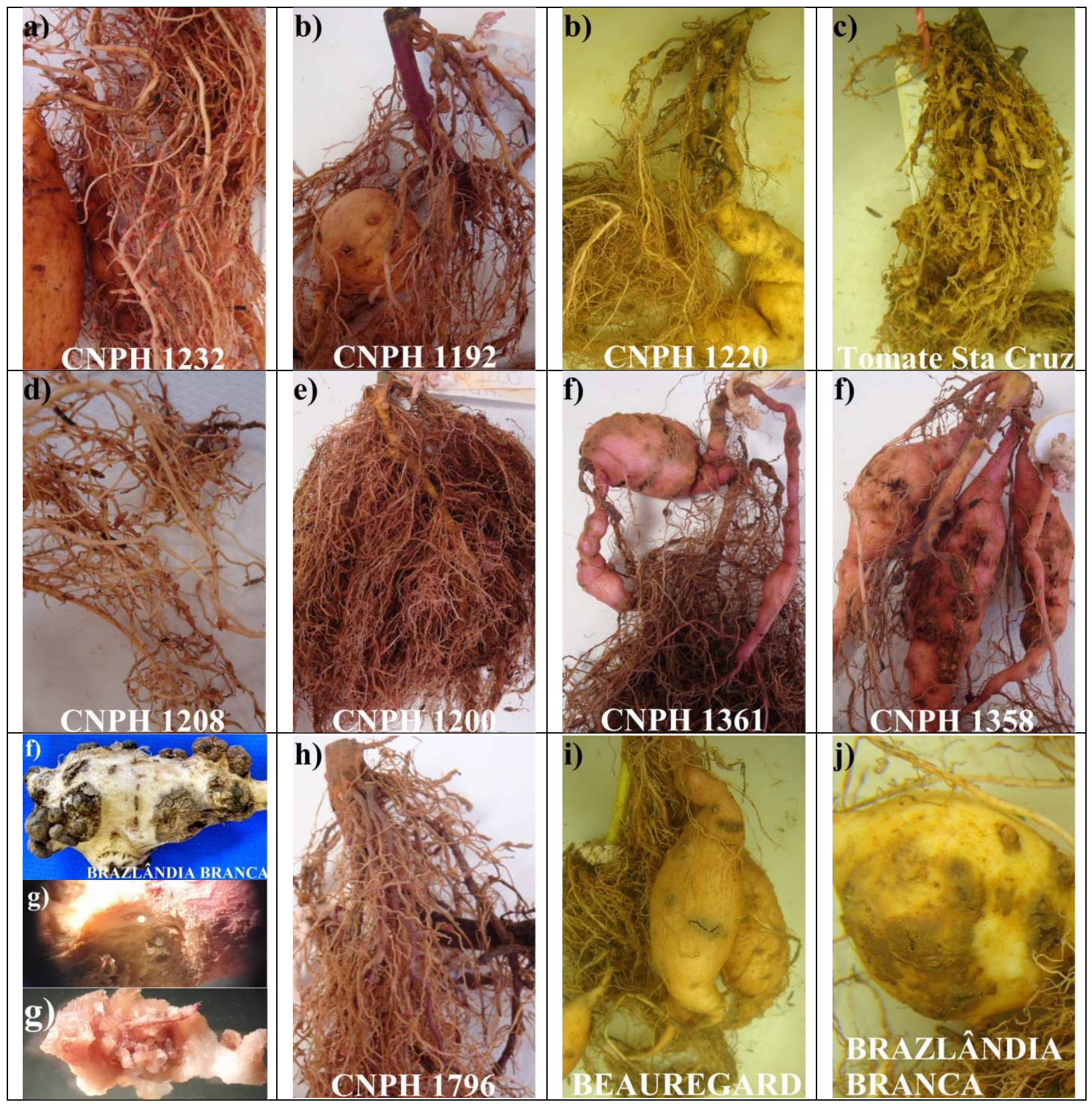

Figura 9 Dano ocasionado por Meloidogyne spp. em raízes absorventes e na parte interna e externa de raízes tuberosas de batata-doce. 
Também foram observadas raízes com pontas inchadas (Figura 9h) e raízes tuberosas com rachaduras (Figura 9i), necrose e apodrecimento em torno da lesão (Figura 9j). Os nematoides per se podem ocasionar rachaduras e o apodrecimento das raízes absorventes e tuberosas devido à extensa perfuração do tecido vegetal gerando necrose e morte do tecido e da raiz (COYNE et al., 2007).

Fazendo-se uma análise geral da reação dos 44 genótipos de batata-doce à infecção por $M$. javanica, $M$. incognita raça 1 e $M$. enterolobii, pode-se concluir que houve diferenças no nível de resistência à reprodução dos nematoides-das-galhas entre os diferentes materiais avaliados. De modo geral, os genótipos que apresentaram índices de galhas e de massas de ovos nos seus sistemas radiculares superiores a 2 , foram suscetíveis, como verificado pelo fator de reprodução dos nematoides. $M$. javanica foi a espécie menos agressiva, infectando e se reproduzindo ligeiramente em apenas 9,09\% dos genótipos estudados. Em contraste, a raça 1 de $M$. incognita reproduziu-se exitosamente em $47,73 \%$ dos materiais. Já $79,55 \%$ dos clones foram hospedeiros suscetíveis de $M$. enterolobii, que foi a espécie mais virulenta. Os genótipos Brazlândia Rosada, Brazlândia Roxa, CNPH 02, CNPH 05, CNPH 08, CNPH 1197, CNPH 1200, CNPH 1202, CNPH 1219, CNPH 1232, CNPH 1292, CNPH 1310, CNPH 1358, CNPH 1361, CNPH 1392, CNPH 1393, CNPH 1394, CNPH 1796, CNPH 56, CNPH 60, CNPH 69, Coquinho e Rainha, que totalizaram 52,27\% dos materiais analisados, foram resistentes a $M$. javanica e $M$. incognita raça $1.18,18 \%$ dos clones foram resistentes à infecção por M. javanica e M. enterolobii (CNPH 1200, CNPH 1219, CNPH 1221, CNPH 1292, CNPH 1392, CNPH 46, CNPH 60 e Coquinho). Finalmente, os genótipos CNPH 1200, CNPH 1219, CNPH 1292, CNPH 1392, CNPH 60 e Coquinho, os quais representam 13,64\% do total dos materiais explorados, foram resistentes a $M$. incognita raça 1 e $M$. enterolobii. Estes mesmos materiais foram simultaneamente resistentes a $M$. javanica, $M$. incognita raça 1 e M. enterolobii, sendo os hospedeiros mais eficientes, pois inibiram a multiplicação das três espécies. A confirmação desses clones apresentando níveis de resistência às 3 espécies avaliadas, abre a perspectiva de descobertas de novos genes (ou alelos) de resistência em Ipomoea batatas.

Toda vez que alguns genótipos apresentaram resistência a uma ou duas espécies, mas não às três espécies de Meloidogyne avaliadas (M. javanica, M. incognita raça 1 e M. enterolobii), pode-se prezumir que a resistência às diversas espécies de Meloidogyne que infectam a batatadoce é específica. 
Cervantes-Flores et al. (2002b) estudaram 26 genótipos de batata-doce quanto à resistência aos nematoides-das-galhas $M$. arenaria, raças 1 e 2 e $M$. incognita, raças 1, 2, 3 e 4. Com relação a $M$. incognita raças 1, 2, 3 e 4 foi observado que o número de massas de ovos por sistema radicular variou entre 0 e $85 ; 0$ e 90; 0 e 50 e 0 e 22, respectivamente. Já em $M$. arenaria raças 1 e 2 esta variável oscilou entre 0 e 3 e 0 e 1,6, respectivamente. A cultivar Beauregard foi suscetível a $M$. incognita raças 1, 2, 3 e 4, apresentando 39; 27; 5 e 22 massas de ovos produzidas por sistema radicular, respectivamente; contudo, foi resistente às raças $1 \mathrm{e}$ 2 de $M$. arenaria, as quais não formaram massas de ovos nas raízes desta cultivar. Ainda, estes autores avaliando 3 populações de cada raça de $M$. incognita, constataram que a cv. Beauregard foi suscetível às 12 populações com número médio de massas de ovos variando entre 21 e 37; 19 e 39; 26 e 48 e 33 e 48, para as 3 populações de $M$. incognita raça 1, 2, 3 e 4, respectivamente. De acordo com estes pesquisadores, a espécie de Meloidogyne, a raça fisiológica avaliada, o genótipo de batata-doce, o local de origem da população e as interações entre as últimas duas variáveis, tiveram efeito estatisticamente significativo sobre a infecção de $M$. incognita e $M$. arenaria, sendo que, há provavelmente diferentes genes e/ou alelos que estão associados com a resistência em batata-doce a diferentes espécies e raças de Meloidogyne, sugerindo que a herança da resistência é de natureza quantitativa.

Piedra-Buena et al. (2011) também observaram que a resposta às espécies do gênero Meloidogyne e às raças de $M$. incognita foi dependente da cultivar. Estes autores avaliaram a suscetibilidade de três cultivares de batata-doce (C4, TIS 3290 e TIS 9162) a 156 isolados correspondentes às raças 1, 2 e 3 de Meloidogyne arenaria; raças 1, 2, 3 e 4 de M. incognita e Meloidogyne javanica. Os isolados testados de M. javanica parasitaram as cultivares C4 e TIS 3290, mas não o material genético TIS 9162, enquanto $M$. arenaria parasitou as cultivares C4 e TIS 9162, mas não o genótipo TIS 3290. Já M. incognita foi considerada a espécie mais virulenta, pois parasitou as três cultivares de batata-doce. Com relação aos isolados de $M$. incognita (raças 1, 2, 3 e 4) e à cultivar mais suscetível, "C4", não foram observadas diferenças significativas na quantidade de plantas suscetíveis entre as raças (86 a 100\%); no entanto, as raças 1 e 3 produziram índices de galhas ligeiramente maiores (5,8 e 5,6, respectivamente). A cultivar TIS 9162 mostrou pequenas diferenças em relação à suscetibilidade das plantas entre as raças (50 a 77\%), sendo mais agredida pela raça 1. Já a cultivar TIS 3290 não foi parasitada por M. incognita raça 2, enquanto apenas 14, 23 e 43\% 
dos isolados correspondentes às raças 4,1 e 3, respectivamente, foram capazes de parasitar esta cultivar.

Peixoto et al. (1998) estudando a reação de 70 genótipos de batata-doce quanto à resistência a $M$. javanica e às raças 1,2 e 3 de $M$. incognita, de acordo com o número de massas de ovos por sistema radicular, observaram que 24 materiais genéticos foram simultaneamente resistentes às duas espécies e às três raças de $M$. incognita. Segundo estes autores, o processo de seleção para resistência a nematoides deve incluir um grande número de isolados e/ou espécies, dado que as correlações genotípicas entre o grau de resistência a diferentes isolados de Meloidogyne sp. foram baixas.

Em outras hortaliças como tomateiro, Cantu et al. (2009), avaliaram oito porta-enxertos comerciais de tomateiro, considerados resistentes a $M$. incognita, $M$. javanica e $M$. arenaria, com relação à reação a $M$. enterolobii e observaram que todos os porta-enxertos testados mostraram-se suscetíveis a esta espécie, demonstrando que a resistência dos porta-enxertos conferida às espécies $M$. incognita, $M$. javanica e $M$. arenaria não contempla a espécie $M$. enterolobii. Ainda, Melo et al. (2011) avaliando genótipos de tomate quanto à resistência a Meloidogyne enterolobii, observou que apesar da linhagem TOM-684 ser portadora do gene dominante $M i$, que confere resistência às espécies $M$. incognita, $M$. arenaria e $M$. javanica, a resistência não foi efetiva para $M$. enterolobii. De igual forma, estes autores verificaram que o acesso $S$. peruvianum PI-126443, portador do gene $M i$ e do gene $M i-3$, que confere resistência a $M$. incognita sob altas temperaturas, também mostrou-se bastante suscetível a $M$. enterolobii.

Segundo Cervantes-Flores (2000) e Cervantes-Flores et al. (2008) devido ao nível de ploidia, auto-incompatibilidade e alta heterozigosidade da batata-doce, a genética da herança de muitas características importantes na cultura, dentre elas a resistência aos nematoides-dasgalhas, não é bem compreendida. Cervantes-Flores et al. (2008) relataram que a resistência a M. incognita raça 3 em batata-doce é determinada pela herança quantitativa ou poligênica (ou seja, de 2 a 7 regiões genômicas diferentes, dependendo da cultivar avaliada), com alta herdabilidade ( $89 \%$ ), como determinado pelo número de massas de ovos, sendo que os efeitos aditivos são os que mais contribuem para esta característica. Contudo, Ukoskit et al. (1997) ao avaliar 71 progênies de batata-doce obtidas a partir de um cruzamento entre as cultivares 'Regal' (resistente) e 'Vardaman' (suscetível), observaram que a resistência a $M$. incognita raça 3 é de herança qualitativa, como verificado pelo número total de ovos $+\mathrm{J} 2$. 
Embora estes parasitas penetram determinadas cultivares de batata-doce suscetíveis e resistentes em números aproximadamente iguais, o desenvolvimento do nematoide, uma vez que este penetra nas raízes das cultivares é afetado pelo genótipo das plantas e o ambiente. Mecanismos preexistentes, tais como a secreção de exsudatos radiculares, que repelem os nematoides e dificultam a penetração do juvenil na raiz de certas cultivares e respostas induzidas, que incluem a hipersensibilidade da planta; a produção de metabólitos secundários e compostos químicos inibitórios pós-infecção; a incapacidade dos juvenis para estabelecer uma relação nutritiva uma vez dentro da planta e o atraso ou a inabilidade dos juvenis para desenvolver a maturidade, são fatores que governam a resistência aos nematoides em batatadoce (JATALA e RUSSELL, 1972; LAWRENCE e CLARK, 1986).

As principais classes de metabólitos secundários incluem alcaloides, terpenoides e fenilpropanoides, os quais agem como atraentes ou repelentes, induzindo paralisia, reduzindo o tempo de incubação ou causando a morte (WUYTS, 2006). Este autor em estudo sobre a interação de cinco variedades de banana com $M$. incognita, encontrou que as variedades resistentes apresentaram uma maior concentração de fenilpropanoides. Adicionalmente, as paredes celulares das raízes resistentes continham níveis significativamente mais elevados de lignina e ésteres de ácido ferúlico, que contribuem para as modificações que aumentam a resistência às enzimas hidrolíticas secretadas pelos nematoides durante a infecção.

Os dados obtidos pela medição objetiva da cor no sistema Hunter estão expressos no Anexo E. Os valores colorimétricos " $\mathrm{L}^{*}$ ", " $\mathrm{C}^{*}$ " e " $\mathrm{H}^{*}$ " tanto para a película externa, quanto para a polpa das raízes tuberosas, demonstraram grande diversidade de cores entre as raízes das cultivares de batata-doce estudadas.

Os materiais avaliados apresentaram periderme branca, creme, creme escura, amarela pálida, marron alaranjada, vermelha-arroxeada, rosa, roxa-avermelhada, roxa e roxa-escura; enquanto a cor da polpa das raízes dos diversos genótipos variou entre branca, creme, creme escura, laranja pálida, laranja intenso, laranja avermelhada, roxa-avermelhada e vermelha púrpura (Anexo E).

Apesar da análise de cor ter sido realizada com o propósito de verificar as correlações entre a reação de resistência dos genótipos analisados ao parasitismo de $M$. javanica, $M$. incognita raça 1 e $M$. enterolobii e a cor da periderme e da polpa das raízes tuberosas, as mesmas foram não significativas ( $p>0,05$ ) (Anexos F, G e H). Na literatura, não foram encontradas pesquisas que estudassem a correlação entre os parâmetros de cor das raízes e a 
resistência à infecção por Meloidogyne. Contudo, existem alguns relatos que correlacionam a cor das folhas ou das raízes de algumas culturas com a resistência a insetos.

Figueiredo (2010) avaliando 12 materiais de batata-doce em Diamantina-MG observou que o clone BD-25, com coloração de película externa roxa, obteve a menor e melhor nota para a resistência a insetos de solo (nota 1,10). Coelho et al. (2009) avaliando os efeitos da superfície das folhas de diferentes genótipos de meloeiro sobre a mosca-branca (B. tabaci biótipo B), observaram que a cultivar Neve, a qual apresentou a maior intensidade de verde na folha, foi a menos atrativa aos adultos de B. tabaci e a menos preferida para oviposição. De acordo com estes autores, a coloração das folhas dos genótipos de meloeiro afetou B. tabaci biótipo B, tanto na atratividade, como fator físico, como também associada a algum fator químico, influindo no desenvolvimento do inseto. Contudo, Cadena et al. (2005) ao avaliar o dano em tubérculos ocasionado por Tecia solanivora (Povolny, 1973) (Lepidoptera: Gelechiidae) em 60 genótipos da espécie Solanum phureja, observaram que a cor e o formato dos tubérculos, considerados como fatores importantes para a seleção do hospedeiro à distância e relacionados com algum grau de resistência, não se correlacionaram com as altas ou baixas porcentagens de danos, dado que, em ambos os casos, os tubérculos apresentaram diferentes cores de película externa (roxa, amarela, preta ou rosa) e diversos formatos; sendo outros os fatores responsáveis pela resposta da resistência de Solanum phureja.

As matrizes de correlação de Pearson entre as características índice de galhas, índice de massas de ovos, fator de reprodução e número de ovos $+\mathrm{J} 2$ por grama de raiz de Meloidogyne javanica, Meloidogyne incognita raça 1 e Meloidogyne enterolobii são apresentadas na Tabela 4.4, Tabela 4.5 e Tabela 4.6, respectivamente.

As correlações entre as variáveis avaliadas apresentaram o mesmo comportamento nas três espécies de Meloidogyne (Tabela 4.4, Tabela 4.5 e Tabela 4.6).

Verificou-se uma correlação muito forte e positiva $(p<0,01)$ entre o índice de galhas e o índice de massas de ovos nos sistemas radiculares das plantas infectadas com Meloidogyne enterolobii, Meloidogyne incognita raça 1 e Meloidogyne javanica $(0,974 ; 0,978$ e 0,989, respectivamente); indicando que, quanto maior o número de galhas nas raízes das plantas, maior a quantidade de massas de ovos produzidas pelos nematoides.

O fator de reprodução de $M$. enterolobii e $M$. incognita raça 1 correlacionou-se forte e positivamente com os índices de galhas $(0,758$ e 0,828 , respectivamente) e de massas de ovos $(0,716$ e 0,817 , respectivamente); já a magnitude da correlação foi média entre o fator de 
reprodução de Meloidogyne javanica e estas duas variáveis (0,672 e 0,669, respectivamente). Estas correlações positivas sugerem que as populações finais dos nematoides das três espécies incrementaram com o aumento do número de galhas e de massas de ovos nos sistemas radiculares das plantas.

Uma estimativa de correlação positiva e alta entre caracteres demonstra que na prática tem-se necessidade da avaliação apenas da característica de mais fácil mensuração, pois a seleção estará sendo realizada de forma indireta também para a outra variável (GONÇALVES NETO et al., 2012).

Maiores quantidades de ovos $+\mathrm{J} 2$ por grama de raiz, de Meloidogyne enterolobii, Meloidogyne javanica e Meloidogyne incognita raça 1, foram atingidas com o aumento dos índices de galhas $(0,734 ; 0,766$ e 0,903, respectivamente) e de massas de ovos por sistema radicular $(0,652 ; 0,765$ e 0,868, respectivamente); igualmente, a maior multiplicação dos nematoides favoreceu o incremento do número de ovos $+\mathrm{J} 2$ por grama de raiz $(0,865 ; 0,949$ e 0,867 , respectivamente).

Tabela 4.4 Matriz de correlação de Pearson entre as variáveis resposta à infecção por $M$. javanica

\begin{tabular}{cccc}
\hline & IMO & FR & OMRT \\
\hline IG & $0,989^{* *}$ & $0,672^{* *}$ & $0,766^{* *}$ \\
IMO & & $0,669^{* *}$ & $0,765^{* *}$ \\
FR & & & $0,949^{* *}$ \\
\hline
\end{tabular}

Tabela 4.5 Matriz de correlação de Pearson entre as variáveis resposta à infecção por $M$. incognita raça 1

\begin{tabular}{cccc}
\hline & IMO & FR & OMRT \\
\hline IG & $0,978^{* *}$ & $0,828^{* *}$ & $0,903^{* *}$ \\
IMO & & $0,817^{* *}$ & $0,868^{* *}$ \\
FR & & & $0,867^{* *}$ \\
\hline
\end{tabular}

Tabela 4.6 Matriz de correlação de Pearson entre as variáveis resposta à infecção por $M$. enterolobii

\begin{tabular}{cccc}
\hline & IMO & FR & OMRT \\
\hline IG & $0,974^{* *}$ & $0,758^{* *}$ & $0,734^{* *}$ \\
IMO & & $0,716^{* *}$ & $0,652^{* *}$ \\
FR & & & $0,865^{* *}$ \\
\hline
\end{tabular}

**: Significativo a $1 \%$ de probabilidade pelo teste t. IG: índice de galhas; IMO: índice de massas de ovos; FR: fator de reprodução; OMRT: ovos $+\mathrm{J}_{2}$ por grama de raiz. 
Cervantes-Flores et al. (2002a) ao avaliar 5 cultivares de batata-doce com relação à resistência às espécies $M$. arenaria raça $2, M$. incognita raça 3 e $M$. javanica, também verificaram uma correlação estatisticamente significativa e alta entre o número de ovos produzidos por grama de raiz e a porcentagem de galhas no sistema radicular $(\mathrm{r}=0,9)$.

Na Tabela 4.7 são apresentadas as estimativas da herdabilidade no sentido amplo $\left(\mathrm{h}_{\mathrm{a}}{ }^{2}\right)$, os coeficientes de variação genético $\left(\mathrm{CV}_{\mathrm{g}}\right)$, ambiental $\left(\mathrm{CV}_{\mathrm{e}}\right)$ e a razão entre os coeficientes de variação genético e ambiental $\left(\mathrm{CV}_{\mathrm{g}} / \mathrm{CV}_{\mathrm{e}}\right)$ para os caracteres estudados.

Os coeficientes de variação experimental $\left(\mathrm{CV}_{\mathrm{e}}\right)$ foram baixos para as características índice de galhas $(17,23 ; 15,26$ e 11,82\%) e índice de massas de ovos $(17,11 ; 16,04$ e 12,27\%) nas raízes das plantas infectadas com $M$. javanica, $M$. incognita raça 1 e $M$. enterolobii, respectivamente, demonstrando existir uma boa precisão experimental; já os maiores $\mathrm{CV}_{\mathrm{e}}$ obtidos para o fator de reprodução $(38,15 ; 36,17$ e $51,16 \%$, respectivamente) e o número de ovos $+\mathrm{J} 2$ por grama de raiz $(76,81 ; 60,3$ e 54,1\%, respectivamente) destas espécies, enquadram-se dentro da faixa encontrada para estes caracteres na batata-doce. Marchese (2010) reportou $\mathrm{CV}_{\mathrm{e}}$ de $71,85 \%$ para o fator de reprodução de $M$. incognita raça 1.

Tabela 4.7 Parâmetros genéticos populacionais de variáveis resposta à infecção por $M$. javanica, $M$. incognita raça 1 e $M$. enterolobii

\begin{tabular}{ccccccccccccc}
\hline & \multicolumn{4}{c}{ M. javanica } & \multicolumn{4}{c}{ M. incognita raça 1 } & \multicolumn{3}{c}{ M. enterolobii } \\
\hline Parâmetros & IG & IMO & FR & OGR & IG & IMO & FR & OGR & IG & IMO & FR & OGR \\
\hline $\mathbf{h}_{\mathbf{a}}{ }^{2}(\%)$ & 94,42 & 94,43 & 97,43 & 97,28 & 94,67 & 93,97 & 96,75 & 93,98 & 94,09 & 92,78 & 85,53 & 86,72 \\
$\mathbf{C V}_{\mathbf{g}}(\mathbf{\%})$ & 28,95 & 28,75 & 95,76 & 187,41 & 26,25 & 25,83 & 80,66 & 97,08 & 19,26 & 17,92 & 50,65 & 56,26 \\
$\mathbf{C V}_{\mathbf{e}}(\mathbf{\%})$ & 17,23 & 17,11 & 38,15 & 76,81 & 15,26 & 16,04 & 36,17 & 60,3 & 11,82 & 12,27 & 51,16 & 54,1 \\
$\mathbf{C V}_{\mathbf{g}} / \mathbf{C V}_{\mathbf{e}}$ & 1,68 & 1,68 & 2,51 & 2,44 & 1,72 & 1,61 & 2,23 & 1,61 & 1,63 & 1,46 & 0,99 & 1,04 \\
\hline
\end{tabular}

IG: índice de galhas; IMO: índice de massas de ovos; FR: fator de reprodução e OGR: ovos $+\mathrm{J}_{2}$ por grama de raiz e parte da raiz tuberosa com galhas produzidos por M. javanica, M. incognita raça 1 e M. enterolobii.

Com exceção do fator de reprodução de $M$. enterolobii, os coeficientes de variação genéticos foram superiores aos coeficientes de variação ambiental $\left(\mathrm{CV}_{\mathrm{g}} / \mathrm{CV}_{\mathrm{e}}\right)$ para as características índice de galhas, índice de massas de ovos, fator de reprodução e número de ovos+J2 por grama de raiz de $M$. javanica $(1,68 ; 1,68 ; 2,51$ e 2,44, respectivamente) e $M$. incognita raça $1(1,72 ; 1,61 ; 2,23$ e 1,61, respectivamente) e para os caracteres índice de galhas, índice de massas de ovos e número de ovos $+\mathrm{J} 2$ por grama de raiz de $M$. enterolobii $(1,63 ; 1,46$ e 1,04 , respectivamente). Os altos valores dos coeficientes de variação genéticos demonstram alta variabilidade entre os genótipos e uma situação bastante favorável em termos de seleção nessa população. 
Finalmente, as estimativas de herdabilidade no sentido amplo foram altas, superiores a 85\%, para as variáveis índice de galhas $(94,42 ; 94,67$ e 94,09\%), índice de massas de ovos $(94,43 ; 93,97$ e $92,78 \%)$; fator de reprodução $(97,43 ; 96,75$ e $85,53 \%)$ e número de ovos+J2 por grama de raiz $(97,28 ; 93,98$ e 86,72\%) de $M$. javanica, $M$. incognita raça 1 e $M$. enterolobii, respectivamente. Estes valores de alta magnitude refletem considerável presença do componente genético na expressão destes caracteres e ratificam que a seleção baseada nessas características poderia ser realizada com eficiência.

Maluf et al. (1996), também constataram altas estimativas de herdabilidade no sentido amplo, que foram de 0,$87 ; 0,91 ; 0,81 ; 0,95$ e 0,93, para a resistência a $M$. javanica e às raças 1, 2, 3 e 4 de $M$. incognita, respectivamente. Contudo, as correlações genotípicas entre a resistência aos diferentes isolados de Meloidogyne utilizados, foram fracas, variando entre 0,11 e 0,57 , sugerindo controles genéticos independentes.

Valores de herdabilidade elevados também foram verificados por Marchese et al. (2010) para o fator de reprodução de $M$. incognita raça 1 (74,63\%); Gomes (2014) para os fatores de reprodução de Meloidogyne javanica e M. incognita raças 1 e 3 (96,36; 93,80 e 94,85\%, respectivamente) e Gonçalves (2011) para as variáveis número de ovos por grama de raiz e fator de reprodução de $M$. enterolobii (85,78 e 82,72\%, respectivamente), em raízes de clones de batata-doce. 


\subsection{CONCLUSÕES}

Os 44 genótipos avaliados apresentam considerável variabilidade genética e reação diferenciada à infecção por $M$. javanica, $M$. incognita raça 1 e $M$. enterolobii.

M. javanica foi a espécie menos agressiva, infectando e se reproduzindo ligeiramente em apenas 9,09\% dos genótipos estudados. A raça 1 de $M$. incognita reproduziu-se exitosamente em $47,73 \%$ dos materiais. $M$. enterolobii foi a espécie mais virulenta tendo como hospedeiros suscetíveis $79,55 \%$ dos clones avaliados.

Os genótipos Brazlândia Rosada, Brazlândia Roxa, CNPH 02, CNPH 05, CNPH 08, CNPH 1197, CNPH 1200, CNPH 1202, CNPH 1219, CNPH 1232, CNPH 1292, CNPH 1310, CNPH 1358, CNPH 1361, CNPH 1392, CNPH 1393, CNPH 1394, CNPH 1796, CNPH 56, CNPH 60, CNPH 69, Coquinho e Rainha foram resistentes a $M$. javanica e $M$. incognita raça 1 .

Os clones CNPH 1200, CNPH 1219, CNPH 1221, CNPH 1292, CNPH 1392, CNPH 46, CNPH 60 e Coquinho foram resistentes à infecção por M. javanica e M. enterolobii.

Os genótipos CNPH 1200, CNPH 1219, CNPH 1292, CNPH 1392, CNPH 60 e Coquinho foram resistentes a $M$. incognita raça 1 e $M$. enterolobii. Estes mesmos materiais foram simultaneamente resistentes a $M$. javanica, $M$. incognita raça 1 e $M$. enterolobii.

Os resultados obtidos neste estudo, em conjunto com a avaliação morfoagronômica realizada em campo (Capítulos 2 e 3), indicam que os materiais CNPH 1392, CNPH 60 e Coquinho são muito promissores.

As correlações entre a resistência à infecção por $M$. javanica, $M$. incognita raça 1 e $M$. enterolobii e as cores da periderme e da polpa das raízes tuberosas não foram significativas.

As populações finais dos nematoides das três espécies incrementaram com o aumento do número de galhas e de massas de ovos nos sistemas radiculares das plantas.

As estimativas de herdabilidade no sentido amplo foram superiores a $85 \%$ para as variáveis índice de galhas, índice de massas de ovos, fator de reprodução e número de ovos $+\mathrm{J} 2$ por grama de raiz. 


\subsection{REFERÊNCIAS BIBLIOGRÁFICAS}

ARAUJO, M. T.; BASSETT, M. J.; AUGUSTINE, J. J.; DICKSON, D. W. Effect of diurnal changes in soil temperatures on resistance to Meloidogyne incognita in tomato. Journal of nematology, v. 14, n. 3, p. 414-416, 1982.

BONETI, J. I. S.; FERRAZ, S. Modificação do método de Hussey \& Barker para extração de ovos de Meloidogyne exigua de raízes de cafeeiro. Fitopatologia Brasileira, v. 6, n. 3, p. 553, 1981.

BORGES, D. C.; ANTEDOMÊNICO, S. R.; SANTOS, V. P.; INOMOTO, M. M. Reação de genótipos de Avena spp. a Meloidogyne incognita raça 4. Tropical Plant Pathology, v. 34, n. 1, p. 24-28, 2009.

CADENA, M.; NARANJO, A.; NUÚSTEZ, C. E. Evaluación de la respuesta de 60 genotipos de Solanum phureja (Juz. et Buk.) al ataque de la Polilla guatemalteca (Tecia solanivora Povolny). Agronomía Colombiana, v. 23, n. 1, p. 112-116, 2005.

CANTU, R. R.; WILCKEN, S. R. S.; ROSA, J. M. O.; GOTO, R. Reação de porta-enxertos comerciais de tomateiro a Meloidogyne mayaguensis. Summa Phytopathologica, v. 35, n. 3, p. 216-218, 2009.

CARNEIRO, R. M. D. G; ALMEIDA, M. R. A.; BRAGA, R. S.; ALMEIDA, C. A. de; GIORIA, R. Primeiro registro de Meloidogyne mayaguensis parasitando plantas de tomate e pimentão resistentes à meloidoginose no estado de São Paulo. Nematologia Brasileira, v. 30, n. 1, p. 81-86, 2006.

CARNEIRO, R. G; MÔNACO, A. P. do A.; MORITZ, M. P.; NAKAMURA, K. C.; SCHERER, A. Identificação de Meloidogyne mayaguensis em goiabeira e em plantas invasoras, em solo argiloso, no Estado do Paraná. Nematologia Brasileira, v. 30, n. 3, p. 293-298, 2006.

CARNEIRO, R. M. D. G.; CARNEIRO, R. G.; NEVES, D. I. das; ALMEIDA, M. R. A. Nova raça de Meloidogyne javanica detectada em Arachis pintoi no estado do Paraná. Nematologia brasileira, v. 27, n. 2, p. 219-221, 2003.

CARNEIRO, R. M. D. G.; ALMEIDA, M. R. A. Técnica de eletroforese usada no estudo de enzimas dos nematoides de galhas para identificação de espécies. Nematologia Brasileira, v. 25, n. 2, p. 35-44, 2001a.

CARVALHO, F. I. F.; LORENCETTI, C.; BENIN, G. Estimativas e implicações da correlação no melhoramento vegetal. Pelotas: Universitárias da UFPel, 2004. 
CERVANTES-FLORES, J. C. Root-knot Nematode Resistance in Sweetpotato and Development of Sweetpotato Differential Host Genotypes for Meloidogyne spp. 2000. 75 f. Dissertação (Master in science Thesis)- Department of Horticultural Science, North Carolina State University, Raleigh, 2000.

CERVANTES-FLORES, J. C.; YENCHO, G. C.; PECOTA, K. V.; SOSINSKI, B. Detection of quantitative trait loci and inheritance of root-knot nematode resistance in sweetpotato. Journal of the American Society for Horticultural Science, v. 133, n. 6, p. 844-851, 2008.

CERVANTES-FLORES, J. C.; YENCHO, G. C.; DAVIS, E. L. Efficient evaluation of resistance to three root-knot nematode species in selected sweetpotato cultivars. HortScience, v. 37, n. 2, p. 390-392, 2002a.

CERVANTES-FLORES, J. C.; YENCHO, G. C.; DAVIS, E. L. Host reactions of sweetpotato genotypes to root-knot nematodes and variation in virulence of Meloidogyne incognita populations. HortScience, v. 37, n. 7, p. 1112-1116, 2002 b.

CHARCHAR, J. M.; RITSCHEL, P. S. Avaliação do banco de germoplasma de batatadoce da Embrapa Hortaliças para resistência a Meloidogyne spp. Brasília: Embrapa Hortaliças, 2004, 28 p. Boletim de Pesquisa e Desenvolvimento 03.

CHAVES, P. P. N.; SANTOS, G. R. dos; SILVEIRA, M. A. da; GOMES, L. A. A.; MOMENTÉ, V. G.; NASCIMENTO, I. R. do. Reação de genótipos de batata-doce a nematóides de galhas em condições de temperatura elevada. Bioscience Journal, v. 29, n. 6, p. 1869-1877, 2013.

COELHO, S. A. M. P.; LOURENÇÃO, A. L.; MELO, A. M. T. de; SCHAMMASS, E. A. Resistance of melon to Bemisia Tabaci biotype B. Bragantia, v. 68, n. 4, p. 1025-1035, 2009.

COYNE, D. L.; NICOL, J. M.; CLAUDIUS-COLE, B. Nematología práctica: Una guía de campo y laboratorio. SP-IPM Secretariat, International Institute of Tropical Agriculture (IITA), Cotonou, Benin, 2007, 93 p. ISBN 978-131-338-2.

CRUZ C, D. GENES - a software package for analysis in experimental statistics and quantitative genetics. Acta Scientiarum, v. 35, n. 3, p. 271-276, 2013.

EPPO Bulletin. Meloidogyne enterolobii, v. 44, n. 2, p. 159-163, 2014.

FIGUEIREDO, J. A. Seleção de clones de batata-doce com potencial de utilização na alimentação humana e animal. 2010. 55 f. Dissertação (Mestrado em Produção Vegetal)Faculdade de Ciências Agrárias, Universidade Federal dos Vales do Jequitinhonha e Mucuri, Diamantina, 2010.

FREITAS, J. A. de; SANTOS, G. C. dos; SOUZA, V. S.; AZEVEDO, S. M. de. Resistência de clones de batata-doce, Ipomoea batatas L., aos nematóides causadores de galhas. Acta Scientiarum. Agronomy, v. 23, p. 1257-1261, 2001. 
GAO, B.; WANG, R. Y.; CHEN, S. L.; LI, X. H.; MA, J. First report of root-knot nematode Meloidogyne enterolobii on sweet potato in China. Plant Disease, v. 98, n. 5, p. 702-702, 2014.

GOMES, J. A. A. Resistência de clones de batata-doce a nematoides (Meloidogyne spp.). 2014. 79 f. Dissertação (Mestrado em Produção Vegetal)- Faculdade de Ciências Agrárias, Universidade Federal dos Vales do Jequitinhonha e Mucuri, Diamantina - MG, 2014.

GONÇALVES NETO, Á. C.; MALUF, W. R.; GOMES, L. A. A.; MACIEL, G. M.; FERREIRA, R. P. D.; CARVALHO, R.C. Correlação entre caracteres e estimação de parâmetros populacionais para batata-doce. Horticultura Brasileira, v. 30, n. 4, p. 713-719, 2012.

GONÇALVES, R. J. de S. Variabilidade genética para produção de etanol e para resistência a Meloidogyne enterolobii em coleção de clones de batata-doce. 2011. $110 \mathrm{f}$. Tese (Doutorado em Genética e Melhoramento de Plantas)- Universidade Federal de Lavras, Lavras, 2011.

HUSSEY, R. S.; BARKER, K. R. Comparison of methods of collecting inocula of Meloidogyne spp., including a new technique. Plant disease reporter, v. 57, n. 12, p. 10251028, 1973.

JATALA, P. Biology and management of plant-parasitic nematodes on sweet potato. In: JANSSON, R. K.; RAMAN, K.V. (Ed.). Sweet potato pest management: a global perspective. San Francisco: Westview Press, 1991. p. 359-378.

JATALA, P.; RUSSELL, C. C. Nature of sweet potato resistance to Meloidogyne incognita and the effects of temperature on parasitism. Journal of Nematology, v. 4, n. 1, p. 1-7, 1972.

KOMIYAMA, A.; SANO, Z.-I.; MURATA, T.; MATSUDA, Y.; YOSHIDA, M.; SAITO, A.; OKADA, Y. Resistance to two races of Meloidogyne incognita and resistance mechanism in diploid Ipomoea trifida. Breeding science, v. 56, n. 1, p. 81-83, 2006.

LAWRENCE, G. W.; CLARK, C. A. Infection and morphological development of Meloidogyne incognita in roots of susceptible and resistant sweet potato cultivars. Plant Disease, v. 70, p. 545-547, 1986.

LAWRENCE, G. W.; CLARK, C. A.; WRIGHT, V. L. Influence of Meloidogyne incognita on resistant and suscetible sweet potato cultivars. Journal of Nematology, v. 18, n. 1, p. 59$65,1986$.

MALUF, W. R.; AZEVEDO, S. M.; CAMPOS, V. P. Heritability of root-knot nematode (Meloidogyne spp.) resistance in sweetpotatoes. HortScience, v. 31, n. 4, p. 622-622, 1996.

MARCHESE, A.; MALUF, W. R.; GONÇALVES NETO, A. C.; GONÇALVES, R. J. do S.; GOMES, L. A. A. Seleção de clones de batata-doce resistentes a Meloidogyne incognita raça 1. Pesquisa Agropecuária Brasileira, v. 45, p. 997-1004, 2010. 
MARCHESE, A. Seleção de clones de batata-doce resistentes ao Meloidogyne incognita raça 1. 2010, 21 f. Dissertação (Mestrado em Fitotecnia)- Universidade Federal de Lavras, Lavras, 2010.

MASSAROTO, J. A.; GOMES, L. A. A.; MALUF, W. R.; SILVA, R. R.; GOMES, A. R. do V. A. Reação de clones de batata-doce ao Meloidogyne incognita raça 1. Revista de Ciências Agro-Ambientais, v. 8, n. 1, p. 1-8, 2010.

MELO, O. D. de; MALUF, W. R.; GONÇALVES, R. J. de S.; GONÇALVES NETO, A. C.; GOMES, L. A. A.; CARVALHO, R. de C. Screening vegetable crop species for resistance to Meloidogyne enterolobii. Pesquisa Agropecuária Brasileira, v. 46, n. 8, p. 829-835, 2011.

MENDES, M. L.; RODRIGUEZ, P. B. N. Reação de cultivares de soja [Glycine max (L.) Merrill] aos nematóides de galhas Meloidogyne javanica e $M$. incognita raças 1, 2, 3 e 4. Nematologia Brasileira, v. 24, n. 2, p. 211-217, 2000.

MONTES, L.; CROZZOLI, R.; VARGAS, G. Respuesta de selecciones de batata al nematodo agallador Meloidogyne incognita en Venezuela. Nematropica, v. 28, n. 1, p. 113-117, 1998.

OOSTENBRINK, M. Major characteristics of the relation between nematodes and plants. Mededelingen Van De landbouwhogeschool Te Wageningen, v. 66, p. 1-46, 1966.

PEIXOTO, J. R.; FERRAZ, F. M.; SANTOS, L. C.; ANGELIS, B.; JULIATTI, F. C. Seleção de genótipos de batata-doce resistentes ao nematóide das galhas (Meloidogyne spp.). Fitopatologia Brasileira, v. 23, n.1, p. 51-53, 1998.

PERRY, R. N.; MOENS, M. (Ed.). Plant nematology. Cambridge, MA: CABI, 2006.

PIEDRA-BUENA, A.; LÓPEZ-PÉREZ, J. A.; DÍEZ-ROJO, M. A.; ROBERTSON, L.; CASTRO-LIZAZO, I.; BELLO, A. Screening of three sweet potato (Ipomoea batatas L.) cultivars for resistance to different virulence groups of root-knot nematodes (Meloidogyne spp.) under controlled conditions. Crop Protection, v. 30, n. 2, p. 134-140, fev. 2011.

PILCO, G. D.; CROZZOLI, R.; PERICHI, G. Reacción de selecciones de batata al nematodo agallador Meloidogyne javanica. Revista Fitopatología Venezolana, v. 24, n. 2, p. 52-55, 2011.

R Core Team. R: A language and environment for statistical computing. R Foundation for Statistical Computing, Vienna, Austria. 2013. Disponível em: 〈http://www.R-project.org/>. Acesso em: 26 dez. 2013.

RITSCHEL, P. S.; HUAMÁN, Z. Variabilidade morfológica da coleção de germoplasma de batata-doce da Embrapa - Centro Nacional de Pesquisa de Hortaliças. Pesquisa Agropecuária Brasileira, v. 37, n. 4, p. 485-492, 2002

ROBERTS, P. A. Current status of the availability, development, and use of host plant resistance to nematodes. Journal of Nematology, v. 24, n. 2, p. 213-227, 1992. 
ROBERTS, P. A. Conceptual and practical aspects of variability in root-knot nematodes related to host plant resistance. Annual Review of Phytopathology, v. 33, p. 199-221, 1995.

RODRÍGUEZ, M. G.; GÓMEZ, L.; PETEIRA, B. Meloidogyne mayaguensis Rammah y Hirschmann, plaga emergente para la agricultura tropical y subtropical. Revista de Protección Vegetal, v. 22, n. 3, p. 183-198, 2007.

ROSA, J. M. O. Levantamento das espécies de nematoides das galhas em áreas de cultivo de olerícolas e reação de espécies vegetais a Meloidogyne enterolobii e M. javanica. 2010, 120 f. Tese (Doutorado em Proteção de Plantas)- Faculdade de Ciências Agronômicas da Unesp, Universidade Estadual Paulista "Júlio de Mesquita Filho”, Botucatu, 2010.

SASSER, J. N. Root knot nematodes: a global menace to crop production. Plant Disease, v. 64, p. 36-41, 1980.

SCURRAH, M. I.; NIERE, B.; BRIDGE, J. Nematode parasites of Solanum and sweet potatoes. In: LUC, M.; SIKORA, R. A.; BRIDGE, J. (Ed.). Plant parasitic nematodes in subtropical and tropical agriculture, Cambridge, MA: CABI, 2006. p. 193-220.

SILVEIRA, M. DA; MALUF, W. R. Resistência de clones de batata-doce a Meloidogyne spp. Horticultura Brasileira, v. 11, n. 2, p. 131-133, 1993.

STEFANOVIĆ, S.; KRUEGER, L.; OLMSTEAD, R. G. Monophyly of the Convolvulaceae and circumscription of their major lineages based on DNA sequences of multiple chloroplast loci. American Journal of Botany, v. 89, n. 9, p. 1510-1522, 2002.

TAYLOR, A. L.; SASSER, J. N. Biology, identification and control of root-knot nematodes (Meloidogyne species). Raleigh: North Carolina State University Graphics, 1978, $111 \mathrm{p}$.

UKOSKIT, K.; THOMPSON, P. G.; WATSON, C. E.; LAWRENCE, G. W. Identifying a randomly amplified polymorphic DNA (RAPD) marker linked to a gene for root-knot nematode resistance in sweetpotato. Journal of the American Society for Horticultural Science, v. 122, n. 6, p. 818-821, 1997.

WANDERLEY, M. J.; SANTOS, J. M. Resistência de cultivares de batata-doce a Meloidogyne incognita. Fitopatologia Brasileira, v. 29, p. 437-440, 2004.

WUYTS, N. Interacciones entre los nematodos fitoparásiticos y el metabolismo secundario de las plantas, con énfasis en los fenilpropanoides en las raíces. InfoMusa, v. 15, n. 1-2, p. 43 44, 2006.

YANG, B.; EISENBACK, J. D. Meloidogyne enterolobii n. sp. (Meloidogynidae), a root-knot nematode parasitizing Pacara Earpod Tree in China. Journal of Nematology, v. 15, n. 3, p. 381-391, 1983. 


\section{CONSIDERAÇÕES FINAIS}

Os clones CNPH 60, CNPH 59, CNPH 05, CNPH 1796, CNPH 80, CNPH 08, CNPH 1232, CNPH 1357, CNPH 1298, CNPH 1197 e CNPH 1208 com boas produtividades comercial e total, moderada resistência aos insetos de solo e bom formato são promissores visando o consumo humano. Adicionalmente, os clones CNPH 05, CNPH 80 e CNPH 1796 são boa fonte de antocianinas.

Dado que os clones CNPH 1796, CNPH 80 e CNPH 05 apresentam coloração de polpa roxa, seria interessante avaliar o grau de aceitação através de análises sensoriais. Também é recomendável avaliar em áreas com histórico de pragas a resistência aos insetos de solo.

Os clones CNPH 46, CNPH 69 e CNPH 66 apresentaram altas produtividades totais e moderada resistências aos insetos de solo; porém, formato não desejável para a comercialização, podendo ser empregados para alimentação animal ou processamento industrial.

Contudo, recomenda-se estudar o plantio em diferentes épocas do ano; escalonar os ciclos de colheita e avaliar o desempenho agronômico desses materiais genéticos em diversos ambientes, toda vez que de acordo com o desempenho apresentado pelas cultivares, empregadas como testemunhas, nos três experimentos realizados em campo, foi possível observar que houve influência da época de plantio e do local de cultivo e que alguns materiais apresentaram raízes tuberosas excessivamente grandes na única época de colheita estudada.

Os clones CNPH 1232 e CNPH 55 apresentaram altos teores de fibra bruta. Adicionalmente, o acesso CNPH 55 produziu o maior teor de proteína bruta e o clone CNPH 1232 produziu a maior concentração de carotenoides totais. Os clones CNPH 1796, CNPH 08 e CNPH 69 mostraram bons rendimentos de amido. Os clones CNPH 1796 e CNPH 59 apresentaram altos teores de matéria seca e de sólidos solúveis totais. O clone CNPH 05 produziu altos teores de cinzas.

Dos genótipos citados anteriormente apenas o clone CNPH 59 foi suscetível à infecção pelas três espécies de nematoides estudadas ( $M$. javanica, $M$. incognita raça 1 e $M$. enterolobii). Os clones CNPH 80, CNPH 1357, CNPH 1298, CNPH 1208 e CNPH 66 foram resistentes a $M$. javanica. Os clones CNPH 05, CNPH 1796, CNPH 08, CNPH 1232, CNPH 1197 e CNPH 69 foram resistentes à infecção por $M$. javanica e M. incognita raça 1 e 
suscetíveis a $M$. enterolobii. O clone CNPH 46 foi resistente a $M$. javanica e $M$. enterolobii e suscetível a $M$. incognita raça 1 . Finalmente, o clone CNPH 60 foi resistente às três espécies de nematoides avaliadas.

Além do clone CNPH 60, os clones CNPH 1200, CNPH 1219, CNPH 1292, CNPH 1392 e Coquinho também foram simultaneamente resistentes a $M$. javanica, $M$. incognita raça 1 e

\section{M. enterolobii.}

Sugere-se ainda que novos ensaios sejam realizados aumentando a população inicial de nematoides, avaliando a idade das plantas e estudando outras épocas de inoculação bem como o tempo de avaliação e o tamanho dos vasos, para confirmar a resistência dos genótipos às espécies de nematoides estudadas.

As altas estimativas de herdabilidade para as características produtividade comercial, número de raízes comerciais por planta, produtividade total, comprimento, diâmetro, porcentagem de raízes comerciais, formato, número total de raízes por planta, proteína, cinzas, umidade, amido e sólidos solúveis totais das raízes de batata-doce, evidenciaram alta presença do componente genético na expressão destes caracteres e grande possibilidade de sucesso com a seleção nessa população. As estimativas de herdabilidade no sentido amplo também foram superiores a $85 \%$ para as variáveis índice de galhas, índice de massas de ovos, fator de reprodução e número de ovos $+\mathrm{J} 2$ por grama de raiz. 


\section{ANEXOS}




\section{ANEXO A: TABELAS DAS ANÁLISES DE VARIÂNCIA (CAPÍTULO 1) CARACTERIZAÇÃO MORFOAGRONÔMICA E FÍSICO-QUÍMICA DAS RAÍZES}

\begin{tabular}{|c|c|c|c|c|c|}
\hline \multicolumn{6}{|c|}{ Diâmetro (DR) } \\
\hline $\mathrm{FV}$ & Gl & SQ & $\mathrm{QM}$ & $\mathrm{F}$ & $\operatorname{Pr}(>\mathrm{F})$ \\
\hline Tratamentos & 22 & 16811,55692 & 764,161678 & 6,857895905 & $5,19 \mathrm{E}-10^{* * * ;}$ \\
\hline Blocos & 3 & 831,91608 & 277,30536 & 2,488650436 & 0,06799 \\
\hline Resíduo & 66 & 7354,24851 & 111,4280077 & & \\
\hline Total & 91 & 24997,72151 & & & \\
\hline \multicolumn{6}{|c|}{ Comprimento (CR) } \\
\hline $\mathrm{FV}$ & Gl & SQ & QM & $\mathrm{F}$ & $\operatorname{Pr}(>\mathrm{F})$ \\
\hline Tratamentos & 22 & 518,5385063 & 23,5699321 & 6,819937676 & $5,81 \mathrm{E}-10^{* * * *}$ \\
\hline Blocos & 3 & 24,98685867 & 8,328952891 & 2,409974682 & 0,07476 \\
\hline Resíduo & 66 & 228,0982016 & 3,456033358 & & \\
\hline Total & 91 & 771,6235666 & & & \\
\hline \multicolumn{6}{|c|}{ Dados transformados em $(x+1)^{0,5}, * * *$ Diferença estatisticamente significativa $(\mathrm{p} \leq 0,01)$} \\
\hline \multicolumn{6}{|c|}{ Espessura do córtex (EC) } \\
\hline FV & Gl & SQ & QM & $\mathrm{F}$ & $\operatorname{Pr}(>\mathrm{F})$ \\
\hline Tratamentos & 22 & 1,692691527 & 0,076940524 & 4,676684696 & $5,66 \mathrm{E}-07^{* * * *}$ \\
\hline Blocos & 3 & 0,068553178 & 0,022851059 & 1,388958554 & 0,25391 \\
\hline Resíduo & 66 & 1,08582787 & 0,016451937 & & \\
\hline Total & 91 & 2,847072575 & & & \\
\hline
\end{tabular}

\begin{tabular}{cccccc}
\hline \multicolumn{7}{c}{ Formato (FTO) } \\
\hline FV & Gl & SQ & QM & F & Pr(>F) \\
\hline Tratamentos & 22 & 22,26590757 & 1,012086708 & 3,962845496 & $7,47 \mathrm{E}-06^{\text {***** }}$ \\
Blocos & 3 & 2,80342923 & 0,93447641 & 3,658960842 & 0,01671 \\
Resíduo & 66 & 16,85599976 & 0,255393936 & & \\
\hline Total & 91 & 41,92533655 & & & \\
\hline
\end{tabular}

\begin{tabular}{cccccc}
\hline \multicolumn{7}{c}{ Número de furos ocasionados por insetos de solo nas raízes tuberosas (NF) } \\
\hline FV & Gl & SQ & QM & F & Pr(>F) \\
\hline Tratamentos & 22 & 54,25621367 & 2,466191531 & 2,438884605 & $2,84 \mathrm{E}-03^{* * * *}$ \\
Blocos & 3 & 10,63558026 & 3,54519342 & 3,505939237 & 0,02005 \\
Resíduo & 66 & 66,73896776 & 1,011196481 & \\
\hline Total & 91 & 131,6307617 & & \\
\hline \multicolumn{7}{c}{ Dados transformados em $(x+1)^{0,5}{ }^{* * * *}$ Diferença estatisticamente significativa $(\mathrm{p} \leq 0,01)}$. \\
\end{tabular}

\begin{tabular}{cccccc}
\hline \multicolumn{5}{c}{ Incidência de danos ocasionados por insetos do solo (ID) } \\
\hline FV & Gl & SQ & QM & F & Pr $(>\mathrm{F})$ \\
\hline Tratamentos & 22 & 1,380537813 & 0,062751719 & 2,923483752 & $4,10 \mathrm{E}-04^{* * * *}$ \\
Blocos & 3 & 0,020757035 & 0,006919012 & 0,322343657 & 0,80918 \\
Resíduo & 66 & 1,416670585 & 0,021464706 & \\
\hline Total & 91 & 2,817965434 & & \\
\hline \multicolumn{7}{c}{ Dados transformados em $(x+1)^{0,5} \cdot{ }^{* * * *}$ Diferença estatisticamente significativa $(\mathrm{p} \leq 0,01)}$. \\
\end{tabular}

\begin{tabular}{cccccc}
\hline \multicolumn{6}{c}{ Produtividade comercializável (PC) } \\
\hline FV & Gl & SQ & QM & F $(>\mathrm{F})$ \\
\hline Tratamentos & 22 & 218,5691307 & 9,934960487 & 5,418840922 & $4,53 \mathrm{E}-08^{* * *}$ \\
Blocos & 3 & 7,159339594 & 2,386446531 & 1,301643237 & 0,28131 \\
Resíduo & 66 & 121,0051008 & 1,833410619 & \\
\hline Total & 91 & 346,7335711 & & \\
\hline \multicolumn{7}{c}{ Dados transformados em $(x+1)^{0,5}{ }^{* * * *}$ Diferença estatisticamente significativa $(\mathrm{p} \leq 0,01)}$. \\
\end{tabular}




\begin{tabular}{|c|c|c|c|c|c|}
\hline \multicolumn{6}{|c|}{ Produtividade total (PT) } \\
\hline FV & Gl & SQ & $\mathrm{QM}$ & $\mathrm{F}$ & $\operatorname{Pr}(>\mathrm{F})$ \\
\hline Tratamentos & 22 & 175,2190476 & 7,964502161 & 4,444904407 & $1,29 \mathrm{E}-06^{* * * *}$ \\
\hline Blocos & 3 & 5,172303114 & 1,724101038 & 0,962202552 & 0,41591 \\
\hline Resíduo & 66 & 118,2606181 & 1,791827547 & & \\
\hline Total & 91 & 298,6519688 & & & \\
\hline \multicolumn{6}{|c|}{ Dados transformados em $(x+1)^{0,5}$} \\
\hline \multicolumn{6}{|c|}{ Teor de fibra bruta (FB) } \\
\hline $\mathrm{FV}$ & Gl & SQ & $\mathrm{QM}$ & $\mathrm{F}$ & $\operatorname{Pr}(>\mathrm{F})$ \\
\hline Tratamentos & 22 & 19,17781054 & 0,871718661 & 2,156534107 & $8,76 \mathrm{E}-03^{* * * *}$ \\
\hline Blocos & 3 & 0,700803279 & 0,233601093 & 0,57790288 & 0,63157 \\
\hline Resíduo & 66 & 26,67865601 & 0,404222061 & & \\
\hline Total & 91 & 46,55726982 & & & \\
\hline \multicolumn{6}{|c|}{ Acidez total titulável (AT) } \\
\hline $\mathrm{FV}$ & Gl & SQ & $\mathrm{QM}$ & $\mathrm{F}$ & $\operatorname{Pr}(>\mathrm{F})$ \\
\hline Tratamentos & 22 & 263,0382019 & 11,9562819 & 5,735440564 & $1,62 \mathrm{E}-08^{* * * *}$ \\
\hline Blocos & 3 & 8,609490752 & 2,869830251 & 1,376660484 & 0,25761 \\
\hline Resíduo & 66 & 137,5857002 & 2,084631821 & & \\
\hline Total & 91 & 409,2333928 & & & \\
\hline \multicolumn{6}{|c|}{ Teor de proteína bruta (PTN) } \\
\hline $\mathrm{FV}$ & G1 & SQ & $\mathrm{QM}$ & $\mathrm{F}$ & $\operatorname{Pr}(>\mathrm{F})$ \\
\hline Tratamentos & 22 & 8,355180614 & 0,379780937 & 8,860024784 & $2,30 \mathrm{E}-12^{* * * *}$ \\
\hline Blocos & 3 & 0,132105813 & 0,044035271 & 1,027312204 & 0,3863 \\
\hline Resíduo & 66 & 2,829060014 & 0,042864546 & & \\
\hline Total & 91 & 11,31634644 & & & \\
\hline \multicolumn{6}{|c|}{ Dados transformados em $(x+1)^{0,5}{ }^{* * *}$ Diferença estatisticamente significativa $(\mathrm{p} \leq 0,01)$} \\
\hline \multicolumn{6}{|c|}{ Ratio $(\mathrm{RT})$} \\
\hline $\mathrm{FV}$ & Gl & SQ & $\mathrm{QM}$ & $\mathrm{F}$ & $\operatorname{Pr}(>\mathrm{F})$ \\
\hline Tratamentos & 22 & 4,572405987 & 0,207836636 & 10,39147102 & $6,01 \mathrm{E}-14^{\text {**** }}$ \\
\hline Blocos & 3 & 0,155225664 & 0,051741888 & 2,587004576 & 0,06039 \\
\hline Resíduo & 66 & 1,320045828 & 0,020000694 & & \\
\hline Total & 91 & 6,047677479 & & & \\
\hline \multicolumn{6}{|c|}{ Dados transformados em $(x+1)^{0,5} . * * *$ Diferença estatisticamente significativa $(\mathrm{p} \leq 0,01)$} \\
\hline \multicolumn{6}{|c|}{ Teor de cinzas (CZ) } \\
\hline FV & Gl & SQ & QM & $\mathrm{F}$ & $\operatorname{Pr}(>\mathrm{F})$ \\
\hline Tratamentos & 22 & 22,83354441 & 1,037888382 & 5,38985296 & $4,99 \mathrm{E}-08^{* * * *}$ \\
\hline Blocos & 3 & 13,65882144 & 4,552940481 & 23,64385241 & $1,66 \mathrm{E}-10$ \\
\hline Resíduo & 66 & 12,70918404 & 0,192563395 & & \\
\hline Total & 91 & 49,2015499 & & & \\
\hline \multicolumn{6}{|c|}{ Teor de umidade (UM) } \\
\hline $\mathrm{FV}$ & Gl & SQ & QM & $\mathrm{F}$ & $\operatorname{Pr}(>\mathrm{F})$ \\
\hline Tratamentos & 22 & 610,8392376 & 27,76541989 & 5,808622658 & $1,28 \mathrm{E}-08^{* * * *}$ \\
\hline Blocos & 3 & 69,9790284 & 23,3263428 & 4,879952251 & 3,99E-03 \\
\hline Resíduo & 66 & 315,4823132 & 4,780035049 & & \\
\hline Total & 91 & 996,3005793 & & & \\
\hline
\end{tabular}




\begin{tabular}{|c|c|c|c|c|c|}
\hline \multicolumn{6}{|c|}{ Teor de amido (AM) } \\
\hline $\mathrm{FV}$ & Gl & SQ & $\mathrm{QM}$ & $\mathrm{F}$ & $\operatorname{Pr}(>\mathrm{F})$ \\
\hline Tratamentos & 22 & 1463,122132 & 66,50555146 & 5,986733138 & $7,28 \mathrm{E}-09^{* * * *}$ \\
\hline Blocos & 3 & 101,9724222 & 33,99080741 & 3,059803109 & $3,42 \mathrm{E}-02$ \\
\hline Resíduo & 66 & 733,1822373 & 11,10882178 & & \\
\hline Total & 91 & 2298,276792 & & & \\
\hline \multicolumn{6}{|c|}{$\mathrm{PH}$} \\
\hline FV & Gl & SQ & QM & $\mathrm{F}$ & $\operatorname{Pr}(>\mathrm{F})$ \\
\hline Tratamentos & 22 & 0,087389136 & 0,003972233 & 6,436054682 & $1,82 \mathrm{E}-09^{* * * * *}$ \\
\hline Blocos & 3 & 0,007391969 & 0,00246399 & 3,992306307 & $1,13 \mathrm{E}-02$ \\
\hline Resíduo & 66 & 0,04073418 & 0,000617185 & & \\
\hline Total & 91 & 0,135515284 & & & \\
\hline \multicolumn{6}{|c|}{ Dados transformados em $(x+1)^{0,5} . * * *$ Diferença estatisticamente significativa $(\mathrm{p} \leq 0,01)$} \\
\hline \multicolumn{6}{|c|}{ Sólidos solúveis totais (SS) } \\
\hline $\mathrm{FV}$ & Gl & SQ & $\mathrm{QM}$ & $\mathrm{F}$ & $\operatorname{Pr}(>\mathrm{F})$ \\
\hline Tratamentos & 22 & 2,520161801 & 0,114552809 & 5,184190338 & $9,90 \mathrm{E}-08^{* * * *}$ \\
\hline Blocos & 3 & 0,131083528 & 0,043694509 & 1,977434286 & $1,26 \mathrm{E}-01$ \\
\hline Resíduo & 66 & 1,458373422 & 0,022096567 & & \\
\hline Total & 91 & 4,10961875 & & & \\
\hline
\end{tabular}

\section{ANEXO B: TABELAS DAS ANÁLISES DE VARIÂNCIA (CAPÍTULO 2)} CARACTERIZAÇÃO MORFOAGRONÔMICA E FÍSICO-QUÍMICA DAS RAÍZES

\begin{tabular}{|c|c|c|c|c|c|}
\hline \multicolumn{6}{|c|}{ Número total de raízes por planta (NTRPP) } \\
\hline FV & Gl & SQ & QM & $\mathrm{F}$ & $\operatorname{Pr}(>F)$ \\
\hline Tratamentos & 25 & 10,62725527 & 0,425090211 & 2,266090516 & $3,53 \mathrm{E}-03^{* * * 3}$ \\
\hline Blocos & 3 & 0,51798341 & 0,172661137 & 0,920429956 & 0,43522 \\
\hline Resíduo & 75 & 14,06906104 & 0,187587481 & & \\
\hline Total & 103 & 25,21429972 & & & \\
\hline \multicolumn{6}{|c|}{ Dados transformados em $(x+1)^{0,5} \cdot * * *$ Diferença estatisticamente significativa $(\mathrm{p} \leq 0,01)$} \\
\hline \multicolumn{6}{|c|}{ Produtividade total $(\mathrm{PT})$} \\
\hline FV & Gl & SQ & $\mathrm{QM}$ & $\mathrm{F}$ & $\operatorname{Pr}(>\mathrm{F})$ \\
\hline Tratamentos & 25 & 233,7847016 & 9,351388063 & 4,050967521 & $1,38 \mathrm{E}-06^{* * * 3}$ \\
\hline Blocos & 3 & 0,973055268 & 0,324351756 & 0,140507315 & 0,93542 \\
\hline Resíduo & 75 & 173,1324927 & 2,308433236 & & \\
\hline Total & 103 & 407,8902495 & & & \\
\hline \multicolumn{6}{|c|}{ Dados transformados em $(x+1)^{0,5} \cdot * * *$ Diferença estatisticamente significativa $(\mathrm{p} \leq 0,01)$} \\
\hline \multicolumn{6}{|c|}{ Número de raízes comerciais por planta (NRCPP) } \\
\hline $\mathrm{FV}$ & Gl & SQ & $\mathrm{QM}$ & $\mathrm{F}$ & $\operatorname{Pr}(>\mathrm{F})$ \\
\hline Tratamentos & 25 & 10,58844854 & 0,423537942 & 4,161021519 & $8,75 \mathrm{E}-07^{* * * 2}$ \\
\hline Blocos & 3 & 0,109931855 & 0,036643952 & 0,360006169 & 0,78205 \\
\hline Resíduo & 75 & 7,634025799 & 0,101787011 & & \\
\hline Total & 103 & 18,3324062 & & & \\
\hline
\end{tabular}




\begin{tabular}{|c|c|c|c|c|c|}
\hline \multicolumn{6}{|c|}{ Produtividade comercial (PC) } \\
\hline FV & Gl & SQ & $\mathrm{QM}$ & $\mathrm{F}$ & $\operatorname{Pr}(>\mathrm{F})$ \\
\hline Tratamentos & 25 & 260,7940659 & 10,43176264 & 5,286484145 & $1,02 \mathrm{E}-08^{* * * *}$ \\
\hline Blocos & 3 & 0,357913466 & 0,119304489 & 0,060459705 & 0,98039 \\
\hline Resíduo & 75 & 147,996698 & 1,973289307 & & \\
\hline Total & 103 & 409,1486774 & & & \\
\hline \multicolumn{6}{|c|}{ Dados transformados em $(x+1)^{0,5} . * * *$ Diferença estatisticamente significativa $(\mathrm{p} \leq 0,01)$} \\
\hline \multicolumn{6}{|c|}{ Peso médio de raízes comerciais (PMRC) } \\
\hline $\mathrm{FV}$ & Gl & SQ & $\mathrm{QM}$ & $\mathrm{F}$ & $\operatorname{Pr}(>\mathrm{F})$ \\
\hline Tratamentos & 25 & 1317,543159 & 52,70172636 & 2,473401139 & $1,39 \mathrm{E}-03^{* * * *}$ \\
\hline Blocos & 3 & 76,48899331 & 25,4963311 & 1,19659561 & 0,31693 \\
\hline Resíduo & 75 & 1598,054361 & 21,30739148 & & \\
\hline Total & 103 & 2992,086513 & & & \\
\hline \multicolumn{6}{|c|}{ Dados transformados em $(x+1)^{0,5} \cdot * * *$ Diferença estatisticamente significativa $(\mathrm{p} \leq 0,01)$} \\
\hline \multicolumn{6}{|c|}{ Porcentagem de raízes comerciais (RC) } \\
\hline FV & Gl & SQ & $\mathrm{QM}$ & $\mathrm{F}$ & $\operatorname{Pr}(>\mathrm{F})$ \\
\hline Tratamentos & 25 & 156,1625628 & 6,246502511 & 1,945044655 & $1,46 \mathrm{E}-02^{* *}$ \\
\hline Blocos & 3 & 13,1654799 & 4,388493299 & 1,366495158 & 0,25956 \\
\hline Resíduo & 75 & 240,8621762 & 3,211495682 & & \\
\hline Total & 103 & 410,1902188 & & & \\
\hline \multicolumn{6}{|c|}{ Dados transformados em $(x+1)^{0,5} \cdot * *$ Diferença estatisticamente significativa $(\mathrm{p} \leq 0,05)$} \\
\hline \multicolumn{6}{|c|}{ Formato (FTO) } \\
\hline FV & $\mathrm{Gl}$ & SQ & $\mathrm{QM}$ & $\mathrm{F}$ & $\operatorname{Pr}(>F)$ \\
\hline Tratamentos & 25 & 2,284756216 & 0,091390249 & 4,930194252 & $3,99 \mathrm{E}-08^{* * * *}$ \\
\hline Blocos & 3 & 0,062938768 & 0,020979589 & 1,131777752 & 0,34175 \\
\hline Resíduo & 75 & 1,390263405 & 0,018536845 & & \\
\hline Total & 103 & 3,737958389 & & & \\
\hline \multicolumn{6}{|c|}{ Dados transformados em $(x+1)^{0,5}, * * *$ Diferença estatisticamente significativa $(\mathrm{p} \leq 0,01)$} \\
\hline \multicolumn{6}{|c|}{ Incidência de danos ocasionados por insetos do solo (ID) } \\
\hline $\mathrm{FV}$ & $\mathrm{Gl}$ & SQ & $\mathrm{QM}$ & $\mathrm{F}$ & $\operatorname{Pr}(>\mathrm{F})$ \\
\hline Tratamentos & 25 & 0,459244112 & 0,018369764 & 2,117695375 & $6,83 \mathrm{E}-03^{\text {***** }}$ \\
\hline Blocos & 3 & 0,024821168 & 0,008273723 & 0,953807772 & 0,41912 \\
\hline Resíduo & 75 & 0,650580982 & 0,008674413 & & \\
\hline Total & 103 & 1,134646262 & & & \\
\hline \multicolumn{6}{|c|}{ Dados transformados em $(x+1)^{0,5} . * * *$ Diferença estatisticamente significativa $(\mathrm{p} \leq 0,01)$} \\
\hline \multicolumn{6}{|c|}{ Comprimento (CR) } \\
\hline FV & Gl & SQ & $\mathrm{QM}$ & $\mathrm{F}$ & $\operatorname{Pr}(>F)$ \\
\hline Tratamentos & 25 & 93548,15222 & 3741,926089 & 6,2943454 & $2,65 \mathrm{E}-10^{* * * *}$ \\
\hline Blocos & 3 & 754,9845182 & 251,6615061 & 0,423323285 & 0,73682 \\
\hline Resíduo & 75 & 44586,75824 & 594,4901099 & & \\
\hline Total & 103 & 138889,895 & & & \\
\hline \multicolumn{6}{|c|}{ Diâmetro (DR) } \\
\hline $\mathrm{FV}$ & Gl & SQ & $\mathrm{QM}$ & $\mathrm{F}$ & $\operatorname{Pr}(>F)$ \\
\hline Tratamentos & 25 & 16778,32641 & 671,1330564 & 9,246013529 & $2,84 \mathrm{E}-14^{* * * *}$ \\
\hline Blocos & 3 & 1028,031307 & 342,6771024 & 4,720967169 & 0,00451 \\
\hline Resíduo & 75 & 5443,965561 & 72,58620748 & & \\
\hline Total & 103 & 23250,32328 & & & \\
\hline
\end{tabular}




\begin{tabular}{|c|c|c|c|c|c|}
\hline \multicolumn{6}{|c|}{ Espessura do córtex (EC) } \\
\hline $\mathrm{FV}$ & Gl & SQ & $\mathrm{QM}$ & $\mathrm{F}$ & $\operatorname{Pr}(>\mathrm{F})$ \\
\hline Tratamentos & 25 & 15,66618479 & 0,626647392 & 4,266189341 & $5,67 \mathrm{E}-07^{\text {***** }}$ \\
\hline Blocos & 3 & 3,618748367 & 1,206249456 & 8,212096053 & $8,53 \mathrm{E}-05$ \\
\hline Resíduo & 75 & 11,01651863 & 0,146886915 & & \\
\hline Total & 103 & 30,30145179 & & & \\
\hline \multicolumn{6}{|c|}{ Teor de umidade (UM) } \\
\hline FV & Gl & SQ & QM & $\mathrm{F}$ & $\operatorname{Pr}(>\mathrm{F})$ \\
\hline Tratamentos & 12 & 779,3740343 & 64,94783619 & 14,17324991 & $4,32 \mathrm{E}-08^{* * *}$ \\
\hline Blocos & 2 & 91,31370141 & 45,65685071 & 9,963472121 & 0,00071 \\
\hline Resíduo & 24 & 109,9781686 & 4,582423692 & & \\
\hline Total & 38 & 980,6659043 & & & \\
\hline \multicolumn{6}{|c|}{ Teor de cinzas $(\mathrm{CZ})$} \\
\hline $\mathrm{FV}$ & $\mathrm{Gl}$ & SQ & $\mathrm{QM}$ & $\mathrm{F}$ & $\operatorname{Pr}(>\mathrm{F})$ \\
\hline Tratamentos & 12 & 1,511579028 & 0,125964919 & 2,836314594 & $1,43 \mathrm{E}-02^{* *}$ \\
\hline Blocos & 2 & 0,856804797 & 0,428402398 & 9,646209316 & 0,00084 \\
\hline Resíduo & 24 & 1,065875436 & 0,044411477 & & \\
\hline Total & 38 & 3,434259261 & & & \\
\hline \multicolumn{6}{|c|}{ Dados transformados em $(x+1)^{0,5} . * *$ Diferença estatisticamente significativa $(\mathrm{p} \leq 0,05)$} \\
\hline \multicolumn{6}{|c|}{ Sólidos solúveis totais (SS) } \\
\hline $\mathrm{FV}$ & Gl & SQ & $\mathrm{QM}$ & $\mathrm{F}$ & $\operatorname{Pr}(>\mathrm{F})$ \\
\hline Tratamentos & 12 & 60,24923077 & 5,020769231 & 8,281243392 & $6,77 \mathrm{E}-06^{* * * *}$ \\
\hline Blocos & 2 & 7,829230769 & 3,914615385 & 6,456756185 & 0,00571 \\
\hline Resíduo & 24 & 14,55076923 & 0,606282051 & & \\
\hline Total & 38 & 82,62923077 & & & \\
\hline \multicolumn{6}{|c|}{ Acidez total titulável (AT) } \\
\hline FV & Gl & SQ & $\mathrm{QM}$ & $\mathrm{F}$ & $\operatorname{Pr}(>\mathrm{F})$ \\
\hline Tratamentos & 12 & 106,5683526 & 8,880696054 & 6,496722348 & $5,28 \mathrm{E}-05^{* * * *}$ \\
\hline Blocos & 2 & 39,5619554 & 19,7809777 & 14,47088371 & $7,53 \mathrm{E}-05$ \\
\hline Resíduo & 24 & 32,80680532 & 1,366950222 & & \\
\hline Total & 38 & 178,9371134 & & & \\
\hline \multicolumn{6}{|c|}{$\mathrm{PH}$} \\
\hline $\mathrm{FV}$ & Gl & SQ & $\mathrm{QM}$ & $\mathrm{F}$ & $\operatorname{Pr}(>\mathrm{F})$ \\
\hline Tratamentos & 12 & 0,021179687 & 0,001764974 & 1,746616976 & $1,18 \mathrm{E}-01$ \\
\hline Blocos & 2 & 0,012598586 & 0,006299293 & 6,233775752 & $6,60 \mathrm{E}-03$ \\
\hline Resíduo & 24 & 0,02425224 & 0,00101051 & & \\
\hline Total & 38 & 0,058030513 & & & \\
\hline \multicolumn{6}{|c|}{ Dados transformados em $(x+1)^{0,5}$} \\
\hline \multicolumn{6}{|c|}{ Concentração de carotenoides totais (CTN) } \\
\hline $\mathrm{FV}$ & Gl & SQ & $\mathrm{QM}$ & $\mathrm{F}$ & $\operatorname{Pr}(>\mathrm{F})$ \\
\hline Tratamentos & 12 & 1492,803701 & 124,4003084 & 192,2578722 & $8,37 \mathrm{E}-21^{* * * *}$ \\
\hline Blocos & 2 & 1,361685126 & 0,680842563 & 1,052226832 & $3,65 \mathrm{E}-01$ \\
\hline Resíduo & 24 & 15,52918155 & 0,647049231 & & \\
\hline Total & 38 & 1509,694568 & & & \\
\hline
\end{tabular}




\begin{tabular}{|c|c|c|c|c|c|}
\hline \multicolumn{6}{|c|}{ Teor de fibra bruta (FB) } \\
\hline $\mathrm{FV}$ & Gl & SQ & $\mathrm{QM}$ & $\mathrm{F}$ & $\operatorname{Pr}(>\mathrm{F})$ \\
\hline Tratamentos & 12 & 11,51826144 & 0,959855120 & 6,012351495 & $9,83 \mathrm{E}-05^{* * *}$ \\
\hline Blocos & 2 & 3,485638460 & 1,742819230 & 10,91669105 & 4,25E-04 \\
\hline Resíduo & 24 & 3,831532954 & 0,159647206 & & \\
\hline Total & 38 & 18,83543286 & & & \\
\hline \multicolumn{6}{|c|}{ Teor de proteína bruta (PTN) } \\
\hline $\mathrm{FV}$ & Gl & SQ & QM & $\mathrm{F}$ & $\operatorname{Pr}(>F)$ \\
\hline Tratamentos & 12 & 91,47344887 & 7,622787405 & 3,781853726 & $2,69 \mathrm{E}-03^{* * *}$ \\
\hline Blocos & 2 & 26,60250639 & 13,30125319 & 6,599081316 & $5,20 \mathrm{E}-03$ \\
\hline Resíduo & 24 & 48,37492695 & 2,015621956 & & \\
\hline Total & 38 & 166,4508822 & & & \\
\hline \multicolumn{6}{|c|}{ Teor de amido (AM) } \\
\hline $\mathrm{FV}$ & Gl & SQ & $\mathrm{QM}$ & $\mathrm{F}$ & $\operatorname{Pr}(>\mathrm{F})$ \\
\hline Tratamentos & 12 & 1784,478885 & 148,7065738 & 17,57698030 & $4,88 \mathrm{E}-09^{* * *}$ \\
\hline Blocos & 2 & 43,72071773 & 21,86035886 & 2,583874320 & 9,63E-02 \\
\hline Resíduo & 24 & 203,0472646 & 8,460302691 & & \\
\hline Total & 38 & 2031,246867 & & & \\
\hline \multicolumn{6}{|c|}{ Ratio (RT) } \\
\hline $\mathrm{FV}$ & Gl & SQ & $\mathrm{QM}$ & $\mathrm{F}$ & $\operatorname{Pr}(>\mathrm{F})$ \\
\hline Tratamentos & 12 & 0,897307671 & 0,074775639 & 5,731912978 & $1,43 \mathrm{E}-04^{\text {**** }}$ \\
\hline Blocos & 2 & 0,320450081 & 0,160225041 & 12,28202125 & $2,12 \mathrm{E}-04$ \\
\hline Resíduo & 24 & 0,313091868 & 0,013045494 & & \\
\hline Total & 38 & 1,53084962 & & & \\
\hline \multicolumn{6}{|c|}{ Dados transformados em $(x+1)^{0,5} . * * *$ Diferença estatisticamente significativa $(\mathrm{p} \leq 0,01)$} \\
\hline \multicolumn{6}{|c|}{ Concentração de antocianinas totais (ANT) } \\
\hline $\mathrm{FV}$ & $\mathrm{Gl}$ & SQ & $\mathrm{QM}$ & $\mathrm{F}$ & $\operatorname{Pr}(>\mathrm{F})$ \\
\hline Tratamentos & 2 & 0,027860632 & 0,013930316 & 1,043495440 & 0,43183 \\
\hline Blocos & 2 & 0,015175740 & 0,007587870 & 0,568393974 & 0,60637 \\
\hline Resíduo & 4 & 0,053398666 & 0,013349666 & & \\
\hline Total & 8 & 0,096435038 & & & \\
\hline \multicolumn{6}{|c|}{ Dados transformados em $(x+1)^{0,5}$.*** Diferença estatisticamente significativa $(\mathrm{p} \leq 0,01)$. } \\
\hline \multicolumn{6}{|c|}{ Luminosidade da periderme das raízes tuberosas $\left(\mathrm{L}_{\mathrm{c}}{ }_{\mathrm{c}}\right)$} \\
\hline FV & Gl & SQ & QM & $\mathrm{F}$ & $\operatorname{Pr}(>\mathrm{F})$ \\
\hline Tratamentos & 12 & 9432,076771 & 786,0063976 & 89,60638221 & $6,56 \mathrm{E}-17^{* * *}$ \\
\hline Blocos & 2 & 9,741994896 & 4,870997448 & 0,555303952 & 0,5811 \\
\hline Resíduo & 24 & 210,5224324 & 8,771768017 & & \\
\hline Total & 38 & 9652.341198 & & & \\
\hline \multicolumn{6}{|c|}{ Croma da periderme das raízes tuberosas $\left(\mathrm{C}^{*}{ }_{\mathrm{c}}\right)$} \\
\hline $\mathrm{FV}$ & Gl & SQ & $\mathrm{QM}$ & $\mathrm{F}$ & $\operatorname{Pr}(>\mathrm{F})$ \\
\hline Tratamentos & 12 & 1019,309571 & 84,94246425 & 57,99294120 & $9,97 \mathrm{E}-15^{* * *}$ \\
\hline Blocos & 2 & 4,463860659 & 2,231930329 & 1,523810329 & 0,23822 \\
\hline Resíduo & 24 & 35,15288412 & 1,464703505 & & \\
\hline Total & 38 & 1058,926316 & & & \\
\hline
\end{tabular}




\begin{tabular}{|c|c|c|c|c|c|}
\hline \multicolumn{6}{|c|}{ Ângulo de tom Hue da periderme das raízes tuberosas $\left(\mathrm{H}_{\mathrm{c}}{ }_{\mathrm{c}}\right)$} \\
\hline $\mathrm{FV}$ & Gl & SQ & $\mathrm{QM}$ & $\mathrm{F}$ & $\operatorname{Pr}(>\mathrm{F})$ \\
\hline Tratamentos & 12 & 34479,41248 & 2873,284374 & 5,452469155 & $2,09 \mathrm{E}-04^{* * *}$ \\
\hline Blocos & 2 & 1264,192155 & 632,0960774 & 1,199492955 & 0,31878 \\
\hline Resíduo & 24 & 12647,26549 & 526,9693954 & & \\
\hline Total & 38 & 48390,87013 & & & \\
\hline \multicolumn{6}{|c|}{ Luminosidade da polpa das raízes tuberosas $\left(\mathrm{L}_{\mathrm{p}}^{*}\right)$} \\
\hline FV & Gl & SQ & $\mathrm{QM}$ & $\mathrm{F}$ & $\operatorname{Pr}(>\mathrm{F})$ \\
\hline Tratamentos & 12 & 18343,40597 & 1528,617164 & 540,9390751 & $3,80 \mathrm{E}-26^{* * *}$ \\
\hline Blocos & 2 & 2,445521275 & 1,222760638 & 0,432704162 & 0,65371 \\
\hline Resíduo & 24 & 67,82059872 & 2,82585828 & & \\
\hline Total & 38 & 18413,67209 & & & \\
\hline \multicolumn{6}{|c|}{ Croma da polpa das raízes tuberosas $\left(\mathrm{C}_{\mathrm{p}}^{*}\right)$} \\
\hline $\mathrm{FV}$ & Gl & SQ & $\mathrm{QM}$ & $\mathrm{F}$ & $\operatorname{Pr}(>\mathrm{F})$ \\
\hline Tratamentos & 12 & 5193,542336 & 432,7951947 & 108,9851799 & $6,67 \mathrm{E}-18^{* * * * *}$ \\
\hline Blocos & 2 & 4,732565316 & 2,366282658 & 0,595870158 & 0,55903 \\
\hline Resíduo & 24 & 95,3073132 & 3,97113805 & & \\
\hline Total & 38 & 5293,582215 & & & \\
\hline \multicolumn{6}{|c|}{ Ângulo de tom Hue da polpa das raízes tuberosas $\left(\mathrm{H}_{\mathrm{p}}^{*}\right)$} \\
\hline $\mathrm{FV}$ & Gl & SQ & QM & $\mathrm{F}$ & $\operatorname{Pr}(>\mathrm{F})$ \\
\hline Tratamentos & 12 & 493965,8421 & 41163,82017 & 16261,27929 & $7,40 \mathrm{E}-44^{* * *}$ \\
\hline Blocos & 2 & 16,39447009 & 8,197235046 & 3,238220553 & 0,05688 \\
\hline Resíduo & 24 & 60,75362622 & 2,531401093 & & \\
\hline Total & 38 & 494042,9902 & & & \\
\hline
\end{tabular}

\section{ANEXO C: TABELAS DAS ANÁLISES DE VARIÂNCIA (CAPÍTULO 3) CARACTERIZAÇÃO MORFOAGRONÔMICA DAS RAÍZES TUBEROSAS}

\begin{tabular}{|c|c|c|c|c|c|}
\hline \multicolumn{6}{|c|}{ Número total de raízes por planta (NTRPP) } \\
\hline FV & Gl & SQ & $\mathrm{QM}$ & $\mathrm{F}$ & $\operatorname{Pr}(>F)$ \\
\hline Tratamentos & 29 & 19,40767112 & 0,669230039 & 5,363110094 & $5,61 \mathrm{E}-10^{* * * * *}$ \\
\hline Blocos & 3 & 0,706624452 & 0,235541484 & 1,887594456 & $1,38 \mathrm{E}-01$ \\
\hline Resíduo & 87 & 10,85620328 & 0,124783946 & & \\
\hline Total & 119 & 30,97049885 & & & \\
\hline \multicolumn{6}{|c|}{ Dados transformados $\mathrm{em}(x+1)^{0,5} . * * *$ Diferença estatisticamente significativa $(\mathrm{p} \leq 0,01)$} \\
\hline \multicolumn{6}{|c|}{ Produtividade total (PT) } \\
\hline $\mathrm{FV}$ & Gl & SQ & $\mathrm{QM}$ & $\mathrm{F}$ & $\operatorname{Pr}(>\mathrm{F})$ \\
\hline Tratamentos & 29 & 599,0287399 & 20,65616344 & 12,82228148 & $1,07 \mathrm{E}-20^{* * * * *}$ \\
\hline Blocos & 3 & 9,475396759 & 3,158465586 & 1,960612623 & $1,26 \mathrm{E}-01$ \\
\hline Resíduo & 87 & 140,1533902 & 1,610958508 & & \\
\hline Total & 119 & 748,6575268 & & & \\
\hline \multicolumn{6}{|c|}{ Dados transformados em $(x+1)^{0,5} . * * *$ Diferença estatisticamente significativa $(\mathrm{p} \leq 0,01)$} \\
\hline \multicolumn{6}{|c|}{ Número de raízes comerciais por planta (NRCPP) } \\
\hline $\mathrm{FV}$ & Gl & SQ & $\mathrm{QM}$ & $\mathrm{F}$ & $\operatorname{Pr}(>\mathrm{F})$ \\
\hline Tratamentos & 29 & 25,97533535 & 0,895701219 & 15,20250304 & $3,57 \mathrm{E}-23^{* * * *}$ \\
\hline Blocos & 3 & 0,324888115 & 0,108296038 & 1,838080395 & $1,46 \mathrm{E}-01$ \\
\hline Resíduo & 87 & 5,125866829 & 0,05891801 & & \\
\hline Total & 119 & 31,42609029 & & & \\
\hline
\end{tabular}




\begin{tabular}{|c|c|c|c|c|c|}
\hline \multicolumn{6}{|c|}{ Produtividade comercial (PC) } \\
\hline $\mathrm{FV}$ & Gl & SQ & QM & $\mathrm{F}$ & $\operatorname{Pr}(>\mathrm{F})$ \\
\hline Tratamentos & 29 & 651,3695742 & 22,4610198 & 18,12072303 & $7,88 \mathrm{E}-26^{* * * *}$ \\
\hline Blocos & 3 & 2,051180586 & 0,683726862 & 0,551605635 & $6,48 \mathrm{E}-01$ \\
\hline Resíduo & 87 & 107,8383418 & 1,23952117 & & \\
\hline Total & 119 & 761,2590965 & & & \\
\hline \multicolumn{6}{|c|}{ Dados transformados em $(x+1)^{0,5} . * * *$ Diferença estatisticamente significativa $(\mathrm{p} \leq 0,01)$} \\
\hline \multicolumn{6}{|c|}{ Peso médio de raízes comerciais (PMRC) } \\
\hline $\mathrm{FV}$ & Gl & SQ & QM & $\mathrm{F}$ & $\operatorname{Pr}(>\mathrm{F})$ \\
\hline Tratamentos & 29 & 4873,725959 & 168,0595158 & 4,928075012 & $3,83 \mathrm{E}-09^{* * *}$ \\
\hline Blocos & 3 & 36,41325172 & 12,13775057 & 0,355920014 & $7,85 \mathrm{E}-01$ \\
\hline Resíduo & 87 & 2966,914636 & 34,10246708 & & \\
\hline Total & 119 & 7877,053847 & & & \\
\hline \multicolumn{6}{|c|}{ Dados transformados em $(x+1)^{0,5} . * * *$ Diferença estatisticamente significativa $(\mathrm{p} \leq 0,01)$} \\
\hline \multicolumn{6}{|c|}{ Porcentagem de raízes comerciais $(\mathrm{RC})$} \\
\hline $\mathrm{FV}$ & Gl & SQ & QM & $\mathrm{F}$ & $\operatorname{Pr}(>\mathrm{F})$ \\
\hline Tratamentos & 29 & 807,2611237 & 27,83659047 & 7,159507317 & $4,03 \mathrm{E}-13^{* * * *}$ \\
\hline Blocos & 3 & 2,581960646 & 0,860653549 & 0,221358122 & $8,81 \mathrm{E}-01$ \\
\hline Resíduo & 87 & 338,2611769 & 3,888059505 & & \\
\hline Total & 119 & 1148,104261 & & & \\
\hline \multicolumn{6}{|c|}{ Dados transformados em $(x+1)^{0,5} . * * *$ Diferença estatisticamente significativa $(\mathrm{p} \leq 0,01)$} \\
\hline \multicolumn{6}{|c|}{ Formato (FTO) } \\
\hline FV & Gl & SQ & $\mathrm{QM}$ & $\mathrm{F}$ & $\operatorname{Pr}(>\mathrm{F})$ \\
\hline Tratamentos & 29 & 4,086468495 & 0,140912707 & 6,195658829 & $1,71 \mathrm{E}-11^{* * * *}$ \\
\hline Blocos & 3 & 0,305295439 & 0,101765146 & 4,474416415 & $5,71 \mathrm{E}-03$ \\
\hline Resíduo & 87 & 1,978708936 & 0,022743781 & & \\
\hline Total & 119 & 6,370472871 & & & \\
\hline \multicolumn{6}{|c|}{ Dados transformados em $(x+1)^{0,5} \cdot * * *$ Diferença estatisticamente significativa $(\mathrm{p} \leq 0,01)$} \\
\hline \multicolumn{6}{|c|}{ Incidência de danos ocasionados por insetos do solo (ID) } \\
\hline $\mathrm{FV}$ & Gl & SQ & QM & $\mathrm{F}$ & $\operatorname{Pr}(>\mathrm{F})$ \\
\hline Tratamentos & 29 & 1,199147412 & 0,041349911 & 2,629754377 & $2,90 \mathrm{E}-04^{* * * *}$ \\
\hline Blocos & 3 & 0,288351996 & 0,096117332 & 6,112829996 & $8,01 \mathrm{E}-04$ \\
\hline Resíduo & 87 & 1,367976518 & 0,015723868 & & \\
\hline Total & 119 & 2,855475926 & & & \\
\hline \multicolumn{6}{|c|}{ Dados transformados em $(x+1)^{0,5} \cdot * * *$ Diferença estatisticamente significativa $(\mathrm{p} \leq 0,01)$} \\
\hline \multicolumn{6}{|c|}{ Comprimento $(\mathrm{CR})$} \\
\hline $\mathrm{FV}$ & Gl & SQ & $\mathrm{QM}$ & $\mathrm{F}$ & $\operatorname{Pr}(>\mathrm{F})$ \\
\hline Tratamentos & 29 & 146602,7974 & 5055,268875 & 9,372173762 & $1,96 \mathrm{E}-16^{* * * *}$ \\
\hline Blocos & 3 & 4539,735264 & 1513,245088 & 2,805468168 & 4,44E-02 \\
\hline Resíduo & 87 & 46927,04204 & 539,3912878 & & \\
\hline Total & 119 & 198069,5747 & & & \\
\hline \multicolumn{6}{|c|}{ Diâmetro (DR) } \\
\hline $\mathrm{FV}$ & Gl & SQ & $\mathrm{QM}$ & $\mathrm{F}$ & $\operatorname{Pr}(>\mathrm{F})$ \\
\hline Tratamentos & 29 & 25829,76583 & 890,6815803 & 8,556801796 & $2,82 \mathrm{E}-15^{* * * *}$ \\
\hline Blocos & 3 & 405,5863687 & 135,1954562 & 1,298826369 & $2,80 \mathrm{E}-01$ \\
\hline Resíduo & 87 & 9055,871497 & 104,090477 & & \\
\hline Total & 119 & 35291,22369 & & & \\
\hline
\end{tabular}




\begin{tabular}{cccccc}
\hline \multicolumn{7}{c}{ Espessura do córtex (EC) } \\
\hline FV & Gl & SQ & QM & F & Pr $(>$ F $)$ \\
\hline Tratamentos & 29 & 22,11014037 & 0,762418633 & 4,860724428 & $5,18 \mathrm{E}-09^{* * * *}$ \\
Blocos & 3 & 3,15659542 & 1,052198473 & 6,708187076 & $3,99 \mathrm{E}-04$ \\
Resíduo & 87 & 13,6462007 & 0,156852882 & & \\
\hline Total & 119 & 38,91293649 & & & \\
\hline
\end{tabular}

ANEXO D: TABELAS DAS ANÁLISES DE VARIÂNCIA (CAPÍTULO 4) RESISTÊNCIA DOS CLONES À INFECÇÃO PELOS NEMATOIDES-DAS-GALHAS

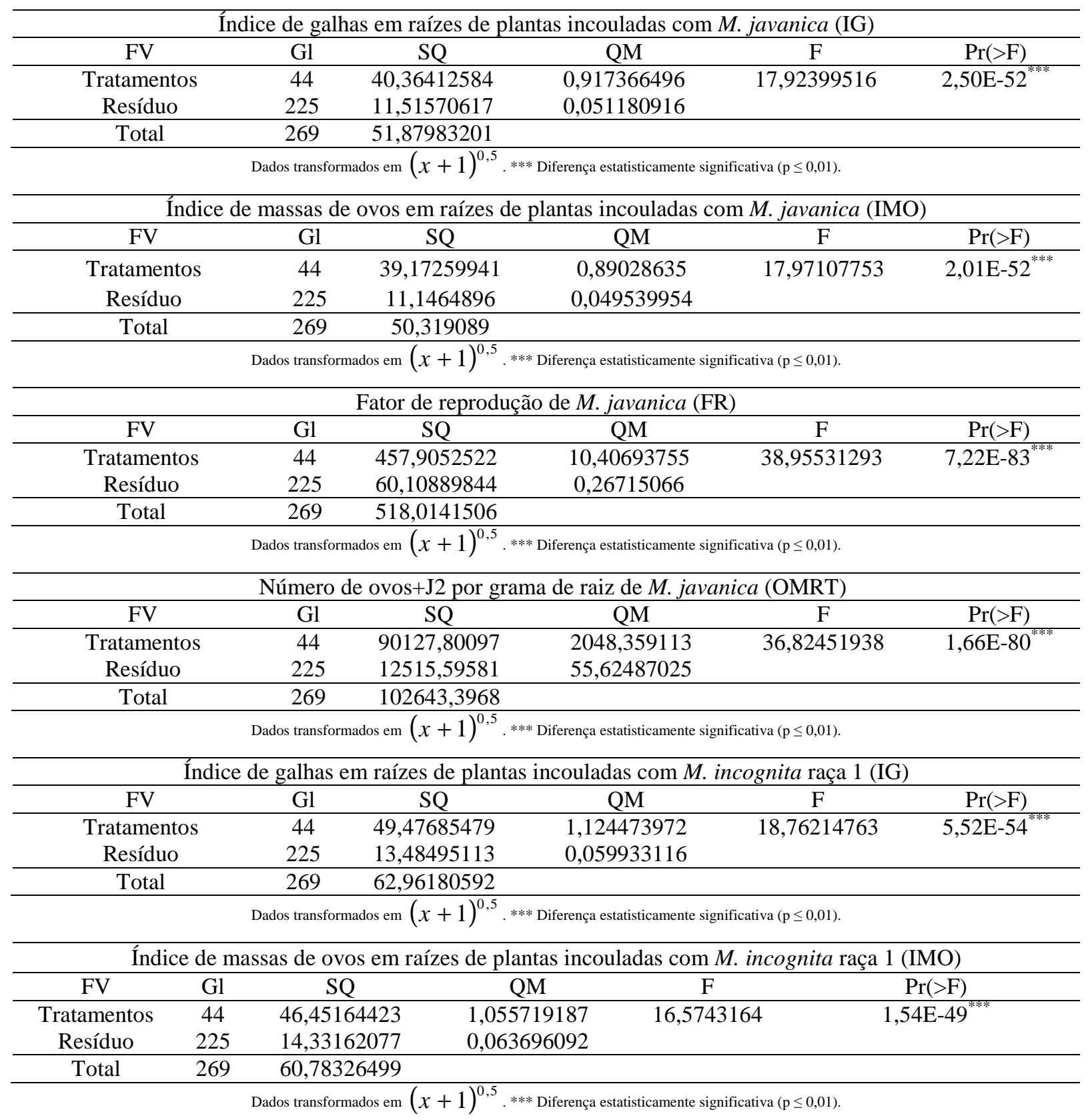




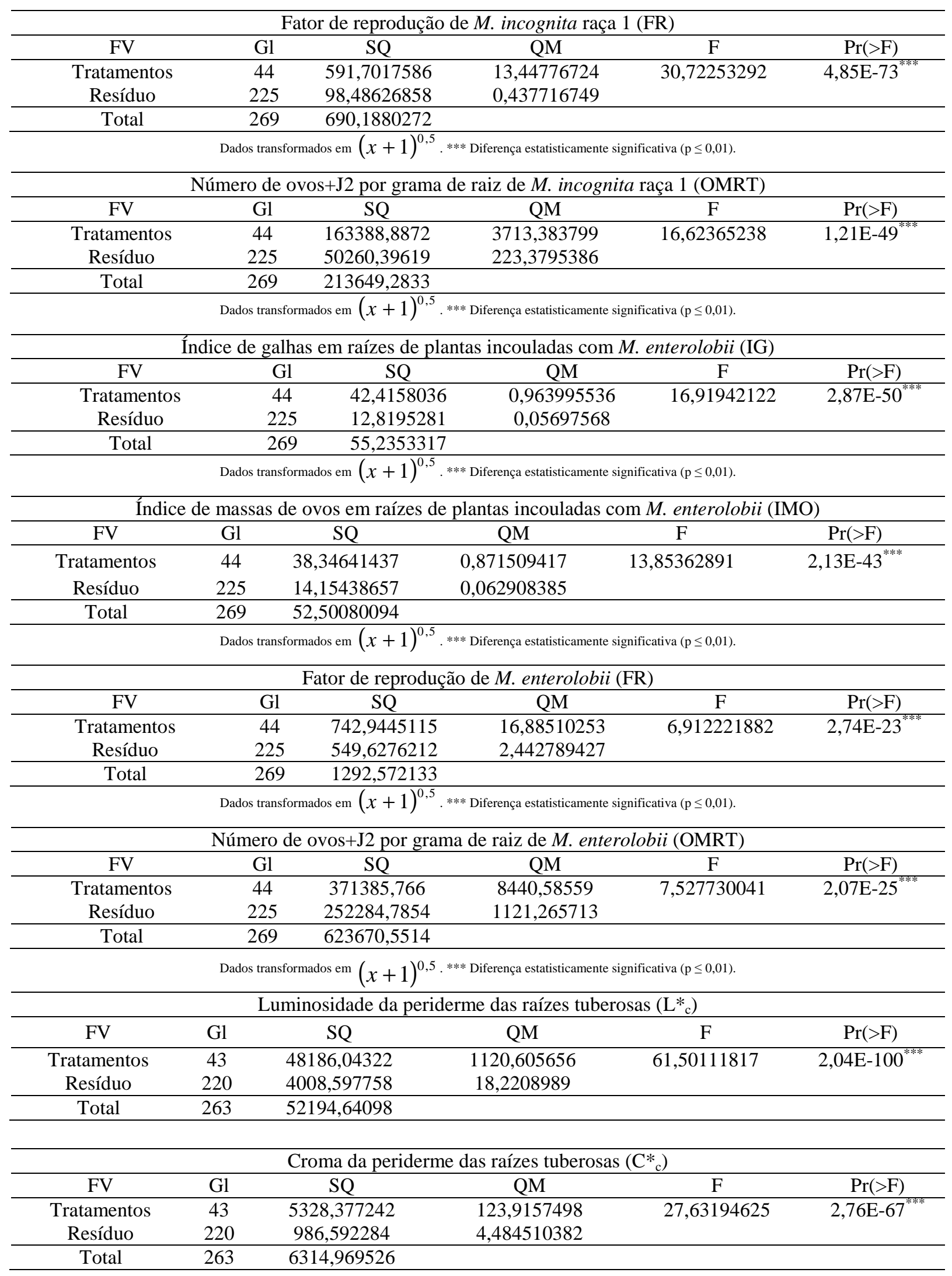




\begin{tabular}{|c|c|c|c|c|c|}
\hline \multicolumn{6}{|c|}{ Ângulo de tom Hue da periderme das raízes tuberosas $\left(\mathrm{H}_{\mathrm{c}}{ }_{\mathrm{c}}\right)$} \\
\hline $\mathrm{FV}$ & Gl & SQ & QM & $\mathrm{F}$ & $\operatorname{Pr}(>\mathrm{F})$ \\
\hline Tratamentos & 43 & 212454,6592 & 4940,806027 & 56,13047671 & $1,82 \mathrm{E}-96^{* * *}$ \\
\hline Resíduo & 220 & 19365,18964 & 88,02358926 & & \\
\hline Total & 263 & 231819,8488 & & & \\
\hline \multicolumn{6}{|c|}{ Luminosidade da polpa das raízes tuberosas $\left(\mathrm{L}^{*}{ }_{\mathrm{p}}\right)$} \\
\hline $\mathrm{FV}$ & Gl & SQ & QM & $\mathrm{F}$ & $\operatorname{Pr}(>\mathrm{F})$ \\
\hline Tratamentos & 43 & 69118,89342 & 1607,416126 & 386,2567569 & $2,03 \mathrm{E}-184^{* * * *}$ \\
\hline Resíduo & 220 & 915,5349167 & 4,161522348 & & \\
\hline Total & 263 & 70034,42833 & & & \\
\hline \multicolumn{6}{|c|}{ Croma da periderme das raízes tuberosas $\left(\mathrm{C}_{\mathrm{p}}^{*}\right)$} \\
\hline $\mathrm{FV}$ & Gl & SQ & QM & $\mathrm{F}$ & $\operatorname{Pr}(>\mathrm{F})$ \\
\hline Tratamentos & 43 & 54058,31313 & 1257,170073 & 113,0891691 & $1,69 \mathrm{E}-127^{* * * *}$ \\
\hline Resíduo & 220 & 2445,657866 & 11,11662666 & & \\
\hline Total & 263 & 56503,971 & & & \\
\hline \multicolumn{6}{|c|}{ Ângulo de tom Hue da periderme das raízes tuberosas $\left(\mathrm{H}_{\mathrm{p}}{ }_{\mathrm{p}}\right)$} \\
\hline $\mathrm{FV}$ & Gl & SQ & QM & $\mathrm{F}$ & $\operatorname{Pr}(>\mathrm{F})$ \\
\hline Tratamentos & 43 & 1472220,85 & 34237,6942 & 73,50444178 & $3,20 \mathrm{E}-108^{* * * *}$ \\
\hline Resíduo & 220 & 102473,9804 & 465,7908198 & & \\
\hline Total & 263 & 1574694,831 & & & \\
\hline
\end{tabular}


ANEXO E: PARÂMETROS DE COR DOS CLONES AVALIADOS QUANTO À RESISTÊNCIA A MELOIDOGYNE (CAPÍTULO 4)

\begin{tabular}{|c|c|c|c|c|c|c|c|c|}
\hline Genótipo & $\mathbf{L}_{\mathrm{c}}^{*}$ & $\mathbf{C}_{\mathrm{c}}^{*}$ & $\mathbf{H}_{\mathrm{c}}^{*}$ & Cor da periderme & $\mathbf{L}_{\mathrm{p}}^{*}$ & $\mathbf{C}_{\mathrm{p}}^{*}$ & $\mathbf{H}_{\mathrm{p}}^{*}$ & Cor da polpa \\
\hline CNPH 1292 & $51,79 \mathrm{e}$ & $30,53 \mathrm{c}$ & $47,67 \mathrm{f}$ & Roxa-avermelhada & $69,08 \mathrm{~d}$ & $57,09 \mathrm{a}$ & $60,49 \mathrm{~d}$ & Laranja avermelhada \\
\hline CNPH 1298 & $41,53 \mathrm{~g}$ & $29,70 \mathrm{c}$ & $30,36 \mathrm{~g}$ & Roxa & $69,99 \mathrm{~d}$ & $55,97 \mathrm{a}$ & $61,93 \mathrm{~d}$ & Laranja avermelhada \\
\hline CNPH 1195 & $54,98 \mathrm{~d}$ & $30,85 \mathrm{c}$ & $49,43 \mathrm{f}$ & Rosa & $70,34 \mathrm{~d}$ & $53,46 \mathrm{~b}$ & $63,20 \mathrm{~d}$ & Laranja intenso \\
\hline CNPH 1216 & $60,78 \mathrm{c}$ & $33,06 \mathrm{~b}$ & $58,14 \mathrm{e}$ & Marron alaranjada & $72,57 \mathrm{c}$ & 56,69 a & $63,77 \mathrm{~d}$ & Laranja intenso \\
\hline Beauregard & $51,35 \mathrm{e}$ & $32,02 \mathrm{~b}$ & $39,07 \mathrm{f}$ & Vermelha-arroxeada & $71,64 \mathrm{~d}$ & $58,70 \mathrm{a}$ & $64,41 \mathrm{~d}$ & Laranja intenso \\
\hline CNPH 1200 & $51,26 \mathrm{e}$ & $32,54 \mathrm{~b}$ & $50,77 \mathrm{f}$ & Rosa & $72,82 \mathrm{c}$ & $52,01 \mathrm{~b}$ & $64,42 \mathrm{~d}$ & Laranja intenso \\
\hline CNPH 1202 & $56,79 \mathrm{~d}$ & $36,45 \mathrm{a}$ & $55,09 \mathrm{e}$ & Marron alaranjada & $73,31 \mathrm{c}$ & $53,61 \mathrm{~b}$ & $64,43 \mathrm{~d}$ & Laranja intenso \\
\hline CNPH 1365 & $57,06 \mathrm{~d}$ & $33,48 \mathrm{~b}$ & $56,56 \mathrm{e}$ & Marron alaranjada & $71,47 \mathrm{~d}$ & 55,06 a & $64,86 \mathrm{~d}$ & Laranja intenso \\
\hline CNPH 1310 & $63,14 \mathrm{c}$ & $34,11 \mathrm{a}$ & $60,55 \mathrm{e}$ & Marron alaranjada & $72,99 \mathrm{c}$ & $50,80 \mathrm{~b}$ & $65,44 \mathrm{~d}$ & Laranja intenso \\
\hline CNPH 1220 & $72,84 \mathrm{~b}$ & $35,15 \mathrm{a}$ & $76,70 \mathrm{~d}$ & Amarela pálida & $74,41 \mathrm{c}$ & 54,81 a & $67,67 \mathrm{~d}$ & Laranja intenso \\
\hline CNPH 1192 & $66,56 \mathrm{c}$ & 34,95 a & $69,11 \mathrm{e}$ & Amarela pálida & $77,19 \mathrm{~b}$ & $51,11 \mathrm{~b}$ & $69,87 \mathrm{~d}$ & Laranja pálida \\
\hline CNPH 1232 & $63,47 \mathrm{c}$ & 35,66 a & $61,61 \mathrm{e}$ & Marron alaranjada & $77,35 \mathrm{~b}$ & $43,05 \mathrm{c}$ & $70,66 \mathrm{~d}$ & Laranja pálida \\
\hline CNPH 1392 & $63,07 \mathrm{c}$ & $34,21 \mathrm{a}$ & $56,13 \mathrm{e}$ & Marron alaranjada & $79,05 \mathrm{~b}$ & $45,02 \mathrm{c}$ & $71,81 \mathrm{~d}$ & Laranja pálida \\
\hline CNPH 02 & $72,00 \mathrm{~b}$ & $29,89 \mathrm{c}$ & $81,45 \mathrm{~d}$ & Creme escura & 86,73 a & $33,80 \mathrm{~d}$ & $96,42 \mathrm{c}$ & Creme \\
\hline CNPH 1344 & $58,35 \mathrm{~d}$ & $23,01 \mathrm{f}$ & $53,78 \mathrm{e}$ & Rosa & 84,61 a & $27,45 \mathrm{f}$ & $96,44 \mathrm{c}$ & Creme escura \\
\hline CNPH 56 & 80,17 a & $29,40 \mathrm{c}$ & $89,81 \mathrm{c}$ & Branca & $86,63 \mathrm{a}$ & $20,23 \mathrm{~g}$ & $96,81 \mathrm{c}$ & Branca \\
\hline CNPH 1361 & $55,41 \mathrm{~d}$ & $25,63 \mathrm{e}$ & $40,63 \mathrm{f}$ & Roxa & $85,92 \mathrm{a}$ & $17,03 \mathrm{~h}$ & $96,85 \mathrm{c}$ & Branca \\
\hline CNPH 1219 & $42,67 \mathrm{~g}$ & $30,92 \mathrm{c}$ & $10,07 \mathrm{~h}$ & Roxa-avermelhada & 85,36 a & $30,62 \mathrm{e}$ & $97,01 \mathrm{c}$ & Creme \\
\hline CNPH 1358 & $59,06 \mathrm{~d}$ & $25,94 \mathrm{e}$ & $44,81 \mathrm{f}$ & Roxa & $87,08 \mathrm{a}$ & $15,72 \mathrm{~h}$ & $97,20 \mathrm{c}$ & Branca \\
\hline CNPH 1394 & $46,55 \mathrm{f}$ & $30,11 \mathrm{c}$ & $18,60 \mathrm{~h}$ & Roxa-avermelhada & 86,94 a & $25,19 \mathrm{f}$ & $97,51 \mathrm{c}$ & Branca \\
\hline Coquinho & $70,85 \mathrm{~b}$ & 33,85 a & $79,96 \mathrm{~d}$ & Amarela pálida & $87,53 \mathrm{a}$ & $17,79 \mathrm{~h}$ & $97,54 \mathrm{c}$ & Branca \\
\hline CNPH 1208 & $46,73 \mathrm{f}$ & $27,20 \mathrm{~d}$ & $21,94 \mathrm{~g}$ & Roxa & $86,92 \mathrm{a}$ & $16,89 \mathrm{~h}$ & $97,85 \mathrm{c}$ & Branca \\
\hline CNPH 1357 & $70,87 \mathrm{~b}$ & $27,79 \mathrm{~d}$ & $82,81 \mathrm{~d}$ & Branca & 86,44 a & $20,73 \mathrm{~g}$ & $98,25 \mathrm{c}$ & Branca \\
\hline CNPH 69 & $71,65 \mathrm{~b}$ & $34,91 \mathrm{a}$ & $74,25 \mathrm{~d}$ & Amarela pálida & 87,37 a & $15,98 \mathrm{~h}$ & $98,30 \mathrm{c}$ & Branca \\
\hline Rainha & $60,3 \mathrm{c}$ & $24,88 \mathrm{e}$ & $44,58 \mathrm{f}$ & Rosa & $87,28 \mathrm{a}$ & $18,79 \mathrm{~h}$ & $98,41 \mathrm{c}$ & Branca \\
\hline CNPH 1221 & $43,13 \mathrm{~g}$ & $28,17 \mathrm{~d}$ & $25,70 \mathrm{~g}$ & Roxa & $86,55 \mathrm{a}$ & $29,85 \mathrm{e}$ & $98,77 \mathrm{c}$ & Creme \\
\hline CNPH 59 & $79,79 \mathrm{a}$ & $29,89 \mathrm{c}$ & $89,90 \mathrm{c}$ & Creme escura & 86,35 a & $21,56 \mathrm{~g}$ & $98,77 \mathrm{c}$ & Branca \\
\hline CNPH 41 & $69,93 \mathrm{~b}$ & $27,65 \mathrm{~d}$ & $81,26 \mathrm{~d}$ & Branca & $86,50 \mathrm{a}$ & $17,95 \mathrm{~h}$ & $98,78 \mathrm{c}$ & Branca \\
\hline CNPH 08 & $56,21 \mathrm{~d}$ & $32,28 \mathrm{~b}$ & $59,58 \mathrm{e}$ & Rosa & $88,30 \mathrm{a}$ & $21,47 \mathrm{~g}$ & $98,93 \mathrm{c}$ & Branca \\
\hline CNPH 46 & $69,43 \mathrm{~b}$ & $34,04 \mathrm{a}$ & $78,85 \mathrm{~d}$ & Amarela pálida & $86,62 \mathrm{a}$ & $30,87 \mathrm{e}$ & $98,94 \mathrm{c}$ & Creme \\
\hline CNPH 60 & 79,04 a & $29,58 \mathrm{c}$ & $90,18 \mathrm{c}$ & Creme escura & 87,14 a & $21,09 \mathrm{~g}$ & $98,99 \mathrm{c}$ & Branca \\
\hline CNPH 1393 & 80,19 a & $30,56 \mathrm{c}$ & $100,08 \mathrm{~b}$ & Branca & 87,66 a & $21,67 \mathrm{~g}$ & $99,01 \mathrm{c}$ & Creme \\
\hline CNPH 66 & $77,45 \mathrm{a}$ & $29,75 \mathrm{c}$ & $87,29 \mathrm{c}$ & Creme escura & 87,90 a & $25,47 \mathrm{f}$ & $99,01 \mathrm{c}$ & Creme escura \\
\hline Brazlândia Roxa & $41,58 \mathrm{~g}$ & $29,21 \mathrm{c}$ & $17,75 \mathrm{~h}$ & Roxa-avermelhada & 87,26 a & $26,21 \mathrm{f}$ & $99,02 \mathrm{c}$ & Creme escura \\
\hline CNPH 1805 & $45,37 \mathrm{f}$ & $28,22 \mathrm{~d}$ & $11,72 \mathrm{~h}$ & Roxa & 87,67 a & $30,54 \mathrm{e}$ & $99,08 \mathrm{c}$ & Creme \\
\hline Princesa & 75,84 a & $29,65 \mathrm{c}$ & $85,68 \mathrm{c}$ & Creme & $88,09 \mathrm{a}$ & $20,69 \mathrm{~g}$ & $99,21 \mathrm{c}$ & Branca \\
\hline Brazlândia Rosada & $58,98 \mathrm{~d}$ & $29,94 \mathrm{c}$ & $65,01 \mathrm{e}$ & Rosa & 86,89 a & $27,89 \mathrm{f}$ & $99,35 \mathrm{c}$ & Creme \\
\hline CNPH 1197 & $46,25 \mathrm{f}$ & $31,00 \mathrm{c}$ & $15,70 \mathrm{~h}$ & Roxa-avermelhada & $88,47 \mathrm{a}$ & $17,73 \mathrm{~h}$ & $99,73 \mathrm{c}$ & Branca \\
\hline CNPH 53 & $46,00 \mathrm{f}$ & $28,25 \mathrm{~d}$ & $14,92 \mathrm{~h}$ & Roxa & 88,21 a & $19,81 \mathrm{~g}$ & $100,08 \mathrm{c}$ & Branca \\
\hline Brazlândia Branca & $78,36 \mathrm{a}$ & $29,00 \mathrm{c}$ & $120,31 \mathrm{a}$ & Branca & $85,98 \mathrm{a}$ & $20,63 \mathrm{~g}$ & $101,07 \mathrm{c}$ & Branca \\
\hline CNPH 1796 & $47,25 \mathrm{f}$ & $26,20 \mathrm{e}$ & $11,85 \mathrm{~h}$ & Roxa & $42,78 \mathrm{e}$ & $33,75 \mathrm{~d}$ & $294,32 \mathrm{~b}$ & Vermelha púrpura \\
\hline CNPH 1809 & $31,87 \mathrm{~h}$ & $14,93 \mathrm{~h}$ & $16,48 \mathrm{~h}$ & Roxa escura & $25,16 \mathrm{~g}$ & $26,33 \mathrm{f}$ & 355,87 a & Vermelha púrpura \\
\hline CNPH 80 & $34,95 \mathrm{~h}$ & $18,62 \mathrm{~g}$ & $19,75 \mathrm{~h}$ & Roxa escura & $28,85 \mathrm{f}$ & $35,72 \mathrm{~d}$ & 356,43 a & Roxa-avermelhada \\
\hline CNPH 05 & $35,8 \mathrm{~h}$ & $18,65 \mathrm{~g}$ & $19,73 \mathrm{~h}$ & Roxa & $28,29 \mathrm{f}$ & $36,05 \mathrm{~d}$ & 356,65 a & Roxa-avermelhada \\
\hline
\end{tabular}


ANEXO F: Correlação entre a resistência de genótipos a $M$. javanica e a cor da periderme e da polpa das raízes tuberosas (Capítulo 4)

\begin{tabular}{|c|c|c|c|c|c|c|c|c|c|c|}
\hline & IG & IMO & FR & OMRT & $\mathbf{L}_{\mathbf{c}}$ & $\mathbf{C} *_{c}$ & $\mathbf{H}_{\mathbf{c}}$ & $\mathbf{L} *_{\mathrm{p}}$ & $C^{*}{ }_{p}$ & $\mathbf{H}_{\mathrm{p}}$ \\
\hline IG & 1 & $0,989 * *$ & $0,672 * *$ & $0,766 * *$ & $-0,001^{\mathrm{ns}}$ & $-0,123^{\mathrm{ns}}$ & $0,052^{\mathrm{ns}}$ & $-0,073^{\mathrm{ns}}$ & $0,011^{\mathrm{ns}}$ & $0,069^{\mathrm{ns}}$ \\
\hline IMO & & 1 & $0,669 * *$ & $0,765 * *$ & $0,046^{\mathrm{ns}}$ & $-0,064^{\mathrm{ns}}$ & $0,089^{\mathrm{ns}}$ & $-0,042^{\mathrm{ns}}$ & $0,024^{\mathrm{ns}}$ & $0,021^{\mathrm{ns}}$ \\
\hline FR & & & 1 & $0,949 * *$ & $0,167^{\mathrm{ns}}$ & $-0,060^{\mathrm{ns}}$ & $0,157^{\mathrm{ns}}$ & $-0,028^{\mathrm{ns}}$ & $-0,049^{\mathrm{ns}}$ & $0,035^{\mathrm{ns}}$ \\
\hline OMRT & & & & 1 & $0,214^{\mathrm{ns}}$ & $-0,020^{\mathrm{ns}}$ & $0,203^{\mathrm{ns}}$ & $0,056^{\mathrm{ns}}$ & $-0,038^{\mathrm{ns}}$ & $-0,060^{\mathrm{ns}}$ \\
\hline $\mathbf{L}_{\mathbf{c}}$ & & & & & 1 & $0,471 * *$ & $0,944 * *$ & $0,545 * *$ & $-0,203^{\mathrm{ns}}$ & $-0,466 * *$ \\
\hline $\mathrm{C}^{*}{ }_{\mathrm{c}}$ & & & & & & 1 & $0,395 * *$ & $0,549 * *$ & $0,368 *$ & $-0,785^{*} *$ \\
\hline $\mathbf{H}_{\mathrm{c}}$ & & & & & & & 1 & $0,404 * *$ & $-0,114^{\mathrm{ns}}$ & $-0,379 *$ \\
\hline $\mathbf{L}_{\mathbf{p}}$ & & & & & & & & 1 & $-0,378 *$ & $-0,823^{* *}$ \\
\hline $\mathbf{C}^{*}{ }_{\mathrm{p}}$ & & & & & & & & & 1 & $-0,181^{\mathrm{ns}}$ \\
\hline $\mathbf{H}^{*}{ }_{\mathrm{p}}$ & & & & & & & & & & 1 \\
\hline
\end{tabular}
determinação de cor da película externa; L*p, $\mathrm{C}^{*} \mathrm{p}$ e $\mathrm{H}^{*} \mathrm{p}$ : valores da determinação de cor da polpa

ANEXO G: Correlação entre a resistência de genótipos de batata-doce a $M$. incognita raça 1 e a cor da periderme e da polpa das raízes

\begin{tabular}{|c|c|c|c|c|c|c|c|c|c|c|}
\hline & IG & IMO & FR & OMRT & $\mathbf{L}_{\mathbf{c}}$ & $\mathrm{C}_{\mathrm{c}}$ & $H^{*}$ & $\mathbf{L}_{\mathbf{p}}$ & $\mathbf{C}_{\mathrm{p}}$ & $\mathbf{H}_{\mathbf{p}}$ \\
\hline IG & 1 & $0,978 * *$ & $0,828 * *$ & $0,903 * *$ & $-0,019^{\mathrm{ns}}$ & $-0,183^{\mathrm{ns}}$ & $0,046^{\mathrm{ns}}$ & $-0,130^{\mathrm{ns}}$ & $0,154^{\mathrm{ns}}$ & $0,047 \mathrm{~ns}$ \\
\hline IMO & & 1 & $0,817 * *$ & $0,868 * *$ & $0,022^{\mathrm{ns}}$ & $-0,105^{\mathrm{ns}}$ & $0,076^{\mathrm{ns}}$ & $-0,071^{\mathrm{ns}}$ & $0,178^{\mathrm{ns}}$ & $-0,036 \mathrm{~ns}$ \\
\hline FR & & & 1 & $0,867 * *$ & $-0,093^{\mathrm{ns}}$ & $-0,263^{\mathrm{ns}}$ & $0,001^{\mathrm{ns}}$ & $-0,205^{\mathrm{ns}}$ & $0,113^{\mathrm{ns}}$ & $0,146 \mathrm{~ns}$ \\
\hline OMRT & & & & 1 & $-0,026^{\mathrm{ns}}$ & $-0,185^{\mathrm{ns}}$ & $0,024^{\mathrm{ns}}$ & $-0,180^{\mathrm{ns}}$ & $0,194^{\mathrm{ns}}$ & $0,078 \mathrm{~ns}$ \\
\hline $\mathbf{L}_{\mathbf{c}}$ & & & & & 1 & $0,471 * *$ & $0,944 * *$ & $0,545 * *$ & $-0,203^{\mathrm{ns}}$ & $-0,466 * *$ \\
\hline $\mathbf{C}^{*}$ & & & & & & 1 & $0,395 * *$ & $0,549 * *$ & $0,368^{*}$ & $-0,785^{* *}$ \\
\hline $\mathbf{H}^{*}$ & & & & & & & 1 & $0,404 * *$ & $-0,114^{\mathrm{ns}}$ & $-0,379 *$ \\
\hline $\mathbf{L} * \mathbf{p}$ & & & & & & & & 1 & $-0,378 *$ & $-0,823 * *$ \\
\hline C* & & & & & & & & & 1 & $-0,181 \mathrm{~ns}$ \\
\hline$\underset{*: \text { Significativ }}{\mathbf{H}_{\mathbf{p}}^{*}}$ & proba & este $t ; n s: n$ & ivo. IG: índ & s. & $\mathrm{COC}$ & & & & & $\frac{1}{c \text { e } \mathrm{H}^{* \mathrm{c}: \text { valores }}}$ \\
\hline
\end{tabular}


ANEXO H: Correlação entre a resistência de genótipos de batata-doce a M. enterolobii e a cor da periderme e da polpa das raízes tuberosas (Capítulo 4)

\begin{tabular}{|c|c|c|c|c|c|c|c|c|c|c|}
\hline & IG & IMO & FR & OMRT & $\mathbf{L}_{\mathbf{c}}$ & $\mathrm{C}_{\mathrm{c}}$ & $\mathbf{H}_{\mathrm{c}}$ & $\mathbf{L} *_{\mathbf{p}}$ & $C^{*}{ }_{p}$ & $\mathbf{H}_{\mathrm{p}}$ \\
\hline IG & 1 & $0,974 * *$ & $0,758 * *$ & $0,734 * *$ & $0,078^{\mathrm{ns}}$ & $-0,048^{\mathrm{ns}}$ & $0,031^{\mathrm{ns}}$ & $0,037^{\mathrm{ns}}$ & $-0,145^{\mathrm{ns}}$ & $0,037^{\mathrm{ns}}$ \\
\hline IMO & & 1 & $0,716^{* * *}$ & $0,652 * *$ & $0,019^{\text {ns }}$ & $-0,083^{\mathrm{ns}}$ & $-0,013^{\mathrm{ns}}$ & $0,026^{\mathrm{ns}}$ & $-0,141^{\mathrm{ns}}$ & $0,041^{\mathrm{ns}}$ \\
\hline FR & & & 1 & $0,865 * *$ & $0,063^{\mathrm{ns}}$ & $-0,029^{\mathrm{ns}}$ & $0,063^{\mathrm{ns}}$ & $-0,065^{\mathrm{ns}}$ & $0,058^{\mathrm{ns}}$ & $0,030^{\mathrm{ns}}$ \\
\hline OMRT & & & & 1 & $0,144^{\mathrm{ns}}$ & $-0,010^{\mathrm{ns}}$ & $0,110^{\mathrm{ns}}$ & $-0,030^{\mathrm{ns}}$ & $0,068^{\mathrm{ns}}$ & $-0,011^{\mathrm{ns}}$ \\
\hline $\mathbf{L}_{\mathbf{c}}$ & & & & & 1 & $0,471 * *$ & $0,944 * *$ & $0,545 * *$ & $-0,203^{\mathrm{ns}}$ & $-0,466^{* *}$ \\
\hline $\mathrm{C}_{\mathrm{c}}$ & & & & & & 1 & $0,395 * *$ & $0,549 * *$ & $0,368 *$ & $-0,785 * *$ \\
\hline $\mathbf{H}_{\mathrm{c}}$ & & & & & & & 1 & $0,404 * *$ & $-0,114^{\mathrm{ns}}$ & $-0,379 *$ \\
\hline $\mathbf{L}_{\mathbf{p}}$ & & & & & & & & 1 & $-0,378 *$ & $-0,823 * *$ \\
\hline$C^{*}{ }_{p}$ & & & & & & & & & 1 & $-0,181^{\mathrm{ns}}$ \\
\hline $\mathbf{H}^{*}{ }_{\mathrm{p}}$ & & & & & & & & & & 1 \\
\hline
\end{tabular}
determinação de cor da película externa; $L^{*}$ p, C*p e H*p: valores da determinação de cor da polpa. 